\title{
Field Test of Electrokinetically-Delivered Thermally Activated Persulfate for Remediation of Chlorinated Solvents in Clay
}

Nicholas Andrew Head, The University of Western Ontario

Supervisor: Gerhard, Jason I., The University of Western Ontario

Co-Supervisor: O'Carroll, Denis M., The University of Western Ontario

A thesis submitted in partial fulfillment of the requirements for the Master of Engineering

Science degree in Civil and Environmental Engineering

(C) Nicholas Andrew Head 2018

Follow this and additional works at: https://ir.lib.uwo.ca/etd

Part of the Environmental Engineering Commons

\section{Recommended Citation}

Head, Nicholas Andrew, "Field Test of Electrokinetically-Delivered Thermally Activated Persulfate for Remediation of Chlorinated Solvents in Clay" (2018). Electronic Thesis and Dissertation Repository. 5710. https://ir.lib.uwo.ca/etd/5710

This Dissertation/Thesis is brought to you for free and open access by Scholarship@Western. It has been accepted for inclusion in Electronic Thesis and Dissertation Repository by an authorized administrator of Scholarship@Western. For more information, please contact wlswadmin@uwo.ca. 


\begin{abstract}
Due to extensive industrial applications, chlorinated solvents are among the most prevalent groundwater contaminants found at hazardous sites. Given their recalcitrant nature and adverse health effects upon exposure, effective remediation technologies are needed to treat sites impacted by chlorinated solvents. In-situ chemical oxidation (ISCO) has shown success; however, its performance is often hindered in low-permeability media due to the transport of oxidants in such soils being limited. This field-scale study investigated the novel approach of applying electrokinetics $(\mathrm{EK})$ to enhance the delivery of persulfate and electrical resistance heating (ERH) to activate the delivered persulfate for low-permeability soil remediation. Results demonstrated that EK has the potential to enhance delivery, where the overall mass of persulfate that was observed to be delivered into the chlorinated solventimpacted clay formation of the field site being a factor of both EK and advection. The application of ERH to activate the delivered persulfate was found to be precluded by catalytic reactions involving naturally occurring iron. Significant chlorinated solvent reduction was observed in groundwater $(>80 \%)$ resulting from chemical oxidation and dilution from advective flux. To the authors' knowledge, this was the first literature study to investigate EK and ERH for persulfate delivery and activation for low-permeability soil remediation at the field-scale.
\end{abstract}

\title{
Keywords
}

Electrokinetics, in-situ chemical oxidation, persulfate, activation, soil and groundwater remediation, chlorinated solvents, low-permeability soil 


\section{Co-Authorship Statement}

This thesis was written by the candidate in accordance with the guidelines and regulations as stipulated by the Faculty of Graduate Studies at the University of Western Ontario. The candidate conducted the field work, laboratory analyses, data collection, and data analysis and interpretation under the guidance of Dr. Denis M. O'Carroll and Dr. Jason I. Gerhard. The co-authorship of Chapter 3 is as follows:

Chapter 3: Field Test of Electrokinetically-Delivered Thermally Activated Persulfate (EKTAP) for Remediation of Chlorinated Solvents in Clay

By Nicholas A. Head, Jason I. Gerhard, Ainsley M. Inglis, Ahmed I.A. Chowdhury, Ariel Núñez García, and Denis M. O’Carroll

Contributions:

Nicholas A. Head: Completed all of the field work and laboratory analyses (except chlorinated organic compounds). Performed all of the data collection, analyses, and interpretation. Wrote the draft of the paper.

Jason I. Gerhard: Assisted in data interpretation and reviewed/revised the draft chapter.

Ainsley M. Inglis: Provided support with the field work, completed volatile organic compound laboratory analyses, and assisted in data interpretation. 
Ahmed I.A. Chowdhury: Provided support with the field work, laboratory analyses, and data interpretation.

Ariel Núñez García: Provided support with the field work, laboratory analyses, and data interpretation.

Denis M. O'Carroll: Initiated the research topics, supervised field work, assisted in data interpretation, and reviewed/revised the draft chapter. 


\section{Acknowledgements}

I am indebted to my supervisors, Dr. Denis M. O’Carroll and Dr. Jason I. Gerhard, for providing me the opportunity to work with them and on this field study. I will forever be grateful for their mentorship, encouragement, and support.

Ainsley M. Inglis, we have spent countless hours together working on this field study. I cannot envision a better person to have worked with and experienced the highs and lows of graduate school. Your friendship provided me the strength to persevere through it all. Thank you.

Dr. Ahmed I.A. Chowdhury, I cannot thank you enough for all your hard work and guidance throughout this field study. I have learned so much from you over the last two years and greatly appreciated your mentorship. This research could not have been possible without your involvement.

Ariel Nunez Garcia, I greatly appreciate all your help with this field study that involved a ton of meetings, field and laboratory work. Your great sense of humour always lightened up the mood.

Thank you, Geosyntec Consultants, including Dr. David A. Reynolds, David Hogberg, Marlaina Auger, and Kevin Andries for designing, implementing, and operating the EKTAP remediation system. Specific thanks are due to Dr. David A. Reynolds and David Hogberg for their heavy involvement throughout the field study. Your help, guidance, and input were much appreciated and proved key to this research.

Thank you, JACOBS and DOW, for allowing the University of Western Ontario to work and complete research at the field site. It has been an invaluable experience. More specific 
thanks go to Brian Wilson, Jennifer Hayman, Jake Eimers, Alexander Stevenson, and Matthew Horlings from JACOBS for their incredible help with field work and management of the field study. Specific thanks are also warranted to Audrey Sidebottom, who acted as a liason for DOW.

Thank you, Leanne Austrins, for the important role of managing the field study in its early stages.

Thank you RESTORE for all your encouragement and making graduate school as enjoyable as it can be. Specific thanks to Dr. Clare Robinson for her understanding and support.

Thank you, Caitlin Corcoran, for all your amazing support and help with laboratory work.

Thank you to my family for their tremendous support throughout my studies.

Finally, I would like to extend my sincerest gratitude to all my amazing friends who I have shared countless memories throughout my undergraduate and graduate studies. I could not have achieved all that I have without you. Thank you for making this journey incredible and something that I will never forget. 


\section{Table of Contents}

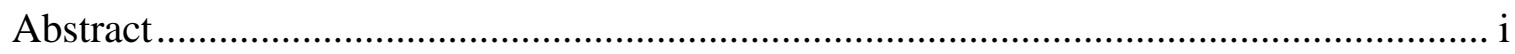

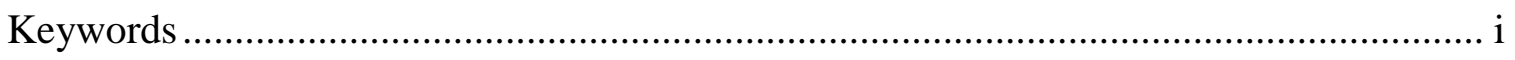

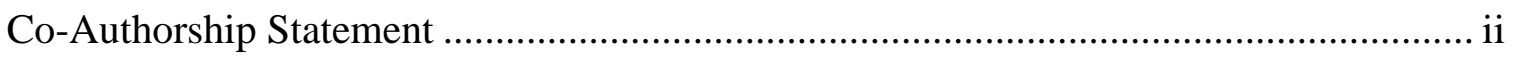

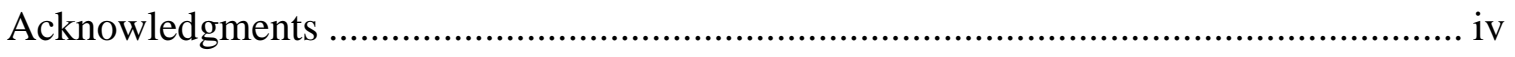

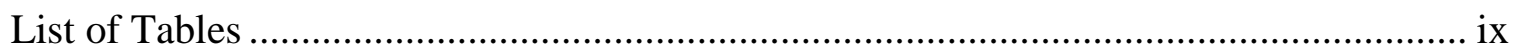

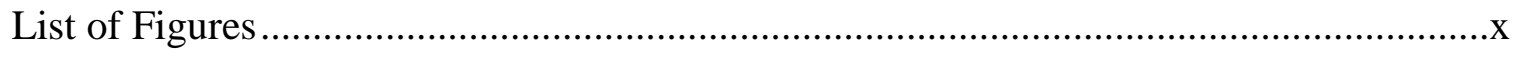

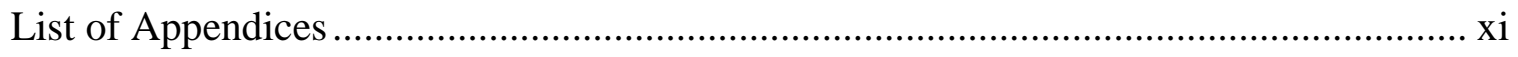

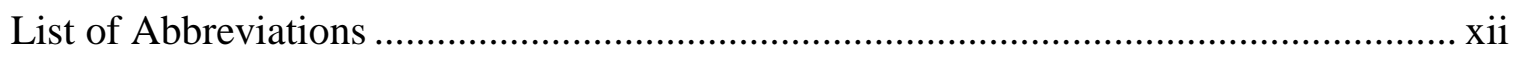

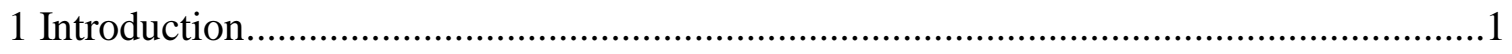

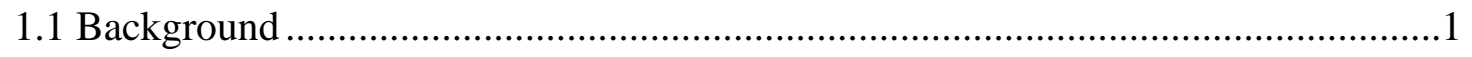

1.2 Research Objectives .............................................................................

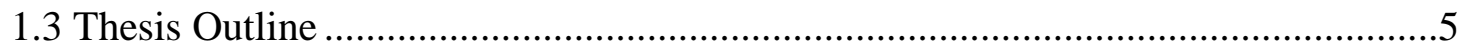

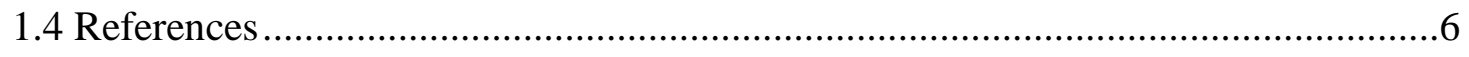

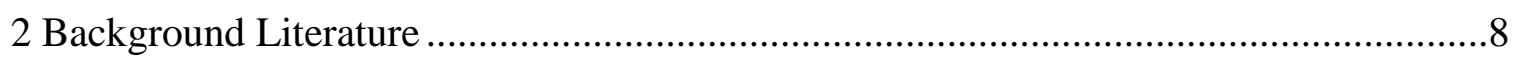

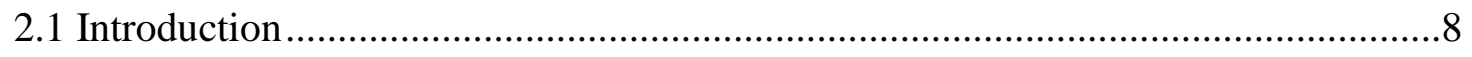

2.2 Physiochemical Properties and Uses of Persulfate ..........................................11

2.3 Persulfate Oxidation of Organic Contaminants ..............................................13

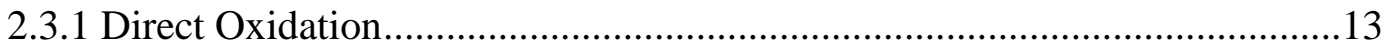

2.3.2 Free Radical Oxidation ................................................................... 14

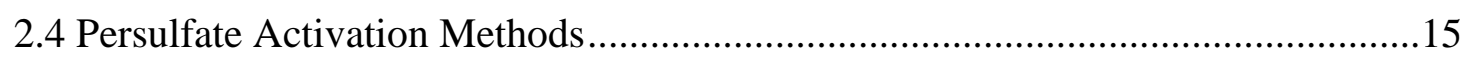

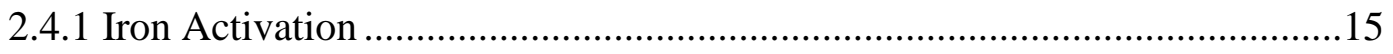

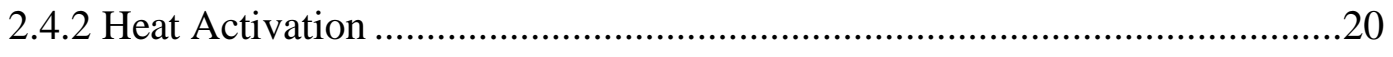

2.5 Factors Affecting Efficiency and Effectiveness of Persulfate Oxidation ...............24

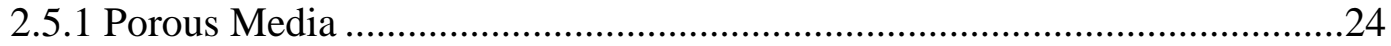


2.5.2 Free Radical Scavengers and $\mathrm{pH}$ .26

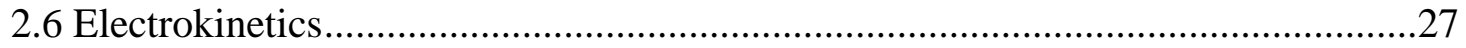

2.6.1 Electroosmosis-Induced Transport .....................................................29

2.6.2 Electromigration-Induced Transport ……………….................................30

2.6.3 Electrokinetic-Enhanced Persulfate Oxidation ............................................31

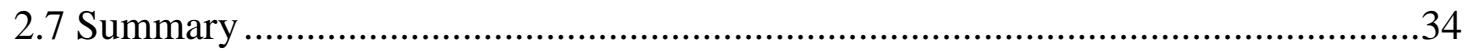

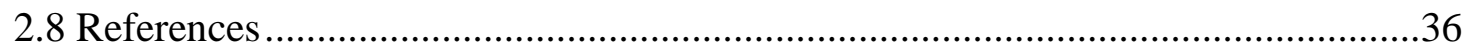

3 Field Test of Electrokinetically-Delivered Thermally Activated Persulfate (EKTAP) for Remediation of Chlorinated Solvents in Clay ................................................................46

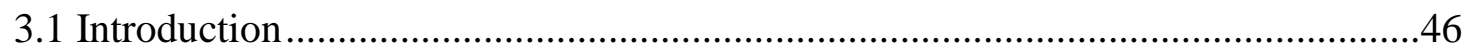

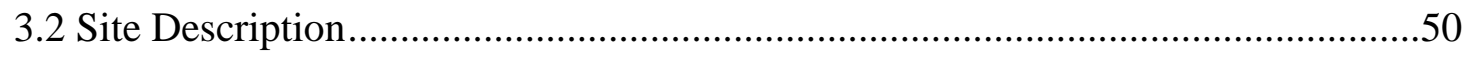

3.3 Materials and Methodology ………………….................................................50

3.3.1 Well Installation and Field Test Design ....................................................50

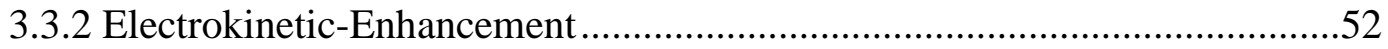

3.3.3 Persulfate and Buffer Injection ..............................................................53

3.3.4 Electrical Resistance Heating for Thermal Activation ..................................54

3.3.5 Soil Coring and Analysis .......................................................................54

3.3.6 Groundwater Sampling and Analysis ........................................................56

3.3.7 Falling Head Tests ………………………….........................................56

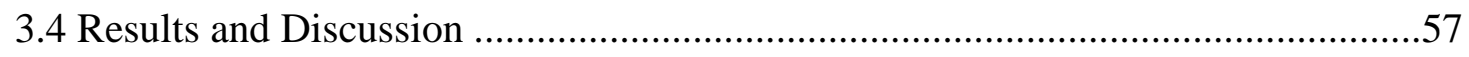

3.4.1 Electrokinetically-Enhanced Subsurface Transport of Persulfate ................57

3.4.2 Electrical Resistance Heating for Thermal Activation ..................................63

3.4.3 Persulfate Oxidation of Chlorinated Organic Compounds ...........................65

3.5 Environmental Implications …………………..............................................

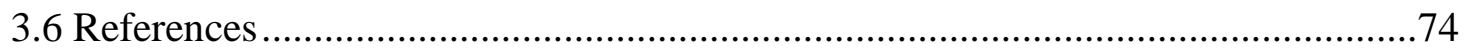




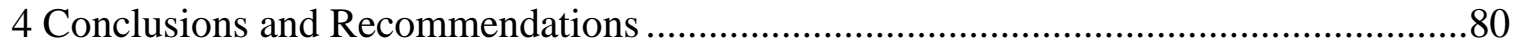

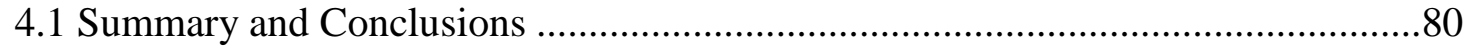

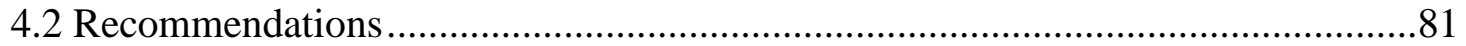

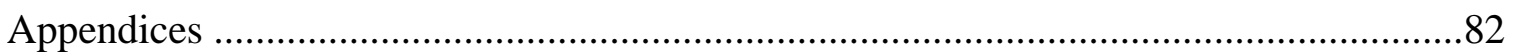

Curriculum Vitae ........................................................................................... 146 


\section{List of Tables}

Table 2.1: Properties of Common Oxidants Used for Environmental Remediation

Table 2.2: Activation Temperature Required to Achieve $>90 \%$ Degradation of Common

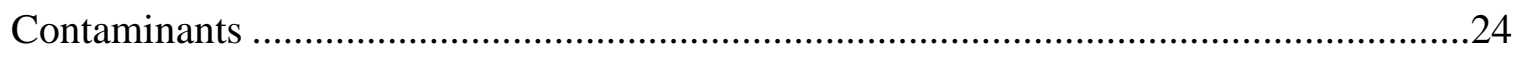

Table 2.3: Diffusion Coefficient and Effective Ionic Mobility for Common Ions ............31 


\section{List of Figures}

Figure 2.1: Aqueous decomposition of persulfate in the presence of 13 trace minerals ...18

Figure 2.2: The effects of metal oxides on the reactivity of persulfate with and without dissolved $\mathrm{Fe}^{2+}$ to degrade diesel-contaminated sand.....

Figure 2.3: Thermal decomposition of persulfate in aqueous and soil slurry batch experiments fitted to Arrhenius plots.

Figure 2.4: Electrokinetic transport processes including electromigration, electroosmosis, and electrophoresis .28

Figure 3.1: Cross-section of EK-TAP displaying site geology, water table, wells, and boreholes

Figure 3.2: Plan view of test area displaying EK-TAP and Control transects including well and borehole locations .52

Figure 3.3: Groundwater concentration of sulfur, sulfate, and persulfate $\left(\mathrm{mmol} \mathrm{L}^{-1}\right)$ in all monitoring wells of EK-TAP over the entire course of the field test.

Figure 3.4: Temperature profile of EK-TAP during applied ERH

Figure 3.5: Soil concentration of COCs (total mmoles $\mathrm{kg}^{-1}$ ) with depth at SC1-1 and SC12 of EK-TAP

Figure 3.6: Groundwater concentration of COCs $\left(\right.$ mmoles $\left.^{-1}\right)$ in all monitoring wells of EK-TAP over the entire field test. .68 


\section{List of Appendices}

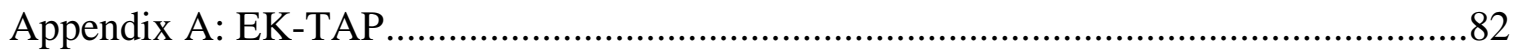

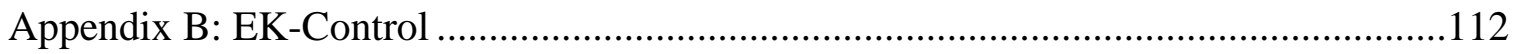

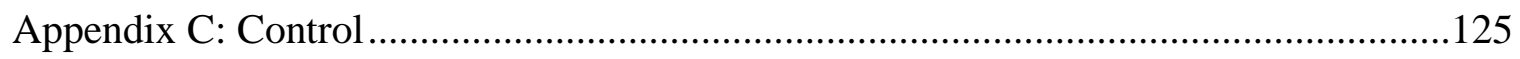

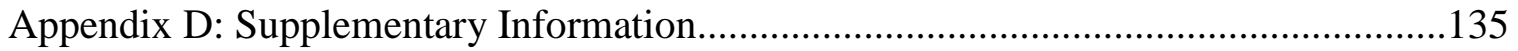

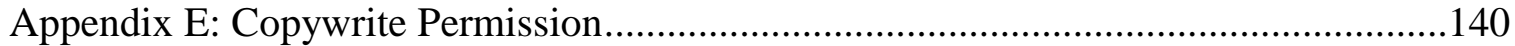




\section{List of Abbreviations}

EK

Electrokinetics

DC Direct Current

EM Electromigration

EO Electroosmosis

EOF Electroosmotic Flow

ERH Electrical Resistance Heating $\mathrm{AC}$ Alternating Current

ISCO In-Situ Chemical Oxidation

ISCR. .In-Situ Chemical Reduction

EISB .Enhanced In-Situ Bioremediation

NOD Natural Oxidand Demand

OoM Orders of Magnitude 1,2-DCA. 1,2-Dichloroethane

TCE Trichloroethene PCE Tetrachloroethene

1,1,2-TCA 1,1,2-Tichloroethane VC Vinyl Chloride 
PCB Polychlorinated Biphenyl

MTBE Methyl Tert-Butyl Ether

BTEX Benzene, Toluene, Ethylbenzene, and Xylene

RNO p-nitrosodimethylaniline COCs Chlorinated Organic Compounds U.S. United States USEPA United States Environmental Protection Agency ORP Oxidation-Reduction Potential

EC Electrical Conductivity MCL Maximum Concentration Limit VOCs Volatile Organic Compounds 


\section{Chapter 1}

\section{Introduction}

\subsection{Background}

Chlorinated solvents are used in numerous commercial and industrial applications and can be found in many household and consumer products (Moran et al., 2007). Although their usage has declined since the mid-late 1970s due to growing environmental concerns (McCarty, 2010), chlorinated solvents still find their way into the environment by spills, improper disposals, usage, transfers, and or leaks from drums and underground storage tanks (Pankow and Cherry, 1996). Some of the most prevalent solvents include dichloromethane (DCM), tetrachloroethene (PCE), 1,1,1-trichloroethane (1,1,1-TCA), and trichloroethene (TCE) (Kueper et al., 2014; Moran et al., 2007). During 1998-2001, the U.S. Environmental Protection Agency (USEPA) reported that total on-and off-site releases of DCM, PCE 1,1,1-TCA, and TCE amounted to approximately 33 million pounds, 4 million pounds, 0.5 million pounds, and 11 million pounds, respectively (Moran et al., 2007). Once released into the environment, chlorinated solvents have a tendency to contaminate groundwater due to their unique set of physiochemical properties (Pankow and Cherry, 1996). With a large population of North America depending on groundwater as a source of drinking water, the contamination of groundwater poses a serious risk to public health where exposure to many of these solvents can cause acute to chronic health ailments (e.g., kidney effects, liver damage, cancer, etc) (Brautbar and Williams II, 2002). Due to the recalcitrant nature of chlorinated solvents, groundwater sources could remain contaminated for centuries. This had led to a call for the remediation of contaminated groundwater sources and the development of various in-situ source zone remediation techniques, such as thermal desorption (e.g., electrical resistance heating, thermal conduction, steam injection, etc), enhanced in-situ bioremediation (EISB), surfactant flushing, air sparging, in-situ chemical reduction (ISCR), and in-situ chemical oxidation (ISCO) (Krembs et al., 2010). 
ISCO has garnered much attention over recent decades (Siegrest et al., 2011). This is due to the many advantages of applying ISCO, including rapid and effective treatment, compatibility with a large spectrum of contaminants, innocuous end products, moderate cost, suitability for source zones, and acceptance by most regulatory agencies (Siegrest et al., 2011). ISCO is most commonly applied at contaminated sites by hydraulic injection, with hydrogen peroxide, ozone, permanganate, and persulfate being the most typical oxidants that are applied (Krembs et al., 2010). Although promising results have been shown at homogeneous, highly permeable sites, the performance of ISCO at impermeable and or heterogeneous sites is often poor (Krembs et al., 2010; NRC, 2005). This is due to the delivery of oxidants into low-permeability media being limited to diffusion-controlled rates that are often inefficient for remediation (Struse et al., 2002). Therefore, there is a need in industry for the development of more efficient techniques to deliver oxidants into low-permeability media.

Electrokinetics (EK) is an emerging remediation technology that has successfully demonstrated the capability of enhancing the transport of oxidants in low-permeability media at the bench-scale (Chowdhury et al., 2017; Fan et al., 2016; Fan et al., 2014; Isosaari et al., 2007; Reynolds et al., 2008; Roach and Reddy, 2006; Yukselen-Aksoy and Reddy, 2012). Although EK has the potential to enhance the transport of oxidants, the appropriate oxidant should be selected for such applications. Given its high stability in the presence of aquifer materials and ability to degrade a wide spectrum of chlorinated solvents upon activation, persulfate has shown to be an ideal oxidant for chlorinated solvent-impacted low-permeability soils (Huling and Pivetz, 2006; Krembs et al., 2010; Watts and Teel, 2006; Sra et al., 2010). Several activation methods have been developed (e.g., heat, chelated or unchelated transition metals, alkaline solution, hydrogen peroxide, etc); however, thermal activation is believed to be advantageous in low-permeability media as it is not dependent on intrinsic permeability (Petri et al., 2011; Matzek and Carter, 2016; Tsitonaki et al., 2010). Electrokinetically-enhanced thermally activated persulfate (EKTAP) has demonstrated the ability of treating chlorinated solvent-impacted lowpermeability soil at the bench-scale but has received limited investigation at the field-scale 
(Chowdhury et al., 2017; Yukselen-Aksoy and Reddy, 2012). All emerging technologies require pilot field-scale testing prior to being accepted for site treatment. 


\subsection{Research Objectives}

The overall objective of the study was to evaluate the performance of EK-TAP at the fieldscale. Specific objectives of this study include the following:

i) Investigate the ability of EK to enhance the delivery of persulfate through relatively homogeneous clay soil using a dipole electrode design and direct current (DC) in a field pilot test.

ii) Evaluate the performance of electrical resistance heating (ERH) to thermally activate persulfate in the field pilot test using existing electrodes from EK operations and an alternating current (AC).

iii) In the field pilot test, assess the capability of EK-TAP to degrade chlorinated solvents, including a mix of chlorinated ethanes and chlorinated ethenes (i.e., TCE, PCE, 1,2-DCA, 1,1,2-TCA, VC). 


\subsection{Thesis Outline}

This thesis is written in integrated article format. A brief description of each chapter is listed below.

Chapter 1: Topic introduction and research objectives.

Chapter 2: Provides a review of the relevant literature. Specific topics include persulfate oxidation, thermal and iron activation of persulfate, and the use of EK to enhance the delivery of persulfate in low-permeability media.

Chapter 3: Is an integrated article summarizing the research. This includes a detailed description of the materials and methodologies used; including EK-TAP field installation and operation, soil and groundwater sampling procedures, laboratory analyses, and hydrogeologic testing. Results and discussion for each objective are presented and discussed, providing insight into the field application of EK-TAP for the remediation of a chlorinated solvent-impacted low-permeable soil.

Chapter 4: Summarizes conclusions for each objective and provides recommendations for future work. 


\subsection{References}

Brautbar, N., \& Williams II, J. (2002). Industrial solvents and liver toxicity: risk assessment, risk factors and mechanisms. International journal of hygiene and environmental health, 205(6), 479-491.

Costanza, J., Otaño, G., Callaghan, J., \& Pennell, K. D. (2010). PCE oxidation by sodium persulfate in the presence of solids. Environmental science \& technology, 44(24), 9445-9450.

Chowdhury, A. I., Gerhard, J. I., Reynolds, D., \& O’Carroll, D. M. (2017). Low Permeability Zone Remediation via Oxidant Delivered by Electrokinetics and Activated by Electrical Resistance Heating: Proof of Concept. Environmental science \& technology, 51(22), 13295-13303.

Fan, G., Cang, L., Gomes, H. I., \& Zhou, D. (2016). Electrokinetic delivery of persulfate to remediate PCBs polluted soils: Effect of different activation methods. Chemosphere, 144, 138-147.

Fan, G., Cang, L., Fang, G., Qin, W., Ge, L., \& Zhou, D. (2014). Electrokinetic delivery of persulfate to remediate PCBs polluted soils: Effect of injection spot. Chemosphere, 117, 410-418.

Huang, K. C., Zhao, Z., Hoag, G. E., Dahmani, A., \& Block, P. A. (2005). Degradation of volatile organic compounds with thermally activated persulfate oxidation. Chemosphere, 61(4), 551-560.

Huling, S. G., \& Pivetz, B. E. (2006). In-situ chemical oxidation(No. EPA/600/R-06/072). ENVIRONMENTAL PROTECTION AGENCY WASHINGTON DC OFFICE OF WATER.

Isosaari, P., Piskonen, R., Ojala, P., Voipio, S., Eilola, K., Lehmus, E., \& Itävaara, M. (2007). Integration of electrokinetics and chemical oxidation for the remediation of creosote-contaminated clay. Journal of hazardous materials, 144(1-2), 538-548.

Krembs, F. J., Siegrist, R. L., Crimi, M. L., Furrer, R. F., \& Petri, B. G. (2010). ISCO for groundwater remediation: analysis of field applications and performance. Groundwater Monitoring \& Remediation, 30(4), 42-53.

Liang, C. J., Bruell, C. J., Marley, M. C., \& Sperry, K. L. (2003). Thermally activated persulfate oxidation of trichloroethylene (TCE) and 1, 1, 1-trichloroethane (TCA) in aqueous systems and soil slurries. Soil and sediment contamination: An international journal, 12(2), 207-228.

Matzek, L. W., \& Carter, K. E. (2016). Activated persulfate for organic chemical degradation: a review. Chemosphere, 151, 178-188.

McCarty, P. L. (2010). Groundwater contamination by chlorinated solvents: history, remediation technologies and strategies. In In situ remediation of chlorinated solvent plumes (pp. 1-28). Springer, New York, NY. 
Moran, M. J., Zogorski, J. S., \& Squillace, P. J. (2007). Chlorinated solvents in groundwater of the United States. Environmental Science \& Technology, 41(1), 7481.

National Research Council. (2005). Contaminants in the subsurface: Source zone assessment and remediation. National Academies Press.

Pankow, J. F., \& Cherry, J. A. (1996). Dense chlorinated solvents and other DNAPLs in groundwater: History, behavior, and remediation.

Petri, B. G., Watts, R. J., Teel, A. L., Huling, S. G., \& Brown, R. A. (2011). Fundamentals of ISCO using hydrogen peroxide. In In situ chemical oxidation for groundwater remediation (pp. 33-88). Springer, New York, NY.

Reynolds, D. A., Jones, E. H., Gillen, M., Yusoff, I., \& Thomas, D. G. (2008). Electrokinetic Migration of Permanganate Through Low-Permeability Media. Groundwater, 46(4), 629-637.

Roach, N., \& Reddy, K. R. (2006). Electrokinetic delivery of permanganate into lowpermeability soils. International Journal of Environment and Waste Management, 1(1), 4-19.

Siegrist, R. L., Crimi, M., \& Brown, R. A. (2011). In situ chemical oxidation: Technology description and status. In In situ chemical oxidation for groundwater remediation (pp. 1-32). Springer, New York, NY.

Sra, K. S., Thomson, N. R., \& Barker, J. F. (2010). Persistence of persulfate in uncontaminated aquifer materials. Environmental science \& technology, 44(8), 3098-3104.

Struse, A. M., Siegrist, R. L., Dawson, H. E., \& Urynowicz, M. A. (2002). Diffusive transport of permanganate during in situ oxidation. Journal of Environmental Engineering, 128(4), 327-334.

Stroo, H. F., Vogel, C. M., \& Ward, C. H. (2014). Chlorinated solvent source zone remediation. B. H. Kueper (Ed.). Springer.

Tsitonaki, A., Petri, B., Crimi, M., Mosbæk, H., Siegrist, R. L., \& Bjerg, P. L. (2010). In situ chemical oxidation of contaminated soil and groundwater using persulfate: a review. Critical Reviews in Environmental Science and Technology, 40(1), 55-91.

Watts, R. J., \& Teel, A. L. (2006). Treatment of contaminated soils and groundwater using ISCO.Practice Periodical of Hazardous, Toxic, and Radioactive Waste Management, 10(1), 2-9.

Yukselen-Aksoy, Y., \& Reddy, K. R. (2012). Electrokinetic delivery and activation of persulfate for oxidation of PCBs in clayey soils. Journal of Geotechnical and Geoenvironmental Engineering, 139(1), 175-184. 


\section{Chapter 2}

\section{Background Literature}

\subsection{Introduction}

Chlorinated solvents were first produced in the 1900s and began widespread use in the manufacturing industries by the mid-late 1900s (Pankow and Cherry, 1996). Solvents such as tetrachloroethene (PCE), trichloroethene (TCE), carbon tetrachloride (CT) and trichloroethane (1,1,1 TCA) have been commonly used in industry as degreasing agents, chemical intermediates, dyes, heat-transfer fluids, adhesives, paint stripping, and drycleaning fluids (Kueper et al., 2014). In the United States (U.S.), production of chlorinated solvents peaked in the 1970s at several hundred million pounds (Kueper et al., 2014; McCarty, 2010). During large scale production and use, solvents were consistently released into the environment by spills, disposals, usage, transfers, and or leaks from drums and underground storage tanks (Pankow and Cherry, 1996). Estimates in 1994 suggested there were approximately 30,000-50,000 contaminated sites in the U.S., where $48 \%$ of these sites where contaminated with solvents such as PCE, TCE, and CT (Kavanaugh et al., 2003). Once released into the environment, solvents have a tendency for widespread groundwater contamination due to their unique combination of physiochemical properties (e.g., density, solubility in water, viscosity, vapor pressure). The contamination of groundwater poses a serious risk to public health, where in 2010 approximately $47 \%$ of the U.S. population depended on groundwater for domestic use (includes drinking water) (Maupin et al., 2014). Human exposure to these solvents have been associated with both acute and chronic human-health ailments including liver damage and possible kidney effects, spontaneous abortions, reduced fertility, cancer, and childhood leukemia (Moran et al., 2007). Following the 1970s, production of chlorinated solvents in the U.S. declined because of growing environmental concerns (McCarty, 2010). Although, it was not until the mid1980s where chlorinated solvents were officially recognized in the U.S. as soil and groundwater contaminants by regulators, industry, and researchers, following the discovery that many groundwater supplies were contaminated with such solvents (Pankow and Cherry, 1996). 
Due to the recalcitrant nature of chlorinated solvents, soil and groundwater can remain contaminated for centuries (Pankow and Cherry, 1996). This led to large-scale efforts to remediate chlorinated solvent-impacted sites. In the 1990s, it was estimated that remediation costs in the U.S. would amount to $\$ 750$ billion USD over the next three decades (Soesilo and Wilson, 1997). As a result, the development of effective but costefficient remediation technologies were required. Early treatment strategies focused around pump-and-treat, although limited success was achieved due its impractically and required duration of operations for many sites (i.e., years-decades). Since the 1990s, research has focused on the development of in-situ technologies for source zone remediation. Common in-situ technologies that have been applied include in-situ chemical oxidation (ISCO), insitu chemical reduction (ISCR), enhanced in-situ bioremediation (EISB), and thermal desorption (e.g., electrical resistance heating, steam injection, thermal conduction, etc) (Krembs et al., 2010). Although many of these technologies have removed considerable contaminant mass, removing enough to achieve typical concentration-based cleanup goals in soil and groundwater remains technically challenging at many sites (Kueper et al., 2014; Kavanaugh et al., 2013; NRC, 2005; Stroo et al., 2012).

ISCO has been a rapidly growing field for the remediation of contaminated soils and groundwater (Krembs et al., 2010). Common oxidants that have been applied for remediation include hydrogen peroxide, ozone, permanganate, and persulfate. Although success has been shown at the laboratory-scale and field-scale, the effectiveness of ISCO in clayey soils and or heterogeneous subsurface conditions is often limited (e.g., clay lenses within sand formation) (Krembs et al., 2010; NRC, 2005; Reddy, 2010). This is due the technical challenges of delivering oxidants into clayey and or heterogeneous soil.

Organic contaminants have shown the ability to penetrate low-permeability materials such as clay aquitards at diffusion-control rates (Ball et al., 1997a; Barone et al., 1992; Johnson et al., 1989; Liu and Ball, 1998). Although oxidants can also penetrate such materials at diffusion-control rates, contaminants have often had years-decades to diffuse into lowpermeable media. With diffusion being a relatively slow transport process, the time 
required for oxidants to penetrate contaminated low-permeability materials can be ineffective for remediation (Sale et al., 2013; Struse et al., 2002). This is especially true for oxidants such as ozone and hydrogen peroxide that have low stabilities in the subsurface (i.e., hours-days) (Huling and Pivetz, 2006; Watts and Teel, 2006). Although oxidants like persulfate and permanganate that have higher stabilities (i.e., months-years) to allow for diffusion transport processes to potentially occur (Huling and Pivetz, 2006; Sra et al., 2010; Struse et al., 2002; Watts and Teel, 2006), injected oxidants into a heterogeneous subsurface tend to flow preferentially around lower permeable zones and into higher permeable zones (Honning et al., 2007; Chowdhury et al., 2017). This has shown to create a concentration gradient, where contaminants have been degraded in higher permeable zones but left untreated in lower permeable zones. This gradient results in the slow and steady release of contaminants from the less permeable zones by a process known as backdiffusion. At 72 sites where ISCO has been applied, 62\% observed back-diffusion of contaminants (Krembs et al., 2010). Back-diffusion can persist for years-centuries following remediation attempts, resulting in maximum concentration limits (MCLs) not being achieved at sites where remediation activities have been completed (Chapman et al., 2005; Liu and Ball, 2002; Parker et al., 2008, Seyedabbasi et al., 2012; Yang et al., 2014).

Given the difficulty of remediating and delivering oxidants into clayey soils and or heterogeneous subsurface conditions, the use of electrokinetics (EK) has been proposed (Virkutyte et al., 2002; Lima et al., 2017). Recent bench-scale testing has demonstrated that EK can successfully enhance the delivery of oxidants into low-permeable zones (Chowdhury et al., 2017; Fan et al., 2016; Fan et al., 2014; Isosaari et al., 2007; Reynolds et al., 2008; Roach and Reddy, 2006; Yukselen-Aksoy and Reddy, 2012). Therefore, the coupling of EK with ISCO technology can be used to enhance the delivery of oxidants into low-permeability soils in order to prevent the rebounding of contaminants caused by backdiffusion. Although EK can enhance the delivery of oxidants, the appropriate oxidant should be selected for such applications. Persulfate and permanganate provide the highest chance of success in low-permeability media due to their higher stabilities (i.e., monthsyears), allowing them to be delivered more efficiently (Huling and Pivetz, 2006; Krembs 
et al., 2010; Watts and Teel, 2006; Sra et al., 2010). For low-permeability soils contaminated with a mix of chlorinated solvents (i.e., chlorinated ethenes and ethanes), the use of persulfate is advantageous over permanganate due to its higher reactivity with such contaminants (Watts and Teel, 2006).

\subsection{Physiochemical Properties and Uses of Persulfate}

Persulfate is a strong oxidizing agent with the chemical formula $\mathrm{S}_{2} \mathrm{O}_{8}^{2-}$. Persulfate is most commonly supplied as a salt (e.g., $\mathrm{Na}_{2} \mathrm{~S}_{2} \mathrm{O}_{8}$ ) and has a solubility of $46 \mathrm{wt}$. $\%$ at $25^{\circ} \mathrm{C}$ (Petri et al., 2011). In water, persulfate salts dissociate into persulfate anions:

$$
\begin{aligned}
& \mathrm{Na}_{2} \mathrm{~S}_{2} \mathrm{O}_{8} \rightarrow 2 \mathrm{Na}^{+}+\mathrm{S}_{2} \mathrm{O}_{8}^{2-} \\
& \mathrm{S}_{2} \mathrm{O}_{8}^{2-}+2 \mathrm{e}^{-} \rightarrow 2 \mathrm{SO}_{4}^{2-} \\
& \mathrm{S}_{2} \mathrm{O}_{8}^{2-} \stackrel{\Delta \text { or hv }}{\longrightarrow} 2 \mathrm{SO}_{4}^{{ }^{-}} \\
& \mathrm{S}_{2} \mathrm{O}_{8}^{2-}+\mathrm{M}^{\mathrm{n}+} \rightarrow \mathrm{SO}_{4}^{--}+\mathrm{SO}_{4}^{2-}+\mathrm{M}^{\mathrm{n}+1} \\
& \mathrm{SO}_{4}^{--}+\mathrm{OH}^{-} \rightarrow \mathrm{SO}_{4}^{2-}+\cdot \mathrm{OH}
\end{aligned}
$$

Persulfate anions can react by direct-electron transfer via self-decomposition Eq. (2.2), where the standard reduction potential is $2.01 \mathrm{~V}$ (House et al., 1962). Under neutral pH and ambient temperature, persulfate anions are quite stable in aqueous solution (i.e., kinetically slow) (House et al., 1962; Tsitonaki et al., 2010). Therefore, most applications of persulfate require the introduction of a catalyst (or activator) to increase reactivity by producing free radicals (Osgerby, 2006). Sulfate free radicals $\left(\mathrm{SO}_{4}^{--}\right)$and hydroxyl radicals $\left(\mathrm{OH}^{*}\right)$ are most commonly produced following catalytic reactions (or activation) (Eq. 2.3, 2.4, and 2.5), which can initiate a set of chain reactions that may include other free radicals (House et al., 1962; Petri et al., 2011; Tsitonaki et al., 2010). The production of free radicals is preferred due their stronger reactivity, where the standard reduction potential of sulfate and hydroxyl radicals are $2.6 \mathrm{~V}$ and $2.7 \mathrm{~V}$, respectively (Liang et al., 2003). Persulfate has been widely used in the chemical process industry for tasks including initiators in polymerization, 
polymetric concrete, coatings, oxidants in metals cleaning/plating, cleaning/activation of adsorbents such as graphite and carbon, and in organic synthesis (Osgerby, 2006). Persulfate has also been commonly used in academia for laboratory analyses involving total and dissolved organic carbon (Doyle et al., 2004; Koprivnjak et al., 1995; Mikutta et al., 2005; Osgerby, 2006; Peyton et al., 1993).

Persulfate has also been used in environmental remediation, being the most recent oxidant introduced to ISCO. The application of persulfate first began in the late 1990s, and by 2007 approximately 10-15 field applications were recorded (Krembs, 2011). These field applications were conducted in highly permeable homogeneous and or heterogeneous sites contaminated with chlorinated ethanes, chlorinated ethenes, BTEX, and methyl tert-butyl ether (MTBE). Aqueous bench-scale testing has suggested that persulfate can be effective on a wide array of contaminants if implemented with the appropriate catalyst (or activator); these contaminants include BTEX, chlorinated ethenes, chlorinated ethanes, chlorinated benzenes, energetics, MTBE, polychlorinated biphenyls (PCBs), and 1,4-dioxane (Block at al., 2004; Huang et al., 2005; Tsitonaki et al., 2010). Currently, most of the research regarding persulfate has focused on catalysts and the activation of persulfate at the benchscale, as well as its compatibility with various contaminants. The use of persulfate can be advantageous over other commonly used oxidants (i.e., hydrogen peroxide, ozone, and permanganate) due to its high stability in the subsurface and strong reactivity (i.e., high standard reduction potential) (Huling and Pivetz, 2006; Krembs et al., 2010; Liang et al., 200;3 Petri et al., 2011; Tsitonaki et al., 2010; Watts and Teel, 2006) (Table 2.1). 
Table 2.1: Properties of Common Oxidants Used for Environmental Remediation $\underline{\text { (Huling and Pivetz, 2006) }}$

\begin{tabular}{|c|c|c|c|c|c|}
\hline Oxidant & Chemical & Reactive Species & Form & Stability & Standard \\
& Formula & & & Reduction \\
& & & & & Potential \\
\hline Catalyzed & $\mathrm{H}_{2} \mathrm{O}_{2}$ & $\mathrm{OH}^{\bullet}, \mathrm{O}_{2}^{--}, \mathrm{HO}_{2}^{-}, \mathrm{HO}_{2}^{-}$ & Liquid & Minutes-days & $2.7 \mathrm{~V}$ \\
Hydrogen & & & & & \\
\hline Peroxide & & & & & \\
\hline Persulfate & $\mathrm{Na}_{2} \mathrm{~S}_{2} \mathrm{O}_{8}$ & $\mathrm{~S}_{2} \mathrm{O}_{8}^{2-}$ & Salt & Weeks-months & $2.01 \mathrm{~V}$ \\
\hline Catalyzed & $\mathrm{Na}_{2} \mathrm{~S}_{2} \mathrm{O}_{8}$ & $\mathrm{SO}_{4}^{+-}, \mathrm{OH}^{\bullet}$ & Salt & Days-months & $2.7 \mathrm{~V}$ \\
\hline Persulfate & & & & & \\
\hline Ozone & $\mathrm{O}_{3}$ & $\mathrm{O}_{3}, \mathrm{OH}^{\bullet}$ & Gas & Minutes-days & $2.07 \mathrm{~V}$ \\
\hline Permanganate & $\mathrm{KMnO}_{4}$ & $\mathrm{MnO}_{4}^{-}$ & Salt & Months-years & $1.68 \mathrm{~V}$ \\
& $\mathrm{NaMnO}_{4}$ & & Liquid & & \\
\hline
\end{tabular}

\subsection{Persulfate Oxidation of Organic Contaminants}

\subsubsection{Direct Oxidation}

The high standard reduction potential of Eq. (2.2) indicates that persulfate is a strong aqueous oxidizing agent, making oxidation reactions thermodynamically favorable (Petri et al., 2011). However, it has been observed by House (1962) that many direct reactions (i.e., two-electron transfer) involving persulfate anions are kinetically slow and could be unfavorable for subsurface remediation involving organic contaminants. Liang et al. (2003) completed an aqueous batch-scale study examining persulfate oxidation of TCE and 1,1,1TCA at ambient temperature $\left(20^{\circ} \mathrm{C}\right)$ and neutral $\mathrm{pH}$ with oxidant to contaminant molar ratios of 10:1. Pseudo-first order reaction rates of 0.0018 and $0.0127 \mathrm{hr}^{-1}$ were observed for TCE and 1,1,1-TCA with respect to persulfate. At these rates, limited degradation (i.e., $<5 \%$ ) was observed for both TCE and 1,1,1-TCA systems during the entire length of the 
experiment (6-hours). Huang et al. (2005) investigated the treatability of 59 volatile organic compounds (VOCs) with $1 \mathrm{~g} \mathrm{~L}^{-1}$ of persulfate at ambient temperature and neutral $\mathrm{pH}$ in aqueous reaction vials with persulfate to contaminant molar ratios of 8,633-2,590:1. Out of the 59 VOCs tested, 26 registered decreases below $20 \%$ after a reaction time of 72 hours. No degradation of any compound registered above $67 \%$ at the end of the experiment, where an average $21.1 \%$ reduction was observed. Reaction rates obtained in Huang et al. (2005) were found to be in correlation with Liang et al. (2003), where first-order rate constants ranged from 0.004 to $0.009 \mathrm{hr}^{-1}$ for common chlorinated ethenes and BTEX compounds in the presence of persulfate. These studies suggest that although persulfate can react directly with common organic contaminants and provide some degradation at high persulfate to contaminant molar ratios, direct oxidation is likely inefficient for remediation.

\subsubsection{Free Radical Oxidation}

While direct oxidation of organic contaminants by persulfate anions may not be sufficient for remediation, free radicals produced from catalyzed persulfate have shown strong potential. The production of these radicals, typically sulfate and hydroxyl radicals, from persulfate is termed activation (House et al., 1962; Johnson et al., 2008; Matzek and Carter, 2016; Petri et al., 2011; Tsitonaki et al., 2010). Hydroxyl radicals can react by several mechanisms including direct-electron transfer, hydrogen abstraction, and addition to multiple bonds (Bossmann et al., 1998; Liang et al., 2003). Reactions involving hydroxyl radicals can occur at near diffusion-controlled rates of $10^{6}-10^{11} \mathrm{M}^{-1} \mathrm{~s}^{-1}$ (Buxton et al., 1988). Sulfate radicals react primarily by direct-electron transfer (Liang et al., 2003). Reactions involving sulfate radicals also occur at near diffusion-controlled rates of $10^{5}-10^{9} \mathrm{M}^{-1} \mathrm{~S}^{-1}$ (Neta et al., 1977; Tsitonaki et al., 2010). Several activation methods have been applied for subsurface remediation, such as heat, chelated or unchelated transition metals (i.e., $\mathrm{Fe}^{2+}$, $\mathrm{Mn}^{2+}, \mathrm{Cu}^{2+}$, etc), hydrogen peroxide, and alkaline solution $(\mathrm{pH}>10)$ (Matzek and Carter, 2016; Petri et al., 2011; Tsitonaki et al., 2010). Revisiting the aqueous batch study completed by Huang et al. (2005), the treatability of 59 VOCs increased substantially with heat activation (at $40^{\circ} \mathrm{C}$ ), where the average degradation increased from $21.1 \%$ to $51.5 \%$. 
Pseudo-first order rate constants between persulfate and common chlorinated ethene and BTEX contaminants increased by 1 order of magnitude (OoM) when increasing temperature from $20^{\circ} \mathrm{C}$ to $40^{\circ} \mathrm{C}$. In the 6-hour aqueous batch study completed by Liang et al. (2003), the degradation of TCE and 1,1,1-TCA increased from $<5 \%$ to $100 \%$ when increasing the temperature from $20^{\circ} \mathrm{C}$ to $60^{\circ} \mathrm{C}$. Pseudo-first order reaction rates were observed to increase by 1 and 3 OoM for 1,1,1-TCA and TCE, respectively. Overall, literature provides strong evidence that the effectiveness of persulfate oxidation can be greatly enhanced by activation when applied for subsurface remediation (Bougie and Dube, 2007; Chowdhury et al., 2017; Costanza et al., 2010; Dahmani et al., 2006; Huang et al., 2002; Liang et al., 2004; Tsitonaki, 2008; Waldemer et al., 2007; Zhao et al., 2013). For the purpose of this study, a detailed discussion of heat and iron activation is provided in the subsequent sections.

\subsection{Persulfate Activation Methods}

\subsubsection{Iron Activation}

The production of sulfate free radicals by persulfate-ferrous iron $\left(\mathrm{Fe}^{2+}\right)$ catalyzed reactions typically occur by a one-electron transfer (Eq. 2.6) (Kolthoff et al., 1951):

$$
\begin{aligned}
& \mathrm{Fe}^{2+}+\mathrm{S}_{2} \mathrm{O}_{8}^{2-} \rightarrow \mathrm{Fe}^{3+}+\mathrm{SO}_{4}^{\circ-}+\mathrm{SO}_{4}^{2-} \\
& \mathrm{SO}_{4}^{\circ-}+\mathrm{Fe}^{2+} \rightarrow \mathrm{Fe}^{3+}+\mathrm{SO}_{4}^{2-} \\
& 2 \mathrm{Fe}^{2+}+\mathrm{S}_{2} \mathrm{O}_{8}^{2-} \rightarrow 2 \mathrm{Fe}^{3+}+2 \mathrm{SO}_{4}^{2-}
\end{aligned}
$$

The reaction coefficient of Eq. (2.6) is reported to be $27 \mathrm{M}^{-1} \mathrm{~s}^{-1}$. If $\mathrm{Fe}^{2+}$ is not depleted in solution following the reaction shown in Eq. (2.6), $\mathrm{SO}_{4}^{--}$will subsequently oxidize remaining $\mathrm{Fe}^{2+}$ to ferric iron $\left(\mathrm{Fe}^{3+}\right)$ (Eq. 2.7). The reaction coefficient of Eq. (2.7) is

reported to be $3 \times 10^{8} \mathrm{M}^{-1} \mathrm{~s}^{-1}$. The overall stoichiometric reaction between $\mathrm{S}_{2} \mathrm{O}_{8}{ }^{2-}$ and $\mathrm{Fe}^{2+}$ is shown in Eq. (2.8) (Xu and Li, 2010; Wood et al., 1963). The reaction coefficient of Eq. (2.8) is reported to be $1 \times 10^{9} \mathrm{M}^{-1} \mathrm{~s}^{-1}$ (Heckel et al., 1966; Neta et al., 1988). The rate of reaction between $\mathrm{S}_{2} \mathrm{O}_{8}{ }^{2-}$ and $\mathrm{Fe}^{2+}$ is dependent on the concentration of each reactant. 
Although Eq. (2.8) shows a $\mathrm{Fe}^{2+}$ to $\mathrm{S}_{2} \mathrm{O}_{8}{ }^{2-}$ molar ratio of $2: 1$, the rate determining step is the oxidation of $\mathrm{Fe}^{2+}$ by $\mathrm{S}_{2} \mathrm{O}_{8}{ }^{2-}$ to form $\mathrm{SO}_{4}^{--}$(Eq. 2.6) (Liang et al., 2004). The reaction between $\mathrm{SO}_{4}^{--}$and excess $\mathrm{Fe}^{2+}$ of Eq. (2.2) occurs rapidly (Balabenova and Markevich, 1966; Liang et al., 2004). Once the reaction of Eq. (2.7) is gone to completion, there is no $\mathrm{SO}_{4}^{--}$remaining in solution. Therefore, the concentration of dissolved $\mathrm{Fe}^{2+}$ in the activating solution and subsurface is of concern. If $\mathrm{Fe}^{2+}$ is in excess within the subsurface, low efficiencies of contaminant degradation can occur due to $\mathrm{Fe}^{2+}$ and contaminants competing for sulfate free radicals. Persulfate will also be consumed within short distances of injection wells. Therefore, to optimize $\mathrm{Fe}^{2+}$ activated persulfate for the degradation of contaminants, it is important to delay the reaction of Eq. (2.7) and or control the ratio of $\mathrm{Fe}^{2+}$ to $\mathrm{S}_{2} \mathrm{O}_{8}{ }^{2-}$ in the system (Dahmani et al., 2006; Liang et al., 2004).

A soil slurry batch-scale study completed by Yen et al. (2011) evaluated the impact of $\mathrm{S}_{2} \mathrm{O}_{8}{ }^{2-}$ to $\mathrm{Fe}^{2+}$ molar ratios of a solution on the degradation of diesel $\left(5 \mathrm{mg} \mathrm{kg}^{-1}\right)$, where ratios of 10:1 and 100:1 were evaluated. An additional batch using the same soil containing $50,030 \mathrm{mg} \mathrm{kg}^{-1}$ of $\mathrm{Fe}_{\text {total }}$ was also performed without the addition of $\mathrm{Fe}^{2+}$. Within 40 days, diesel removal efficiencies in the soil slurry batches using $\mathrm{S}_{2} \mathrm{O}_{8}{ }^{2-}$ to $\mathrm{Fe}^{2+}$ molar ratios of 10:1 and 100:1 were 55\% and 40\%, respectively. In the soil slurry batch without the addition of $\mathrm{Fe}^{2+}, 25 \%$ diesel removal was observed. The study indicates that a higher $\mathrm{S}_{2} \mathrm{O}_{8}{ }^{2-}$ to $\mathrm{Fe}^{2+}$ molar ratio (>100:1) can negatively impact contaminant degradation, likely due to insufficient $\mathrm{Fe}^{2+}$ for activation. Furthermore, it was shown that naturally occurring iron in soil can potentially activate persulfate, although additional injection of $\mathrm{Fe}^{2+}$ into the subsurface is likely needed for field-scale applications. An aqueous batch-scale study completed by Chen et al. (2009) showed that MTBE could be completely degraded within 78-hours when $\mathrm{S}_{2} \mathrm{O}_{8}{ }^{2-}: \mathrm{Fe}^{2+}$ :MBTE molar ratios of 300-50:31:1 were used. This suggests that high $\mathrm{S}_{2} \mathrm{O}_{8}{ }^{2-}: \mathrm{Fe}^{2+}$ molar ratios may not be required for complete degradation. In an additional batch, no MTBE degradation was observed after 250-hours when a molar ratio of 10:31:1 was used; this is assumed to be due to sulfate free radicals being scavenged by excess $\mathrm{Fe}^{2+}$ in solution. An aqueous batch-scale study completed by Long et al. (2014) showed the following percent degradation of toluene after 1-hour at $\mathrm{S}_{2} \mathrm{O}_{8}{ }^{2-}$ :Fe ${ }^{2+}$ :TCE 
molar ratios of 20:5:1 (>60\%), 20:10:1 (>50\%), 20:2:1 (>30\%), and 20:0:1 (<20\%). A similar aqueous batch study completed by Liang et al. (2004) showed the following percent degradation of TCE at $\mathrm{S}_{2} \mathrm{O}_{8}{ }^{2-}: \mathrm{Fe}^{2+}$ :TCE molar ratios of 30:10:1 (64\%), 20:10:1 (57\%), 15:10:1 (55\%), 10:10:1 (29\%), 5:10:1 (9\%). These studies suggest that the molar ratio of $\mathrm{S}_{2} \mathrm{O}_{8}{ }^{2-}$ to $\mathrm{Fe}^{2+}$ has a direct impact on the efficiency of persulfate activation and contaminant degradation. Likely specific to the type and amount of contaminant present, an ideal $\mathrm{S}_{2} \mathrm{O}_{8}{ }^{2-}$ to $\mathrm{Fe}^{2+}$ molar ratio should be determined prior to field applications.

It is established in the literature that dissolved $\mathrm{Fe}^{2+}$ can activate persulfate; however, the role of other forms of iron such as dissolved $\mathrm{Fe}^{3+}$ and iron minerals is still under investigation. An aqueous batch-scale study completed by Ahmad et al. (2010) evaluated the ability of three common subsurface iron minerals, surface soil, iron-only soil fraction, and a mineral-only soil fraction to activate persulfate. The tested iron minerals were goethite, hematite, and ferrihydrate. Results demonstrated that although high masses of goethite can activate persulfate, the mineral and iron-only soil fractions did not promote measurable activation of persulfate. The findings suggest that crystalline iron oxide contents usually found in soils are not sufficient to promote persulfate activation during ISCO applications and that aqueous $\mathrm{Fe}^{2+}$ injection would be required. Teel et al. (2011) evaluated 13 common subsurface minerals for their potential to activate persulfate by means of aqueous batch tests (Figure 2.1). Only four of the 13 minerals (cobaltite, ilmenite, pyrite, and siderite) were capable of decomposing persulfate at rates greater than the persulfate-water control system. Out of these four, three were iron-based minerals (ilmenite, pyrite, and siderite). Reaction-specific probe compounds including anisole, nitrobenzene, and hexachloroethane were used to measure sulfate and hydroxyl radicals. Pyrite was the most capable of activating persulfate (i.e., producing sulfate and hydroxyl radicals). The other three iron-based minerals produced sulfate and hydroxyl radicals at rates slower than pyrite and in some cases the persulfate-water control system. 


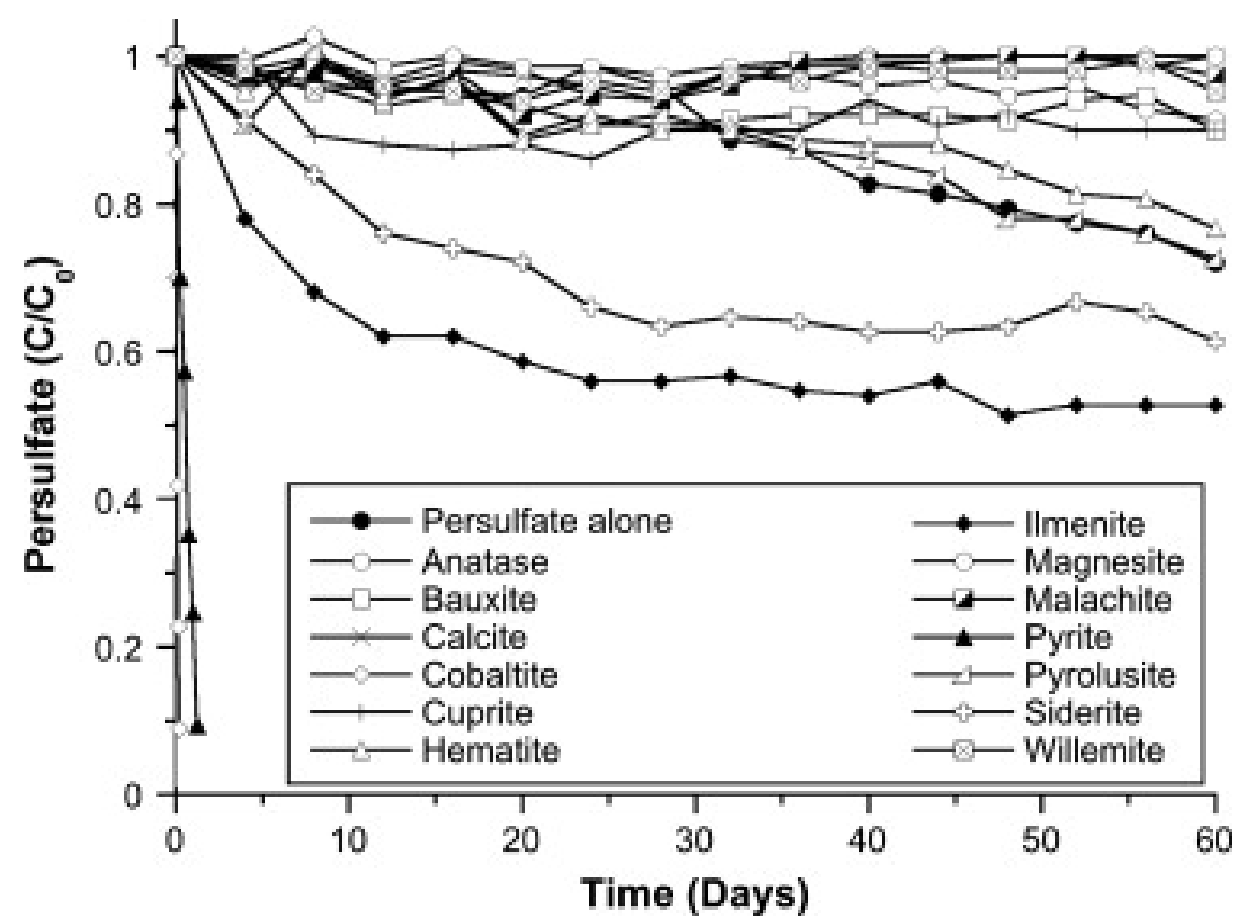

Figure 2.1: Aqueous decomposition of persulfate in the presence of 13 trace minerals. Reactors contained $5 \mathrm{~mL}$ of $0.5 \mathrm{M}$ persulfate and $2 \mathrm{~g}$ of mineral; $\mathrm{T}=25^{\circ} \mathrm{C}$ (Teel et al., 2011).

Do et al. (2010) also investigated the ability of common iron oxide soil minerals to activate persulfate. Iron oxides including goethite, hematite, and magnetite were individually added to diesel contaminated sand batches with a stand-alone persulfate solution or a mixed solution containing a $\mathrm{S}_{2} \mathrm{O}_{8}{ }^{2-}$ : $\mathrm{Fe}^{2+}$ molar ratio of 100:1. The results indicated that iron oxides could activate persulfate to a small degree without the presence of aqueous $\mathrm{Fe}^{2+}$. The degradation of diesel was highest in all cases with the addition of metal oxides and $\mathrm{Fe}^{2+}$ solution (Figure 2.2). 


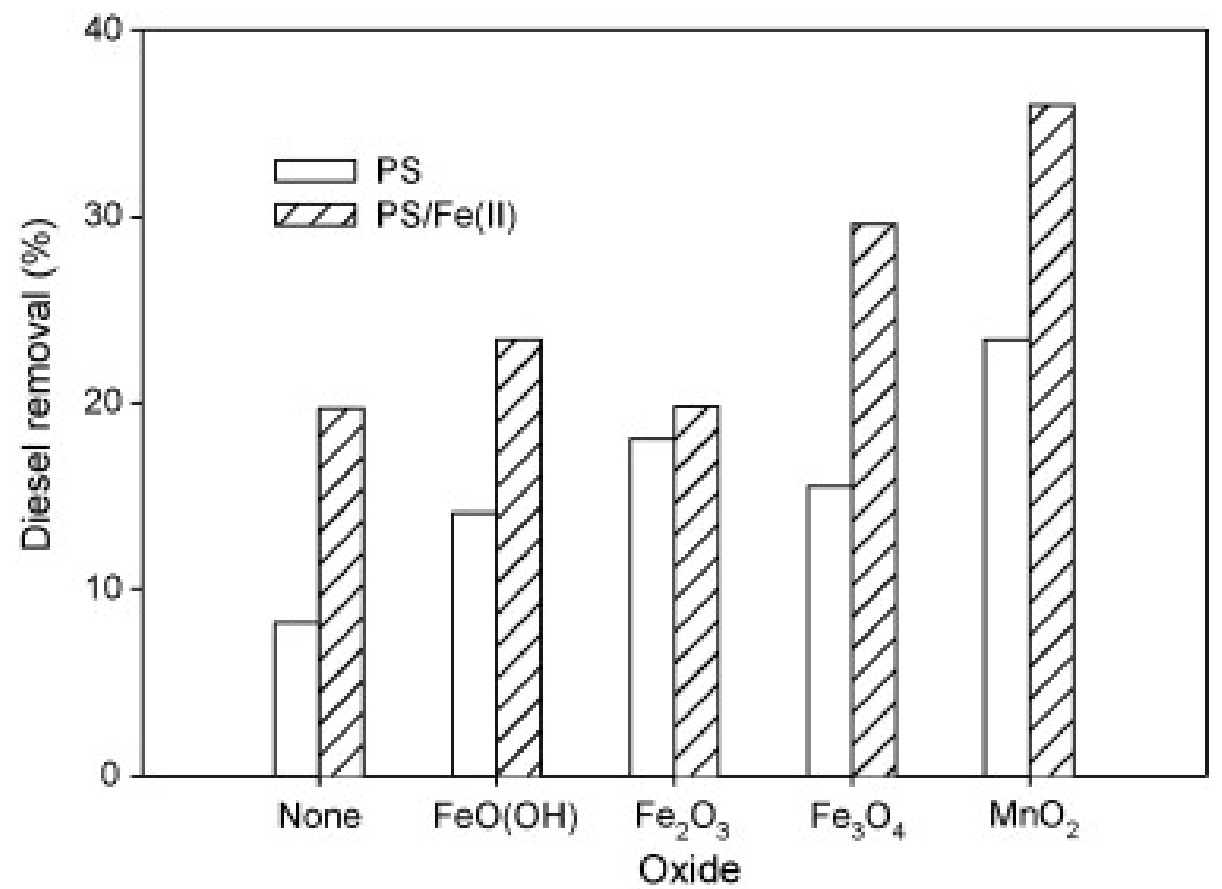

Figure 2.2: The effects of metal oxides on the reactivity of persulfate with and without dissolved $\mathrm{Fe}^{2+}$ to degrade diesel-contaminated sand (Do et al., 2010).

The role of aqueous $\mathrm{Fe}^{3+}$ on persulfate activation is much less clear. Liang et al. (2004) completed an aqueous batch study with a $\mathrm{S}_{2} \mathrm{O}_{8}^{2-}: \mathrm{Fe}^{2+}$ :TCE molar ratio of 20:5:1. TCE was observed to be degraded up to $47 \%$, stalling once $\mathrm{Fe}^{2+}$ completely reacted with $\mathrm{S}_{2} \mathrm{O}_{8}^{2-}$. After the degradation of TCE had stalled, $1 \mathrm{~mL}$ of thiosulfate $\left(\mathrm{S}_{2} \mathrm{O}_{3}^{2-}\right)$ (i.e., reductant) was added to the batches resulting in a $\mathrm{S}_{2} \mathrm{O}_{8}^{2-}: \mathrm{S}_{2} \mathrm{O}_{3}^{2-}: \mathrm{Fe}^{2+}$ :TCE molar ratio of 20:10:5:1. Thiosulfate was observed to reduce the accumulated $\mathrm{Fe}^{3+}$ to $\mathrm{Fe}^{2+}$. This resulted in TCE being degraded up to $92 \%$. These results suggested that the addition of thiosulfate could enhance TCE degradation after the halt of $\mathrm{Fe}^{2+}$ activated persulfate, indicating the limited involvement of $\mathrm{Fe}^{3+}$. One possibility explored by Petri et al. (2010) is that $\mathrm{Fe}^{3+}$ could be indirectly activating persulfate by a Haber-Weiss like catalytic system where $\mathrm{Fe}^{2+}$ and $\mathrm{Fe}^{3+}$ are being continuously cycled until the oxidant has been consumed. This is supported by the aqueous decomposition of persulfate in dilute acid (House, 1962), and the decomposition of hydrogen peroxide by $\mathrm{Fe}^{3+}$ (De Laat and Gallard, 1999): 
$\mathrm{S}_{2} \mathrm{O}_{8}^{2-}+\mathrm{H}_{2} \mathrm{O} \rightarrow 2 \mathrm{HSO}_{4}^{1-}+\mathrm{H}_{2} \mathrm{O}_{2}$

$\mathrm{Fe}^{3+}+\mathrm{H}_{2} \mathrm{O}_{2} \leftrightarrow \mathrm{Fe}\left(\mathrm{OH}_{2}\right)^{2+}+\mathrm{H}^{+}$

$\mathrm{Fe}\left(\mathrm{OH}_{2}\right)^{2+} \rightarrow \mathrm{Fe}^{2+}+\mathrm{HO}_{2}^{*}$

$\mathrm{Fe}^{3+}+\mathrm{HO}_{2}^{\cdot} \rightarrow \mathrm{Fe}^{2+}+\mathrm{O}_{2}+\mathrm{H}^{+}$

Although these series of reactions can produce $\mathrm{Fe}^{2+}$ that could be available for persulfate activation, the likelihood of this being an effective method for persulfate-oxidation of contaminants is limited. Based on first-order kinetics, House (1962) determined a persulfate half-life of 80 days in an acidic solution at ambient temperature (Petri et al., 2010). Thus, Eq. (2.9) might be too slow of a reaction for efficient contaminant degradation to occur. Furthermore, House (1962) determined that at neutral and alkaline $\mathrm{pH}$, oxygen was produced as opposed to hydrogen peroxide. Alternatively, Liu et al. (2016) has suggested that a direct redox cycle could occur between persulfate and iron:

$\mathrm{S}_{2} \mathrm{O}_{8}^{2-}+\mathrm{Fe}^{2+} \rightarrow \mathrm{SO}_{4}^{--}+\mathrm{SO}_{4}^{2-}+\mathrm{Fe}^{3+}$

$\mathrm{S}_{2} \mathrm{O}_{8}^{2-}+\mathrm{Fe}^{3+} \rightarrow \mathrm{S}_{2} \mathrm{O}_{8}^{\cdot-}+\mathrm{Fe}^{2+}$

although limited evidence exists to suggest this would be an effective process for subsurface remediation.

\subsubsection{Heat Activation}

Thermally activated persulfate involves the production of two sulfate radicals from the uncatalyzed decomposition of a persulfate anion by thermolysis (House, 1962):

$\mathrm{S}_{2} \mathrm{O}_{8}^{2-} \stackrel{\text { heat }}{\longrightarrow} 2 \mathrm{SO}_{4}^{--}$

where higher temperatures can significantly increase the rate of sulfate radical production (Johnson et al., 2008). Heat activation has been extensively studied at the bench-scale between temperatures of $30-60^{\circ} \mathrm{C}$ (Chowdhury et al., 2017; Huang et al., 2002; Huang et al., 2005; Johnson et al., 2008; Liang et al., 2003; Liang et al., 2007; Liang et al., 2010; Waldemer et al., 2007; Zhao et al., 2013). 
The relationship between temperature and rate of persulfate decomposition has been well investigated by aqueous and soil slurry batch experiments completed by Johnson et al. (2008). Results for the aqueous experiments followed pseudo-first order kinetics:

$$
-\frac{d\left[\mathrm{~S}_{2} \mathrm{O}_{8}^{2-}\right]}{d t}=k_{1}\left[\mathrm{~S}_{2} \mathrm{O}_{8}^{2-}\right]
$$

The observed $k_{0}\left(\mathrm{~h}^{-1}\right)$ values were $0.094,0.0062$, and 0.00023 at $70^{\circ} \mathrm{C}, 50^{\circ} \mathrm{C}$, and $30^{\circ} \mathrm{C}$, respectively (Figure 2.3). These values correspond with other aqueous batch studies investigating the relationship between the rate of persulfate decomposition and temperature (House, 1962; Goulden and Anthony, 1978; Kolthoff and Miller, 1951; Singh and Venkatarao, 1976). Increased rate constants due to rising temperatures have been found to typically obey the relationship shown in the Arrhenius equation (Petri et al., 2011; Tsitonaki et al., 2010):

$\ln \mathrm{k}=-\frac{\mathrm{E}_{\mathrm{a}}}{\mathrm{R}} \frac{1}{\mathrm{~T}}+\ln \mathrm{A}$

where $\mathrm{k}$ is the rate constant, $E_{a}$ is the activation energy $\left(\mathrm{kJ} \mathrm{mol}^{-1}\right), \mathrm{R}$ is the ideal gas constant $\left(8.314 \mathrm{~J} \mathrm{~K}^{-1} \mathrm{~mol}^{-1}\right.$ ), $\mathrm{T}$ is the absolute temperature (kelvin), and $\mathrm{A}$ is the frequency factor (units of $k$ ). The aqueous batch experiments completed by Johnson et al. (2008) yielded the following Arrhenius equation (see Figure 2.3):

$\operatorname{lnk}_{1}=(36.6 \pm 0.8)-\frac{134 \pm 2}{\mathrm{RT}}$ 


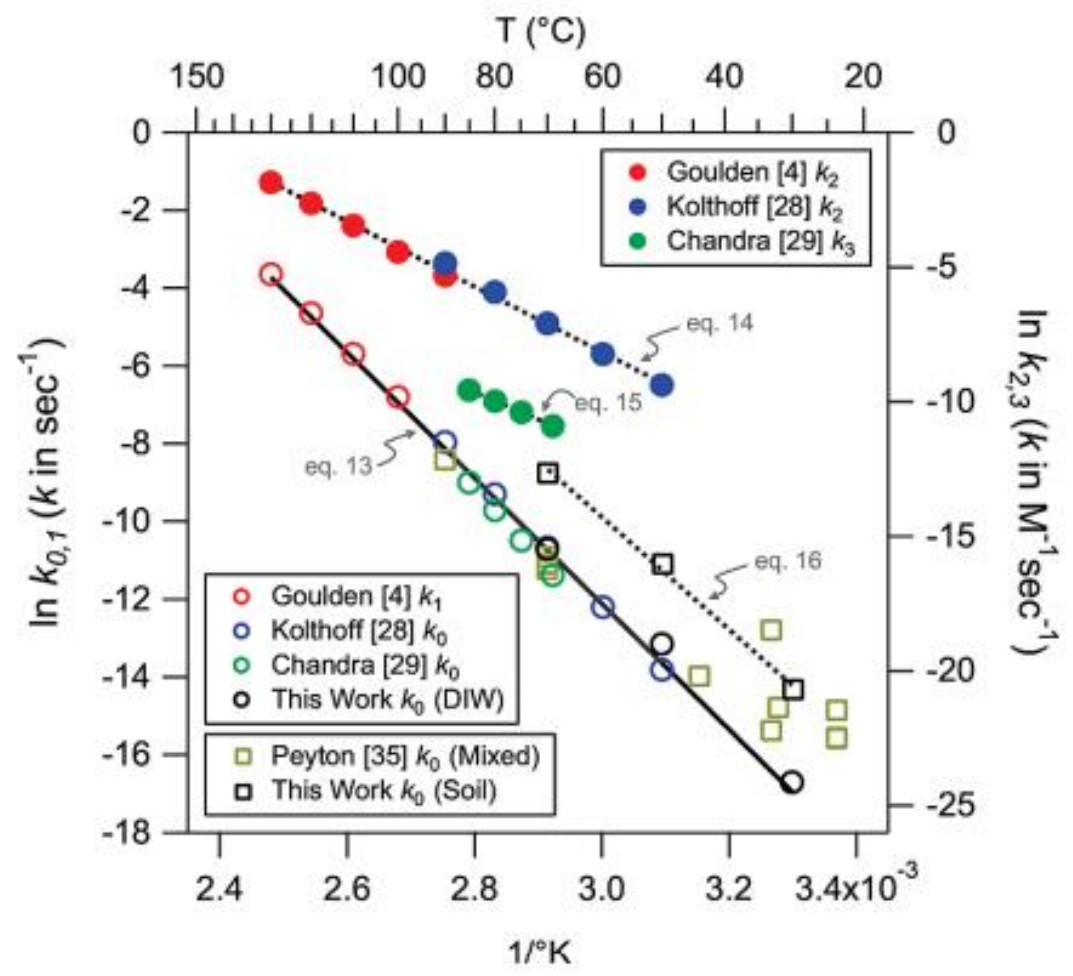

Figure 2.3: Thermal decomposition of persulfate in aqueous (circles) and soil slurry (squares) batch experiments fitted to Arrhenius plots. The constants $k_{0}, k_{1}, k_{2}$, and $k_{3}$ refer to neutral, acidic, and basic-initiated pathways. Open circles are first-order rate constants (i.e., $k_{0}$ and $k_{1}$ ), while filled circles are second-order rate constants (i.e., $k_{2}$ and $k_{3}$ ) (Johnson et al., 2008).

Examining the soil slurry batch experiments completed by Johnson et al. (2008), $k_{0}\left(\mathrm{~h}^{-1}\right)$ values $\left(0.566,0.055,0.002\right.$ for $70^{\circ} \mathrm{C}, 50^{\circ} \mathrm{C}$, and $30^{\circ} \mathrm{C}$, respectively) increased by $6-10$ times in comparison to the aqueous batch experiments (Figure 2.3). The experiments were reported to follow second-order kinetics until the natural oxidant demand (NOD) was met, where first-order kinetics by thermolysis continued until persulfate was completely consumed:

$\frac{\mathrm{d}\left[\mathrm{S}_{2} \mathrm{O}_{8}^{2-}\right]}{\mathrm{dt}}=-\mathrm{k}_{2}\left[\mathrm{~S}_{2} \mathrm{O}_{8}^{2-}\right][\mathrm{NOD}]-\mathrm{k}_{1}\left[\mathrm{~S}_{2} \mathrm{O}_{8}^{2-}\right]$ 
The soil slurry batch experiments yielded the following Arrhenius equation:

$\operatorname{lnk}_{0}=(33.6 \pm 2.6)-\frac{120 \pm 7}{\mathrm{RT}}$

It should be noted that the $E_{a}$ value is only slighty less in Eq. (2.20) compared to Eq. (2.18).

The more significant difference between datasets arises from the pre-exponential term that is dictated by the uncatalyzed decomposition of persulfate in water, $\mathrm{pH}$ of the system, and porous medium. Liang et al. (2010) also investigated the impact of aquifer solids on the rate of persulfate decomposition during thermal activation. Rates of persulfate decomposition of $0.0792,0.0737$, and $0.0311 \mathrm{hr}^{-1}$ were observed at $1.608,1.092$, and 0.316 soil foc $(\%)$ in TCE soil slurry systems heated to $50^{\circ} \mathrm{C}$. Therefore, an increase in the rate of persulfate decomposition is expected with aquifer solids containing a higher organic content. Translating these experimental batch studies to in-situ applications at the field scale, the literature suggests that the NOD of the subsurface should be considered when determining the rate of persulfate decomposition by heat (Johnson et al., 2008; Liang et al., 2008). Based on the literature, it is recommended that persulfate is delivered into the subsurface prior to heating, as the rate of decomposition by heat coupled with NOD could limit the transport of persulfate from injection wells. Overall, increasing the temperature of an aqueous persulfate system has shown a positive correlation with the rate of contaminant degradation (Costanza et al., 2010; Gu et al., 2011; Huang et al., 2002; Huang et al., 2005; Liang et al., 2003; Liang et al., 2007; Liang et al., 2010; Waldemer et al., 2007; Zhao et al., 2013). In a 6-hour aqueous batch-scale study completed by Liang et al. (2010), TCE and 1,1,1-TCA degradation increased from $0 \%$ to $100 \%$ when temperature was increased from $20^{\circ} \mathrm{C}$ to $60^{\circ} \mathrm{C}$ with persulfate to contaminant molar ratios of $10: 1$. Huang et al. (2005) tested the treatability of 59 VOCs in 72-hour aqueous batch systems at various temperatures using persulfate to contaminant molar ratios of 8,633-2,590:1. Percent degradation was observed to increase with temperature, where the average degradation of all tested VOCs at $20^{\circ} \mathrm{C}$ and $40^{\circ} \mathrm{C}$ was $21.1 \%$ and $51.5 \%$, respectively. Although increasing the temperature of a persulfate system will likely result in an increase in the rate of contaminant degradation, significant energy inputs into a system to achieve a high temperature may not be required for some contaminants and could result in unnecessary costs in the field. For instance, the temperatures shown in Table 2.2 were suitable to achieve 
$>90 \%$ degradation for common contaminants in 72-hour aqueous persulfate batch systems (Block et al., 2004). It should be noted that the dosing of persulfate also plays an important role in contaminant degradation in these experiments. Increasing the persulfate concentration of a system will likely result in an increase in contaminant degradation (Liang et al., 2008). Based on the literature, determining the appropriate persulfate dosing and temperature for effective thermal activation and degradation is likely site specific to the type and mass of contaminants present, as well as the NOD of the aquifer solids.

Table 2.2: Activation Temperature Required to Achieve $>90 \%$ Degradation of Common Contaminants (Block et al., 2004)

\begin{tabular}{|l|l|l|}
\hline $\mathbf{2 0}{ }^{\circ} \mathrm{C}$ & $\mathbf{3 5}^{\circ} \mathrm{C}$ & $\mathbf{4 5}^{\circ} \mathrm{C}$ \\
\hline Toluene & Benzene & $1,1,1-\mathrm{TCA}$ \\
\hline Ethylbenzene & Chlorobenzene & Chloroform \\
\hline Xylene & 1,2 -DCE & Methyl Chloride \\
\hline $1,1-$ DCE & PCE & \\
\hline 1,2 -Dichlorobenzene & TCE & \\
\hline 1,3 -Dichlorobenzene & $1,1-$ DCA & \\
\hline $1,2,4-$ Trichlorobenzene & 1,2 -DCA & \\
\hline & Vinyl Chloride & \\
\hline & MTBE & \\
\hline & Carbon Tetrachloride & \\
\hline
\end{tabular}

\subsection{Factors Affecting Efficiency and Effectiveness of Persulfate Oxidation}

\subsubsection{Porous Media}

Due to persulfate reaction chemistry being non-selective, interactions with non-target subsurface material will occur. These interactions are important to quantify to determine appropriate loading requirements for subsurface remediation. These interactions are termed NOD. Although still currently under investigation, NOD with respect to ISCO is typically related to the total organic carbon (TOC) and dissolved or mineral based $\mathrm{Fe}^{2+} / \mathrm{Mn}^{2+}$ content 
of a soil (Dahmani et al., 2006; Haselow et al., 2003; Mumford et al., 2005; Petri et al., 2011; Siegrist et al., 2010; Sra et al., 2010; Tsitonaki et al., 2010). Outside of ISCO, persulfate is commonly used as a wet oxidation method tool to measure TOC in water samples due to its reactivity towards organic matter (Doyle et al., 2004; Koprivnjak et al., 1995; Mikutta et al., 2005; Peyton et al., 1993). However, these analytical applications are generally completed in vigorous reaction conditions (i.e., high temperatures, acidic $\mathrm{pH}$, UV) and therefore are not entirely representative of natural subsurface conditions. Even under such aggressive conditions, Koprivniak et al. (1995) reported that significant TOC content may remain in solution, indicating that persulfate might not be reactive towards all types of organic content. In a soil slurry batch study, Sra et al. (2010) tested the NOD of seven different soils in respect to persulfate. Soils with the highest TOC content possessed the highest NOD; however, this was confounded by a high total iron ( $\left.\mathrm{Fe}_{\text {total }}\right)$ content in the soils. Reaction rates of TOC and amorphous $\mathrm{Fe}_{\text {total }}$ with respect to persulfate were found to be on the same order of magnitude. Overall, a positive correlation was found between NOD, TOC, and amorphous Fe $\mathrm{Ftal}_{\text {tal }}$ content of a soil. This is supported by soil slurry batch studies completed by Dahmani et al. (2006) and Liang et al. (2010). In comparison to permanganate, Brown and Robinson (2006) reported that persulfate was not significantly reactive towards natural organic matter (NOM), although was more reactive towards reduced inorganic species (i.e., $\mathrm{FeS}, \mathrm{Fe}^{2+}, \mathrm{Mn}^{2+}$, etc). It was reported that soil mineralogy (or inorganic content) would not play a major role in NOD unless above $0.1 \%$. Liu et al. (2014) reported a higher mineral content of $>2 \%$ to have a significant impact on NOD. In most batch studies, the introduction of a porous medium has led to decreases in contaminant degradation (Costanza et al., 2010; Crimi and Taylor, 2007; Liang et al., 2010). However, like hydrogen peroxide, the mineral content of a porous medium can potentially act as a catalysis to produce free radicals that could be beneficial for contaminant degradation (Do et al., 2010; Kwan and Voelker, 2003; Liu et al., 2014; Sperry et al., 2002; Teel et al., 2007; Teel et al., 2010; Watts and Teel et al., 2006). Pseudo-first order rate constants have been reported for persulfate decomposition in the presence of a porous medium (Crimi and Taylor, 2007; Liang et al., 2003; Liang et al., 2004). Currently, it is uncertain in literature if persulfate acts similar to hydrogen peroxide or permanganate in the presence of a porous medium. Hydrogen peroxide experiences an infinite NOD, 
while permanganate experiences a finite NOD (Gates-Anderson et al., 2001; Haselow et al., 2003; Mumford et al., 2005; Sra et al., 2010; Xu and Thomson, 2010; Xu and Thomson, 2009, Xu and Thomson, 2008). The half-life of persulfate has been measured to range from 2 to 600 days depending on the TOC and mineral content of a soil (Liu et al., 2014; Sra et al., 2010).

\subsubsection{Free Radical Scavengers and $\mathrm{pH}$}

Outside of porous media, competing side reactions with various species in groundwater other than target contaminants can occur where free radicals are scavenged. Species that have been reported to cause the most competition for free radicals are chloride and bicarbonate. Their reactions and rate constants are (Buxton et al., 1999; Liang et al., 2006; Yu and Baker, 2003):

$\mathrm{SO}_{4}^{\bullet-}+\mathrm{Cl}^{-} \rightarrow \mathrm{SO}_{4}^{2-}+\mathrm{Cl}^{\bullet}, k=4.7 \times 10^{8} \mathrm{M}^{-1} \mathrm{~s}^{-1}$

$\mathrm{SO}_{4}^{\cdot-}+\mathrm{HCO}_{3}^{-} \rightarrow \mathrm{SO}_{4}^{2-}+\mathrm{HCO}_{3}^{\bullet}, k=(1.6 \pm 0.2) \times 10^{6} \mathrm{M}^{-1} \mathrm{~s}^{-1}$

An aqueous batch-scale study with a persulfate to TCE molar ratio of 50: 1 was completed at neutral $\mathrm{pH}$ and $20^{\circ} \mathrm{C}$ by Liang et al. (2006). It was found that the rate of TCE oxidation decreased once concentrations of chloride and bicarbonate were raised above $0.2 \mathrm{M}$ and $9.2 \mathrm{mM}$, respectively. Huang et al. (2002) completed a similar study with persulfate to MTBE ratios of $394: 1$ at neutral $\mathrm{pH}$ and $40^{\circ} \mathrm{C}$. It was found that increasing the concentration of $\mathrm{NaCl}$ from $0.001 \mathrm{M}$ to $0.416 \mathrm{M}$ in the aqueous batches resulted in a decrease in MTBE degradation. A similar relationship was observed when increasing $\mathrm{pH}$ from 2.5 to 11 in the batch systems. An additional aqueous batch study with a persulfate to TCE molar ratio of 50:1 was completed at $20^{\circ} \mathrm{C}$ under various $\mathrm{pH}$ levels by Liang et al. (2007). The largest TCE degradation was observed at neutral $\mathrm{pH}$, while increasing or decreasing $\mathrm{pH}$ of the system resulted in a decrease in TCE degradation. Johnson et al. (2008) observed in their aqueous and soil slurry batch experiments that $\mathrm{pH}$ had little influence on thermal activation of persulfate between $\mathrm{pH}$ levels of 3-12. Although persulfate reaction chemistry in batch-scale reactor studies typically result in a drop in $\mathrm{pH}$, 
a change in $\mathrm{pH}$ of $<4$ or $>10$ is unlikely at the field-scale due to the natural buffering capacity of most natural soils (Sra et al., 2010).

More research is needed on the impact of $\mathrm{pH}$ and radical scavengers on the efficiency of persulfate activation and contaminant degradation. A recent study completed by Bennedsen et al. (2012) tested the degradation of p-nitrosodimethylaniline (RNO) under various activation methods of persulfate (i.e., heat, alkaline solution, chelated $\mathrm{Fe}^{2+}$ ). It was found that adding increasing concentrations of chloride (1-400 $\mathrm{mM})$ and bicarbonate (10$100 \mathrm{mM}$ ) had either no effect (i.e., heat and chelated $\mathrm{Fe}^{2+}$ activation systems) or increased contaminant degradation (i.e., alkaline activation system). It is noted that reactions between

free radicals and chloride or bicarbonate ions can produce radical intermediates, although it is uncertain in the literature if they would be significantly reactive towards contaminants.

\subsection{Electrokinetics}

EK is the mechanical motion of charged particles and fluids under the influence of an electric field when a direct current (DC) is applied between two oppositely charged electrodes (i.e., cathode and anode) (Acar et al., 1997; Acar and Alshawabkeh, 1993). Charged particles and fluids can be transported by three EK mechanisms: electrophoresis (EP), electromigration (EM), and electroosmosis (EO) (Figure 2.4) (Virkutyte et al., 2002). EK transport mechanisms have been shown not to be significantly influenced by the hydraulic conductivity of a porous medium, making it advantageous for subsurface applications where low-permeability soils pose a challenge (Acar and Alshawabkeh, 1993; Chowdhury et al., 2017; Reynolds et al., 2008). EK was first used at the beginning of the last century for dewatering, desalination, and stabilizing clays (Lima et al., 2017; Yeung, 2011). In the 1990s, EK was studied for environmental remediation applications that included the removal of heavy metals, radionuclides, and other inorganic species in soils (Acar et al., 1995; Chung and Kang, 1999; Lageman, 1993; Lima et al., 2017; Pamukcu and Wittle, 1992). More recently, EK has been tested for the removal organic contaminants (Lima et al., 2017; Lima et al., 2011; Maturi and Reddy, 2006; Kim et al., 2010; Ribeiro et 
al., 2005). Current focus involves the coupling of EK with various remediants (e.g., oxidants, reductants, biostimulants, etc) to enhance their delivery in low-permeability media that is often diffusion dominated (Chowdhury et al., 2012, Chowdhury et al., 2017; Gill et al., 2014; Lima et al., 2017). Although promising results have been shown, the use of EK for subsurface remediation has yet to achieve commercial status. To date, most of the work completed has been at the laboratory-scale with few field-scale applications.

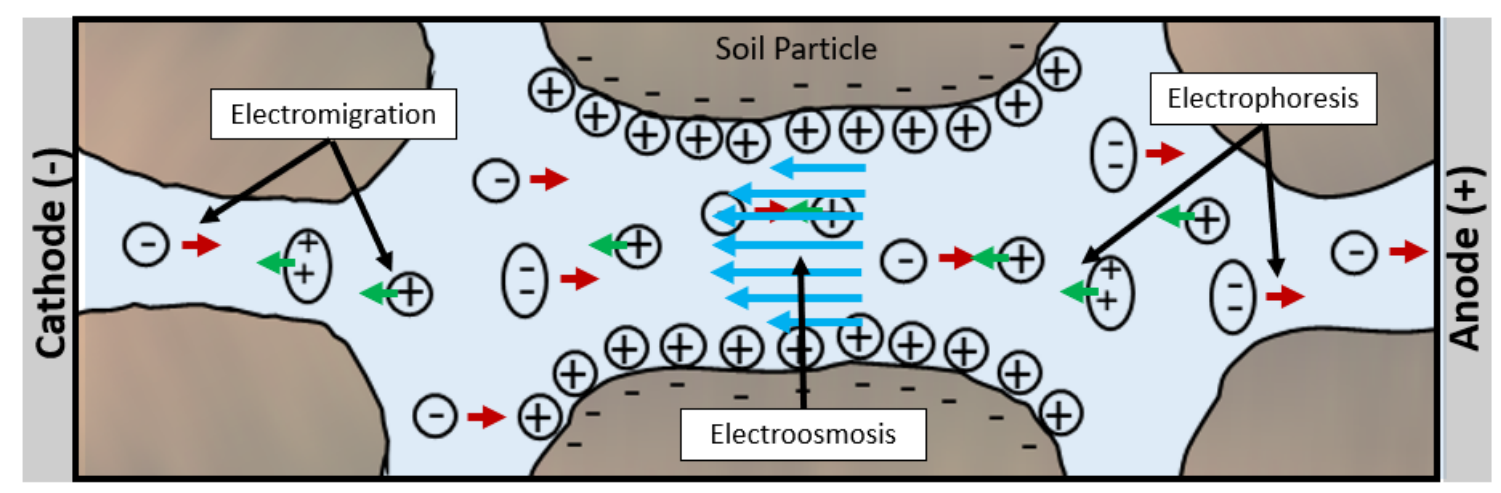

Figure 2.4: Electrokinetic transport processes including electromigration, electroosmosis, and electrophoresis.

Some common difficulties that have occurred from applying EK for subsurface remediation include the alteration of natural $\mathrm{pH}$ levels and redox conditions at the electrodes due to electrolytic reactions. At the cathode, reduction occurs, and hydroxide ions are produced. At the anode, oxidation occurs, and hydrogen ions are produced (Acar and Alshawabkeh, 1993).

$2 \mathrm{H}_{2} \mathrm{O}+2 \mathrm{e}^{-} \rightarrow 2 \mathrm{OH}^{-}+\mathrm{H}_{2}$

$2 \mathrm{H}_{2} \mathrm{O} \rightarrow 4 \mathrm{H}^{+}+\mathrm{O}_{2}+4 \mathrm{e}^{-}$

The $\mathrm{pH}$ between anode and cathode electrodes has shown to vary between 2-12 depending on the buffering capacity of the soil (Acar and Alshawabkeh 1996; Chung and Kang 1999; Yukselen-Aksoy and Reddy, 2012; Zhou et al., 2005). Oxidative and reductive conditions have been observed to increase and decrease the oxidation-reduction potential (ORP) at the 
anode and cathode electrodes, respectively. Along with variations in ionic strength between electrodes, the non-linear complexities in $\mathrm{pH}$ and redox that arise during EK have shown to create complications for the mass flux of any given species (Hodges et al., 2011). Typically, electrodes are submersed in buffer solution to help stabilize geochemical conditions between electrodes. Other complications that could arise during applied EK is the enhanced weathering of porous media during long term applications and the production of hydrogen and chlorine gas at the electrodes (Lima et al., 2017).

\subsubsection{Electroosmosis-Induced Transport}

EO is the movement of an electrolyte solution in a diffuse stationary double layer across a mineral surface (Saichek and Reddy, 2005). The positively charged ions (i.e., counter ions) in the diffuse double layer adjacent to the negatively charged mineral surface move towards the cathode when an external electric field is applied. The counter ions, while migrating, transfer the momentum to the surrounding fluid resulting in electroosmotic flow (EOF) (Acar et al., 1995). This results in the transport of both dissolved ionic and non-ionic species (Figure 2.4). The Helmoltz-Smoluchowski theory for EO is the most commonly accepted theory for pore fluid transport under electric fields (Al-Hamdan and Reddy 2005; Reynolds et al., 2008), despite the number of assumptions involved (Saichek and Reddy 2005). The following relation gives the electroosmotic flow rate in one dimension (AlHamdan and Reddy 2005):

$q_{E O}=k_{e} \frac{d \emptyset_{e}}{d x}=\frac{\varepsilon \varepsilon_{0} \varsigma}{\eta} n$

where, $k_{e}$ is electroosmotic permeability $\left(\mathrm{m}^{2} \mathrm{~V}^{-1} \mathrm{~s}^{-1}\right), \frac{d \emptyset_{e}}{d x}$ is the electrical gradient $\left(\mathrm{V} \mathrm{m}^{-1}\right)$, $\varepsilon$ is the permittivity of the medium (farad $\left.m^{-1}\right), \varepsilon_{o}$ is the permittivity of the vacuum $(8.854$ $\left.\mathrm{x} 10^{-12} \mathrm{C} \mathrm{V}^{-1} \mathrm{~m}^{-1}\right), \zeta$ is the zeta potential (V), $\eta$ is the viscosity $\left(\mathrm{kg} \mathrm{s} \mathrm{m}{ }^{-2}\right)$, and $\mathrm{n}$ is the porosity $\left(\mathrm{m}^{3} \mathrm{~m}^{-3}\right)$. EO is greatly dependent on zeta potential, which can be defined as the potential existing between the rigid and movable parts of the double layer (Eykholt and Daniel et al., 1994). Due to zeta potential being negative in most cases for water saturated silts and clays, EOF typically occurs towards the cathode. Zeta potential can be positive in 
some instances depending on $\mathrm{pH}$ and electrolyte concentrations, which could cause flow in the reverse direction (Acar and Alshawabkeh, 1993). Increasing the electrolyte concentration and decreasing $\mathrm{pH}$ typically reduces $k_{e}$ (Acar and Alshawabkeh, 1993). Reported values of $k_{e}$ range from $8.6 \times 10^{-6}$ to $8.6 \times 10^{-4} \mathrm{~m}^{2} \mathrm{~V}^{-1} \mathrm{day}^{-1}$ for most soils (Chowdhury et al., 2017; Eykholt and Daniel, 1994; Mitchell and Soga, 2005; Shapiro and Probstein, 1993; Shariatmadari et al., 2009; Weng et al., 2003). Under a standard voltage gradient of $1 \mathrm{~V} \mathrm{~cm}^{-1}$, EOF rates typically range from 0.1 and $10 \mathrm{~cm} \mathrm{day}^{-1}$ at the bench-scale (Alshawabkeh, 2009).

\subsubsection{Electromigration-Induced Transport}

EM is the movement of ions in a fluid due to an applied potential field. Ions in solution are attracted to the electrode of opposite charge (Acar et al., 1994). For instance, cations are attracted to a cathode electrode and anions are attracted to an anode electrode (Figure 2.4). EM occurs if there is a connected hydraulic pathway, where the rate is proportional to the voltage gradient of the applied field (Acar et al., 1994). Under several assumptions, EMinduced flow rate can be estimated by (Acar and Alshawabkeh, 1993):

$q_{E M}=u_{i}^{*} i_{e}=\frac{D_{\mathrm{o}} \tau n z_{i} F}{R T} i_{e}$

where $u_{i}^{*}$ is effective ionic mobility of species $\left(\mathrm{m}^{2} \mathrm{~V}^{-1} \mathrm{~s}^{-1}\right), i_{e}$ is voltage gradient $\left(\mathrm{V} \mathrm{m}^{-1}\right)$, $D_{\mathrm{o}}$ is diffusion at infinite dilution $\left(\mathrm{m}^{2} \mathrm{~s}^{-1}\right), \tau$ is soil tortuosity, which varies from 0.01 to 0.84 for most soils (Shackelford and Daniel, 1991), $n$ is porosity, which varies from 0.1 to 0.7 for fine grained soils (Acar and Alshawabkeh, 1993), $z_{i}$ is valence of ionic species, $F$ is Faraday's constant $\left(96,485 \mathrm{C} \mathrm{mol}^{-1}\right), R$ is universal gas constant $\left(8.314 \mathrm{~J} \mathrm{~mol}^{-1} \mathrm{~K}\right)$, and $T$ is temperature $(\mathrm{K})$. Under identical conditions, the EM flow rate of an individual species in an electrolytic solution is dependent on its effective ionic mobility $\left(u_{i}^{*}\right)$, which is directly proportional to its diffusion coefficient in free solution at infinite dilution $\left(\mathrm{D}_{\mathrm{o}}\right)$ (Acar and Alshawabkeh, 1993). The values of these parameters for selected ions are given in Table 2.3 (Chowdhury et al., 2017). 
Table 2.3: Diffusion Coefficient and Effective Ionic Mobility for Common Ions $\underline{\text { (Lide, 2005) }}$

\begin{tabular}{|c|c|c|}
\hline Ions & $\begin{array}{c}\text { Diffusion Coefficient at } \\
\text { Infinite Dilution } \\
\left(\mathbf{D}_{\mathbf{o}}, \mathbf{c m}^{\mathbf{2}} \mathbf{s e c}^{-\mathbf{1}}\right)\end{array}$ & $\begin{array}{c}\text { Effective Ionic Mobility } \\
\left(\boldsymbol{u}_{\boldsymbol{i}}^{*}, \mathbf{~ m}^{\mathbf{2}} \mathbf{V}^{\mathbf{- 1}} \mathbf{d a y}^{-\mathbf{1}}\right)\end{array}$ \\
\hline $\mathrm{HCO}_{3}^{-}$ & $1.19 \times 10^{-5}$ & $5.82 \times 10^{-4}$ \\
\hline $\mathrm{CO}_{3}^{2-}$ & $1.0 \times 10^{-6}$ & $1.34 \times 10^{-4}$ \\
\hline $\mathrm{Na}^{+}$ & $1.33 \times 10^{-5}$ & $6.55 \times 10^{-4}$ \\
\hline $\mathrm{Fe}^{2+}$ & $7.19 \times 10^{-6}$ & $9.06 \times 10^{-4}$ \\
\hline $\mathrm{Cl}^{-}$ & $2.03 \times 10^{-5}$ & $4.57 \times 10^{-3}$ \\
\hline $\mathrm{H}^{+}$ & $9.31 \times 10^{-5}$ & $2.59 \times 10^{-3}$ \\
\hline $\mathrm{OH}^{-}$ & $5.27 \times 10^{-5}$ & $1.05 \times 10^{-3}$ \\
\hline $\mathrm{SO}_{4}^{2-}$ & $1.07 \times 10^{-5}$ & $8.01 \times 10^{-4}$ \\
\hline Permanganate & $1.63 \times 10^{-5}$ & $1.12 \times 10^{-3}$ \\
\hline Persulfate & $1.15 \times 10^{-5}$ & \\
\hline
\end{tabular}

Assuming: $\tau=0.35 ; \mathrm{T}=298 \mathrm{~K} ; \mathrm{F}=96,485 \mathrm{C} \mathrm{mol}^{-1} ; n=0.41$

Eq. 26 can be used to calculate theoretical EM transport rates from known $\mathrm{D}_{\mathrm{o}}$ values. Using the effective ionic mobilities in Table 2.3 and a standard voltage gradient of $1 \mathrm{~V} \mathrm{~cm}^{-1}$, common oxidants used in site remediation such as persulfate and permanganate would posses theoretical EM transport velocities of 8.0 and $11.3 \mathrm{~cm} \mathrm{day}^{-1}$ in clay soil, respectively. EM velocity is typically 1 OoM larger than EO velocity and 1-4 OoM larger than advective velocity in clay soils (Alshawabkeh, 2009; Chowdhury et al., 2017).

\subsubsection{Electrokinetically-Enhanced Persulfate Oxidation}

Both EK and persulfate have gained much interest in recent years regarding environmental remediation. Currently, only a handful of studies have investigated EK-enhanced persulfate oxidation (Chowdhury et al., 2017; Isosaari et al., 2007; Yang and Yeh, 2011; YukselenAksoy and Reddy, 2012; Cang et al., 2012; Fan et al., 2014; Robertson, 2009). Chowdhury et al. (2017) added at separate times, $10 \mathrm{~g} \mathrm{~L}^{-1}$ and $40 \mathrm{~g} \mathrm{~L}^{-1}$ of persulfate, to the cathode 
reservoir of a PCE-silt packed EK cell. EM transport rates of $\sim 2 \mathrm{~cm} \mathrm{day}^{-1}$ were observed under a constant DC of $25 \mathrm{~mA}$. In both instances, persulfate was effectively delivered across the entire cell within 30 days. A maximum breakthrough of $60 \%$ and $29 \%$ was observed during $10 \mathrm{~g} \mathrm{~L}$ and $40 \mathrm{~g} \mathrm{~L}^{-1}$ persulfate injection, respectively. Robertson (2009) obtained similar results, where persulfate was observed to migrate from the cathode to the anode compartment of a clay-packed cell at an EM-induced rate of $1.5 \mathrm{~cm}^{-1 a y^{-1}}$ under 3.7 $\mathrm{V} \mathrm{cm}^{-1}$ voltage gradient. At the end of the 27-day experiment, a breakthrough concentration of $20 \%$ was observed from an input of $4 \mathrm{~g} \mathrm{~L}^{-1}$ at the cathode. Increasing the voltage gradient beyond $3.7 \mathrm{~V} \mathrm{~cm}^{-1}$ resulted in a $30 \%$ increase in breakthrough concentration of persulfate at the anode. Fan et al. (2014) investigated persulfate transport induced by EM and EO through a $12 \mathrm{~cm}$ long column packed with clayey silt. To test for EO-driven transport, 200 $\mathrm{g} \mathrm{L}^{-1}$ of persulfate was added to the anode reservoir. In a separate test run, EM transport was tested by adding $200 \mathrm{~g} \mathrm{~L}^{-1}$ of persulfate to the cathode reservoir. Persulfate was observed to only travel through the entire length of the column under EM-enhancement, with a breakthrough concentration of $8.45 \%$ at the end of the 15-day experiment. Under a $1 \mathrm{~V} \mathrm{~cm}^{-1}$ voltage gradient, EM induced transport was observed to be approximately $2 \mathrm{~cm}$ day $^{-1}$. Although persulfate only reached through $66 \%$ of the column under EO, a higher maximum concentration of persulfate was delivered into the soil column (i.e., $127 \mathrm{~g} \mathrm{~L}^{-1}$ ) when compared to EM (i.e., $44.9 \mathrm{gL}^{-1}$ ).

Although EK has shown the ability to enhance the delivery of persulfate into lowpermeability and or heterogeneous soils, there is also the added complication of activating persulfate once it has been distributed across a target treatment zone in-situ. Few studies have examined EK-enhanced delivery and activation of persulfate (Chowdhury et al., 2017; Fan et al., 2016; Yukselen-Aksoy and Reddy, 2012; Yang and Yeh, 2011). Fan et al. (2016) tested activation methods including alkaline solution, zero-valent iron, iron electrodes, citric acid chelated $\mathrm{Fe}^{2+}$, and hydrogen peroxide in a clayey silt-packed EK cell contaminated with PCBs. Persulfate and activators were loaded in the anode compartment. EOF and mass transfer of persulfate followed the order of: alkaline solution > zero-valent iron $>$ without activation $>$ citric acid chelated $\mathrm{Fe}^{2+}>$ hydrogen peroxide $>$ iron electrodes. 
Alkaline and zero-valent iron activation methods were observed to increase EOF due to increasing the ionic density and current. Activators including citric acid chelated $\mathrm{Fe}^{2+}$ and hydrogen peroxide decreased the EOF as it resulted in complete persulfate decomposition and production of acidic-by products (i.e., $\mathrm{H}^{+}$and $\mathrm{HSO}_{4}^{-}$). It was hypothesized that the large decrease in $\mathrm{pH}$ caused an unfavourable soil surface zeta potential for EOF. A decrease in EOF was also observed for iron electrode activation resulting from a low electric current. The removal efficiency of PCBs in the EK cell followed the order of: alkaline solution $(40.5 \%)>$ hydrogen peroxide $(35.6 \%)>$ citric acid chelated $\mathrm{Fe}^{2+}(34.1 \%)>$ zero-valent iron $(32.4 \%)>$ without activation $(30.8 \%)>$ iron electrodes $(30.5 \%)$. Although these activation methods were found to be effective, their deployment can be difficult as their success is dependent on implementing a correct molar ratio of oxidant to activator, location and method of injection, and complete contact with the oxidant. Regardless of EKenhancement, these activation methods can be difficult to apply in low-permeability soils.

Heat activation has been investigated as a preferred alternative as it does not depend on intrinsic permeability. Yukselen-Aksoy and Reddy (2012) investigated the ability of electrokinetically-enhanced thermally activated persulfate (EK-TAP) to treat $3.7 \mathrm{~cm}$ inner diameter x $13.2 \mathrm{~cm}$ length PCB contaminated kaolin and glacial till packed cells. Persulfate (30\%) was delivered from the anode compartment by EO under a DC voltage gradient of $1 \mathrm{~V} \mathrm{~cm}^{-1}$ and thermally activated at $45^{\circ} \mathrm{C}$ by silicone heating tape. Following the 10-day experiments, $77.9 \%$ and $14.4 \%$ PCB degradation was observed in the kaolin and glacial till cells, respectively. The limited PCB degradation observed in the glacial till packed cell is hypothesized to be a factor of a high soil NOD resulting from a high mineral and organic content. Although EK-TAP showed strong potential in the kaolin packed cell, the method of heating used in the study (i.e., silicone heating tape) cannot be applied in the field. Chowdhury et al. (2017) investigated a novel approach to EK-TAP. In a $36 \mathrm{~cm} \mathrm{x} 15 \mathrm{~cm}$ x $10 \mathrm{~cm}$ PCE silt-packed cell, persulfate was delivered from the cathode department by EM under a DC of $25 \mathrm{~mA}$ and thermally activated using the same electrodes by electrical resistance heating (ERH) from applying an alternating current (AC). More specifically, the bench-scale experiment consisted of two primary phases: i) $10 \mathrm{~g} \mathrm{~L}^{-1}$ persulfate injection 
and $50^{\circ} \mathrm{C}$ thermal activation, and ii) $40 \mathrm{~g} \mathrm{~L}^{-1}$ persulfate injection and $35^{\circ} \mathrm{C}$ thermal activation. Although significant, PCE degradation during phase i) was observed to be less efficient than phase ii). It was hypothesized that producing sulfate free radicals at a slower rate from a lower activation temperature would promote more ideal conditions for free radical oxidation of contaminants to occur. This is confounded, however, by the higher persulfate to PCE ratio obtained during phase ii). To the authors' knowledge, Chowdhury et al. (2017) has been the first published literature study to investigate EK-TAP with ERH as a method for field-scale application. Although it should be noted that this novel approach to EK-TAP is a patented technology by Geosyntec consultants (\#9,004,816, issued April $14,2015)$ that has received some testing both at the bench-scale and field-scale.

\subsection{Summary}

Due to extensive production, industrial use, and improper management practices, chlorinated solvents are among the most prevalent groundwater contaminants found at hazardous waste sites. Over the past decade, persulfate has been established in both academia and industry as an effective oxidant for in-situ remediation of organic contaminants such as chlorinated solvents. For persulfate to be effective, activation is generally required for most contaminants. Several activation methods have been developed (e.g., alkaline solution, chelated or unchelated $\mathrm{Fe}^{2+}$, heat, and hydrogen peroxide), with heat and iron activation being the most researched. For heat activation, the type of contaminants present on site will dictate the temperature required for effective persulfate activation. Typically, higher temperatures applied in persulfate systems will result in more aggressive oxidative conditions being created and increased contaminant degradation rates. For iron activation, bench-scale testing suggests that persulfate to dissolved $\mathrm{Fe}^{2+}$ molar ratios should be pre-determined before field-scale applications to maximize contaminant degradation and to prevent the scavenging of free radicals from excess $\mathrm{Fe}^{2+}$ in solution. Although common iron minerals found in natural soils could potentially aid in the activation of persulfate, injection of aqueous $\mathrm{Fe}^{2+}$ is likely required for most contaminated sites. The use of persulfate can be advantageous over other common oxidants for ISCO due 
to its higher stability and standard reduction potential (i.e., reactivity). Although persulfate can be relatively stable in the presence of aquifer materials, common organic and inorganic species found in soils can be detrimental to persulfate reaction chemistry (i.e., NOD). The interactions between persulfate and aquifer materials requires more investigation. Currently, ISCO has shown to be ineffective at remediating sites containing lowpermeability media due to limited oxidant delivery in such soils by conventional methods (e.g., hydraulic injection). At the bench-scale, EK has demonstrated the ability to enhance the transport of persulfate in low-permeability media. Coupling EK with ERH has shown to be advantageous in that similar infrastructure (i.e., electrodes) can be used for both processes, where persulfate can experience enhanced transport and thermal activation. Heat activation is preferred in low-permeability media as it is not significantly affected by intrinsic permeability. EK-TAP has shown success at the bench-scale in treating lowpermeability media contaminated with organic contaminants; however, limited research has been completed at the field-scale. Further investigation is warranted. 


\subsection{References}

Acar, Y. B., Rabbi, M. F., \& Ozsu, E. E. (1997). Electrokinetic injection of ammonium and sulfate ions into sand and kaolinite beds. Journal of Geotechnical and Geoenvironmental Engineering, 123(3), 239-249.

Acar, Y. B., \& Alshawabkeh, A. N. (1996). Electrokinetic remediation. I: pilot-scale tests with lead-spiked kaolinite. Journal of geotechnical engineering, 122(3), 173-185.

Acar, Y. B., Gale, R. J., Alshawabkeh, A. N., Marks, R. E., Puppala, S., Bricka, M., \& Parker, R. (1995). Electrokinetic remediation: basics and technology status. Journal of hazardous materials, 40(2), 117-137.

Acar, Y. B., Alshawabkeh, A. N., \& Gale, R. J. (1993). Fundamentals of extracting species from soils by electrokinetics. Waste Management, 13(2), 141-151.

Ahmad, M., Teel, A. L., \& Watts, R. J. (2010). Persulfate activation by subsurface minerals. Journal of contaminant hydrology, 115(1-4), 34-45.

Al-Hamdan, A. Z., \& Reddy, K. R. (2005). Surface speciation modeling of heavy metals in kaolin: implications for electrokinetic soil remediation processes. Adsorption, 11(5-6), 529-546.

Alshawabkeh, A. N. (2009). Electrokinetic soil remediation: challenges and opportunities. Separation Science and Technology, 44(10), 2171-2187.

Balabanova, S. A., \& Markevich, A. M. (1966). Kinetics of the reaction of ammonium peroxydisulfate with ferrous iron. Zh. Fiz. Khim, 40(4), 775-780.

Ball, W. P., Liu, C., Xia, G., \& Young, D. F. (1997). A diffusion-based interpretation of tetrachloroethene and trichloroethene concentration profiles in a groundwater aquitard. Water Resources Research, 33(12), 2741-2757.

Barone, F. S., Rowe, R. K., \& Quigley, R. M. (1992). A laboratory estimation of diffusion and adsorption coefficients for several volatile organics in a natural clayey soil. Journal of contaminant hydrology, 10(3), 225-250.

Bennedsen, L. R., Muff, J., \& Søgaard, E. G. (2012). Influence of chloride and carbonates on the reactivity of activated persulfate. Chemosphere, 86(11), 1092-1097.

Block, P. A., Brown, R. A., \& Robinson, D. (2004, May). Novel activation technologies for sodium persulfate in situ chemical oxidation. In Proceedings of the Fourth International Conference on the remediation of chlorinated and recalcitrant compounds (pp. 24-27). Columbus, OH: Battelle Press.

Bossmann, S. H., Oliveros, E., Göb, S., Siegwart, S., Dahlen, E. P., Payawan, L., ... \& Braun, A. M. (1998). New evidence against hydroxyl radicals as reactive intermediates in the thermal and photochemically enhanced Fenton reactions. The Journal of Physical Chemistry A, 102(28), 5542-5550. 
Bougie, S., \& Dube, J. S. (2007). Oxidation of dichlorobenzene isomers using the sodium persulphate subjected to a thermic action. Journal of Environmental Engineering and Science, 6(4), 397-407.

Brown, R. A., Block, P., Watts, R. J., \& Teel, A. L. (2006). Contaminant Specific Persulfate Activation. In Proceedings, Fifth International Conference on the Remediation of Chlorinated and Recalcitrant Compounds, Monterey, CA, USA, May (pp. 22-25).

Buxton, G. V., Bydder, M., \& Salmon, G. A. (1999). The reactivity of chlorine atoms in aqueous solution Part II. The equilibrium SO 4-+ Cl-Cl Nsbd+ SO 4 2. Physical Chemistry Chemical Physics, 1(2), 269-273.

Buxton, G. V., Greenstock, C. L., Helman, W. P., \& Ross, A. B. (1988). Critical review of rate constants for reactions of hydrated electrons, hydrogen atoms and hydroxyl radicals $(\cdot \mathrm{OH} / \cdot \mathrm{O}-$ in aqueous solution. Journal of physical and chemical reference data, 17(2), 513-886.

Cang, L., Zhou, D. M., Wang, Q. Y., \& Fan, G. P. (2012). Impact of electrokinetic-assisted phytoremediation of heavy metal contaminated soil on its physicochemical properties, enzymatic and microbial activities. Electrochimica Acta, 86, 41-48.

Chapman, S. W., \& Parker, B. L. (2005). Plume persistence due to aquitard back diffusion following dense nonaqueous phase liquid source removal or isolation. Water Resources Research, 41(12).

Chen, K. F., Kao, C. M., Wu, L. C., Surampalli, R. Y., \& Liang, S. H. (2009). Methyl tertbutyl ether (MTBE) degradation by ferrous ion-activated persulfate oxidation: feasibility and kinetics studies. Water Environment Research, 81(7), 687-694.

Chowdhury, A. I., Gerhard, J. I., Reynolds, D., \& O’Carroll, D. M. (2017). Low Permeability Zone Remediation via Oxidant Delivered by Electrokinetics and Activated by Electrical Resistance Heating: Proof of Concept. Environmental science \& technology, 51(22), 13295-13303.

Chowdhury, A. I., O’Carroll, D. M., Xu, Y., \& Sleep, B. E. (2012). Electrophoresis enhanced transport of nano-scale zero valent iron. Advances in water resources, 40 , 71-82.

Chung, H. I., \& Kang, B. H. (1999). Lead removal from contaminated marine clay by electrokinetic soil decontamination. Engineering Geology, 53(2), 139-150.

Costanza, J., Otaño, G., Callaghan, J., \& Pennell, K. D. (2010). PCE oxidation by sodium persulfate in the presence of solids. Environmental science \& technology, 44(24), 9445-9450.

Crimi, M. L., \& Taylor, J. (2007). Experimental evaluation of catalyzed hydrogen peroxide and sodium persulfate for destruction of BTEX contaminants. Soil \& Sediment Contamination, 16(1), 29-45. 
Dahmani, M. A., Huang, K., \& Hoag, G. E. (2006). Sodium persulfate oxidation for the remediation of chlorinated solvents (USEPA superfund innovative technology evaluation program). Water, Air, \& Soil Pollution: Focus, 6(1-2), 127-141.

De Laat, J., \& Gallard, H. (1999). Catalytic decomposition of hydrogen peroxide by Fe (III) in homogeneous aqueous solution: mechanism and kinetic modeling. Environmental Science \& Technology, 33(16), 2726-2732.

Do, S. H., Kwon, Y. J., \& Kong, S. H. (2010). Effect of metal oxides on the reactivity of persulfate/Fe (II) in the remediation of diesel-contaminated soil and sand. Journal of hazardous materials, 182(1-3), 933-936.

Doyle, A., Weintraub, M. N., \& Schimel, J. P. (2004). Persulfate digestion and simultaneous colorimetric analysis of carbon and nitrogen in soil extracts. Soil Science Society of America Journal, 68(2), 669-676.

Eykholt, G. R., \& Daniel, D. E. (1994). Impact of system chemistry on electroosmosis in contaminated soil. Journal of geotechnical engineering, 120(5), 797-815.

Fan, G., Cang, L., Gomes, H. I., \& Zhou, D. (2016). Electrokinetic delivery of persulfate to remediate PCBs polluted soils: Effect of different activation methods. Chemosphere, 144, 138-147.

Fan, G., Cang, L., Fang, G., Qin, W., Ge, L., \& Zhou, D. (2014). Electrokinetic delivery of persulfate to remediate PCBs polluted soils: Effect of injection spot. Chemosphere, 117, 410-418.

Gates-Anderson, D. D., Siegrist, R. L., \& Cline, S. R. (2001). Comparison of potassium permanganate and hydrogen peroxide as chemical oxidants for organically contaminated soils. Journal of Environmental Engineering, 127(4), 337-347.

Gill, R. T., Harbottle, M. J., Smith, J. W. N., \& Thornton, S. F. (2014). Electrokineticenhanced bioremediation of organic contaminants: a review of processes and environmental applications. Chemosphere, 107, 31-42.

Goulden, P. D., \& Anthony, D. H. J. (1978). Kinetics of uncatalyzed peroxydisulfate oxidation of organic material in fresh water. Analytical Chemistry, 50(7), 953-958.

Gu, X., Lu, S., Li, L., Qiu, Z., Sui, Q., Lin, K., \& Luo, Q. (2011). Oxidation of 1, 1, 1trichloroethane stimulated by thermally activated persulfate. Industrial \& Engineering Chemistry Research, 50(19), 11029-11036.

Haselow, J. S., Siegrist, R. L., Crimi, M., \& Jarosch, T. (2003). Estimating the total oxidant demand for in situ chemical oxidation design. Remediation Journal: The Journal of Environmental Cleanup Costs, Technologies \& Techniques, 13(4), 5-16.

Heckel, E., Henglein, A., \& Beck, G. (1966). Pulse radiolytic investigation of the radical anion SO4--. Ber. Bunsen-Ges, 70, 149-154.

Hodges, D., Fourie, A., Reynolds, D., \& Thomas, D. (2011). Development of an apparatus for $\mathrm{pH}$-isolated electrokinetic in situ chemical oxidation. Journal of Environmental Engineering, 137(9), 809-816. 
Hønning, J., Broholm, M. M., \& Bjerg, P. L. (2007). Role of diffusion in chemical oxidation of PCE in a dual permeability system. Environmental science \& technology, 41(24), 8426-8432.

House, D. (1962). Kinetics and mechanism of persulfate oxidation. Chem. Rev, 62(185), e203.

Huang, K. C., Zhao, Z., Hoag, G. E., Dahmani, A., \& Block, P. A. (2005). Degradation of volatile organic compounds with thermally activated persulfate oxidation. Chemosphere, 61(4), 551-560.

Huang, K. C., Couttenye, R. A., \& Hoag, G. E. (2002). Kinetics of heat-assisted persulfate oxidation of methyl tert-butyl ether (MTBE). Chemosphere, 49(4), 413-420.

Huling, S. G., \& Pivetz, B. E. (2006). In-situ chemical oxidation (No. EPA/600/R-06/072). ENVIRONMENTAL PROTECTION AGENCY WASHINGTON DC OFFICE OF WATER.

Isosaari, P., Piskonen, R., Ojala, P., Voipio, S., Eilola, K., Lehmus, E., \& Itävaara, M. (2007). Integration of electrokinetics and chemical oxidation for the remediation of creosote-contaminated clay. Journal of hazardous materials, 144(1-2), 538-548.

Johnson, R. L., Cherry, J. A., \& Pankow, J. F. (1989). Diffusive contaminant transport in natural clay: a field example and implications for clay-lined waste disposal sites. Environmental Science \& Technology, 23(3), 340-349.

Johnson, R. L., Tratnyek, P. G., \& Johnson, R. O. B. (2008). Persulfate persistence under thermal activation conditions. Environmental science \& technology, 42(24), 93509356.

Kim, S. H., Han, H. Y., Lee, Y. J., Kim, C. W., \& Yang, J. W. (2010). Effect of electrokinetic remediation on indigenous microbial activity and community within diesel contaminated soil. Science of the total environment, 408(16), 3162-3168.

Kolthoff, I. M., \& Miller, I. K. (1951). The chemistry of persulfate. I. The kinetics and mechanism of the decomposition of the persulfate ion in aqueous medium1. Journal of the American Chemical Society, 73(7), 3055-3059.

Koprivnjak, J. F., Blanchette, J. G., Bourbonniere, R. A., Clair, T. A., Heyes, A., Lum, K. R., ... \& Moore, T. R. (1995). The underestimation of concentrations of dissolved organic carbon in freshwaters. Water research, 29(1), 91-94.

Krembs, F. J., Siegrist, R. L., Crimi, M. L., Furrer, R. F., \& Petri, B. G. (2010). ISCO for groundwater remediation: analysis of field applications and performance. Groundwater Monitoring \& Remediation, 30(4), 42-53.

Kwan, W. P., \& Voelker, B. M. (2003). Rates of hydroxyl radical generation and organic compound oxidation in mineral-catalyzed Fenton-like systems. Environmental science \& technology, 37(6), 1150-1158.

Lageman, R. (1993). Electroreclamation. Applications in the netherlands. Environmental science \& technology, 27(13), 2648-2650. 
Liang, C., Guo, Y. Y., \& Pan, Y. R. (2014). A study of the applicability of various activated persulfate processes for the treatment of 2, 4-dichlorophenoxyacetic acid. International Journal of Environmental Science and Technology, 11(2), 483492.

Liang, C., \& Guo, Y. Y. (2010). Mass transfer and chemical oxidation of naphthalene particles with zerovalent iron activated persulfate. Environmental science \& technology, 44(21), 8203-8208.

Liang, C., Wang, Z. S., \& Bruell, C. J. (2007). Influence of pH on persulfate oxidation of TCE at ambient temperatures. Chemosphere, 66(1), 106-113.

Liang, C., Wang, Z. S., \& Mohanty, N. (2006). Influences of carbonate and chloride ions on persulfate oxidation of trichloroethylene at $20 \mathrm{C}$. Science of the total environment, 370(2-3), 271-277.

Liang, C., Bruell, C. J., Marley, M. C., \& Sperry, K. L. (2004). Persulfate oxidation for in situ remediation of TCE. I. Activated by ferrous ion with and without a persulfatethiosulfate redox couple. Chemosphere, 55(9), 1213-1223.

Liang, C., Bruell, C. J., Marley, M. C., \& Sperry, K. L. (2004). Persulfate oxidation for in situ remediation of TCE. II. Activated by chelated ferrous ion. Chemosphere, 55(9), 1225-1233.

Liang, C. J., Bruell, C. J., Marley, M. C., \& Sperry, K. L. (2003). Thermally activated persulfate oxidation of trichloroethylene (TCE) and 1, 1, 1-trichloroethane (TCA) in aqueous systems and soil slurries. Soil and sediment contamination: An international journal, 12(2), 207-228.

Lide, D. R. (2005). Ionic conductivity and diffusion at infinite dilution. CRC Handbook of Chemistry and Physics.

Lima, A. T., Hofmann, A., Reynolds, D., Ptacek, C. J., Van Cappellen, P., Ottosen, L. M., ... \& Cox, E. (2017). Environmental Electrokinetics for a sustainable subsurface. Chemosphere, 181, 122-133.

Lima, A. T., Kleingeld, P. J., Heister, K., \& Loch, J. G. (2011). Removal of PAHs from contaminated clayey soil by means of electro-osmosis. Separation and Purification Technology, 79(2), 221-229.

Liu, H., Bruton, T. A., Li, W., Buren, J. V., Prasse, C., Doyle, F. M., \& Sedlak, D. L. (2016). Oxidation of benzene by persulfate in the presence of Fe (III)-and Mn (IV)containing oxides: stoichiometric efficiency and transformation products. Environmental science \& technology, 50(2), 890-898.

Liu, H., Bruton, T. A., Doyle, F. M., \& Sedlak, D. L. (2014). In situ chemical oxidation of contaminated groundwater by persulfate: decomposition by Fe (III)-and Mn (IV)containing oxides and aquifer materials. Environmental science \& technology, 48(17), 10330-10336. 
Liu, C., \& Ball, W. P. (2002). Back diffusion of chlorinated solvent contaminants from a natural aquitard to a remediated aquifer under well-controlled field conditions: Predictions and measurements. Groundwater, 40(2), 175-184.

Liu, C., \& Ball, W. P. (1998). Analytical modeling of diffusion-limited contamination and decontamination in a two-layer porous medium. Advances in Water Resources, 21(4), 297-313.

Maturi, K., \& Reddy, K. R. (2006). Simultaneous removal of heavy metals and organic contaminants from soils by electrokinetics using a modified cyclodextrin. Chemosphere, 63(6), 1022-1031.

Matzek, L. W., \& Carter, K. E. (2016). Activated persulfate for organic chemical degradation: a review. Chemosphere, 151, 178-188.

Maupin, M. A., Kenny, J. F., Hutson, S. S., Lovelace, J. K., Barber, N. L., \& Linsey, K. S. (2014). Estimated use of water in the United States in 2010 (No. 1405). US Geological Survey.

McCarty, P. L. (2010). Groundwater contamination by chlorinated solvents: history, remediation technologies and strategies. In In situ remediation of chlorinated solvent plumes (pp. 1-28). Springer, New York, NY.

Mikutta, R., Kleber, M., Kaiser, K., \& Jahn, R. (2005). Review. Soil science society of America journal, 69(1), 120-135.

Mitchell, J. K., \& Soga, K. (2005). Fundamentals of soil behavior (Vol. 3). New York: John Wiley \& Sons.

Moran, M. J., Zogorski, J. S., \& Squillace, P. J. (2007). Chlorinated solvents in groundwater of the United States. Environmental Science \& Technology, 41(1), 7481.

Mumford, K. G., Thomson, N. R., \& Allen-King, R. M. (2005). Bench-scale investigation of permanganate natural oxidant demand kinetics. Environmental science \& technology, 39(8), 2835-2840.

National Research Council. (2005). Contaminants in the subsurface: Source zone assessment and remediation. National Academies Press.

Neta, P., Huie, R. E., \& Ross, A. B. (1988). Rate constants for reactions of inorganic radicals in aqueous solution. Journal of Physical and Chemical Reference Data, 17(3), 1027-1284.

Neta, P., Madhavan, V., Zemel, H., \& Fessenden, R. W. (1977). Rate constants and mechanism of reaction of sulfate radical anion with aromatic compounds. Journal of the American Chemical Society, 99(1), 163-164.

Osgerby, I. T. (2006). ISCO technology overview: do you really understand the chemistry?. In Contaminated soils, sediments and water (pp. 287-308). Springer, Boston, MA. 
Pankow, J. F., \& Cherry, J. A. (1996). Dense chlorinated solvents and other DNAPLs in groundwater: History, behavior, and remediation.

Parker, B. L., Chapman, S. W., \& Guilbeault, M. A. (2008). Plume persistence caused by back diffusion from thin clay layers in a sand aquifer following TCE source-zone hydraulic isolation. Journal of Contaminant Hydrology, 102(1-2), 86-104.

Petri, B. G., Watts, R. J., Teel, A. L., Huling, S. G., \& Brown, R. A. (2011). Fundamentals of ISCO using hydrogen peroxide. In In situ chemical oxidation for groundwater remediation (pp. 33-88). Springer, New York, NY.

Peyton, G. R. (1993). The free-radical chemistry of persulfate-based total organic carbon analyzers. Marine Chemistry, 41(1-3), 91-103.

Pamukcu, S., \& Kenneth Wittle, J. (1992). Electrokinetic removal of selected heavy metals from soil. Environmental Progress, 11(3), 241-250.

Reddy, K. R. (2010). Technical challenges to in-situ remediation of polluted sites. Geotechnical and Geological Engineering, 28(3), 211-221.

Reynolds, D. A., Jones, E. H., Gillen, M., Yusoff, I., \& Thomas, D. G. (2008). Electrokinetic migration of permanganate through low-permeability media. Groundwater, 46(4), 629-637.

Ribeiro, A. B., Rodriguez-Maroto, J. M., Mateus, E. P., \& Gomes, H. (2005). Removal of organic contaminants from soils by an electrokinetic process: the case of atrazine.: Experimental and modeling. Chemosphere, 59(9), 1229-1239.

Roach, N., \& Reddy, K. R. (2006). Electrokinetic delivery of permanganate into lowpermeability soils. International Journal of Environment and Waste Management, 1(1), 4-19.

Robertson, T. (2009). Electrokinetic Transport of Persulfate under Voltage Gradients. $M E$ dissertation, University of Technology Sydney.

Saichek, R. E., \& Reddy, K. R. (2005). Electrokinetically enhanced remediation of hydrophobic organic compounds in soils: a review. Critical reviews in environmental science and technology, 35(2), 115-192.

Sale, T., Parker, B. L., Newell, C. J., \& Devlin, J. F. (2013). Management of Contaminants Stored in Low Permeability Zones-A State of the Science Review. Colorado State Univ Fort Collins Dept Of Civil And Environmental Engineering.

Seyedabbasi, M. A., Newell, C. J., Adamson, D. T., \& Sale, T. C. (2012). Relative contribution of DNAPL dissolution and matrix diffusion to the long-term persistence of chlorinated solvent source zones. Journal of contaminant hydrology, 134, 69-81.

Soesilo, J. A., \& Wilson, S. (1997). Site remediation: planning and management. CRC Press. 
Shackelford, C. D., \& Daniel, D. E. (1991). Diffusion in saturated soil. I: Background. Journal of Geotechnical Engineering, 117(3), 467-484.

Shapiro, A. P., \& Probstein, R. F. (1993). Removal of contaminants from saturated clay by electroosmosis. Environmental Science \& Technology, 27(2), 283-291.

Shariatmadari, N., Weng, C. H., \& Daryaee, H. (2009). Enhancement of hexavalent chromium [Cr (VI)] remediation from clayey soils by electrokinetics coupled with a nano-sized zero-valent iron barrier. Environmental Engineering Science, 26(6), 1071-1079.

Siegrist, R. L., Crimi, M., \& Brown, R. A. (2011). In situ chemical oxidation: Technology description and status. In In situ chemical oxidation for groundwater remediation (pp. 1-32). Springer, New York, NY.

Singh, U. C., \& Venkatarao, K. (1976). Decomposition of peroxodisulphate in aqueous alkaline solution. Journal of Inorganic and Nuclear Chemistry, 38(3), 541-543.

Sperry, K. L., Marley, M. C., Bruell, C. J., Liang, C., \& Hochreiter, J. (2003, May). Iron catalyzed persulfate oxidation of chlorinated solvents. In Third International Conference on Remediation of Chlorinated and Recalcitrant Compounds (p. 2002).

Sra, K. S., Thomson, N. R., \& Barker, J. F. (2010). Persistence of persulfate in uncontaminated aquifer materials. Environmental science \& technology, 44(8), 3098-3104.

Struse, A. M., Siegrist, R. L., Dawson, H. E., \& Urynowicz, M. A. (2002). Diffusive transport of permanganate during in situ oxidation. Journal of Environmental Engineering, 128(4), 327-334.

Stroo, H. F., Vogel, C. M., \& Ward, C. H. (2014). Chlorinated solvent source zone remediation. B. H. Kueper (Ed.). Springer.

Stroo, H. F., Leeson, A., Marqusee, J. A., Johnson, P. C., Ward, C. H., Kavanaugh, M. C., ... \& Unger, M. (2012). Chlorinated ethene source remediation: Lessons learned.

Stroo, H. F., Unger, M., Ward, C. H., Kavanaugh, M. C., Vogel, C., Leeson, A., ... \& Smith, B. P. (2003). Peer reviewed: Remediating chlorinated solvent source zones.

Teel, A. L., Ahmad, M., \& Watts, R. J. (2011). Persulfate activation by naturally occurring trace minerals. Journal of hazardous materials, 196, 153-159.

Teel, A. L., Finn, D. D., Schmidt, J. T., Cutler, L. M., \& Watts, R. J. (2007). Rates of trace mineral-catalyzed decomposition of hydrogen peroxide. Journal of Environmental Engineering, 133(8), 853-858.

Tsitonaki, A., Petri, B., Crimi, M., Mosbæk, H., Siegrist, R. L., \& Bjerg, P. L. (2010). In situ chemical oxidation of contaminated soil and groundwater using persulfate: a review. Critical Reviews in Environmental Science and Technology, 40(1), 55-91.

Virkutyte, J., Sillanpää, M., \& Latostenmaa, P. (2002). Electrokinetic soil remediationcritical overview. Science of the Total Environment, 289(1-3), 97-121. 
Waldemer, R. H., Tratnyek, P. G., Johnson, R. L., \& Nurmi, J. T. (2007). Oxidation of chlorinated ethenes by heat-activated persulfate: kinetics and products. Environmental Science \& Technology, 41(3), 1010-1015.

Watts, R. J., \& Teel, A. L. (2006). Treatment of contaminated soils and groundwater using ISCO.Practice Periodical of Hazardous, Toxic, and Radioactive Waste Management, 10(1), 2-9.

Watts, R. J., \& Teel, A. L. (2005). Chemistry of modified Fenton's reagent (catalyzed H 2 O 2 propagations-CHP) for in situ soil and groundwater remediation. Journal of environmental engineering, 131(4), 612-622.

Weng, C. H., Yuan, C., \& Tu, H. H. (2003). Removal of trichloroethylene from clay soil by series-electrokinetic process. Practice Periodical of Hazardous, Toxic, and Radioactive Waste Management, 7(1), 25-30.

Woods, R., Kolthoff, I. M., \& Meehan, E. J. (1963). Arsenic (IV) as an intermediate in the induced oxidation of arsenic (III) by the iron (II)-persulfate reaction and the photoreduction of iron (III). I. Absence of oxygen. Journal of the American Chemical Society, 85(16), 2385-2390.

Xu, X. R., \& Li, X. Z. (2010). Degradation of azo dye Orange G in aqueous solutions by persulfate with ferrous ion. Separation and purification technology, 72(1), 105111.

Xu, X., \& Thomson, N. R. (2009). A long-term bench-scale investigation of permanganate consumption by aquifer materials. Journal of contaminant hydrology, 110(3-4), 7386.

Xu, X., \& Thomson, N. R. (2008). Estimation of the maximum consumption of permanganate by aquifer solids using a modified chemical oxygen demand test. Journal of Environmental Engineering, 134(5), 353-361.

Yang, M., Annable, M. D., \& Jawitz, J. W. (2014). Back diffusion from thin low permeability zones. Environmental science \& technology, 49(1), 415-422.

Yang, G. C., \& Yeh, C. F. (2011). Enhanced nano-Fe3O4/S2O82- oxidation of trichloroethylene in a clayey soil by electrokinetics. Separation and Purification Technology, 79(2), 264-271.

Yeung, A. T. (2011). Milestone developments, myths, and future directions of electrokinetic remediation. Separation and Purification Technology, 79(2), 124132.

Yen, C. H., Chen, K. F., Kao, C. M., Liang, S. H., \& Chen, T. Y. (2011). Application of persulfate to remediate petroleum hydrocarbon-contaminated soil: Feasibility and comparison with common oxidants. Journal of hazardous materials, 186(2-3), 2097-2102.

Yu, X. Y., \& Barker, J. R. (2003). Hydrogen peroxide photolysis in acidic aqueous solutions containing chloride ions. I. Chemical mechanism. The Journal of Physical Chemistry A, 107(9), 1313-1324. 
Yukselen-Aksoy, Y., \& Reddy, K. R. (2012). Electrokinetic delivery and activation of persulfate for oxidation of PCBs in clayey soils. Journal of Geotechnical and Geoenvironmental Engineering, 139(1), 175-184.

Zhao, D., Liao, X., Yan, X., Huling, S. G., Chai, T., \& Tao, H. (2013). Effect and mechanism of persulfate activated by different methods for PAHs removal in soil. Journal of hazardous materials, 254, 228-235.

Zhu, W., Singer, S. J., Zheng, Z., \& Conlisk, A. T. (2005). Electro-osmotic flow of a model electrolyte. Physical review E, 71(4), 041501. 


\section{Chapter 3}

\section{Field Test of Electrokinetically-Delivered Thermally Activated Persulfate (EK-TAP) for Remediation of Chlorinated Solvents in Clay}

\subsection{Introduction}

The application of in-situ chemical oxidation (ISCO) for the remediation of organic contaminants in soils has gained much interest over the last decade. This is because ISCO has proven to be rapid, aggressive, cost effective, and can be easily applied in-situ avoiding the need for expensive and destructive excavation procedures (ITRC, 2005; Tsitonaki et al., 2010; Watts and Teel, 2006). Common oxidants that have been implemented are permanganate, hydrogen peroxide, and ozone. The effectiveness of these oxidants is often hindered due to their low stability in the subsurface (i.e., hydrogen peroxide and ozone) and high affinity for natural soil organics (i.e., permanganate) (Gates-Anderson et al., 2001; Li and Schwartz, 2004; Navalon et al., 2014; Tsai et al., 2008; Yukselen-Aksoy and Reddy, 2012).

Persulfate $\left(\mathrm{S}_{2} \mathrm{O}_{8}^{2-}\right)$, a strong oxidant $\left(\mathrm{E}^{\circ}=2.01 \mathrm{~V}\right)$, has been proposed due to its higher relative stability (Fan et al., 2015). This allows persulfate to be more persistent in the subsurface and to be transported greater distances, resulting in more contaminant degradation. The half-life of persulfate in the presence of aquifer materials ranges between 15 and 600 days, which is approximately 1-2 OoM longer than hydrogen peroxide and permanganate in the same soil (Brown and Robinson, 2004; Liu et al., 2014). The half-life has been found to be negatively correlated with the amount of reduced iron and manganese in a soil as well as the total organic carbon (TOC), all of which form the natural oxidant demand (NOD) (Dahmani et al., 2007; Sra et al., 2010). Although a higher iron and manganese content can be detrimental to persulfate transport due to enhanced decomposition, the by-products (i.e., free radicals) can potentially benefit contaminant 
degradation (Ahmad et al., 2010; Do et al., 2010; Liang et al., 2010; Liu et al., 2014; Oh et al., 2011; Teel et al., 2011).

Despite being kinetically slow, inactivated persulfate can react with organic contaminants by direct-electron transfer via self-decomposition; however, persulfate activation is typically preferred (Huang et al., 2005; Liang et al.,2010). Activation consists of the homolytic cleavage of the oxygen-oxygen bond of the persulfate anion, resulting in the production of free radicals (Johnson et al., 2008; Tsitonaki et al., 2010). These free radicals, predominantly sulfate and hydroxyl radicals, are more aggressive oxidants $\left(\mathrm{SO}_{4}^{\circ-}, \mathrm{E}^{\circ}=2.6\right.$ $\mathrm{V} ;{ }^{\circ} \mathrm{OH}, \mathrm{E}^{\circ}=2.7 \mathrm{~V}$ ) with quicker reaction kinetics (House et al., 1962). Several activation methods have been tested, including heat (Eq. 3.1), chelated or unchelated $\mathrm{Fe}^{2+}$ (Eq. 3.2), hydrogen peroxide (Eq. 3.3), and strong alkaline solution (Eq. 3.4) and are, respectively, described (Matzek et al., 2016; Petri et al., 2011; Tsitonaki et al., 2010):

$\mathrm{S}_{2} \mathrm{O}_{8}^{2-} \stackrel{\text { heat }}{\longrightarrow} 2 \mathrm{SO}_{4}^{\cdot-}$

$\mathrm{Fe}^{2+}+\mathrm{S}_{2} \mathrm{O}_{8}^{2-} \rightarrow \mathrm{Fe}^{3+}+\mathrm{SO}_{4}^{\cdot-}+\mathrm{SO}_{4}^{2-}$

$\mathrm{S}_{2} \mathrm{O}_{8}^{2-}+\bullet \mathrm{OH} \rightarrow \mathrm{SO}_{4}^{2-}+\mathrm{SO}_{4}^{\cdot-}+\frac{1}{2} \mathrm{O}_{2}+\mathrm{H}^{+}$

$\mathrm{SO}_{4}^{--}+\mathrm{OH}^{-} \rightarrow \mathrm{SO}_{4}^{2-}+\bullet \mathrm{OH}$

During remediation activities, persulfate, like other oxidants, is typically delivered to a target treatment zone in-situ via hydraulic injection relying primarily on advective transport. This has proven to be successful in high-permeability soils. However, the delivery of an oxidant by hydraulic injection into low-permeability and or heterogeneous soil is usually limited by diffusion-controlled rates, which are often insufficient for remediation (Cavanagh et al., 2014; Krembs et al., 2011). Electrokinetics (EK) has been recently investigated as a solution to these challenges associated with oxidant delivery (Chowdhury et al., 2017; Isosaari et al., 2007; Ren et al., 2014; Reynolds et al., 2008; Roach and Reddy, 2006; Wu et al., 2012). EK is the application of a low-voltage direct-current (DC) across two or more electrodes (i.e., negatively charged cathode and positively charged anode), utilizing two dominant transport mechanisms: electroosmosis (EO) and 
electromigration (EM). EO is the movement of bulk fluid (i.e., pore water), including dissolved ionic and non-ionic species, from the anode to the cathode. EM is the transport of charged aqueous ions and species towards the oppositely charged electrode where anions migrate towards the anode and cations migrate towards the cathode (Alshawabkeh, 1993).

EK-enhanced persulfate transport has been examined in laboratory-scale studies (Chowdhury et al., 2017; Isosaari et al., 2007; Yang and Yeh, 2011; Yukselen-Aksoy and Reddy, 2011; Cang et al., 2012; Fan et al., 2014; Robertson, 2009). Chowdhury et al. (2017) reported an EM-induced transport rate of $\sim 2 \mathrm{~cm}$ day $^{-1}$ at a voltage gradient of $1 \mathrm{~V}$ $\mathrm{cm}^{-1}$ when adding persulfate $\left(10-40 \mathrm{~g} \mathrm{~L}^{-1}\right)$ to the cathode reservoir of a silt-packed EK cell. Robertson (2009) obtained similar results, where persulfate $\left(4 \mathrm{~g} \mathrm{~L}^{-1}\right)$ was observed to migrate through a clay-packed EK cell at an EM induced rate of $1.5 \mathrm{~cm} \mathrm{day}^{-1}$ under a 3.7 $\mathrm{V} \mathrm{cm}^{-1}$ gradient. Fan et al. (2014) investigated persulfate $\left(200 \mathrm{~g} \mathrm{~L}^{-1}\right)$ transport induced by EM and EO through a clayey silt packed column under a $1 \mathrm{~V} \mathrm{~cm}^{-1}$ gradient. EM transport was tested by injecting persulfate into the cathode compartment, while EO transport was tested in a separate run by injecting persulfate into the anode compartment. Persulfate was observed to travel through the entire length of the column only under EM induced transport $\left(\sim 2 \mathrm{~cm} \mathrm{day}^{-1}\right)$. Under EO, persulfate travelled through $66 \%$ of the column at a similar rate as EM (i.e., $\sim 2 \mathrm{~cm}$ day ${ }^{-1}$ ); however, a higher maximum concentration of persulfate was delivered into the soil column by EO (i.e., $127 \mathrm{~g} \mathrm{~L}^{-1}$ ) than by EM (i.e., $44.9 \mathrm{~g} \mathrm{~L}^{-1}$ ).

Although these studies suggest that EK can be used to deliver persulfate into lowpermeability soils, there is the added complication of activating persulfate in-situ. Few bench-scale studies have examined EK-enhanced delivery and activation of persulfate. Fan et al. (2016) tested several activation methods including alkaline solution, zero-valent iron, iron electrodes, citric acid chelated $\mathrm{Fe}^{2+}$, and hydrogen peroxide in a clayey silt-packed $\mathrm{EK}$ cell loaded with polychlorinated biphenyls (PCBs). All activators enhanced the decomposition (i.e., activation) of persulfate with the exception iron electrodes, where PCB removal efficiencies followed the order: alkaline solution $>$ hydrogen peroxide $>$ citric acid chelated $\mathrm{Fe}^{2+}>$ zero-valent iron > without activation > iron electrodes. Yukselen-Aksoy 
and Reddy (2012) investigated thermal activation by heating glacial till and kaolin packed EK cells to $45^{\circ} \mathrm{C}$ using a silicone heating tape. PCB degradation resulting from thermally activated persulfate was found to be significant in kaolin (i.e., 77.9\%), while limited degradation of PCB was observed in glacial till. This was due to the glacial till soil containing a higher NOD (Yukselen-Aksoy and Reddy, 2012). Although heat activation was found to be effective in kaolin, this method of heating used cannot be implemented in the field.

Chowdhury et al. (2017) investigated a novel approach: EK-enhanced thermally activated persulfate (EK-TAP). In a tetrachloroethene (PCE) contaminated silt-packed EK cell, persulfate was delivered by EM-induced transport by applying a DC current and then thermally activated by applying an AC current for low-temperature electrical resistance heating (ERH) using the same electrodes. Significant heat propagation and PCE degradation were observed in the bench top experiment. Thermally activated persulfate has also been shown in laboratory-scale studies to be effective on a wide array of contaminants including chloroethanes, chlorothenes, and chloromethanes (Block and Brown, 2004; Huang et al., 2005; Huang et al., 2002; Liang et al., 2003; Tsitonaki et al., 2004; Waldemer et al., 2007). To the authors' knowledge, no published literature studies have investigated EK-TAP at the field-scale. Although it is to be noted that EK-TAP is a patented technology $\left(\# 9,004,816\right.$, issued April $\left.14^{\text {th }}, 2015\right)$ by Geosyntec Consultants that has received some field-scale testing with limited success. Further research and development is needed.

This work presents an 8-month EK-TAP field pilot test that was conducted in a chlorinated solvent-contaminated clay aquitard beneath a former chemical manufacturing facility. 1,2dichloroethane (1,2-DCA) was the primary contaminant of concern. The specific objectives of this study are: i) investigate EK-enhanced persulfate transport in relatively homogeneous clay soil, ii) evaluate the ability of ERH to thermally activate persulfate, and iii) quantify the ability of thermally activated persulfate to degrade chlorinated solvents. This field-scale study provides a basis for the further optimization of the EK-TAP 
technology with the potential for wide-scale applicability for the remediation of lowpermeability sites contaminated with chlorinated solvents.

\subsection{Site Description}

The EK-TAP field test was conducted in southwestern Ontario, Canada from 2016-2017 under a former drum storage area that was adjacent to a vinyl chloride production facility (Figure D1, Appendix D). The top $2.4 \mathrm{~m}$ below ground surface (bgs) of the site consists of heterogeneous fill material (i.e., gravel and clayey sand) followed by $15 \mathrm{~m}$ of glacial till (i.e., St. Joseph Till geological unit), composed of 40-60\% clay, 30-40\% silt, 5-10\% sand, and <5\% gravel (Hanna et al., 1966; Husain et al., 1998; Soderman and Kim, 1970). The upper 4-7 $\mathrm{m}$ of the St. Joseph Till unit, labelled as brown clay, is highly weathered and oxidized. The remaining lower portion of the St. Joseph Till, identified as grey clay, is unweathered and nearly impervious clay (Figure 3.1). The water table is $\sim 2.5 \mathrm{~m}$ (bgs), although it is susceptible to seasonal and spatial variability (Figure 3.1). The ambient hydraulic gradient across the site ranges from 0.004-0.008 (Figure D2, Appendix D), with a hydraulic conductivity $\left(k_{h}\right)$ of $8.6 \times 10^{-4} \mathrm{~m} \mathrm{day}^{-1}$ within the St. Joseph Till unit (Husain et al., 1998). The ambient groundwater velocity is estimated to be $1.4 \times 10^{-5} \mathrm{~m} \mathrm{day}^{-1}$ in the test area, flowing in a northwestern direction (Husain et al., 1998).

\subsection{Materials and Methodology}

\subsubsection{Well Installation and Field Test Design}

The EK-TAP field test consisted of two transects: EK-TAP and Control (Figure 3.2). The Control transect employed no EK. In the EK-TAP transect, persulfate was added to supply wells in the presence of a DC and then thermally activated by low-temperature ERH. EKTAP was equipped with a cathode well $(\mathrm{CW})$, two sets of nested monitoring wells (MW1 and MW2), and one anode well (AW). The CW and AW (i.e., electrode wells) were spaced $3 \mathrm{~m}$ apart and screened from 2.4-4.9 m (bgs) (Figure 3.1). Nested monitoring wells, MW1 
and MW2, were located $0.7 \mathrm{~m}$ and $2.3 \mathrm{~m}$ away from the CW. Nested monitoring wells consisted of two separate adjacent wells that were screened from 3.1-3.7 m (bgs) (MW1A and MW2A) and 3.7-4.3 m (bgs) (MW1B and MW2B) (Figure 3.1). Additionally, the EKTAP transect contained two supply wells, SW1 and SW2, located $0.3 \mathrm{~m}$ and $1.5 \mathrm{~m}$ away from the $\mathrm{CW}$, respectively. Both supply wells were screened from 2.4-4.9 m (bgs) (Figure 3.1). The Control transect consisted of two adjacent monitoring wells, MW1A and MW1B, that were screened from 3.1-3.7 m (bgs) and 3.7-4.3 m (bgs), respectively.

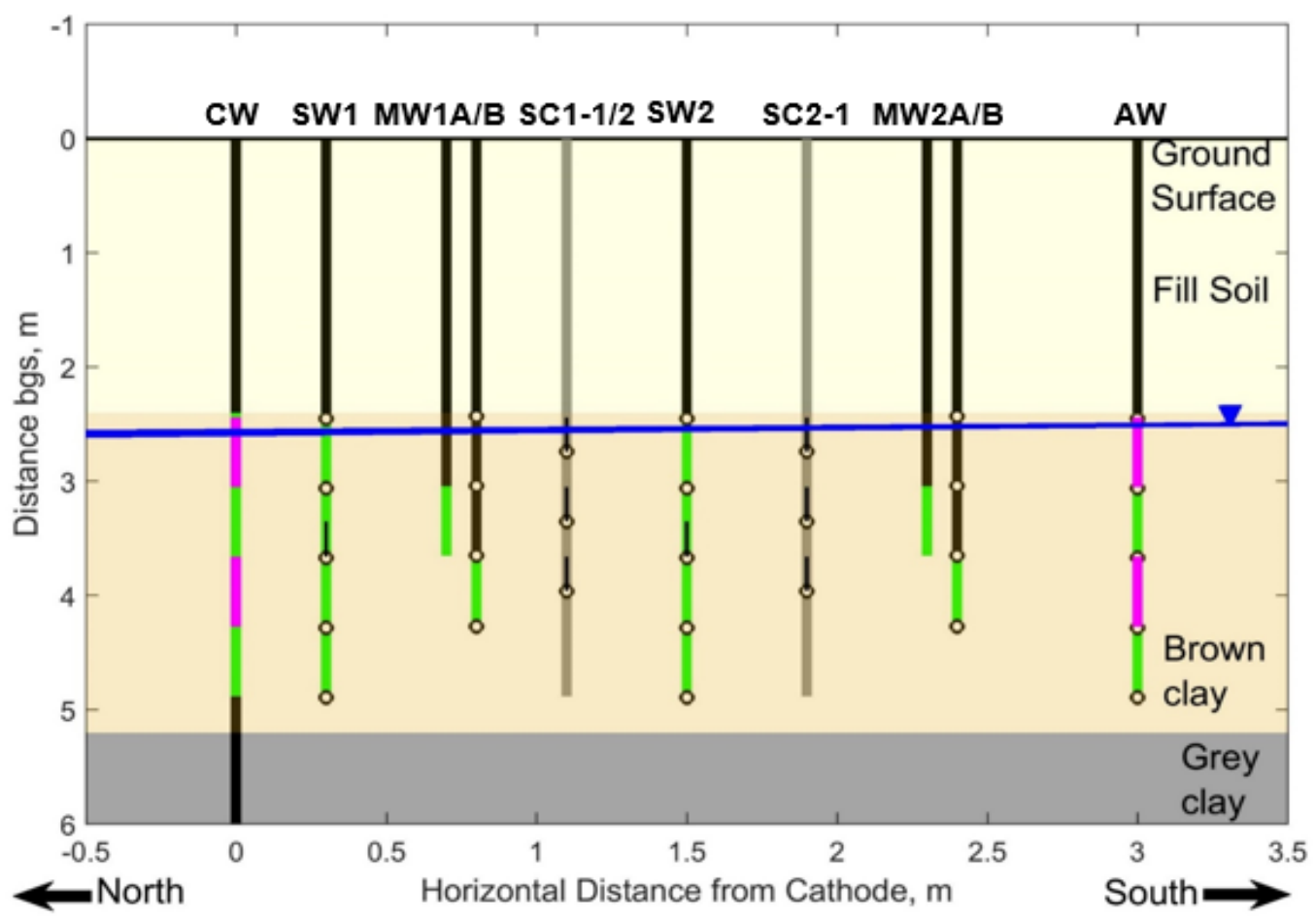

Figure 3.1: Cross-section of EK-TAP displaying site geology, water table, wells, and boreholes. Green and pink regions represent well screens and electrodes, respectively. Open circles are soil sampling locations. Open circles with dashes are thermocouple locations. Natural groundwater flow occurs from the AW to the CW. 


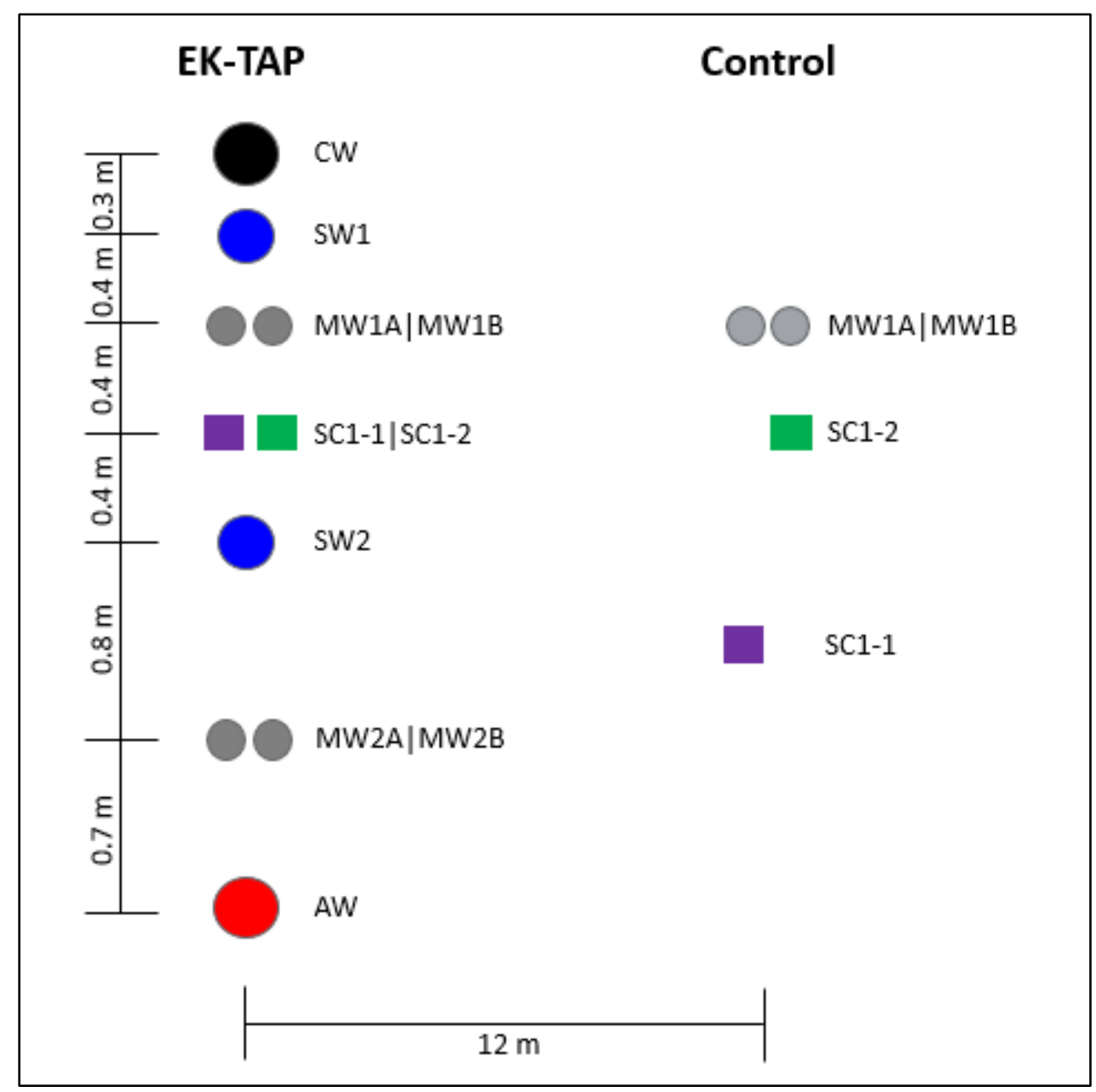

Figure 3.2: Plan view of test area displaying EK-TAP and Control transects including well and borehole locations.

\subsubsection{Electrokinetic-Enhancement}

In EK-TAP, a DC current was applied to provide EK-enhanced persulfate transport. The CW and AW were connected to a central AC/DC power supply (SL Series 1 Programmable DC Power Supply, Magna-Power Electronics). Both the CW and AW contained two electrodes that were hung from 2.4-3.1 m (bgs) and 3.7-4.3 m (bgs) (Figure 3.1). All electrodes were composed of a titanium tube $(61 \mathrm{~cm} \times 2.54 \mathrm{~cm}$ diameter $)$ with WS-30 $\mathrm{IrO}_{2}$ coating, connected with \#12 AWG 7 stranded copper wire (Water Star Inc., OH, USA). DC was applied for 57 days (September $28^{\text {th }}$ to November $24^{\text {th }}, 2016$ ), where applied current was slowly increased from an initial 1.1 A to a target of 9 A over 12 days (Figure 
D3, Appendix D). It is noted there were isolated power reductions as well as system shut downs for maintenance. The target amperage was achieved for 22 days (Figure D3, Appendix D). As the system operated in parallel, applied current was split four ways (i.e., EK-TAP and three other EK transects that are not discussed in this study). The system was designed such that $\sim 1.1$ A was applied to the EK-TAP shallow (i.e., 2.4-3.1 m bgs) and deep (i.e., 3.7-4.6 m bgs) electrodes, assuming similar resistance in all EK transects, when target amperage was achieved. Individual handheld current readings were taken from deep and shallow electrodes of the CW and AW of EK-TAP during applied DC (i.e., day 1, 8, 20, and 28) (all days referenced from the start of injection) (Table A1, Appendix A). Readings taken on day 20 and 28 when target amperage of 9A was applied to the EK transects suggest that $\sim 1.1$ A was indeed being applied to the shallow and deep electrodes.

To measure the applied voltage and impedance of circuits in-situ, voltage probes were installed at $3.2 \mathrm{~m}$ and $4.1 \mathrm{~m}$ (bgs) in SW1 and SW2 of EK-TAP. The probes were composed of grade 304 stainless steel cables, with a diameter of $0.48 \mathrm{~mm}$ and a vinyl coating. Additionally, two mixed metal oxide voltage probes (Titanium Electrode Products Inc., Texas, USA) with a $0.3 \mathrm{~cm}$ diameter and $15 \mathrm{~cm}$ length were attached at identical depths. Similar to supply wells, monitoring wells in EK-TAP were equipped with stainless steel voltage probes at $3.2 \mathrm{~m}$ and $4.1 \mathrm{~m}(\mathrm{bgs})$.

\subsubsection{Persulfate and Buffer Injection}

$925 \mathrm{~L}$ of $40 \mathrm{~g} \mathrm{~L}^{-1}$ sodium persulfate was delivered to the formation continuously at SW1 and SW2 over 57 days while DC current was applied (September $28^{\text {th }}$ to November $24^{\text {th }}$, 2016). Due to subsurface heterogeneities, unequal amounts of persulfate may have been delivered to SW1 and SW2. A constant head was maintained in each supply well at 0.61 m (bgs) with the use of a float switch. Persulfate solution was delivered from a $1000 \mathrm{~L}$ storage tank using FLEXFLO peristaltic pumps (A-100NX, Blue-White Industries Ltd.) and $0.64 \mathrm{~cm}$ high-density polyethylene (HDPE) tubing. Additionally, a pH buffer solution composed of $4 \mathrm{~g} \mathrm{~L}^{-1}$ mono-sodium phosphate and $4 \mathrm{~g} \mathrm{~L}^{-1}$ di-sodium phosphate was 
recirculated through all electrode wells at $13 \mathrm{~mL} \mathrm{~min}^{-1}$ from a $1000 \mathrm{~L}$ storage tank by FLEXFLO peristaltic pumps (A-100NX, Blue-White Industries Ltd.) and $0.64 \mathrm{~cm}$ HDPE tubing.

\subsubsection{Electrical Resistance Heating for Thermal Activation}

To thermally activate the injected persulfate by ERH, applied DC was switched to AC on day 57 (November $24^{\text {th }}, 2016$ ) and controlled using a variable AC power output controller (i.e., Variac) (3PN2210B Variable Transformer, Staco Energy Products Co.) for which the output was set at $\sim 56 \%$ of $120 \mathrm{~V}$ constant input voltage (Figure A1, Appendix A). Applied AC to EK-TAP was measured using a handheld AC/DC clamp meter (DCM269, Velleman). Graphite was added to the $\mathrm{CW}$ on day 121 to increase thermal and electrical conductance. The target temperature was $\sim 40^{\circ} \mathrm{C}$ for effective persulfate activation and subsequent contaminant oxidation (Brown and Block, 2004; Chowdhury et al., 2017; Huang et al., 2005; Liang et al., 2003). To monitor temperature, in-situ thermocouples (KT21412, Kelvin Technologies) were installed at $3.7 \mathrm{~m}$ (bgs) in each of the SWs. Thermocouples (K-Type, Omega Engineering, Inc., USA.) were also installed at 2.7 m, 3.4 $\mathrm{m}$ and $4.0 \mathrm{~m}$ (bgs) in two boreholes completed within EK-TAP (i.e., SC1-1 and SC2-1) on day 127 (February $2^{\text {nd }}, 2017$ ) (Figure 3.1). A borehole was also completed $10 \mathrm{~m}$ east of the EK-TAP transect in a similar manner to serve as a control; quantifying natural subsurface temperatures.

\subsubsection{Soil Coring and Analysis}

Three rounds of soil coring were performed in the EK-TAP and Control transects. The first coring round (i.e., background) was completed from day -32 to -52 (August $8^{\text {th }}$ to $27^{\text {th }}$, 2016) using a hollow-stem auger and split spoon samplers. The borehole locations included all existing electrode wells, supply wells, and monitoring wells of EK-TAP and Control. The second coring round was completed during applied ERH on day 125 (January $30^{\text {th }}$, 2017) using a geoprobe (direct-push) and hollow-core samplers. The borehole locations 
included T-SC1-1 and C-SC1-1 (Figure 3.2). The third coring round was completed postERH on day 286 (July $11^{\text {th }}, 2017$ ) also using a geoprobe and hollow-core samplers. The borehole locations included T-SC1-2 and C-SC1-2 (Figure 3.2). Soil samples were taken from all boreholes at depths ranging from 2.4-4.9 m (bgs). Soil samples collected for iron and sulfur were stored in unpreserved soil jars. Soil samples collected for chlorinated organic compounds (COCs) $(\sim 10 \mathrm{~g})$ were placed in $40 \mathrm{~mL}$ volatile organic analysis (VOA) vials preserved with $10 \mathrm{~mL}$ of methanol.

Iron and sulfur soil concentrations were measured using inductively coupled plasma optical emission spectrometry (ICP-OES) (Varian Vista-Pro Axial, Agilent, Santa Clara, CA) after microwave-assisted digestion following U.S. Environmental Protection Agency (USEPA) method 3051A (MARS 239/60, CEM Co.) (Element, 2007). Soil COC concentrations were quantified following a modified EPA 8021 method using an Agilent $7890 \mathrm{GC}$ with an electron capture detector (ECD). Lesser COCs were analyzed on the Agilent GC by taking headspace samples and using a flame ionization detector (FID). Measured COCs by ECD and FID are listed in Table D1, Appendix D.

Additional analyses were completed on borehole T-SC1-2 of EK-TAP to further determine the iron content of the site soil, where the fraction of $\mathrm{Fe}^{2+}$ to $\mathrm{Fe}_{\text {total }}$ was determined. Subcores were sectioned from the T-SC1-2 soil core during field collection between depths 3.7-4.2 $\mathrm{m}$ (bgs). To prevent oxidation from ambient air, sectioned sub-cores were retained in the plastic soil core liner and were capped. Due to the nature of the clay soil and minimal voids observed in the sub-cores, nitrogen flushing, and pressurization was deemed unnecessary for preservation. All sub-cores were placed on dry ice after collection and transported to The University of Western Ontario, where they were kept frozen until analysis. The $\mathrm{Fe}^{2+}$ content of the sub-cores was measured by the ferrozine method developed by Lovley and Phillips (1987) using a $0.5 \mathrm{M} \mathrm{HCl}$ extraction (Method D1, Appendix D). This method has shown the ability to extract ion-exchangeable $\mathrm{Fe}^{2+}, \mathrm{FeS}$, and $\mathrm{FeCO}_{3}$ species (Heron et al., 1994). 


\subsubsection{Groundwater Sampling and Analysis}

Groundwater samples were collected from all monitoring wells of EK-TAP and Control on a near weekly basis during injection and applied EK from day 0 to 62 (September $28^{\text {th }}$, 2016 to November 29 ${ }^{\text {th }}, 2017$ ). Additional sampling events took place during and postERH, including days 196, 264, and 391 (January $26^{\text {th }}$, April $12^{\text {th }}$, June $19^{\text {th }}$, and October $\left.24^{\text {th }}, 2017\right)$. Samples were collected following low-flow groundwater sampling procedures (Puls and Barcelona, 1996), using a peristaltic pump (i.e., flow rate 150-200 $\mathrm{mL} \mathrm{min}^{-1}$ ) and low-density polyethylene tubing (LDPE) extraction lines installed in all wells. Collected samples were analyzed for iron, sulfur, sodium, persulfate, chloride, sulfate, COCs, and geochemical parameters (i.e., $\mathrm{pH}$, electrical conductance, and oxidation-reduction potential). Samples for iron, sulfur, sodium, persulfate, sulfate, and chloride analysis were collected in HDPE bottles, while COCs were collected in $40 \mathrm{~mL}$ VOA vials with no headspace and preserved with $0.2 \mathrm{~g}$ sodium bisulfate. Groundwater geochemical parameters were measured during sampling with a multiparameter field probe (YSI 556 MPS, Yellow Springs, OH). All monitoring wells were purged 7 days prior to sampling due to low groundwater recovery rates of the site.

Anions, including chloride and sulfate, were analyzed using high-pressure liquid chromatography (HPLC) equipped with a conductivity detector (Model 432, Water, Milford, MA), 4.6 x $50 \mathrm{~cm}$ IC-OAK Anion column (\#Wat007355) and 12\% acetonitrile eluent. Persulfate was analyzed using the UV colorimetric spectrometer method developed by Liang et al. (2008). Iron, sodium, and sulfur were analyzed by ICP-OES (Varian VistaPro Axial, Agilent, Santa Clara, CA). COCs were quantified identically to that of COCs in soil (Section 3.3.5).

\subsubsection{Falling Head Tests}

Falling head tests were completed on May 29 ${ }^{\text {th }}, 2018$ for all monitoring wells of EK-TAP to quantify the formation hydraulic properties in the vicinity of these wells. These tests were intentionally scheduled after the EK-TAP experiment was complete so as not to 
interfere. The tests were performed by adding approximately $2 \mathrm{~L}$ of distilled water to each monitoring well and recording the water level over time (i.e., until static water level was approached). To avoid potential interferences, falling head tests were completed on monitoring wells MW1A and MW2A prior to MW1B and MW2B. Hydraulic conductivity was measured for each monitoring well using the Hvorslev method (1951).

\subsection{Results and Discussion}

\subsubsection{Electrokinetically-Enhanced Subsurface Transport of Persulfate}

During applied DC (i.e., EK-enhanced persulfate injection), voltage was observed to increase at all measuring locations in EK-TAP until day 33, where voltage decreased and fluctuated until day 41 (Figure A2, Appendix A). Following this time, voltage appeared to stabilize and increase until the end of applied DC. The period of voltage fluctuation is hypothesized to be due to an increase in stoppages of applied current and or a decrease in electrical conductivity (Figure D3, Appendix D). Due to EK operations, cations and anions are expected to migrate towards the electrodes by EM and accumulate over time resulting in a decrease in electrical conductivity in the middle of the cell (Acar and Alshawabkeh et al., 1993; Virkutyte et al., 2002; Wang et al., 2016). This decrease in electrical conductivity would increase resistance and therefore voltage would decrease. Within EK-TAP, voltage decreased from the AW to the $\mathrm{CW}$ (Figure A2, Appendix A) with average voltage gradients applied between shallow (i.e., 2.4-3.1 m bgs) and deep electrodes (3.7-4.3 m bgs) of 0.012 $\mathrm{V} \mathrm{cm}^{-1}$ and $0.015 \mathrm{~V} \mathrm{~cm}^{-1}$, respectively (Table A2, Appendix A; Figure A3, Appendix A). Throughout applied DC, the voltage gradient was higher in the deeper electrodes than the shallower electrodes, although these differences are not considered to be large enough to cause significant variations in EK-enhanced transport rates with depth (Calc. A1, Appendix A; Table A2, Appendix A). The applied current readings measured directly from deep and shallow electrodes of the CW and AW are shown in Table A1, Appendix A. During applied

DC, the current density of shallow and deep electrodes ranged from 0.11-0.72 $\mathrm{A} \mathrm{m}^{-2}$ and 0.22-0.56 A m${ }^{-2}$, respectively (Table A1, Appendix A). These current densities are in line 
with the target current density of $0.5 \mathrm{~A} \mathrm{~m}^{-2}$ (D. Reynolds, personal communication, May 23, 2018)

Persulfate subsurface fate and transport was monitored by quantifying persulfate, sulfate (i.e., self-decomposition product), and total sulfur (i.e., constituent) concentrations. Increases in sulfur concentrations (i.e., $1.7 \mathrm{mmol} \mathrm{L}^{-1}$ ) were first observed in MW1A of EKTAP on day 29 and reached a maximum, $36 \mathrm{mmol} \mathrm{L}^{-1}$ or $10.4 \%$ of the source concentration (i.e., persulfate injection at SW1; $330 \mathrm{mmol}$ sulfur $\mathrm{L}^{-1}$ ), on day 43 (Figure 3.3). Maximum persulfate concentration was also observed on day $43,5.2 \mathrm{mmol} \mathrm{L}^{-1}$ or $3.1 \%$ of source concentration (i.e., persulfate injection at SW1 and SW2; $165 \mathrm{mmol} \mathrm{L}^{-1}$ ). Sulfur and sulfate concentrations on day 29 and 36 were similar, suggesting that the source of sulfur during these times was from sulfate. Because sulfate is a by-product of persulfate decomposition, this suggests that persulfate had entirely decomposed during transport. On day 43, at the maximum observed sulfur concentration, $29 \%$ and $71 \%$ of sulfur was from persulfate and sulfate, respectively. This could either suggest that following day 43, persulfate was not entirely decomposed or that persulfate was traveling at a rate faster than the rate of selfdecomposition. It is noted that maximum sulfur breakthrough occurred before the end of applied DC current (i.e., day 57). This is likely because the maximum voltage measured across EK-TAP (i.e., day 33) occurred much before the end of applied DC current. As noted, voltage varied considerably after day 33. Small increases in sulfur beyond background concentrations (i.e., $1.5 \mathrm{mmol} \mathrm{L}^{-1}$ ) were observed at MW1B of EK-TAP starting from day 22 , with maximum sulfur breakthrough (i.e., $4 \mathrm{mmol} \mathrm{L}^{-1}$ ) also occurring on day 43 (Figure 3.3). On day 43, $1.2 \times 10^{-3} \mathrm{mmol} \mathrm{L}^{-1}$ of persulfate (i.e., $0.15 \%$ of injection concentration) was observed at MW1B (Figure 3.3). No increases in sulfur, persulfate, or sulfate concentrations were observed during applied DC at MW2A and MW2B of EK-TAP (Figure 3.3). As expected, sulfur and sulfate did not increase in MW1A or MW1B of Control over the course of the field test (Figure $\mathrm{C} 1$ and $\mathrm{C} 2$, Appendix C). 

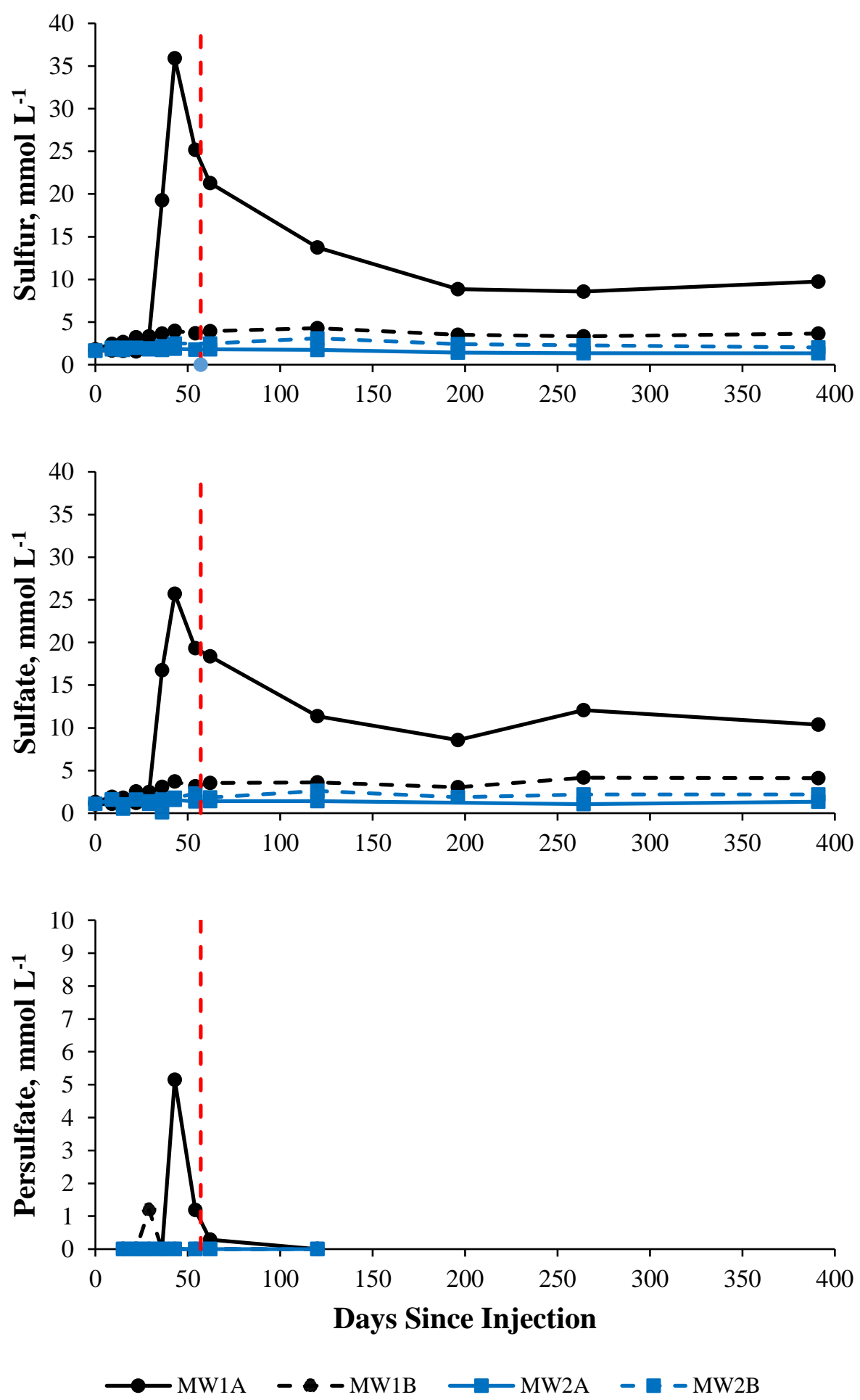

Figure 3.3: Groundwater concentration of sulfur, sulfate, and persulfate ( $\left.\mathrm{mmol} \mathrm{L}^{-1}\right)$ in all monitoring wells of EK-TAP over the entire field test. The red vertical dashed line shows the end of EK and the beginning of ERH. 
It is hypothesized that the soil's NOD was responsible for the considerable conversion of persulfate to sulfate between SW1 and MW1 in the EK-TAP transect. $6-31 \mathrm{~g} \mathrm{~kg}^{-1}$ concentrations of $\mathrm{Fe}_{\text {total }}$ were measured in the EK-TAP transect (i.e., at depths of 2.9-4.7 m bgs) (Figure A4, Appendix A). Additionally, $0.95 \pm 0.44 \mathrm{~g} \mathrm{~kg}^{-1}$ of $\mathrm{Fe}^{2+}$ (i.e., ionexchangeable $\mathrm{Fe}^{2+}, \mathrm{FeS}$, and $\mathrm{FeCO}_{3}$ species) was quantified from borehole T-SC1-2 (3.7$4.2 \mathrm{~m} \mathrm{bgs}$ ), which may have been the key constituent of the NOD. Reduced iron and manganese species as well as TOC have been reported to be the major contributors to NOD during ISCO applications (Brown and Robinson, 2004; Dahmani et al., 2006; Haselow et al., 2003; Mumford et al., 2005; Petri et al., 2011; Siegrist et al., 2010; Sra et al., 2010; Tsitonaki et al., 2010; Watts et al., 2006). It is reported that dissolved $\mathrm{Fe}^{2+}$ and $\mathrm{FeS}$ species

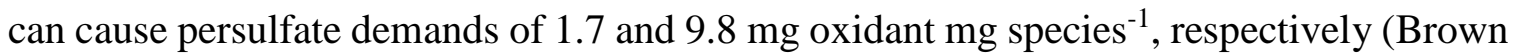
and Robinson, 2004; Liang et al., 2008; Tsitonaki et al., 2010). A batch-scale study completed by Sra et al. (2010) tested the NOD of persulfate from seven different soils and found a range of 1-5.5 g oxidant $\mathrm{kg}$ solids $^{-1}$ demand for soils with a similar $\mathrm{Fe}_{\text {total }}$ content (i.e., $0.9-63.8 \mathrm{~g} \mathrm{~kg}^{-1}$ ) to that of EK-TAP. A similar batch reactor study completed by Dahmani et al. (2006) found an NOD of 0.1-0.3 $\mathrm{g}$ oxidant $\mathrm{kg}$ solids ${ }^{-1}$ using a soil with $\sim 20$ $\mathrm{g} \mathrm{kg}^{-1}$ of $\mathrm{Fe}_{\text {total. }}$ Although $\mathrm{Fe}_{\text {total }}$ was found to be in excess compared to TOC and $\mathrm{Mn}_{\text {total }}$ in the tested soils of these studies, the NOD results are confounded by these constituents as well the reduced nature of the soils. Soil TOC and Mn were not measured in this study.

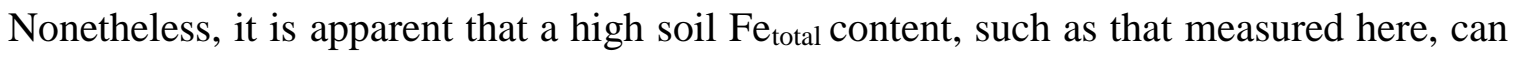
result in considerable persulfate demand. Given that the $\mathrm{Fe}^{2+}$ content of T-SC1-2 was solely in the ion-exchangeable form and that uniform concentrations existed between SW1 and MW1, approximately $13 \%$ of the injected mass of persulfate at SW1 is calculated to have been consumed by $\mathrm{Fe}^{2+}$ (Calc. A2, Appendix A).

Several laboratory and field systems have reported a decrease in $\mathrm{pH}$ due to by-products created from the self-decomposition of persulfate and oxidative reactions with contaminants and porous media (Block et al., 2004; Constanza et al., 2006; Liang et al., 2006; Sperry et al., 2002; Sra et al., 2010; Waisner et al., 2008). In EK-TAP, pH remained circumneutral in MW1A over the field test (Figure A5, Appendix A). This fact contradicts 
the inferred persulfate degradation discussed above. However, it is to be noted that $\mathrm{H}^{+}$ions would be transported by EM towards the $\mathrm{CW}$ within the electric field, making it difficult to use $\mathrm{pH}$ as an indicator of persulfate decomposition. Moreover, the soil would have a $\mathrm{pH}$ buffering capacity.

The transport of persulfate to monitoring wells MW1A and MW1B could have occurred by two possible mechanisms: (i) EM resulting from EK application, and (ii) advection (Figure A6, Appendix A). Considering the first mechanism, bench-scale testing has reported a persulfate EM transport rate on the order of $\sim 2 \mathrm{~cm} \mathrm{day}^{-1}$ (Chowdhury et al., 2017; Fan et al., 2014). Assuming an EM transport rate of $2 \mathrm{~cm} \mathrm{day}^{-1}$ in the field, persulfate could have been transported to MW1A and MW1B by day 20, which is within the applied DC period. The assumed rate of $2 \mathrm{~cm} \mathrm{day}^{-1}$ corresponds with the appearance of sulfurbased compounds in MW1A and MW1B (i.e., days 20 and 29, respectively) (Figure A7, Appendix A). However, the bench-scale tests were performed with a voltage gradient and current density of $1 \mathrm{~V} \mathrm{~cm}^{-1}$ and $\sim 1.5-5 \mathrm{~A} \mathrm{~m}^{2}$, respectively, while the averaged measured values were $\sim 0.016 \mathrm{~V} \mathrm{~cm}^{-1}$ and $\sim 0.61 \mathrm{~A} \mathrm{~m}^{-2}$ in this field study when target DC was applied. Theory suggests that the lower applied voltage gradient in the field would have resulted in a significantly lower persulfate EM transport rate (Eq. 2.26), assuming all other conditions are similar. Practice, however, suggests that field EM transport rates are often similar to those in the laboratory with similar current density despite much lower voltage gradients applied (D. Gent, personal communication, May 23, 2018). Considering the applied current density in EK-TAP, a similar EM transport rate could have been achieved in respect to bench-scale studies. Furthermore, it is possible that the electric fields from the shallow and deep electrodes were overlapping (Figure A8, Appendix A), resulting in double the current density (i.e., $\sim 1.2 \mathrm{~A} \mathrm{~m}^{-2}$ ) than measured at the electrodes being applied at that depth. Considering the depth in which the fields potentially overlapped, this could help explain the larger mass transport in MW1A in comparison to MW1B (Figure A8, Appendix A) (Figure 3.3). 
Note that it is assumed that EO did not deliver persulfate from SW2 to MW1A and MW1B within the duration of applied DC. This is due to the distance of SW2 to MW1A and MW1B (i.e., $80 \mathrm{~cm}$ ), and observed EO rates in bench-scale tests (i.e., $2 \mathrm{~cm} \mathrm{day}^{-1}$ ) (Fan et al., 2014; Fan et al., 2016). It is also likely that the rate of EM transport was not sufficient to deliver persulfate from SW2 to MW2A and MW2B within the duration of applied DC. This is based upon the observed EM transport rate of persulfate in bench-tests (i.e., $2 \mathrm{~cm} \mathrm{day}^{-1}$ ), distance of SW2 to MW2A and MW2B (i.e., $80 \mathrm{~cm}$ ), and duration of applied DC at target amperage (i.e., $\sim 22$ days).

The second mechanism that likely played a role in the transport of persulfate to monitoring wells MW1A and MW1B is advection. Typically, advection is negligible in clay systems; however, it needs to be considered in cases such as this where clay permeability is sufficiently high, engineered injection gradients are large, and transport distances are small. Based on the falling head tests, local hydraulic conductivities were $1.8 \times 10^{-5} \mathrm{~cm} \mathrm{~s}^{-1}$ and $2.6 \times 10^{-6} \mathrm{~cm} \mathrm{~s}^{-1}$ at MW1A and MW1B, respectively (Figure A9, Appendix A). Based on the head maintained in SW1 during injection (i.e., $0.61 \mathrm{~m} \mathrm{bgs}$ ), the hydraulic gradient applied during injection was $~ 1.1$. Moreover, the transport distance from SW1 to MW1A and MW1B was $40 \mathrm{~cm}$. Darcy's law calculations based on these estimates suggests advective groundwater velocities near MW1A and MW1B were on the order of magnitude of $4 \mathrm{~cm} \mathrm{day}^{-1}$ and $0.6 \mathrm{~cm} \mathrm{day}^{-1}$, respectively (Table A3, Appendix A). For MW1A, this is similar to the estimated EM transport rate $\left(\sim 2 \mathrm{~cm} \mathrm{day}^{-1}\right)$ and is consistent with observed sulfur transport rates $\left(\sim 1.4 \mathrm{~cm} \mathrm{day}^{-1}\right)$; this suggests advection could play a role in delivering persulfate to MW1A (Figure A10, Appendix A). The potential role of advective flux in MW1A is further supported by the substantial increase in water level during applied DC and injection (Figure 11, Appendix A). For MW1B, the calculated rate of advection could not be responsible for the appearance of persulfate within the applied DC period (i.e., by day 66) (Table A3, Appendix A). No considerable increase in water level was observed in MW1B during applied DC and injection (Figure 11, Appendix A). 
To further investigate the role of advective flux on persulfate transport in MW1A, sodium transport is considered. Because sodium is a cation, it would migrate from SW2 to MW1A due to EK mechanisms (i.e., EO and EM) (Figure A6, Appendix A). However, it is unlikely sodium appearance in MW1A is due to EK processes, because (a) the large relative distance of SW2 to MW1A and (b) the low relative ionic mobility of sodium (Table 2.3). Thus, the appearance of sodium in MW1A is likely due to advective transport. Increases in sodium beyond background concentrations (i.e., $8.5 \mathrm{mmol} \mathrm{L}^{-1}$ ) were first observed in MW1A on day 29 and the maximum concentration $\left(28.7 \mathrm{mmol} \mathrm{L}^{-1}\right)$ equalling $6.1 \%$ of the source concentration occurred on day 54 (Figure A12, Appendix A). It should be noted that EM and EO transport of sodium from SW1 to $\mathrm{CW}$ could have impacted the overall breakthrough in sodium at MW1A during applied DC; however, these transport processes are assumed to have been negligible. During applied DC, the maximum breakthrough of sodium and sulfur in MW1A amounted to $6.1 \%$ and $10.4 \%$, respectively (Figure A13, Appendix A). Due to this difference, it is estimated that the sulfur mass delivered to MW1A - one core persulfate constituent - is approximately $40 \%$ due to EM and $60 \%$ to advection.

\subsubsection{Electrical Resistance Heating for Thermal Activation}

Temperature increased at $0.8^{\circ} \mathrm{C} \mathrm{day}^{-1}$ and $0.2^{\circ} \mathrm{C}$ day $^{-1}$, at SW1 and SW2, respectively, at $3.7 \mathrm{~m}$ (bgs) from ERH initiation (day 57) through day 104 (Figure 3.4). After day 104, the temperature at SW2 was approximately constant at $\sim 22^{\circ} \mathrm{C}$ (Figure 3.4 ). Temperature at SW1 also stabilized $\left(\sim 47^{\circ} \mathrm{C}\right)$ following day 104 apart from large decreases in temperature on day 121 and 166 (Figure 3.4). Given that temperatures reached steady state after day 104, graphite was added on day 121 to the CW to increase electrical and thermal conductance. The addition of graphite did not appear to have a substantial impact, with temperatures stabilized at $\sim 49^{\circ} \mathrm{C}$ and $\sim 23^{\circ} \mathrm{C}$ from day 140 to 170 at SW1 and SW2, respectively. On day 173, temperatures decreased due to an unexpected decrease in applied current (Figure A14, Appendix A). Voltage (i.e., 115.2 V; 96\% Variac output) was increased on day 189 to increase applied current (Figure A1, Appendix A). This appeared to increase the temperature, although ERH was stopped shortly thereafter on day 
196. Additional thermocouples were installed inside (i.e., SC1-1 and SC2-1) and outside (i.e., Control) of the EK-TAP transect at depths of $2.7 \mathrm{~m}, 3.4 \mathrm{~m}$, and $4 \mathrm{~m}$ (bgs) on day 127 (Figure 3.1). Average temperature recordings of all measured depths from day 123 to the end of ERH at locations SC1-1, SC2-1, and Control were relatively stable at $\sim 22^{\circ} \mathrm{C}, \sim 17^{\circ} \mathrm{C}$, and $\sim 7^{\circ} \mathrm{C}$, respectively (Figure 3.4). No large differences in temperature with depth (i.e., $2.7 \mathrm{~m}$ to $4 \mathrm{~m} \mathrm{bgs}$ ) were observed at any location, regardless of differences in applied current with depth (Figure A14, Appendix A). Applied current at deeper electrodes was measured to be $\sim 10.2$ A from day 57 to 152 , while shallow electrodes exhibited an output of $\sim 2.9$ A during this time (Figure A14, Appendix A). The larger applied current with depth could be due to an increase in electrical conductivity, although this was not directly measured.

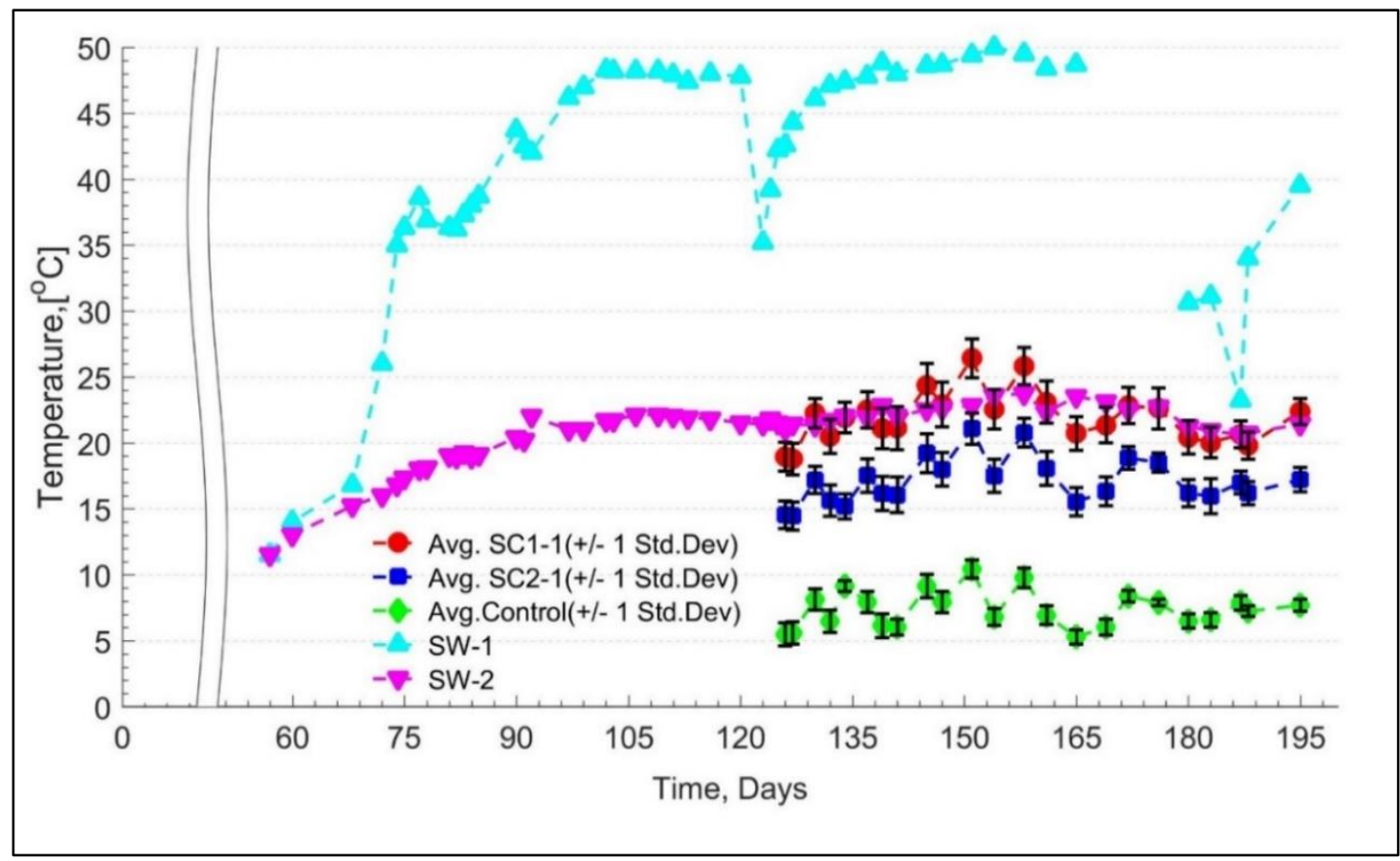

Figure 3.4: Temperature profile of EK-TAP during applied ERH. For SW1 and SW2, temperature measurements were taken from thermocouples installed at $3.7 \mathrm{~m}$ bgs. For SC1-1 and SC2-1, average temperature measurements were taken from thermocouples installed at $2.7 \mathrm{~m}, 3.4 \mathrm{~m}$, and $4.0 \mathrm{~m}$ bgs. For Control, average temperature measurements were taken from thermocouples installed at $2.7 \mathrm{~m}$ and 4.0 $m$ bgs. The axis break shows the end of EK (i.e., 57 days after injection) and the start of ERH. 
Temperature was greater near the CW compared to the AW (Figure 3.4) (Figure A15, Appendix A) potentially due to the dipole design and single-phase heating applied. This, however, requires more investigation. ERH applications typically use 3-phase or 6-phase heating for remediation applications (Baker et al., 2006; Wolf et al., 2009). Temperature at all measured locations in EK-TAP (i.e., SW1, SW2, SC1-1, and SC2-1) were above ambient in-situ temperatures measured at the Control (Figure 3.4). Moreover, temperatures between the CW and SW1 were within the targeted range for efficient persulfate activation and contaminant degradation (i.e., $\sim 40^{\circ} \mathrm{C}$ ) (Brown and Block, 2004; Chowdhury et al., 2017; Huang et al., 2005; Liang et al., 2003), while temperatures at locations beyond SC11 , towards AW, were below the targeted range.

\subsubsection{Persulfate Oxidation of Chlorinated Organic Compounds}

Out of the 16 COCs measured from background groundwater samples, 14 were greater than regulatory limits of Table 3 of O.Reg 153/04 non-potable groundwater (Table A4, Appendix A). In background soil samples, seven of the compounds were greater than regulatory limits of O.Reg 153/04 industrial, commercial, and community property use soil standards (Table A5, Appendix A). A cross-section of background contaminant (1,2-DCA) distribution in EK-TAP is shown in Figure A16, Appendix A. The concentrations of target contaminants varying with depth are shown in Figures A17 to A21, Appendix A.

Boreholes SC1-1 (completed day 124; during ERH) and SC1-2 (completed day 286; postERH) of EK-TAP were compared at six depths; 2.9 m, 3.4 m, 3.7 m, 4 m, $4.3 \mathrm{~m}$, and 4.7 $\mathrm{m}$ (bgs) to investigate any changes in COC concentrations (Figure 3.5). Total moles of COCs appeared to decrease by 7-32\% at depths ranging from 3.7-4.7 m (bgs), respectively, potentially due to EK-TAP application. No decreases in total moles were observed at depths of $2.9 \mathrm{~m}$ and $3.4 \mathrm{~m}$ (bgs) (Figure 3.5). Due to the variability in the soil data set with depth of EK-TAP, boreholes SC1-1 (completed day 124; during ERH) and SC1-2 (day 
286; post-ERH) of Control were compared at similar depths (Figure C3, Appendix C). No decreases in total moles were observed at any depths when comparing SC1-1 and SC1-2 of Control; however, concentration of COCs were observed to be higher with depth at SC12 , suggesting strong heterogeneity in soil COCs. Although a decrease in COCs is suspected from boreholes SC1-1 to SC1-2 of EK-TAP, no sulfur breakthrough was observed at any depths of SC1-1 or SC1-2 (Figure A22, Appendix A; Calc. A3, Appendix A).

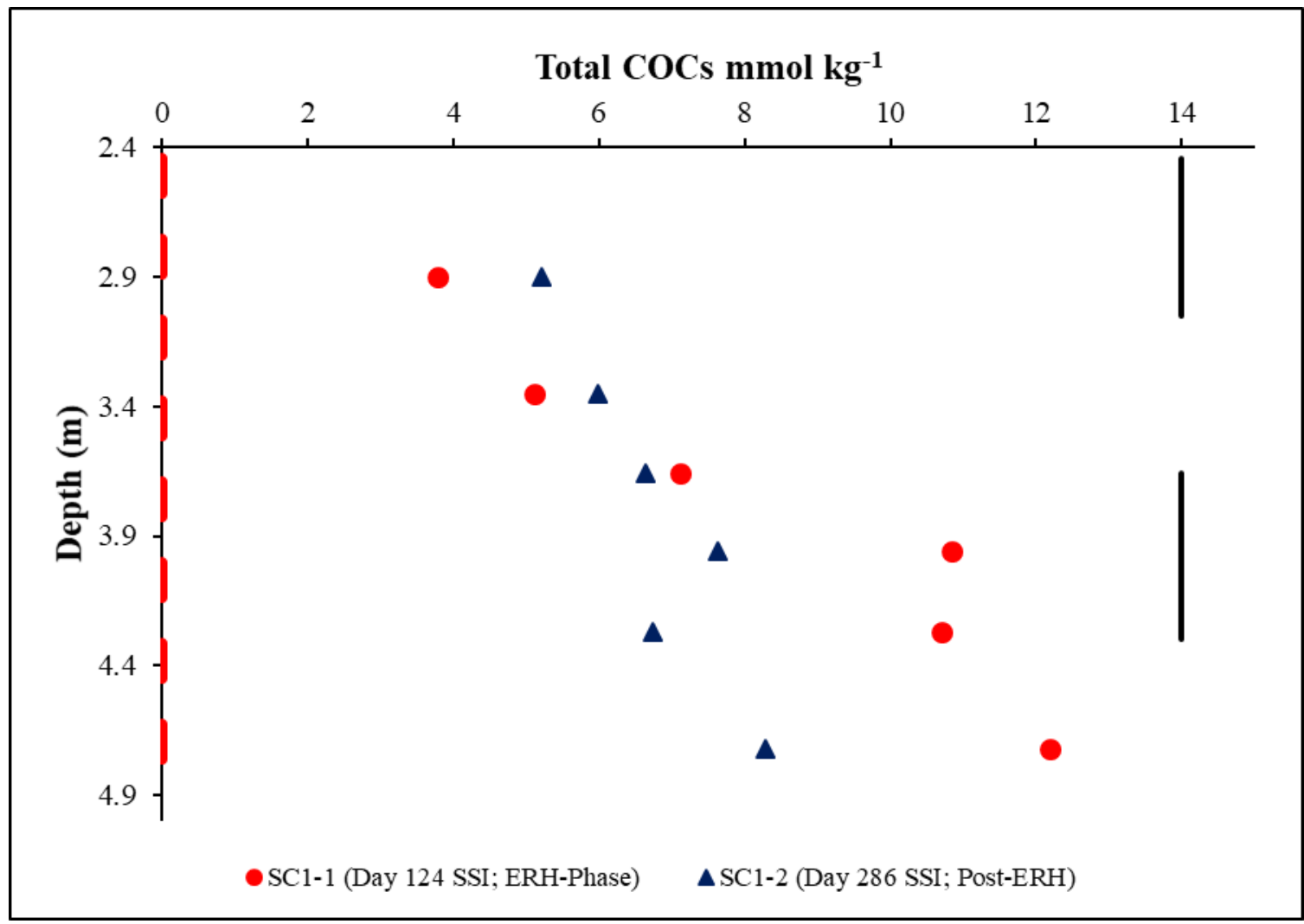

Figure 3.5: Soil concentration of total COCs $\left(\right.$ mmoles $\left.\mathrm{kg}^{-1}\right)$ with depth at SC1-1 and SC1-2 of EK-TAP. SC1-1 was completed on day 124, during the ERH-phase. SC1-2 was completed on day 286, post-ERH. Both boreholes are located $1.1 \mathrm{~m}$ away from the $\mathrm{CW}$. The red vertical dashed line represents the screening depth of the supply wells. The black vertical lines represent the depth of the electrodes. 
Note that boreholes SC1-1 and SC1-2 of EK-TAP were not compared to background boreholes (i.e., MW1, MW2, SW1, SW2, CW, and AW) in terms of COCs for two reasons. The first reason is that the background soil coring was completed by hollow-stem augering and sampled using split spoon samplers, while boreholes SC1-1 and SC1-2 were cored by direct-push and sampled using hollow-core samplers. The two-different soil coring and sampling techniques would have had different impacts on COC concentrations. The second reason is the locations of the boreholes and large site heterogeneity in COC concentrations. Boreholes SC1-1 and SC1-2 of EK-TAP were specifically designed to compare concentration of COCs pre- and post-ERH and thus were located in close proximity to each other. The background boreholes were located at such a distance from SC1-1 and SC1-2 that site heterogeneities could have had significant impact on concentration of COCs.

At MW1A, the total moles of COCs decreased by $82 \%$ on day 43 when compared to averaged background cocentrations (i.e., days -19 to 0) (Figure 3.6). COCs did not decrease in any other monitoring wells of EK-TAP during applied DC. ERH commenced on day 57 and after this, total COCs decreased by $93 \%$ on day 120 when compared to averaged background concentrations (i.e., day -19 to 0) at MW1A of EK-TAP. The concentration of COCs did not decrease at other monitoring wells during the heating period. No decreases in COCs were observed at MW1A and MW1B of the Control transect throughout the field test (Figure C4, Appendix C). 

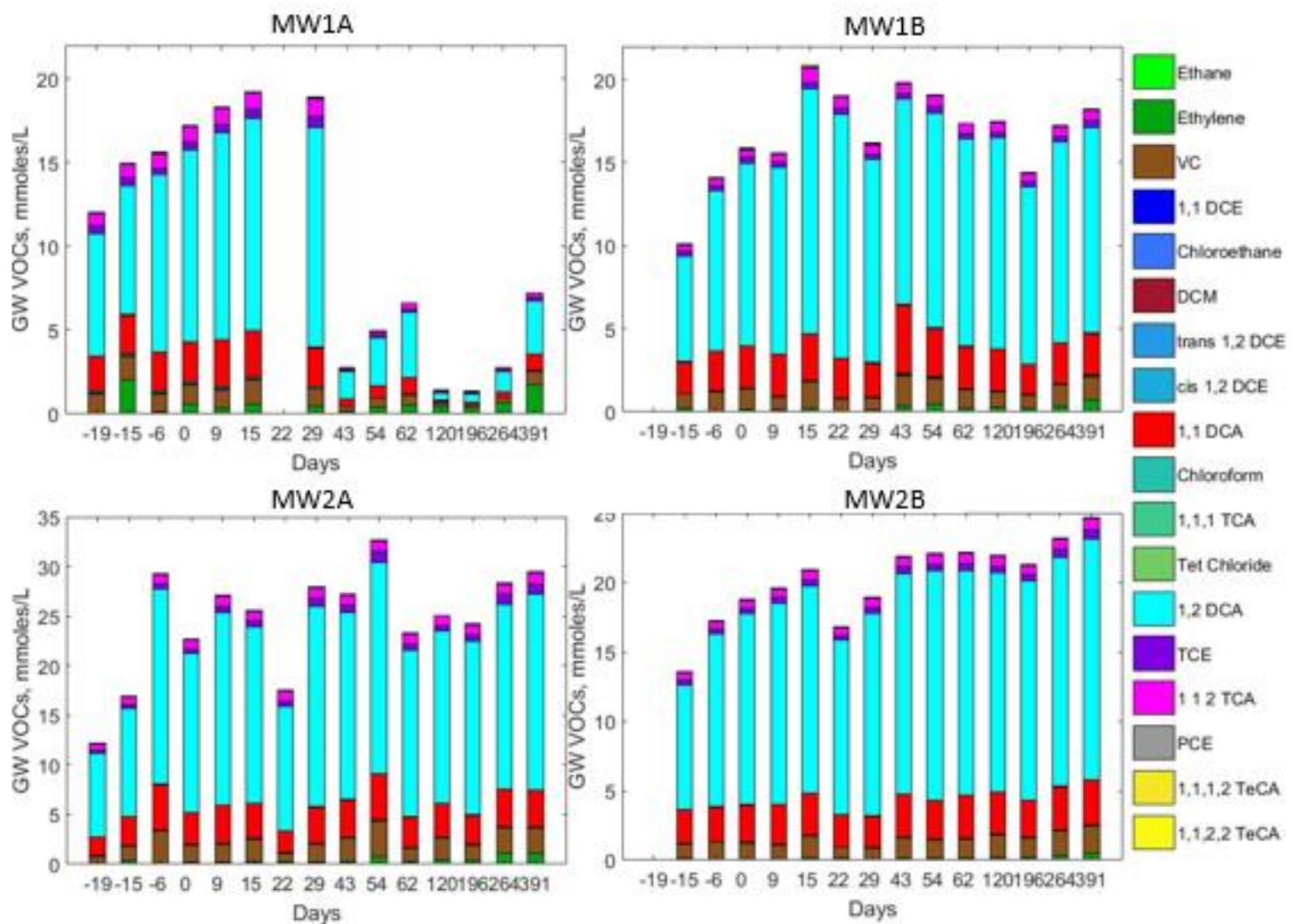

Figure 3.6: Groundwater concentration of COCs $\left(\right.$ mmoles $\left.\mathbf{L}^{-1}\right)$ in all monitoring wells of EK-TAP over the entire field test.

The decreases in COCs observed at MW1A of EK-TAP during applied DC (i.e., day 43) can likely be attributed to two processes: chemical oxidation and dilution. Several lines of evidence support the active role of chemical oxidation. For example, the maximum concentration of sulfur in MW1A (i.e., day 43) is correlated with the observed decreases in COCs on day 43 (Figure A23, Appendix A). Furthermore, at day 43, 29\% and 71\% of the sulfur was in the form of persulfate and sulfate, respectively (Figure 3.3). The presence of persulfate in MW1A on day 43 suggests an environment existed where chemical oxidation could have occurred, while the presence of sulfate (by-product of oxidation) supports that oxidative reactions were occurring. Bench-scale testing has suggested that persulfate anions could have reacted directly with chlorinated ethenes to some degree as they are susceptible to oxidation (Dahmani et al., 2006; Huang et al., 2005; Liang et al., 
2007; Petri et al., 2011). However, chlorinated ethanes have shown to be particularly resistant to oxidation and require persulfate to be activated for oxidation to occur (Gu et al., 2011; Huang et al., 2005; Liang et al., 2003; Petri et al., 2011). Considering that significant decreases in chlorinated ethanes and ethenes occurred during applied DC, persulfate is assumed to have been activated during transport by reduced $\mathrm{Fe}^{2+}$ species as discussed in Section 3.4.1, resulting in some of the observed COC reductions.

Several lines of evidence also support that dilution, resulting from the injected persulfate solution, contributed to the observed decreases in COCs at MW1A on day 43. For example, as discussed in Section 3.4.1, advection transported amendment solution from SW1 to MW1A; if this solution remained uncontaminated, it could have resulted in some degree of concentration decreases in COCs due to dilution (see injection volume radius of influence Calc. A4, Appendix A). It is noted, however, that there is extensive soil phase COC contamination in this part of the cell; as such, it is unlikely that a pristine amendment injection solution would reach MW1A. It is noted that the distribution of chlorinated ethanes and ethenes remained relatively unchanged following the decreases in COCs on day 43, supporting COC concentration decreases due to dilution (Figures A24 and A25, Appendix A). Additionally, a release of chloride ions in solution (i.e., by-product) is expected if COCs are being oxidized (Costanza et al., 2010; Liang et al., 2003; Tsitonaki et al., 2010). Assuming all decreases in COCs on day 43 were a factor of chemical oxidation, an increase in chloride of 1,048 $\mathrm{mg} \mathrm{L}^{-1}$ beyond background levels (i.e., $911 \mathrm{mg}$ $\mathrm{L}^{-1}$ ) would be expected at MW1A (Calc. A5, Appendix A). On day 43, chloride in MW1A decreased by $74 \%$ when normalized to background concentrations (Figure A26, Appendix A). This decrease in chloride at MW1A coincides with the observed decrease in total COCs on day 43 (i.e., $\sim 82 \%$ ). Considering only chloride, this suggests that chemical oxidation and dilution is contributing $\sim 10 \%$ and $\sim 90 \%$ to the decreases in total COCs, respectively. However, the decrease in chloride could be related to the applied current, with chloride ions migrating by EM towards the AW. Yet, chloride concentrations at all other monitoring wells in EK-TAP remain relatively stable throughout applied DC, suggesting the decrease in MW1A is a unique event (Figure A27, Appendix A). Another way to estimate the 
relative influence of the two processes is using the breakthrough of sodium at MW1A. Sodium breakthrough of $\sim 6 \%$ was observed in MW1A during applied DC due to advective flux. This is under the assumption that EM and EO transport of sodium from SW1 to CW was negligible during applied DC and did not impact sodium breakthrough by advective flux. The maximum sodium breakthrough of $\sim 6 \%$ suggests that chemical oxidation and dilution would have contributed $\sim 94 \%$ and $\sim 6 \%$ to the observed decreases in total COCs, respectively.

An additional method used to estimate the proportion of dilution and chemical oxidation contributing to the observed decreases in COCs on day 43 at MW1A of EK-TAP is sulfate breakthrough. Sulfate is a by-product of persulfate oxidation, and therefore can be used to determine the amount of persulfate that was reactive. Assuming the observed decreases in COCs was solely due to persulfate oxidation, a sulfate breakthrough of $\sim 0.15 \mathrm{~mol} \mathrm{~L}^{-1}$ would have been expected (Calc. A5, Appendix A). Based on the observed sulfate breakthrough in MW1A on day 43 (i.e., $0.026 \mathrm{~mol} \mathrm{~L}^{-1}$ ) (Figure 3.3), 20\% and $\sim 80 \%$ of the decreases in COCs can be attributed to chemical oxidation and dilution, respectively. It should be noted that some degree of sulfate breakthrough could have originated from side reactions involving persulfate and NOD. Furthermore, some of the decreases in COCs could have also resulted from other processes such as sorption.

Once ERH was initiated (i.e., heating period), a second decrease in total COCs was observed on day 120 in MW1A. These decreases could not be due to dilution, since injection and therefore advection were terminated, and thus are most likely due to heatactivated persulfate oxidation. Temperature at MW1A is estimated to have reached the target of $\sim 35-40^{\circ} \mathrm{C}$ for approximately 30 days within the period of decreases in total COCs during the heating period (i.e., days 57 to 120). Based on the estimated time in which target temperature was achieved at MW1A during times of decreases in total COCs, approximately $85 \%$ of any remaining mass of persulfate between SW1 and MW1A would have been activated (Figure A28, Appendix A). Although, the target temperature (i.e., 35$40^{\circ} \mathrm{C}$ ) was likely achieved between SW1 and MW1A for effective thermal activation to 
have occurred, it is uncertain whether sufficient mass of persulfate remained in the formation following applied DC. Only trace concentrations of persulfate, $0.29 \mathrm{mmol} \mathrm{L}^{-1}$ (i.e., $0.18 \%$ of injected persulfate concentration at SW1 and SW2; $165 \mathrm{mmol} \mathrm{L}^{-1}$ ), were detected in MW1A at the beginning of ERH (i.e., day 62), dropping below the detection limit for the remainder of the heating period (Figure 3.3). Much of the injected mass of persulfate was likely iron-activated and or depleted by NOD prior to the start of ERH. If sufficient persulfate mass remained in the formation, laboratory-scale studies suggest that the temperatures achieved between SW1 and MW1A could have resulted in decreases of COCs (Chowdhury et al., 2017; Huang et al. 2005; Liang et al., 2003; Liang et al., 2008; Waldemer et al., 2007).

However, there is evidence suggesting that chemical oxidation may not have had a substantial role in the decrease in COCs observed at MW1A on day 120. Like the decreases in COCs at MW1A during applied DC, the distribution of COCs (i.e., chlorinated ethanes and ethenes) remained unchanged (Figure A25, Appendix A). This contradicts laboratoryscale testing, where the distribution of chlorinated ethanes of total COCs should increase following oxidation in comparison to chlorinated ethenes (Block et al., 2004; Cho et al., 2002; Jazdanian et al., 2004; Huang et al., 2005; Liang et al., 2003; Liang et al., 2010; Petri et al., 2011; Tsitonaki et al., 2006). Additionally, the concentration of chloride in MW1A decreased by $78 \%$ from background on day 120 (Figure A26, Appendix A). Chloride concentrations would be expected to increase resulting from chemical oxidation (Chowdhury et al., 2017; Liang et al., 2010; Tsitonaki et al., 2010). Since advection and dilution were not active, and with conflicting lines of evidence about chemical oxidation, the specific causes of the COC decrease at MW1A in this period are uncertain.

\subsection{Environmental Implications}

The application of ISCO for the remediation of organic contaminants in soils has gained much interest over the last decade. ISCO is rapid, aggressive, cost effective, and easy to apply, but its application in lower-permeability soils is limited due to the ineffective 
delivery of oxidants. The current study has shown that EK has the potential to help circumvent this issue. Under EK-enhancement, additional mass of persulfate was observed to be delivered to the clay formation of EK-TAP on top of advection. More specifically, it is estimated that $\sim 40 \%$ of the persulfate delivered to MW1A of EK-TAP was a function of EM under certain assumptions. Given longer EK operations, it is likely that a higher mass delivery of persulfate would have occurred with greater transport distances. The incorporation of low-temperature ERH into the EK-TAP design showed promise for thermal activation of persulfate. Subsurface temperatures from the CW to SW1 were observed to reach target temperatures of $\sim 35-40^{\circ} \mathrm{C}$ for effective persulfate activation. However, non-uniform heat distribution is expected with the current EK-TAP design, where subsurface temperatures beyond SW2 towards the AW were consistently below target temperatures. Limited thermal activation of persulfate is assumed to have occurred in EK-TAP due to persulfate decomposition resulting from a substantial NOD. As a part of the NOD, the iron content of EK-TAP is believed to have played a significant role in persulfate reaction chemistry. An estimated persulfate to $\mathrm{Fe}^{2+}$ molar ratio of 5:1 was measured between SW1 and MW1. This is based on the assumed mass of persulfate injected at SW1 (i.e., $\sim 14.8 \mathrm{~kg}$ ) and estimated mass of $\mathrm{Fe}^{2+}$ present between $\mathrm{SW} 1$ and MW1 at depths of injection (i.e., $1.1 \mathrm{~kg}$ ) (Calculation A2, Appendix A). Aqueous batchscale testing suggests that persulfate to $\mathrm{Fe}^{2+}$ molar ratios of 1:1 or greater could result in effective persulfate activation (Section 2.4.1). However, molar ratios below 1:1 may result in excess $\mathrm{Fe}^{2+}$ and free radical scavenging (Section 2.4.1). The naturally occurring iron content of a soil should be considered for future EK-TAP applications.

Substantial decrease in total COCs (i.e., 82\%) was observed at MW1A of EK-TAP during applied DC. The decrease in total COCs included various chlorinated ethenes (i.e., VC, TCE, PCE, etc) and ethanes (i.e., 1,2 DCA, 1,1,2-TCA, 1,1-DCA, etc). The decrease in total COCs in groundwater is suspected to be due to both chemical oxidation and dilution from advective flux. The percent contribution of each process to the observed decrease proved challenging to determine. Two estimation methods (sulfate, chloride) suggested that dilution and chemical oxidation contributed $\sim 80-90 \%$ and $\sim 10-20 \%$ to the observed 
decreases of COCs, respectively. However, a third method (sodium) suggests $\sim 6 \%$ was due to dilution and $\sim 94 \%$ was due to oxidation. Regardless of the role of advective flux on persulfate transport and dilution of COCs, it is concluded that EK-TAP has shown potential at the field-scale to produce conditions necessary for persulfate transport in lowpermeability media and chemical oxidation of COCs. 


\subsection{References}

Acar, Y. B., \& Alshawabkeh, A. N. (1993). Principles of electrokinetic remediation. Environmental science \& technology, 27(13), 2638-2647.

Ahmad, M., Teel, A. L., \& Watts, R. J. (2010). Persulfate activation by subsurface minerals. Journal of contaminant hydrology, 115(1-4), 34-45.

Baker, R. S., Lachance, J. C., \& Heron, G. (2006, June). Application of thermal remediation techniques for in-situ treatment of contaminated soil and water. In Proceedings of the NATO Advanced Research Workshop, Athens (pp. 12-17).

Beyke, G., \& Fleming, D. (2005). In situ thermal remediation of DNAPL and LNAPL using electrical resistance heating. Remediation Journal: The Journal of Environmental Cleanup Costs, Technologies \& Techniques, 15(3), 5-22.

Block, P. A., Brown, R. A., \& Robinson, D. (2004, May). Novel activation technologies for sodium persulfate in situ chemical oxidation. In Proceedings of the Fourth International Conference on the remediation of chlorinated and recalcitrant compounds (pp. 24-27). Columbus, OH: Battelle Press.

Brown, R. A., Robinson, D., Skladany, G., \& Loeper, J. (2004, May). Response to naturally occurring organic material: permanganate versus persulfate. In Proceedings of the Fourth International Conference of Remediation of Chlorinated and Recalcitrant Compounds (Monterey, CA.

Cang, L., Zhou, D. M., Wang, Q. Y., \& Fan, G. P. (2012). Impact of electrokinetic-assisted phytoremediation of heavy metal contaminated soil on its physicochemical properties, enzymatic and microbial activities. Electrochimica Acta, 86, 41-48.

Cavanagh, B. A., Johnson, P. C., \& Daniels, E. J. (2014). Reduction of diffusive contaminant emissions from a dissolved source in a lower permeability layer by sodium persulfate treatment. Environmental science \& technology, 48(24), 1458214589.

Chen, K. F., Kao, C. M., Wu, L. C., Surampalli, R. Y., \& Liang, S. H. (2009). Methyl tertbutyl ether (MTBE) degradation by ferrous ion-activated persulfate oxidation: feasibility and kinetics studies. Water Environment Research, 81(7), 687-694.

Cho, H. J., Fiacco, R. J., \& Brown, R. (2003, May). Evaluation of technologies for in situ remediation of 1, 1, 1-trichloroethane. In Third International Conference on Remediation of Chlorinated and Recalcitrant Compounds (p. 2002).

Chowdhury, A. I., Gerhard, J. I., Reynolds, D., \& O’Carroll, D. M. (2017). Low Permeability Zone Remediation via Oxidant Delivered by Electrokinetics and Activated by Electrical Resistance Heating: Proof of Concept. Environmental science \& technology, 51(22), 13295-13303.

Costanza, J., Otaño, G., Callaghan, J., \& Pennell, K. D. (2010). PCE oxidation by sodium persulfate in the presence of solids. Environmental science \& technology, 44(24), 9445-9450. 
Dahmani, M. A., Huang, K., \& Hoag, G. E. (2006). Sodium persulfate oxidation for the remediation of chlorinated solvents (USEPA superfund innovative technology evaluation program). Water, Air, \& Soil Pollution: Focus, 6(1), 127-141.

Do, S. H., Kwon, Y. J., \& Kong, S. H. (2010). Effect of metal oxides on the reactivity of persulfate/Fe (II) in the remediation of diesel-contaminated soil and sand. Journal of hazardous materials, 182(1-3), 933-936.

Eykholt, G. R., \& Daniel, D. E. (1994). Impact of system chemistry on electroosmosis in contaminated soil. Journal of geotechnical engineering, 120(5), 797-815.

Fan, G., Cang, L., Gomes, H. I., \& Zhou, D. (2016). Electrokinetic delivery of persulfate to remediate PCBs polluted soils: Effect of different activation methods. Chemosphere, 144, 138-147.

Fan, G., Cang, L., Fang, G., Qin, W., Ge, L., \& Zhou, D. (2014). Electrokinetic delivery of persulfate to remediate PCBs polluted soils: Effect of injection spot. Chemosphere, 117, 410-418.

Fetter, C. W. 2001, Applied Hydrogeology: Prentice-Hall, Upper Saddle River, NJ, 598 p.

Gates-Anderson, D. D., Siegrist, R. L., \& Cline, S. R. (2001). Comparison of potassium permanganate and hydrogen peroxide as chemical oxidants for organically contaminated soils. Journal of Environmental Engineering, 127(4), 337-347.

Gu, X., Lu, S., Li, L., Qiu, Z., Sui, Q., Lin, K., \& Luo, Q. (2011). Oxidation of 1, 1, 1trichloroethane stimulated by thermally activated persulfate. Industrial \& Engineering Chemistry Research, 50(19), 11029-11036.

Hanna, T. H. (1966). Engineering properties of glacial-lake clays near Sarnia, Ontario. Ontario Hydro Research Quarterly.

Haselow, J. S., Siegrist, R. L., Crimi, M., \& Jarosch, T. (2003). Estimating the total oxidant demand for in situ chemical oxidation design. Remediation Journal, 13(4), 5-16.

Heron, G., Crouzet, C., Bourg, A. C., \& Christensen, T. H. (1994). Speciation of Fe (II) and $\mathrm{Fe}$ (III) in contaminated aquifer sediments using chemical extraction techniques. Environmental science \& technology, 28(9), 1698-1705.

House, D. A. (1962). Kinetics and mechanism of oxidations by peroxydisulfate. Chemical reviews, 62(3), 185-203.

Huang, K. C., Zhao, Z., Hoag, G. E., Dahmani, A., \& Block, P. A. (2005). Degradation of volatile organic compounds with thermally activated persulfate oxidation. Chemosphere, 61(4), 551-560.

Husain, M. M., Cherry, J. A., Fidler, S., \& Frape, S. K. (1998). On the long-term hydraulic gradient in the thick clayey aquitard in the Sarnia region, Ontario. Canadian geotechnical journal, 35(6), 986-1003.

Hvorslev, M. J. (1951). Time lag and soil permeability in ground-water observations. 
Isosaari, P., Piskonen, R., Ojala, P., Voipio, S., Eilola, K., Lehmus, E., \& Itävaara, M. (2007). Integration of electrokinetics and chemical oxidation for the remediation of creosote-contaminated clay. Journal of hazardous materials, 144(1-2), 538-548.

ITRC, T. (2005). Technical and Regulatory Guidance for In Situ Chemical Oxidation of Contaminated Soil and Groundwater. ISCO. 2. Interstate Technology Council. Situ Chemical Oxidation Team, Washington, DC.

Jazdanian, A. D., Fieber, L. L., Tisoncik, D., Huang, K. C., Mao, F., \& Dahmani, A. (2004). Chemical Oxidation of Chloroethanes and Chloroethenes in a Rock/Groundwater System. In Proceedings, Fourth International Conference on Remediation of Chlorinated and Recalcitrant Compounds, Monterey, CA, USA, May (pp. 24-27).

Johnson, R. L., Tratnyek, P. G., \& Johnson, R. O. B. (2008). Persulfate persistence under thermal activation conditions. Environmental science \& technology, 42(24), 93509356.

Killian, P. F., Bruell, C. J., Liang, C., \& Marley, M. C. (2007). Iron (II) activated persulfate oxidation of MGP contaminated soil. Soil \& Sediment Contamination, 16(6), 523537.

Kolthoff, I. M., \& Miller, I. K. (1951). The chemistry of persulfate. I. The kinetics and mechanism of the decomposition of the persulfate ion in aqueous medium1. Journal of the American Chemical Society, 73(7), 3055-3059.

Krembs, F. J., Clayton, W. S., \& Marley, M. C. (2011). Evaluation of ISCO field applications and performance. In In Situ Chemical Oxidation for Groundwater Remediation (pp. 319-353). Springer, New York, NY.

Liang, C., Guo, Y. Y., Chien, Y. C., \& Wu, Y. J. (2010). Oxidative degradation of MTBE by pyrite-activated persulfate: proposed reaction pathways. Industrial \& Engineering Chemistry Research, 49(18), 8858-8864.

Liang, C., \& Bruell, C. J. (2008). Thermally activated persulfate oxidation of trichloroethylene: experimental investigation of reaction orders. Industrial \& Engineering Chemistry Research, 47(9), 2912-2918.

Liang, C., Wang, Z. S., \& Bruell, C. J. (2007). Influence of pH on persulfate oxidation of TCE at ambient temperatures. Chemosphere, 66(1), 106-113.

Liang, C., Wang, Z. S., \& Mohanty, N. (2006). Influences of carbonate and chloride ions on persulfate oxidation of trichloroethylene at 20 C. Science of the total environment, 370(2-3), 271-277.

Liang, C., Bruell, C. J., Marley, M. C., \& Sperry, K. L. (2004). Persulfate oxidation for in situ remediation of TCE. I. Activated by ferrous ion with and without a persulfatethiosulfate redox couple. Chemosphere, 55(9), 1213-1223.

Liang, C. J., Bruell, C. J., Marley, M. C., \& Sperry, K. L. (2003). Thermally activated persulfate oxidation of trichloroethylene (TCE) and 1, 1, 1-trichloroethane (TCA) in aqueous systems and soil slurries. Soil and sediment contamination: An international journal, 12(2), 207-228. 
Lide, D.R. (2005). Ionic conductivity and diffusion at infinite dilution. In: D.R. Lide (Editor), CRC handbook of chemistry and physics. CRC Press, Boca Raton, FL.

Li, X. D., \& Schwartz, F. W. (2004). DNAPL remediation with in situ chemical oxidation using potassium permanganate: Part I. Mineralogy of Mn oxide and its dissolution in organic acids. Journal of Contaminant Hydrology, 68(1-2), 39-53.

Liu, H., Bruton, T. A., Doyle, F. M., \& Sedlak, D. L. (2014). In situ chemical oxidation of contaminated groundwater by persulfate: decomposition by Fe (III)-and Mn (IV)containing oxides and aquifer materials. Environmental science \& technology, 48(17), 10330-10336.

Lovley, D. R., \& Phillips, E. J. (1987). Rapid assay for microbially reducible ferric iron in aquatic sediments. Applied and Environmental Microbiology, 53(7), 1536-1540.

Matzek, L. W., \& Carter, K. E. (2016). Activated persulfate for organic chemical degradation: a review. Chemosphere, 151, 178-188.

Mitchell, J. K., \& Soga, K. (2005). Fundamentals of soil behavior.

Mumford, K. G., Thomson, N. R., \& Allen-King, R. M. (2005). Bench-scale investigation of permanganate natural oxidant demand kinetics. Environmental science \& technology, 39(8), 2835-2840.

Petri, B. G., Watts, R. J., Tsitonaki, A., Crimi, M., Thomson, N. R., \& Teel, A. L. (2011). Fundamentals of ISCO using persulfate. In In situ chemical oxidation for groundwater remediation (pp. 147-191). Springer New York.

Puls, R. W., \& Barcelona, M. J. (1996). Low-flow (minimal drawdown) ground-water sampling procedures. US Environmental Protection Agency, Office of Research and Development, Office of Solid Waste and Emergency Response.

Oh, S. Y., Kang, S. G., Kim, D. W., \& Chiu, P. C. (2011). Degradation of 2, 4dinitrotoluene by persulfate activated with iron sulfides. Chemical Engineering Journal, 172(2-3), 641-646.

Ren, L., Lu, H., He, L., \& Zhang, Y. (2014). Enhanced electrokinetic technologies with oxidization-reduction for organically-contaminated soil remediation. Chemical Engineering Journal, 247, 111-124.

Reynolds, D. A., Jones, E. H., Gillen, M., Yusoff, I., \& Thomas, D. G. (2008). Electrokinetic Migration of Permanganate Through Low-Permeability Media. Groundwater, 46(4), 629-637.

Roach, N., \& Reddy, K. R. (2006). Electrokinetic delivery of permanganate into lowpermeability soils. International Journal of Environment and Waste Management, 1(1), 4-19.

Robertson, T. (2009). Electrokinetic Transport of Persulfate under Voltage Gradients.

Siegrist, R. L., Crimi, M., \& Simpkin, T. J. (Eds.). (2011). In situ chemical oxidation for groundwater remediation (Vol. 3). Springer Science \& Business Media. 
Soderman, L. G., \& Kim, Y. D. (1970). Effect of groundwater levels on stress history of the St. Clair clay till deposit. Canadian Geotechnical Journal, 7(2), 173-187.

Sperry, K. L., Marley, M. C., Bruell, C. J., Liang, C., \& Hochreiter, J. (2003, May). Iron catalyzed persulfate oxidation of chlorinated solvents. In Third International Conference on Remediation of Chlorinated and Recalcitrant Compounds (p. 2002).

Sra, K. S., Thomson, N. R., \& Barker, J. F. (2010). Persistence of persulfate in uncontaminated aquifer materials. Environmental science \& technology, 44(8), 3098-3104.

Teel, A. L., Ahmad, M., \& Watts, R. J. (2011). Persulfate activation by naturally occurring trace minerals. Journal of hazardous materials, 196, 153-159.

Tsai, T. T., Kao, C. M., Yeh, T. Y., \& Lee, M. S. (2008). Chemical oxidation of chlorinated solvents in contaminated groundwater. Practice Periodical of Hazardous, Toxic, and Radioactive Waste Management, 12(2), 116-126.

Tsitonaki, A., Petri, B., Crimi, M., Mosbæk, H., Siegrist, R. L., \& Bjerg, P. L. (2010). In situ chemical oxidation of contaminated soil and groundwater using persulfate: a review. Critical Reviews in Environmental Science and Technology, 40(1), 55-91.

Tsitonaki, A., Mosbæk, H., \& Bjerg, P. L. (2006). Activated persulfate oxidation as a first step in a treatment train. In 5th International Conference on Remediation of Chlorinated and Recalcitrant Compounds. Battelle Memorial Institute.

Virkutyte, J., Sillanpää, M., \& Latostenmaa, P. (2002). Electrokinetic soil remediationcritical overview. Science of the Total Environment, 289(1-3), 97-121.

Waisner, S., Medina, V. F., Morrow, A. B., \& Nestler, C. C. (2008). Evaluation of chemical treatments for a mixed contaminant soil. Journal of Environmental Engineering, 134(9), 743-749.

Waldemer, R. H., Tratnyek, P. G., Johnson, R. L., \& Nurmi, J. T. (2007). Oxidation of chlorinated ethenes by heat-activated persulfate: kinetics and products. Environmental Science \& Technology, 41(3), 1010-1015.

Wang, S., Guo, S., Li, F., Yang, X., Teng, F., \& Wang, J. (2016). Effect of alternating bioremediation and electrokinetics on the remediation of n-hexadecanecontaminated soil. Scientific reports, 6, 23833.

Watts, R. J., \& Teel, A. L. (2006). Treatment of contaminated soils and groundwater using ISCO.Practice Periodical of Hazardous, Toxic, and Radioactive Waste Management, 10(1), 2-9.

Wolf, J. W., Barton, T., Gomes, T., \& Damasi, D. (2009). Electrical Resistance Heating: Rapid Treatment for Soil and Groundwater Remediation. Águas Subterrâneas, 1.

Wu, M. Z., Reynolds, D. A., Fourie, A., \& Thomas, D. G. (2013). Optimal field approaches for electrokinetic in situ oxidation remediation. Groundwater Monitoring \& Remediation, 33(1), 62-74. 
Xu, X., \& Thomson, N. R. (2010). Hydrogen peroxide persistence in the presence of aquifer materials. Soil and Sediment Contamination, 19(5), 602-616.

$\mathrm{Xu}, \mathrm{X}$., \& Thomson, N. R. (2008). Estimation of the maximum consumption of permanganate by aquifer solids using a modified chemical oxygen demand test. Journal of Environmental Engineering, 134(5), 353-361.

Yang, G. C., \& Yeh, C. F. (2011). Enhanced nano-Fe3O4/S2O82- oxidation of trichloroethylene in a clayey soil by electrokinetics. Separation and Purification Technology, 79(2), 264-271.

Yukselen-Aksoy, Y., \& Reddy, K. R. (2012). Effect of soil composition on electrokinetically enhanced persulfate oxidation of polychlorobiphenyls. Electrochimica Acta, 86, 164-169. 


\section{Conclusions and Recommendations}

\subsection{Summary and Conclusions}

This thesis evaluated electrokinetically-enhanced thermally activated persulfate (EKTAP), a novel technology, to remediate a chlorinated solvent impacted low-permeability field site. To implement EK, a dipole electrode design was used along with a direct current (DC). Using the same infrastructure as EK, low-temperature electrical resistance heating (ERH) was also tested to provide heat activation of the injected persulfate. The overall ability of EK-TAP to treat a mix of chlorinated ethanes and ethenes in clay soil was also determined. To the authors' knowledge, published literature study has investigated EKTAP at the field-scale.

The major conclusions from this field study are the following:

* Field operations suggest that EK has shown the potential to enhance the delivery of persulfate into a low permeability soil by means of a constant DC.

* Infrastructure (i.e., electrodes) used for EK can also be used to implement lowtemperature ERH by applying an alternating current (AC). Soil temperatures were observed to increase in certain areas of EK-TAP to the targeted range for effective heat activation (i.e., $\sim 35-40^{\circ} \mathrm{C}$ ). However, non-uniform heat distribution is expected with the current EK-TAP design.

* Naturally occurring iron found in the native clay soil likely impacted persulfate reaction chemistry both positively and negatively. Naturally occurring iron was likely a major contributor to the NOD, impacting persulfate transport. However, persulfate likely experienced some degree of iron activation helpful for the degradation of contaminants.

* Significant decreases (i.e., 70-90\%;) were observed for all measured chlorinated organic compounds (COCs) in groundwater in areas were persulfate had been delivered (i.e., MW1A). It is assumed that chemical oxidation resulting from iron and heat activation played a measurable role in the observed decreases. Dilution 
resulting from advective flux of injected persulfate solution is assumed to have had a major role in the observed decreases.

\subsection{Recommendations}

EK migration phase should be run for a greater period of time in future studies to better examine the extent of EK transport.

Method in which persulfate (or amendments) are delivered (i.e., elevated head) into the subsurface should be taken under consideration for future studies to reduce the potential impact of advective flux that could confound EK transport results

Development of an EK transport model could be useful in better understanding and or predicting the extent of persulfate (or amendment) transport under various EK parameters (e.g., applied DC, voltage gradient, electrode spacing, electrode configuration, etc).

Different EK electrode configurations could be more effective in delivering persulfate or amendments in comparison to the tested single electric dipole design. Further field testing is warranted.

Using 3-phase or 6-phase heating during applied ERH may result in better heat distribution than single-phase heating.

Further research is required on the role of naturally occurring iron on persulfate reaction chemistry.

Advanced soil analysis (i.e., reduced iron, manganese, and organic matter species) is recommended prior to future EK-TAP field applications.

NOD and EK column testing is advised prior to EK-TAP field applications to identify factors that may impact performance.

Consistent procedures (e.g., soil sampling) should be followed from baseline to project end so that data is optimally comparable. 
Appendix A: EK-TAP 
Table A1: Applied DC and Current Density of Shallow and Deep Electrodes of EK-TAP

\begin{tabular}{|c|c|c|c|c|c|}
\hline \multirow{2}{*}{$\begin{array}{c}\text { Days Since } \\
\text { Injection }\end{array}$} & \multirow{2}{*}{ Well ID } & \multicolumn{2}{|c|}{ DC Amps } & \multicolumn{2}{c|}{ Current Density $\left(\mathbf{A ~ m}^{-2}\right)$} \\
\cline { 3 - 5 } & & $\begin{array}{c}\text { Shallow } \\
\text { Electrode }\end{array}$ & $\begin{array}{c}\text { Deep } \\
\text { Electrode }\end{array}$ & $\begin{array}{c}\text { Shallow } \\
\text { Electrode }\end{array}$ & $\begin{array}{c}\text { Deep } \\
\text { Electrode }\end{array}$ \\
\hline \multirow{2}{*}{1} & CW & -0.2 & -0.2 & 0.111 & 0.111 \\
& AW & 0.2 & 0.2 & & \\
\hline \multirow{2}{*}{8} & CW & -0.3 & -0.4 & 0.222 & 0.167 \\
\cline { 2 - 4 } & AW & 0.4 & 0.3 & & \\
\hline \multirow{2}{*}{20} & CW & -1.0 & -1.0 & 0.667 & 0.556 \\
\cline { 2 - 4 } & AW & 1.2 & 1.0 & & \\
\hline \multirow{2}{*}{28} & CW & -1.1 & -1.0 & 0.722 & 0.5 \\
\cline { 2 - 4 } & AW & 1.3 & 0.9 & & \\
\hline
\end{tabular}

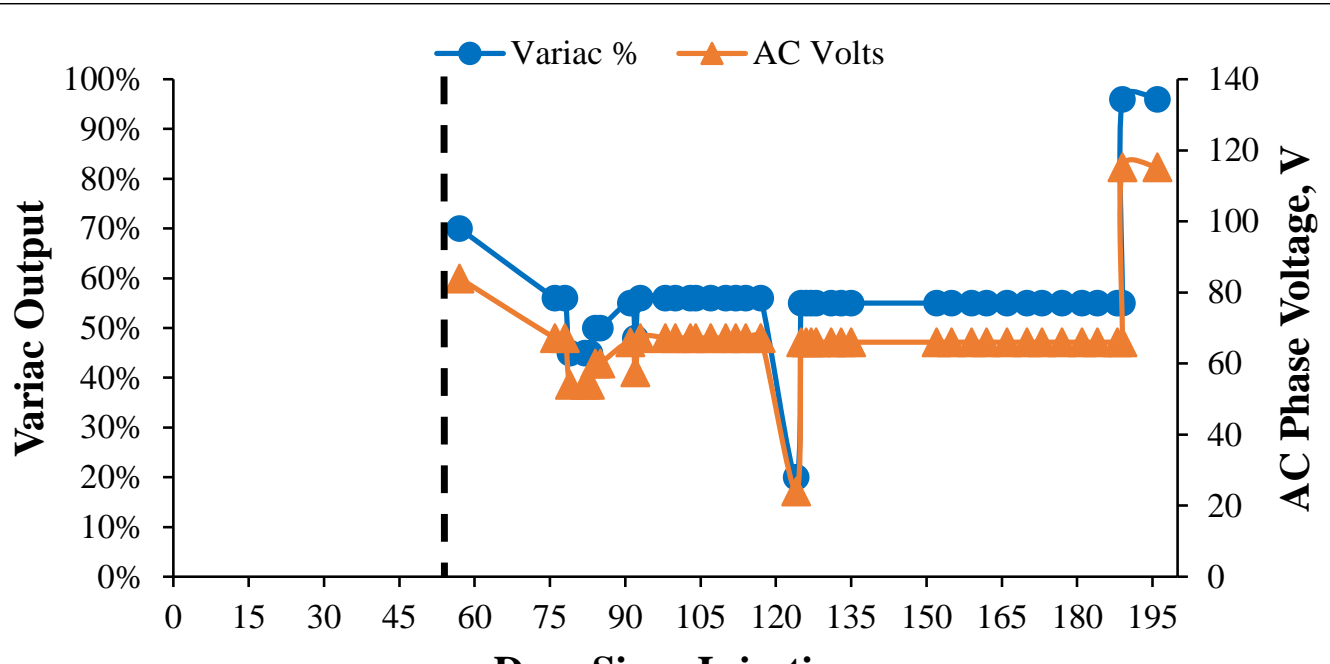

Days Since Injection

Figure A1: Constant voltage output to EK-TAP during ERH operations. Variac was used to control the voltage output from a $120 \mathrm{~V}$ source. The black vertical dashed line shown on day 57 represents the end of EK and the start of ERH. 


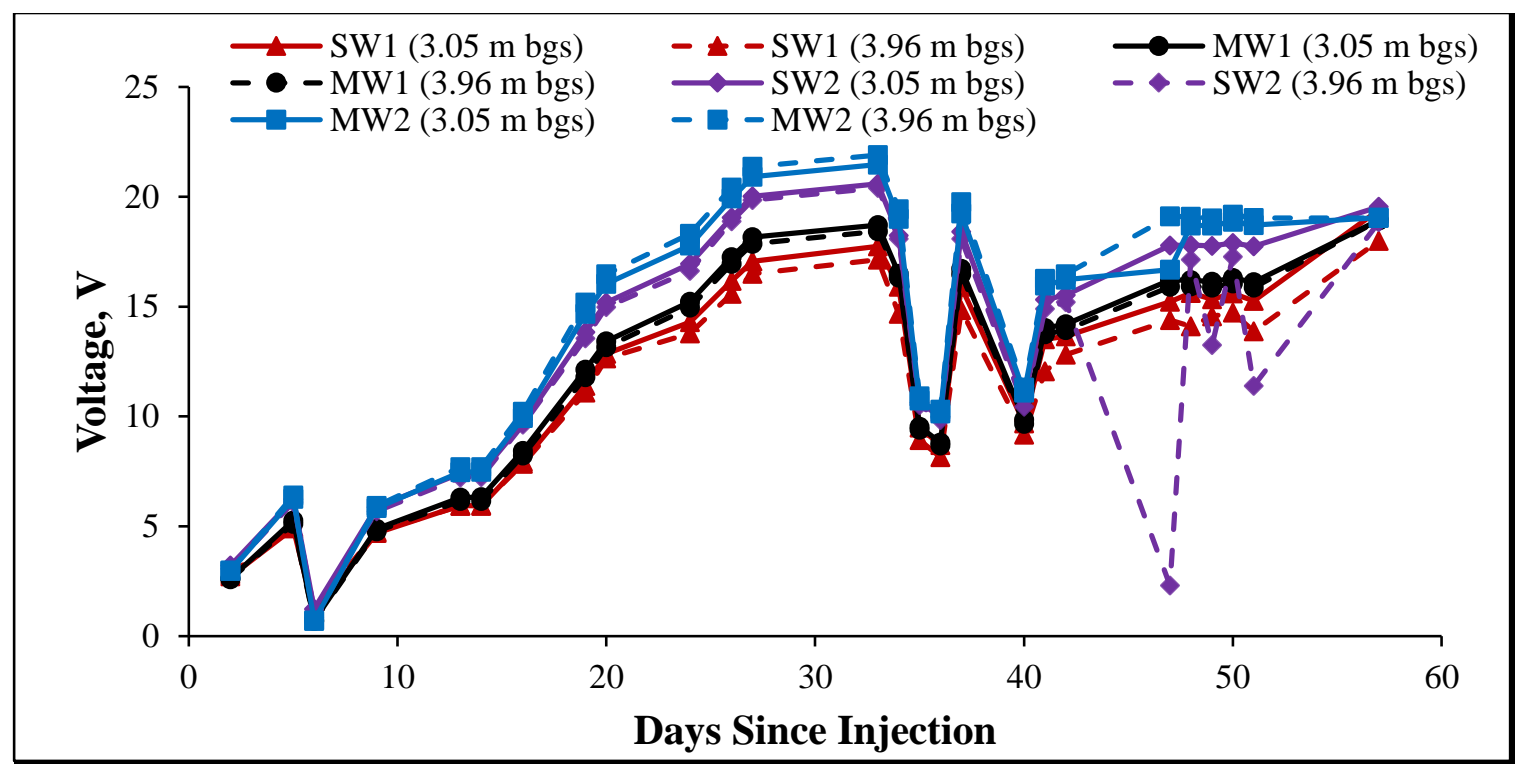

Figure A2: Voltage readings during EK operations (i.e., day 0-57) at SW1, MW1, SW2, and MW2 of the EK-TAP transect. Readings were taken from voltage probes installed at $3.05 \mathrm{~m}$ and $3.96 \mathrm{~m}$ (bgs) at each location. Voltage readings from MW1 and MW2 at 3.05 m (bgs) are representative of MW1A and MW2A, respectively, screened from 3.05-3.66 m (bgs). Voltage readings from MW1 and MW2 at $3.96 \mathrm{~m}$ (bgs) are representative of MW1B and MW2B, respectively, screened from 3.66-4.27 m (bgs). 
Table A2: Voltage Gradient Between Shallow and Deep Electrodes of EK-TAP During EK

\begin{tabular}{|c|c|c|}
\hline Days Since Injection & $\begin{array}{l}\text { Voltage Gradient Shallow } \\
\text { Electrodes }\left(\mathrm{V} \mathrm{m}^{-1}\right)\end{array}$ & $\begin{array}{l}\text { Voltage Gradient Deep } \\
\text { Electrodes }\left(\mathbf{V ~ m}^{-1}\right)\end{array}$ \\
\hline 2 & 0.154 & 0.195 \\
\hline 5 & 0.782 & 0.724 \\
\hline 6 & 0.136 & 0.0623 \\
\hline 9 & 0.659 & 0.641 \\
\hline 13 & 0.936 & 0.823 \\
\hline 14 & 0.925 & 0.834 \\
\hline 16 & 1.25 & 1.05 \\
\hline 19 & 2.07 & 1.69 \\
\hline 20 & 1.97 & 1.66 \\
\hline 24 & 2.22 & 1.77 \\
\hline 26 & 2.38 & 1.88 \\
\hline 27 & 2.41 & 1.94 \\
\hline 33 & 2.36 & 1.89 \\
\hline 34 & 2.30 & 1.61 \\
\hline 35 & 1.03 & 0.714 \\
\hline 36 & 1.11 & 0.814 \\
\hline 37 & 2.36 & 1.70 \\
\hline 40 & 1.06 & 0.756 \\
\hline 41 & 1.97 & 1.32 \\
\hline 42 & 1.77 & 1.32 \\
\hline 47 & 0.353 & 0.795 \\
\hline 48 & 2.32 & 1.59 \\
\hline 49 & 1.64 & 1.71 \\
\hline 50 & 2.12 & 1.66 \\
\hline 51 & 1.6682 & 1.74 \\
\hline
\end{tabular}




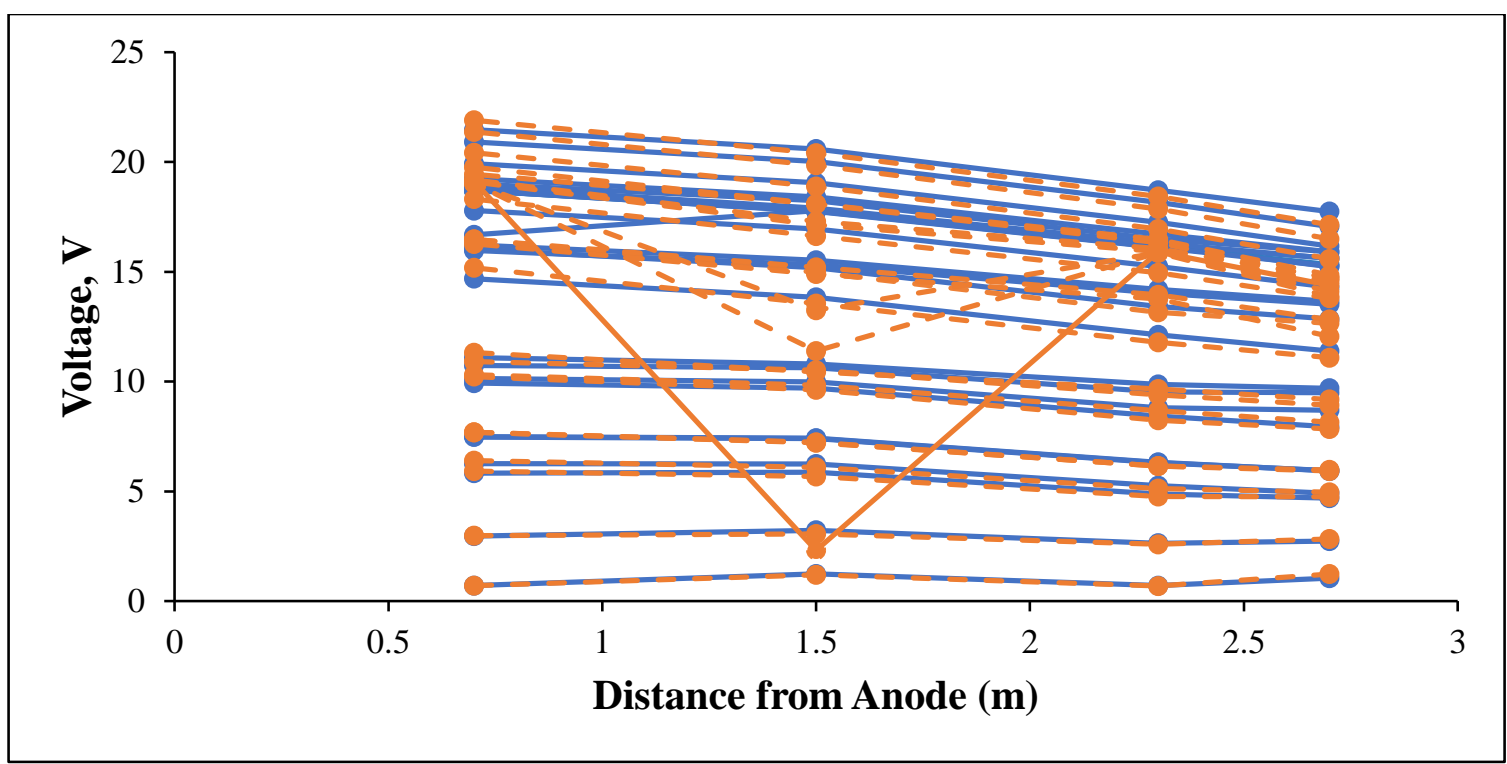

Figure A3: Voltage gradient between the AW and CW of EK-TAP during EK operations. Blue data series represent voltage readings taken at $3.96 \mathrm{~m}$ (bgs) (i.e., depth of deep electrodes). Orange data series represent voltage readings taken at 3.05 m (bgs) (i.e., depth of shallow electrodes). Readings were taken from MW1 (0.7 m), SW1 (1.5 m), SW2 (2.3 m), and MW2 $(2.7 \mathrm{~m})$. Each line represents an individual timestep during EK operations. 
Calculation A1: Theoretical EM and EO transport rates in EK-TAP.

$\mathrm{q}_{\mathrm{EO}}=\mathrm{k}_{\mathrm{EO}} \mathrm{i}_{\mathrm{e}} \quad$ (Acar and Alshawabkeh, 1993)

$\mathrm{q}_{\mathrm{EM}}=\mathrm{u}_{\mathrm{i}}^{*} \mathrm{i}_{\mathrm{e}} \quad$ (Acar and Alshawabkeh, 1993)

Where:

$\mathrm{q}_{\mathrm{EO}}=$ Electroosmotic velocity $\left(\mathrm{m} \mathrm{day}^{-1}\right)$

$\mathrm{q}_{\mathrm{EM}}=$ Electromigration velocity $\left(\mathrm{m}^{\mathrm{day}}{ }^{-1}\right)$

$\mathrm{k}_{\mathrm{EO}}=$ Electroosmostic permeability $\left(\mathrm{m}^{2} \mathrm{~V}\right.$ day $\left.{ }^{-1}\right)=8.6 \times 10^{-6}$ to $8.6 \times 10^{-4} \mathrm{~m}^{2} \mathrm{~V}$ day ${ }^{-1}$ (most soil types) (Chowdhury et al., 2017; Eykholt and Daniel, 1994; Mitchell and Soga, 2005)

$\mathrm{i}_{\mathrm{e}}=$ voltage gradient $\left(\mathrm{V} \mathrm{m}^{-1}\right)=1.24 \mathrm{~V} \mathrm{~m}^{-1}$ or $1.52 \mathrm{~V} \mathrm{~m}^{-1}$; average voltage gradients measured from deep and shallow electrodes during EK operations, respectively

$\mathrm{u}_{\mathrm{i}}^{*}=$ effective ionic mobility of persulfate $\left(\mathrm{m}^{2} \mathrm{~V}\right.$ day $\left.^{-1}\right)=1.12 \times 10^{-3} \mathrm{~m}^{2} \mathrm{~V}$ day ${ }^{-1}$ (Chowdhury et al., 2017; Lide et al., 2005)

$$
\begin{aligned}
\mathrm{q}_{\mathrm{EO}} & =\left(8.6 \times 10^{-6} \mathrm{~m}^{2} \mathrm{~V} \text { day }^{-1}, 8.6 \times 10^{-4} \mathrm{~m}^{2} \mathrm{~V} \text { day }^{-1}\right) \times\left(1.24 \mathrm{~V} \mathrm{~m}^{-1}, 1.52 \mathrm{~V} \mathrm{~m}^{-1}\right) \\
& =1.06 \times 10^{-5} \mathrm{~m} \text { day }^{-1} \text { to } 1.31 \times 10^{-3} \mathrm{~m} \mathrm{day}^{-1} \\
\mathrm{q}_{\mathrm{EM}} & =\left(1.12 \times 10^{-3} \mathrm{~m}^{2} \mathrm{~V}\right. \text { day } \\
& \left.=1.70 \times 10^{-4} \mathrm{~m} \text { day }^{-1} \text { to } 1.39 \times 10^{-3} \mathrm{~m} \mathrm{day}^{-1}, 1.52 \mathrm{~V} \mathrm{~m}^{-1}\right)
\end{aligned}
$$




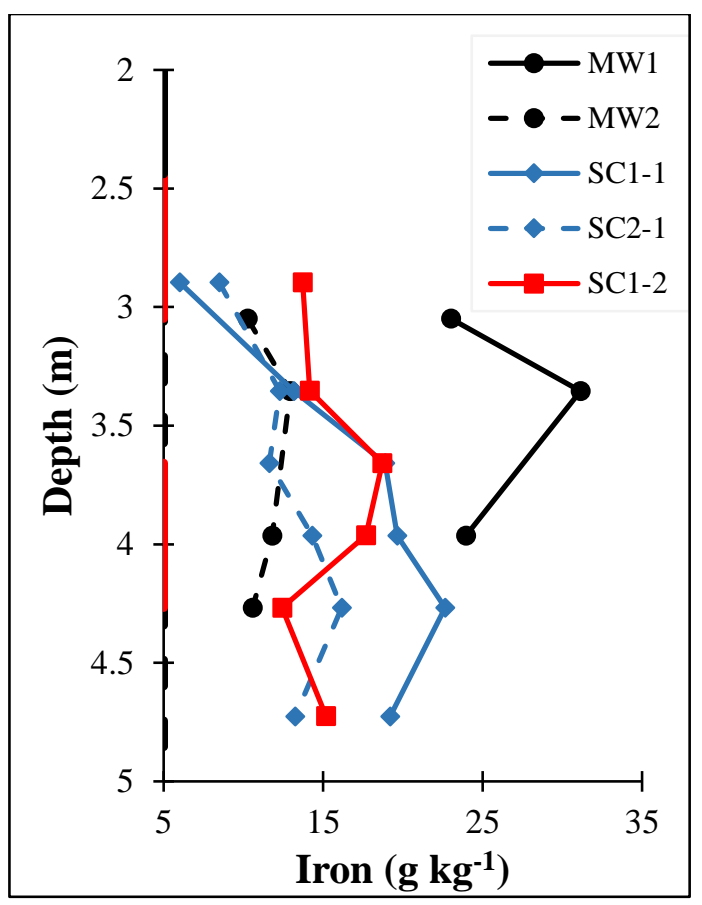

Figure A4: Soil concentration of iron $\left(\mathrm{g} \mathrm{kg}^{-1}\right)$ with depth of boreholes MW1, MW2, SC1-1, SC2-1, and SC1-2 in EK-TAP. The red vertical lines represent the depths of shallow (i.e., 2.44-3.05 $\mathrm{m}$ bgs) and deep (3.66-4.27 $\mathrm{m}$ bgs) electrodes. The black vertical dashed line represents the screening depth of the supply wells (i.e., 2.44-4.88 m bgs). 
Calculation A2: Persulfate consumption (or activation) by naturally occurring iron from SW1 to MW1 in EK-TAP.

\section{Assumptions:}

Control volume (electric field $)=0.72 \mathrm{~m}^{3}$

Soil bulk density $=1,600 \mathrm{~kg} \mathrm{~m}^{-3}$

Amorphous/soluble $\mathrm{Fe}^{2+}=0.945 \mathrm{~g} \mathrm{~kg}^{-1}$

Molar mass of $\mathrm{Fe}^{2+}=55.8 \mathrm{~g} \mathrm{~mol}^{-1}$

Molar mass of $\mathrm{S}_{2} \mathrm{O}_{8}{ }^{2-}=192 \mathrm{~g} \mathrm{~mol}^{-1}$

Mass of injected persulfate $(\mathrm{SW} 1)=14,800 \mathrm{~g}$

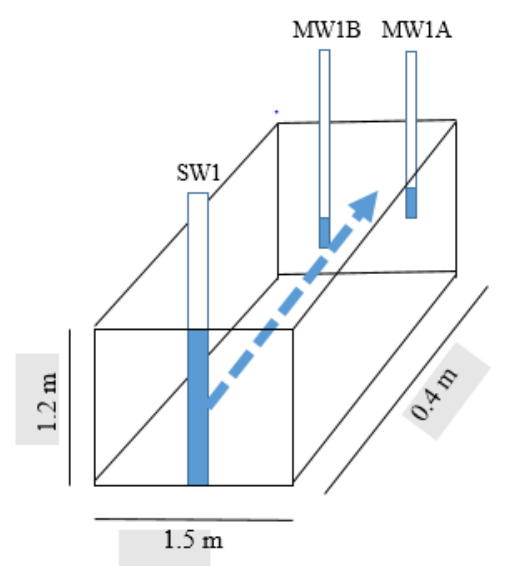

Persulfate is uniformly distributed across control volume

$$
\begin{aligned}
& \mathrm{Fe}^{2+}+\mathrm{S}_{2} \mathrm{O}_{8}^{2-} \rightarrow \mathrm{Fe}^{3+}+\mathrm{SO}_{4}^{--}+\mathrm{SO}_{4}^{2-} \text { (half-reaction) } \\
& \mathrm{Fe}^{2+}+\mathrm{SO}_{4}^{\circ-} \rightarrow \mathrm{Fe}^{3+}+\mathrm{SO}_{4}^{2-} \quad \text { (half-reaction) } \\
& 2 \mathrm{Fe}^{2+}+\mathrm{S}_{2} \mathrm{O}_{8}^{2-} \rightarrow 2 \mathrm{Fe}^{3+}+2 \mathrm{SO}_{4}^{2-} \quad \text { (full reaction) }
\end{aligned}
$$

Mass of soil in control volume $=0.72 \mathrm{~m}^{3} \times 1,600 \mathrm{~kg} \mathrm{~m}^{-3}$

$$
=1,152 \mathrm{~kg}
$$

Mass of amorphous/soluble $\mathrm{Fe}^{2+}$ in control volume $=0.945 \mathrm{~g} \mathrm{~kg}^{-1}$ x $1,152 \mathrm{~kg}$

$$
=1,089 \mathrm{~g}
$$

Moles of amorphous/soluble $\mathrm{Fe}^{2+}$ in control volume $=1,089 \mathrm{~g} / 55.8 \mathrm{~g} \mathrm{~mol}^{-1}$

$$
=19.4 \text { moles }
$$

Moles of persulfate consumed $=19.4$ moles $/ 2$

$$
=9.7 \text { moles }
$$

Mass of persulfate consumed $=9.7$ moles x $192 \mathrm{~g} \mathrm{~mol}^{-1}$

$$
=1,863 \mathrm{~g}
$$

Percent consumption (or activation) of persulfate in control volume $=1,863 \mathrm{~g} / 14,800 \mathrm{~g}$

$$
=12.6 \%
$$




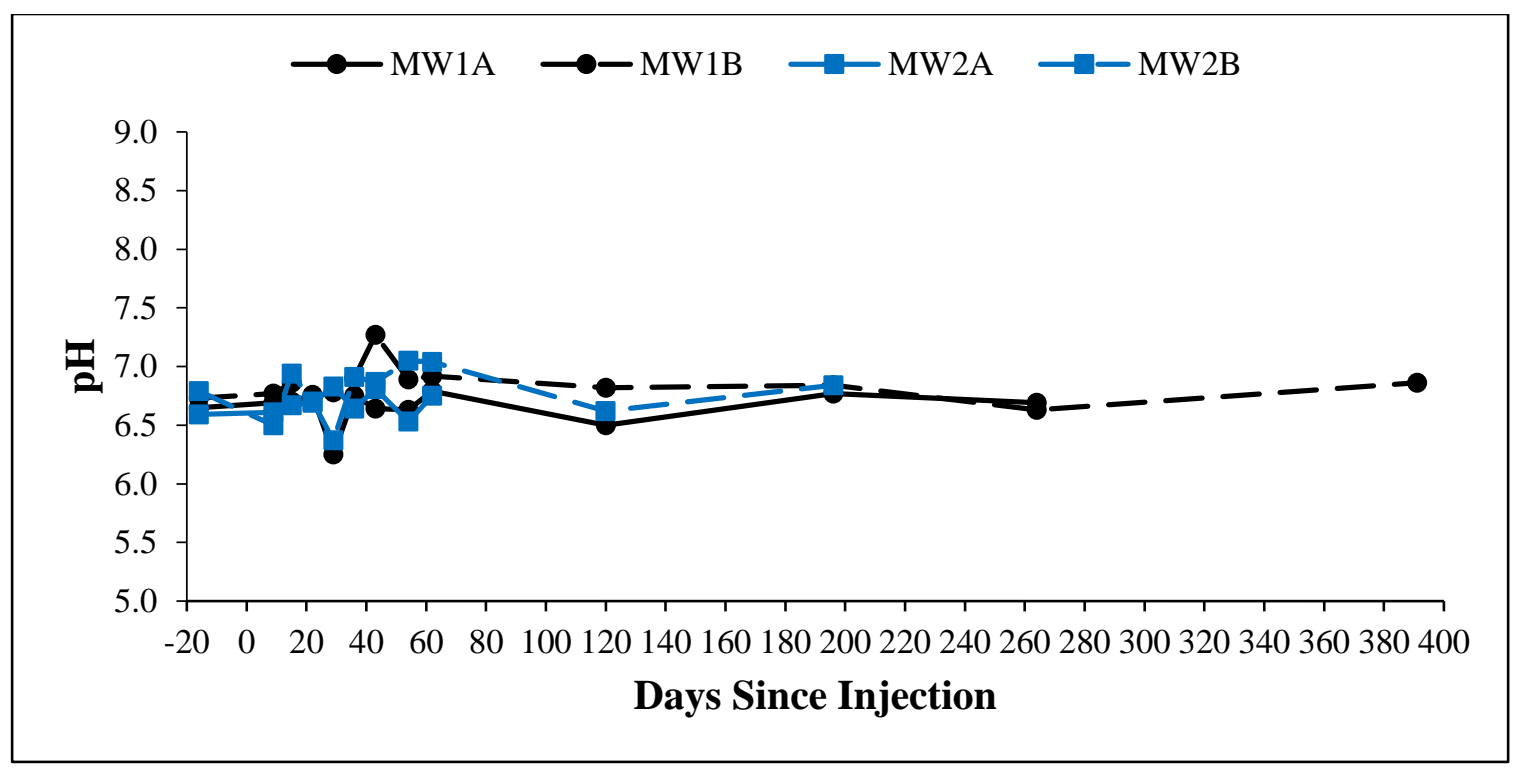

Figure A5: Groundwater $\mathrm{pH}$ in all monitoring wells of EK-TAP over the entire field test.

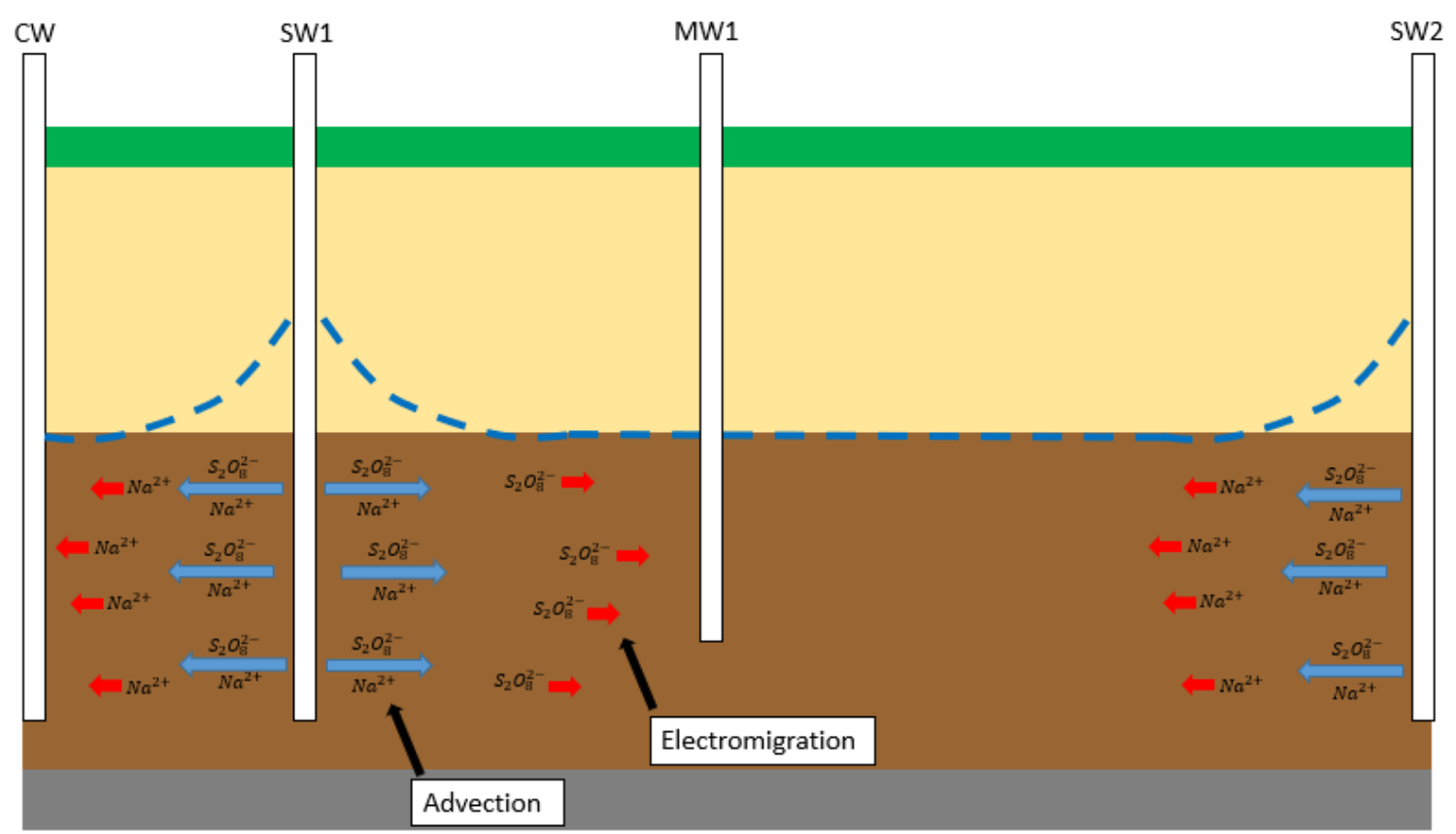

Figure A6: Transport mechanisms of persulfate and sodium from SW1 and SW2. 


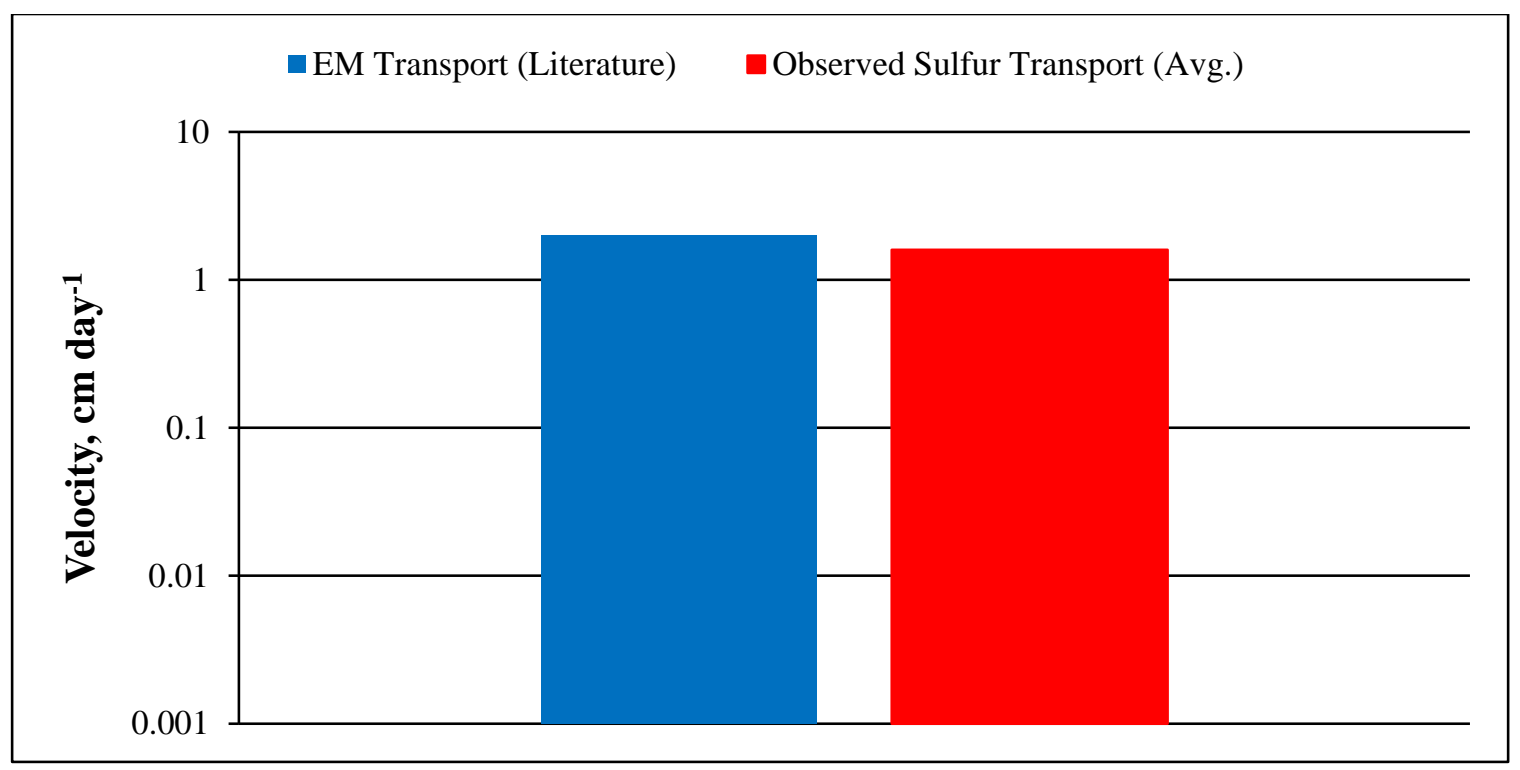

Figure A7: Observed EM transport rate of persulfate in bench-scale studies in respect to the average observed sulfur transport rate in MW1A and MW1B of EK-TAP (Fan et al., 2014; Fan et al., 2016). 


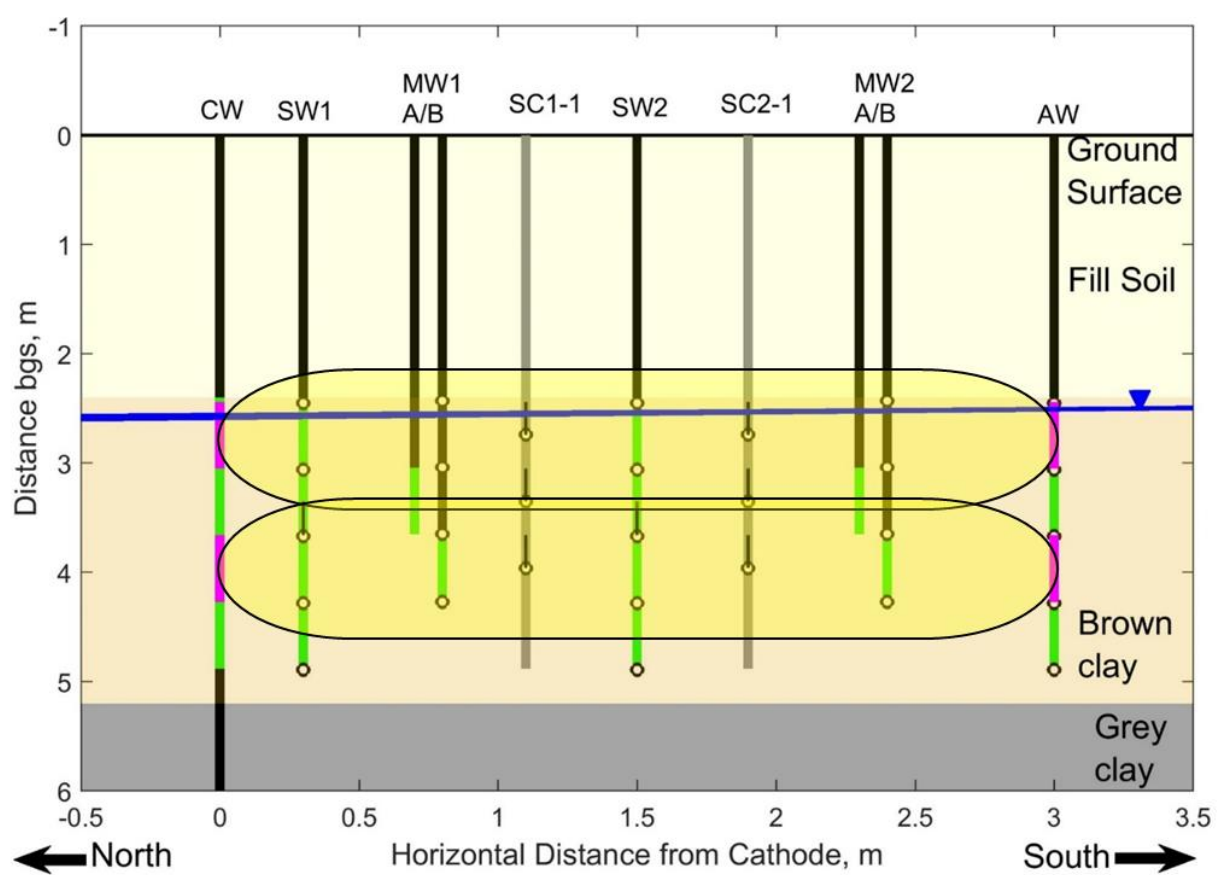

Figure A8: Estimated coverage area of electric fields applied from shallow (2.44-3.05 $\mathrm{m}$ bgs) and deep (3.66-4.27 m bgs) electrodes (D. Gent, personal communication, May 23, 2018).

Height of electric field $=2 \times$ length of electrodes

$$
\begin{aligned}
& =2 \times 0.61 \mathrm{~m} \\
& =1.2 \mathrm{~m}
\end{aligned}
$$

Width of electric field $=0.5 \mathrm{x}$ distance from the $\mathrm{CW}$ and $\mathrm{AW}$

$$
\begin{aligned}
& =0.5 \times 3 \mathrm{~m} \\
& =1.5 \mathrm{~m}
\end{aligned}
$$

Length of electric field $=$ distance from the $\mathrm{CW}$ and $\mathrm{AW}$

$$
=3 \mathrm{~m}
$$

*Upper/lower extent of shallow electric field = 2.1 m (bgs), $3.4 \mathrm{~m}(\mathrm{bgs})$

*Upper/lower extent of deep electric field = $3.4 \mathrm{~m}(\mathrm{bgs}), 4.6 \mathrm{~m}$ (bgs) 

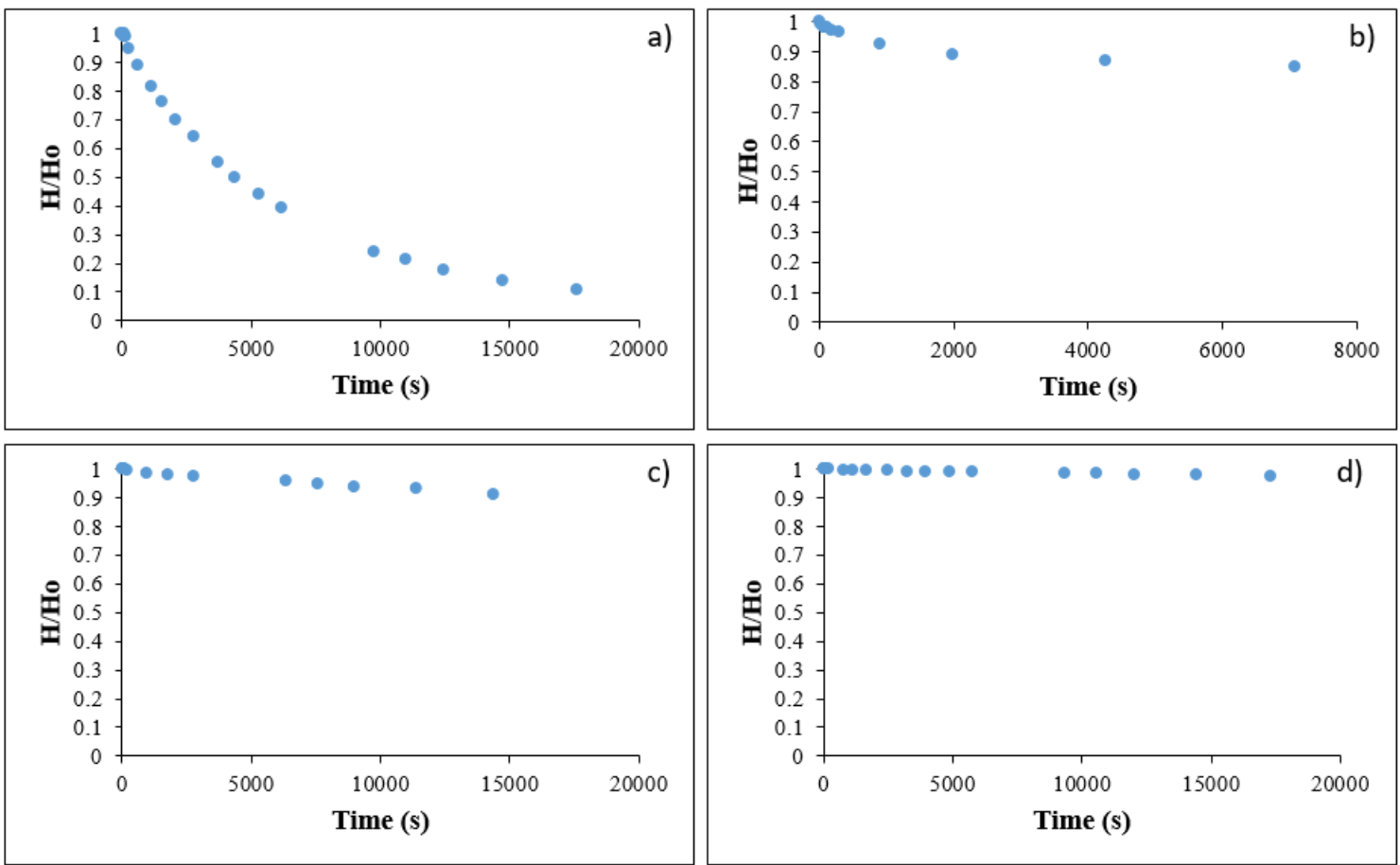

Figure A9: Falling head tests completed in a) MW1A, b) MW1B, c) MW2A, and d) MW2B of EK-TAP. Tests were completed on May $29^{\text {th }}, 2018$.

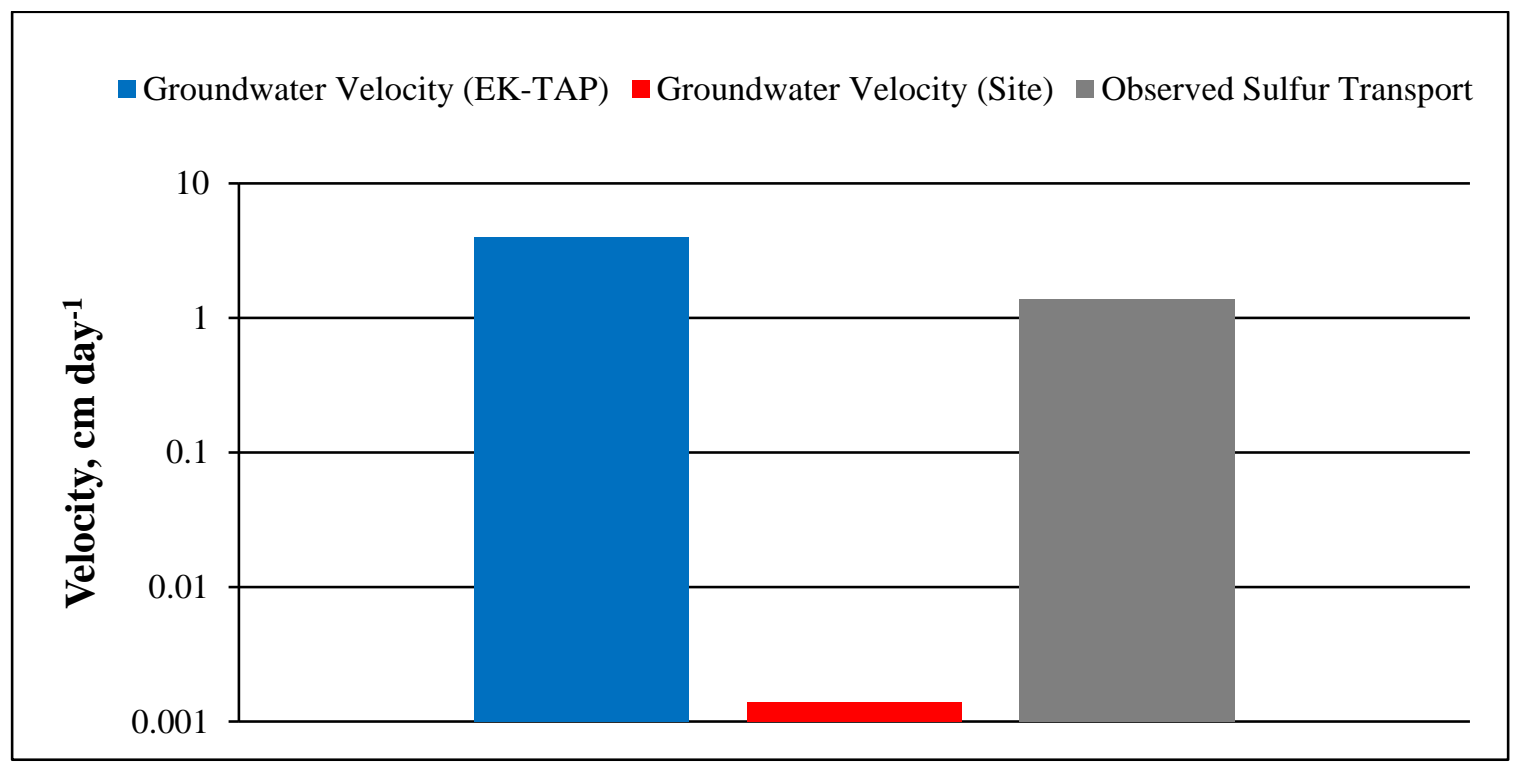

Figure A10: Observed groundwater velocity in MW1A of EK-TAP during injection in respect to the natural groundwater velocity measured on site and observed sulfur transport rate. 
Table A3: Hydraulic Conductivity and Groundwater Velocity in MW1A, MW1B, MW2A, and MW2B of EK-TAP

\begin{tabular}{|c|c|c|}
\hline Monitoring Well & $\begin{array}{c}\text { Hydraulic Conductivity } \\
\left(\mathbf{c m ~ s}^{\mathbf{- 1}}\right)\end{array}$ & $\begin{array}{c}\text { Groundwater Velocity } \\
\left(\mathbf{c m} \text { day }^{-\mathbf{1}}\right)\end{array}$ \\
\hline MW1A & $1.79 \times 10^{-5}$ & 4.24 \\
\hline MW1B & $2.59 \times 10^{-6}$ & 0.613 \\
\hline MW2A & $1.26 \times 10^{-7}$ & 0.0196 \\
\hline MW2B & $7.59 \times 10^{-7}$ & 0.118 \\
\hline
\end{tabular}

Hydraulic conductivity determined from falling head tests (Figure A7, Appendix A) and Hvorslev (1951):

$K=\frac{r^{2} \ln \left(\frac{L}{R}\right)}{2 L T_{L}}$

Where, hydraulic conductivity $(\mathrm{K})$, radius of well (r), length of well screen (L), radius of well and sand pack $(\mathrm{R})$, and time lag $\left(\mathrm{T}_{\mathrm{L}}\right)$

Hydraulic gradient calculated using the equation below:

$i=\frac{d h}{L}$

Where, hydraulic gradient $(i)$, change in hydraulic head $(d h)$, and distance (L)

Groundwater velocity calculated using:

$V=\frac{K i}{n}$

Where, groundwater velocity (V), hydraulic conductivity $(\mathrm{K})$, hydraulic gradient $(i)$, and effective porosity $(n)$

*For MW1A and MW1B, the hydraulic gradient was calculated from SW1. For MW2A and MW2B, the hydraulic gradient was calculated from SW2. Water levels used in MW1A, MW1B, MW2A, and MW2B to calculate the hydraulic gradient were from day 639 (Figure A25, Appendix A). Water levels used for SW1 and SW2 to calculate hydraulic gradients was 184.2 masl (i.e., depth of float switch during persulfate injection). Effective porosity assumed to be 0.4 for clay soils. 


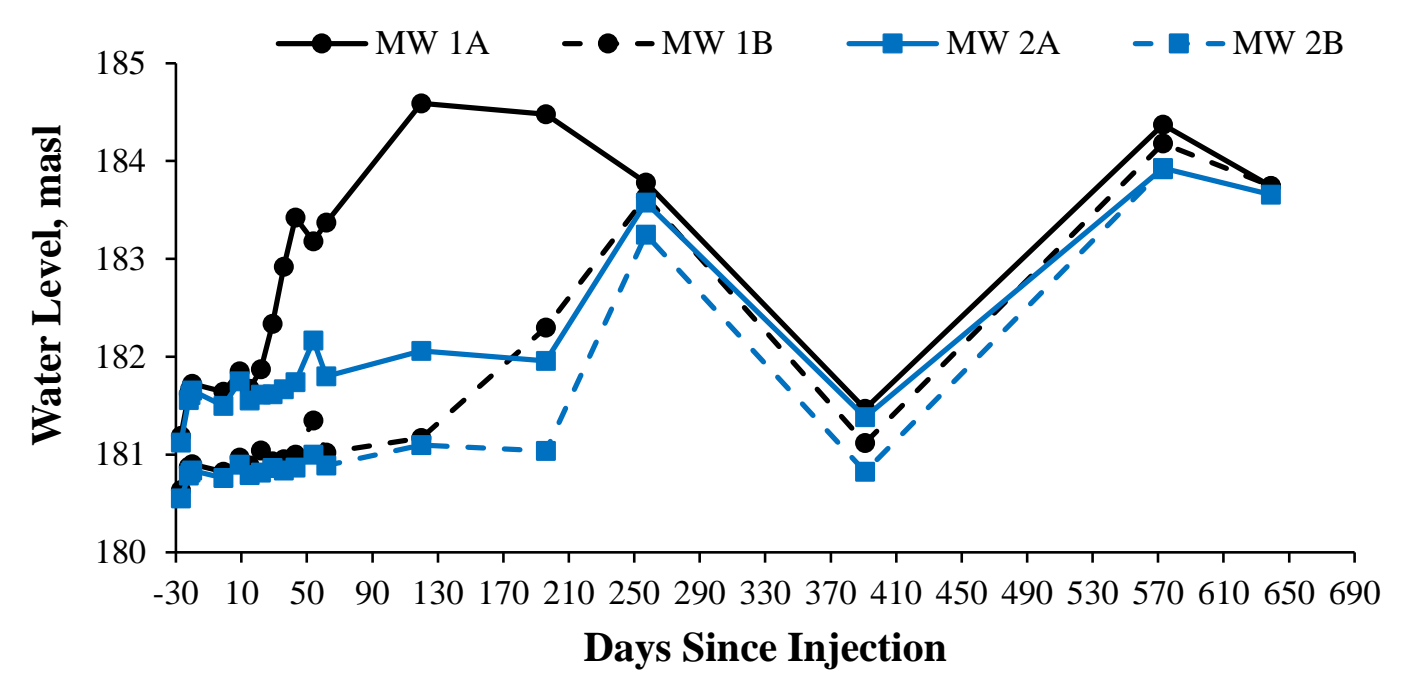

Figure A11: Water levels in all monitoring wells of EK-TAP over the entire field test.

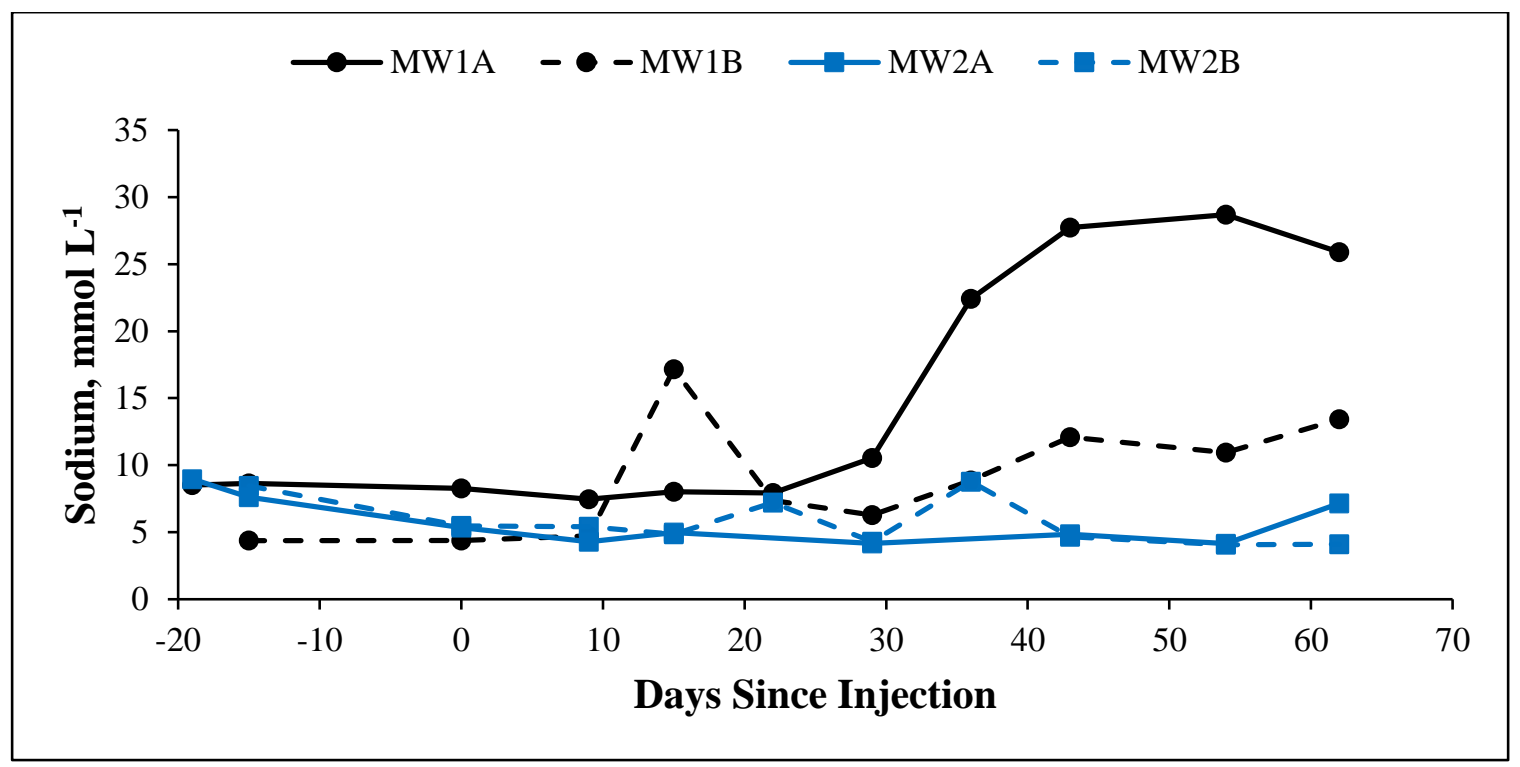

Figure A12: Groundwater concentration of sodium $\left(\mathrm{mmol} \mathrm{L}^{-1}\right)$ in all monitoring wells of EK-TAP over the course of EK operations (i.e., day 0-57). 


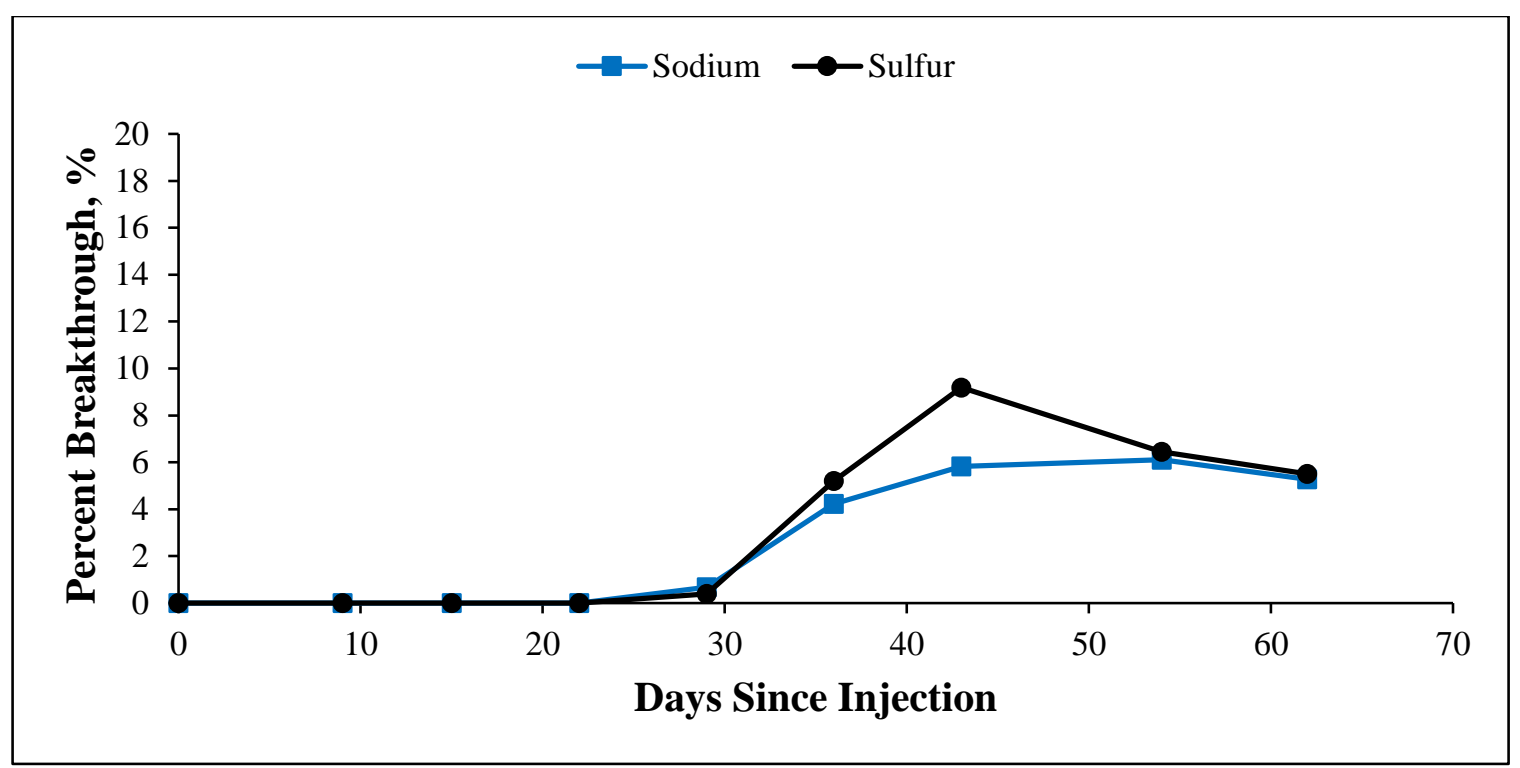

Figure A13: Percent breakthrough of sodium and sulfur in MW1A of EK-TAP during EK operations (i.e., day 0-57) from injected sodium persulfate at SW1.

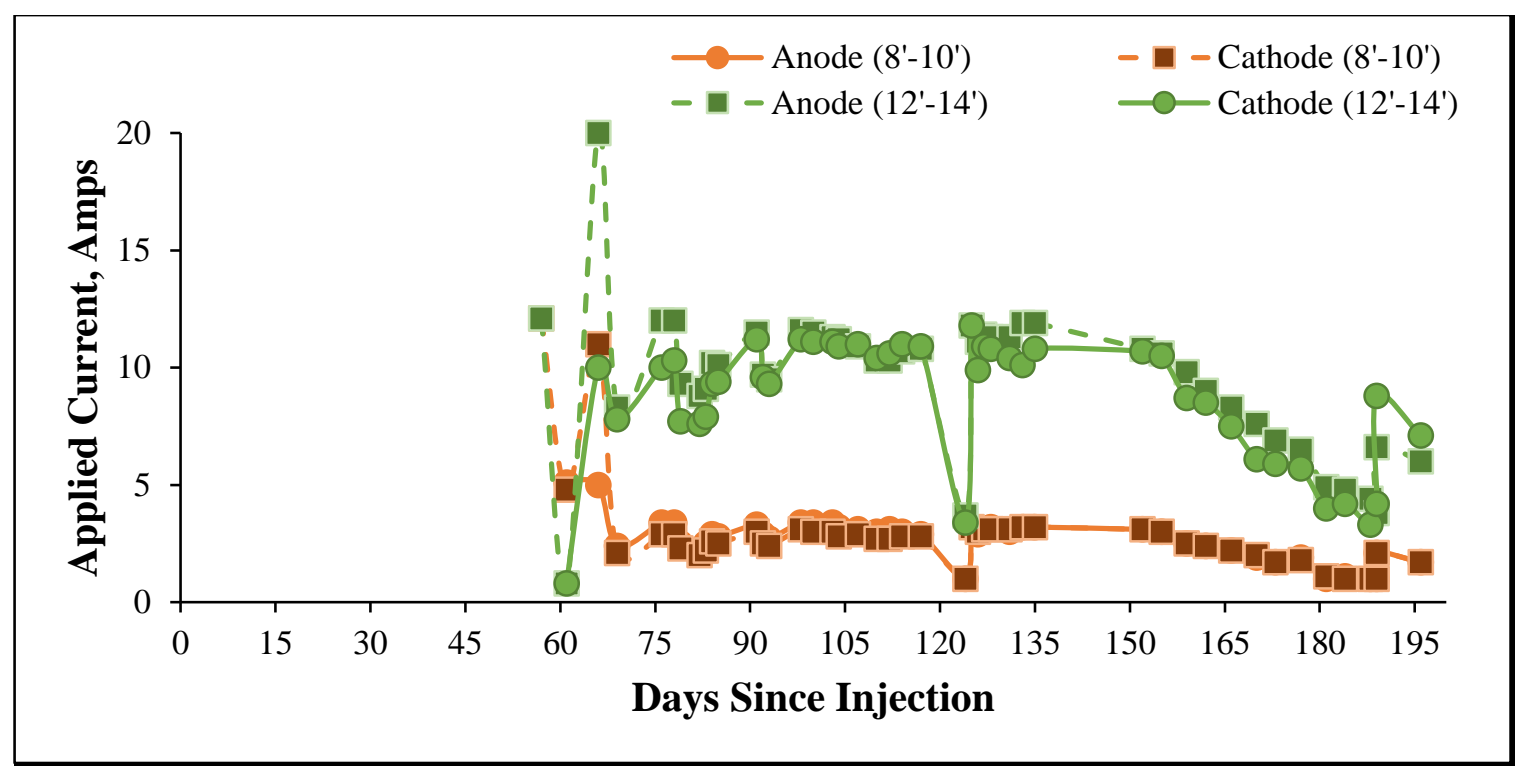

Figure A14: AC applied to EK-TAP during ERH operations (i.e., day 57-196), measured from shallow (i.e., 2.44-3.05 m bgs) and deep (i.e., 3.66-4.27 $\mathrm{m}$ bgs) electrodes of the $\mathrm{CW}$ and $\mathrm{AW}$. 


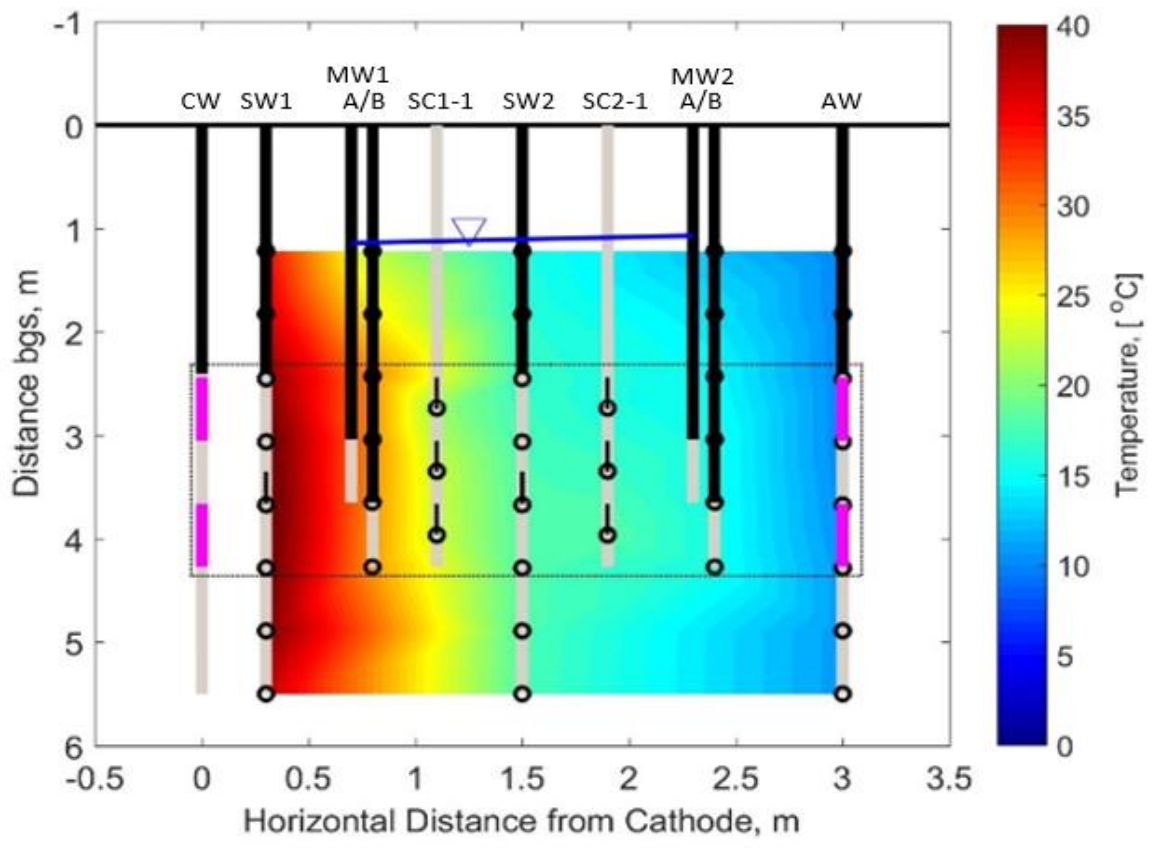

Figure A15: Cross-section of heat distribution in EK-TAP on day 138 of ERH operations (i.e., day 57-196). Pink regions are electrodes, grey regions are well screens and conduits, black regions are PVC well piping, circles are soil sampling locations, and circles with dashes are locations of thermocouples. 
Table A4: Background Groundwater Concentration $\left(\mathrm{mg} \mathrm{L}^{-1}\right)$ of COCs in EK-TAP

\begin{tabular}{|c|c|c|c|c|c|}
\hline \multirow[t]{2}{*}{ Compound } & \multicolumn{4}{|c|}{ EK-TAP } & \multirow{2}{*}{$\begin{array}{c}\text { O. Reg 153/04 } \\
\text { Table } 3 \text { (Ind/Comm) }\end{array}$} \\
\hline & MW1A & MW1B & MW2A & MW2B & \\
\hline Vinyl Chloride & 75.24 & 75.67 & 106.21 & 72.63 & 0.0017 \\
\hline Chloroethane & 1.87 & 1.13 & 1.08 & 0.67 & N/A \\
\hline 1,1-Dichloroethene & 1.60 & 1.77 & 2.00 & 1.81 & 0.017 \\
\hline Dichloromethane & 0.25 & 0.00 & 0.25 & 0.12 & N/A \\
\hline trans-1,2-Dichloroethene & 0.43 & 0.18 & 0.31 & 0.18 & 0.017 \\
\hline 1,1-Dichloroethane & 232.85 & 248.27 & 315.46 & 265.56 & 3.1 \\
\hline cis-1,2-Dichloroethene & 11.81 & 2.51 & 6.12 & 2.18 & 0.017 \\
\hline Chloroform & 1.21 & 1.09 & 1.41 & 1.14 & 0.022 \\
\hline 1,1,1-Trichloroethane & 0.82 & 1.18 & 1.30 & 1.14 & 6.7 \\
\hline Carbon tetrachloride & 0.00 & 0.00 & 0.00 & 0.00 & 0.0084 \\
\hline 1,2-Dichloroethane & 1133.24 & 1090.35 & 1583.14 & 1360.04 & 0.012 \\
\hline Trichloroethene & 59.80 & 40.75 & 62.61 & 48.47 & 0.017 \\
\hline Tetrachloroethene & 3.46 & 8.43 & 4.65 & 6.83 & 0.017 \\
\hline 1,1,2-Trichloroethane & 121.34 & 65.38 & 122.07 & 80.93 & 0.03 \\
\hline 1,1,1,2-Tetrachloroethane & 0.21 & 0.72 & 0.47 & 0.57 & N/A \\
\hline
\end{tabular}


Table A5: Background Soil Concentration ( $\left.\mathrm{mg} \mathrm{kg}^{-1}\right)$ of COCs in EK-TAP

\begin{tabular}{|c|c|c|c|c|c|c|c|c|c|}
\hline \multirow[t]{2}{*}{ Compound } & \multicolumn{4}{|c|}{ MW1 } & \multicolumn{4}{|c|}{ MW2 } & \multirow{2}{*}{$\begin{array}{c}\text { O. Reg 153/04 } \\
\text { Table } 3 \\
\text { (Ind/Comm) }\end{array}$} \\
\hline & $\begin{array}{c}3.05 \\
\text { m (bgs) }\end{array}$ & $\begin{array}{c}3.35 \\
\mathrm{~m}(\mathbf{b g s}) \\
\end{array}$ & $\begin{array}{c}3.96 \\
\text { m (bgs) }\end{array}$ & $\begin{array}{c}4.27 \\
\mathrm{~m}(\mathrm{bgs})\end{array}$ & $\begin{array}{c}3.05 \\
\text { m (bgs) }\end{array}$ & $\begin{array}{c}3.35 \\
\text { m (bgs) }\end{array}$ & $\begin{array}{c}3.96 \\
\text { m (bgs) }\end{array}$ & $\begin{array}{c}4.27 \\
\mathrm{~m} \text { (bgs) }\end{array}$ & \\
\hline Vinyl Chloride & 5.42 & 8.77 & 12.50 & 12.60 & 7.85 & 8.93 & 13.99 & 13.05 & 0.25 \\
\hline Chloroethane & 0.26 & 0.30 & 0.10 & 0.09 & 0.21 & 0.20 & 0.10 & 0.09 & $\mathrm{~N} / \mathrm{A}$ \\
\hline $\begin{array}{l}1,1- \\
\text { Dichloroethene }\end{array}$ & 0.21 & 0.52 & 0.40 & 0.57 & 0.41 & 0.47 & 0.46 & 0.60 & 0.48 \\
\hline Dichloromethane & 0.00 & 0.00 & 0.00 & 0.00 & 0.00 & 0.00 & 0.00 & 0.00 & N/A \\
\hline $\begin{array}{l}\text { trans-1,2- } \\
\text { Dichloroethene }\end{array}$ & 0.10 & 0.19 & 0.08 & 0.07 & 0.17 & 0.17 & 0.11 & 0.06 & 9.3 \\
\hline $\begin{array}{l}1,1- \\
\text { Dichloroethane }\end{array}$ & 29.55 & 62.76 & 80.89 & 76.40 & 50.66 & 63.75 & 91.01 & 85.66 & 21 \\
\hline $\begin{array}{l}\text { cis-1,2- } \\
\text { Dichloroethene }\end{array}$ & 2.41 & 5.32 & 0.76 & 0.18 & 3.87 & 3.59 & 0.58 & 0.20 & 37 \\
\hline Chloroform & 0.00 & 0.00 & 0.00 & 0.00 & 0.00 & 0.00 & 0.00 & 0.51 & 0.18 \\
\hline $\begin{array}{l}1,1,1- \\
\text { Trichloroethane }\end{array}$ & 0.00 & 0.00 & 0.25 & 0.76 & 0.00 & 0,00 & 0,00 & 0.70 & 12 \\
\hline $\begin{array}{l}\text { Carbon } \\
\text { tetrachloride }\end{array}$ & 0.00 & 0.00 & 0.00 & 0.00 & 0.00 & 0.00 & 0.00 & 0.00 & 1.5 \\
\hline $\begin{array}{l}1,2- \\
\text { Dichloroethane }\end{array}$ & 212.35 & 377.40 & 403.84 & 424.85 & 342.99 & 403.55 & 488.06 & 473.06 & 0.05 \\
\hline Trichloroethene & 18.24 & 67.87 & 39.69 & 51.73 & 58.76 & 69.35 & 55.74 & 65.46 & 0.61 \\
\hline Tetrachloroethene & 1.55 & 8.56 & 35.95 & 38.58 & 22.68 & 16.80 & 34.90 & 36.58 & 21 \\
\hline $\begin{array}{l}\text { 1,1,2- } \\
\text { Trichloroethane }\end{array}$ & 28.43 & 79.36 & 43.04 & 42.15 & 68.14 & 82.85 & 54.47 & 57.53 & 0.11 \\
\hline $\begin{array}{l}1,1,1,2- \\
\text { Tetrachloroethane }\end{array}$ & 0.00 & 0.00 & 1.65 & 1.79 & 0.00 & 0.00 & 1.07 & 1.42 & N/A \\
\hline $\begin{array}{l}1,1,2,2- \\
\text { Tetrachloroethane }\end{array}$ & 4.29 & 15.72 & 0.84 & 0.00 & 21.86 & 21.22 & 1.76 & 0.23 & N/A \\
\hline
\end{tabular}




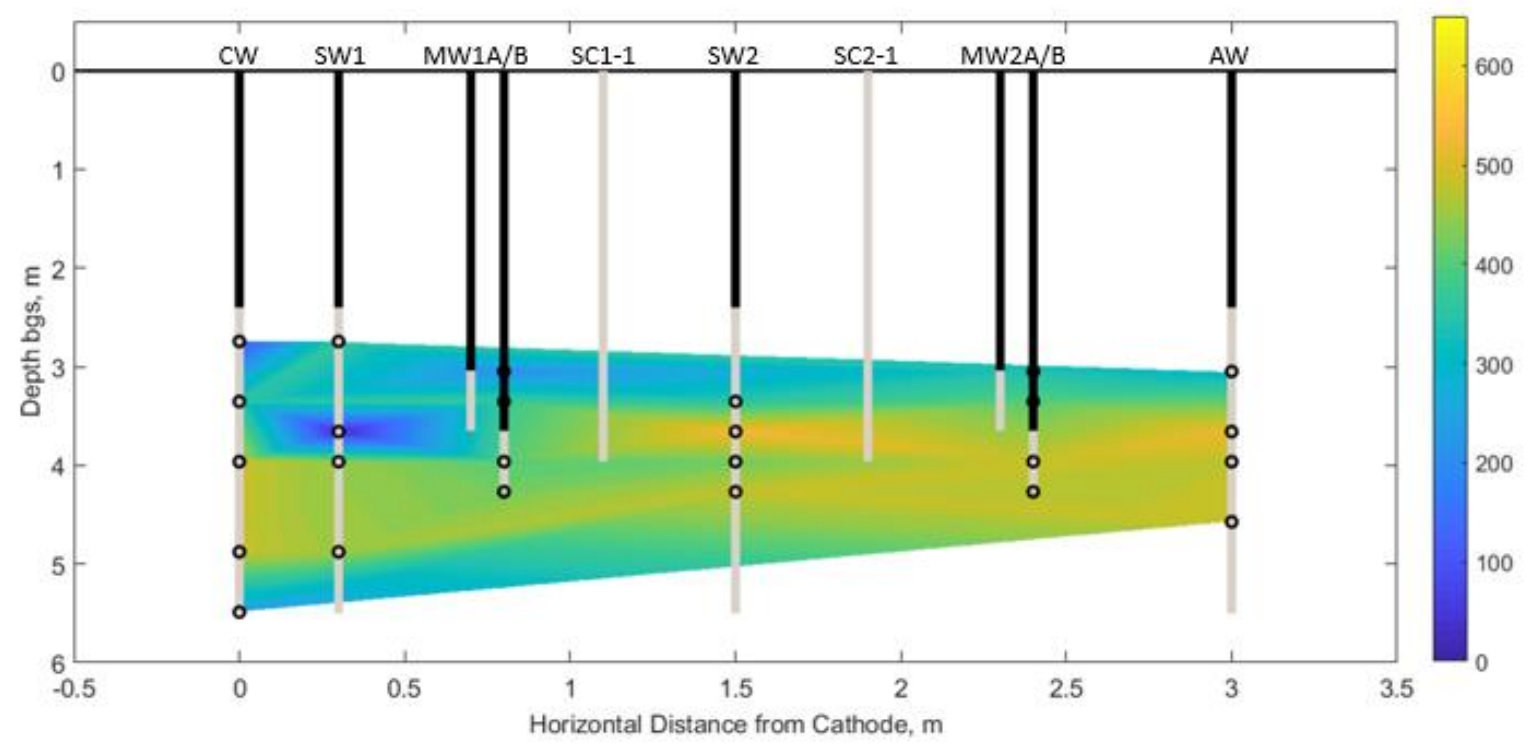

Figure A16: Interpolated background distribution of 1,2-DCA $\left(\mathrm{mg} \mathrm{kg}^{-1}\right)$ in EK-TAP. Open circles are soil sampling locations, grey regions are well screens and conduits, and black regions are solid PVC piping.

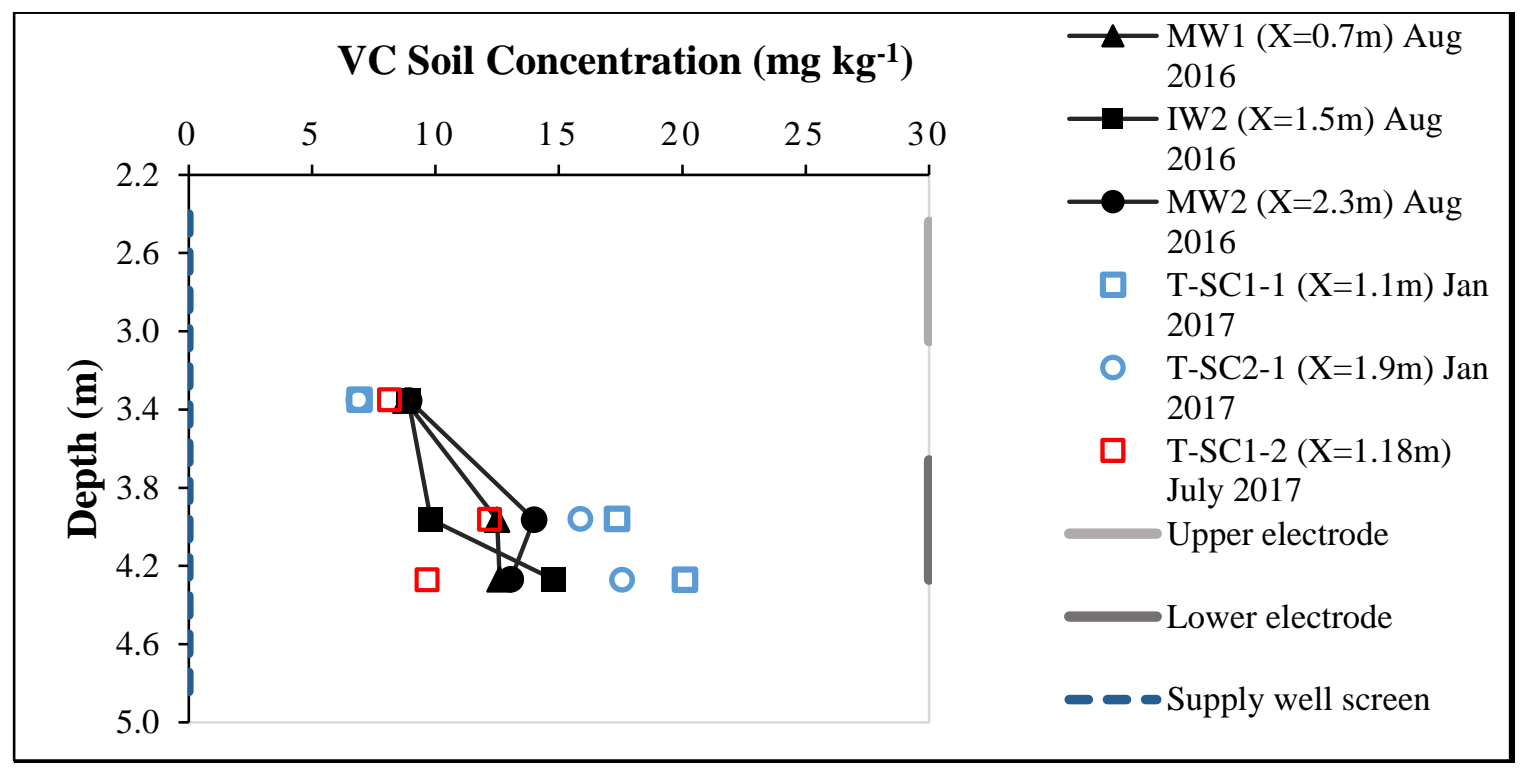

Figure A17: VC soil concentration ( $\mathrm{mg} \mathrm{kg}^{-1}$ ) with depth of boreholes MW1, SW2, MW2, T-SC1-1, T-SC2-1, and T-SC1-2. Sampling depths include $3.35 \mathrm{~m}, 3.96 \mathrm{~m}$, and $4.27 \mathrm{~m}$ (bgs). Black markers are boreholes completed before EK (i.e., MW1 and SW2), blue markers are boreholes (i.e., T-SC1-1 and TSC2-1) completed on day 125 during ERH, and red markers represent a borehole (i.e., T-SC1-2) completed on day 286 post-ERH. 


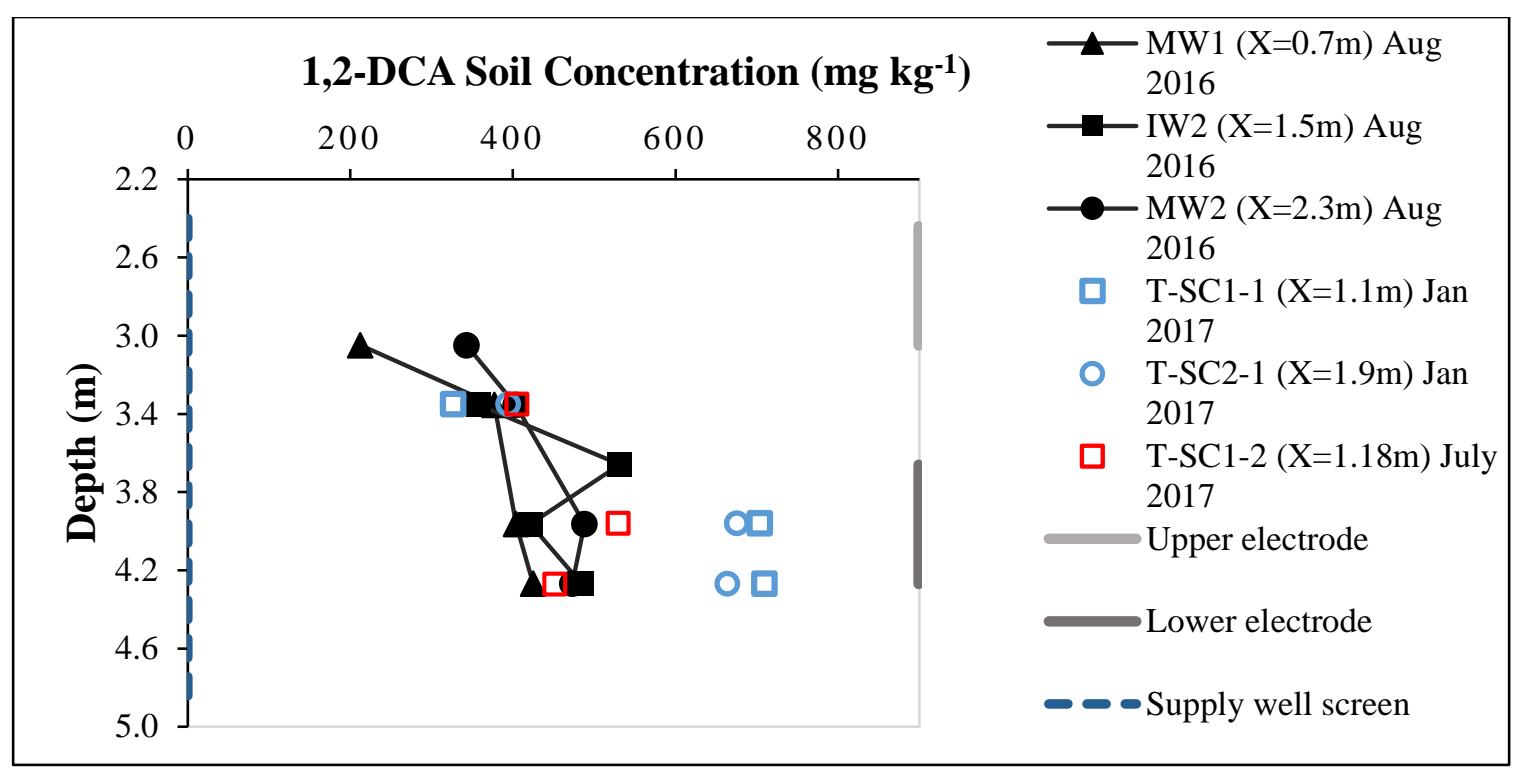

Figure A18: 1,2-DCA soil concentration $\left(\mathrm{mg} \mathrm{kg}^{-1}\right)$ with depth of boreholes MW1, SW2, MW2, T-SC1-1, T-SC2-1, and T-SC1-2. Sampling depths include 3.35 m, 3.96 m, and $4.27 \mathrm{~m}$ (bgs). Black markers are boreholes completed before EK (i.e., MW1 and SW2), blue markers are boreholes (i.e., T-SC1-1 and TSC2-1) completed on day 125 during ERH, and red markers represent a borehole (i.e., T-SC1-2) completed on day 286 post-ERH.

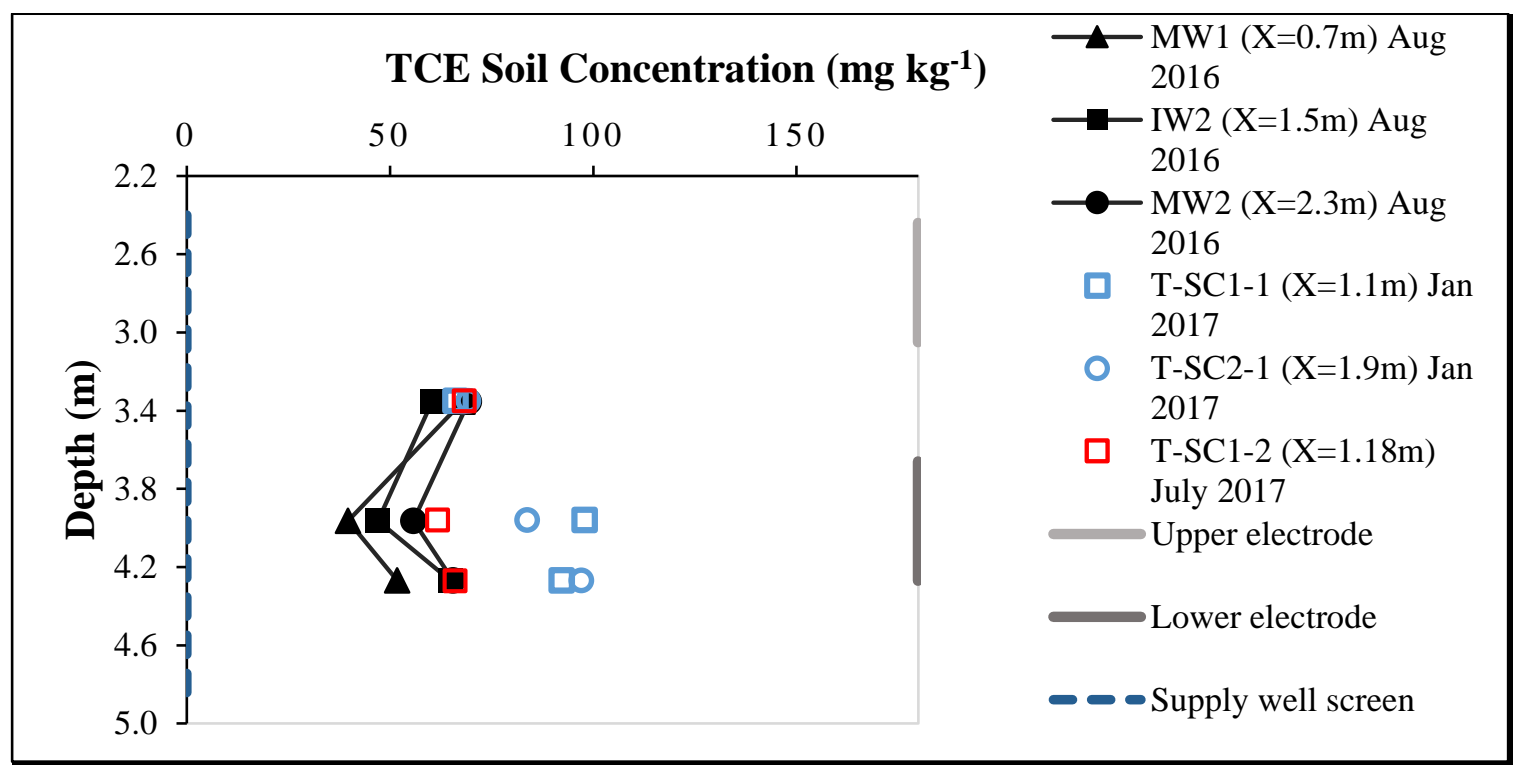

Figure A19: TCE soil concentration $\left(\mathrm{mg} \mathrm{kg}^{-1}\right)$ with depth of boreholes MW1, SW2, MW2, T-SC1-1, T-SC2-1, and T-SC1-2. Sampling depths include $3.35 \mathrm{~m}, 3.96 \mathrm{~m}$, and $4.27 \mathrm{~m}$ (bgs). Black markers are boreholes completed before EK (i.e., MW1 and SW2), blue markers are boreholes (i.e., T-SC1-1 and TSC2-1) completed on day 125 during ERH, and red markers represent a borehole (i.e., T-SC1-2) completed on day 286 post-ERH. 


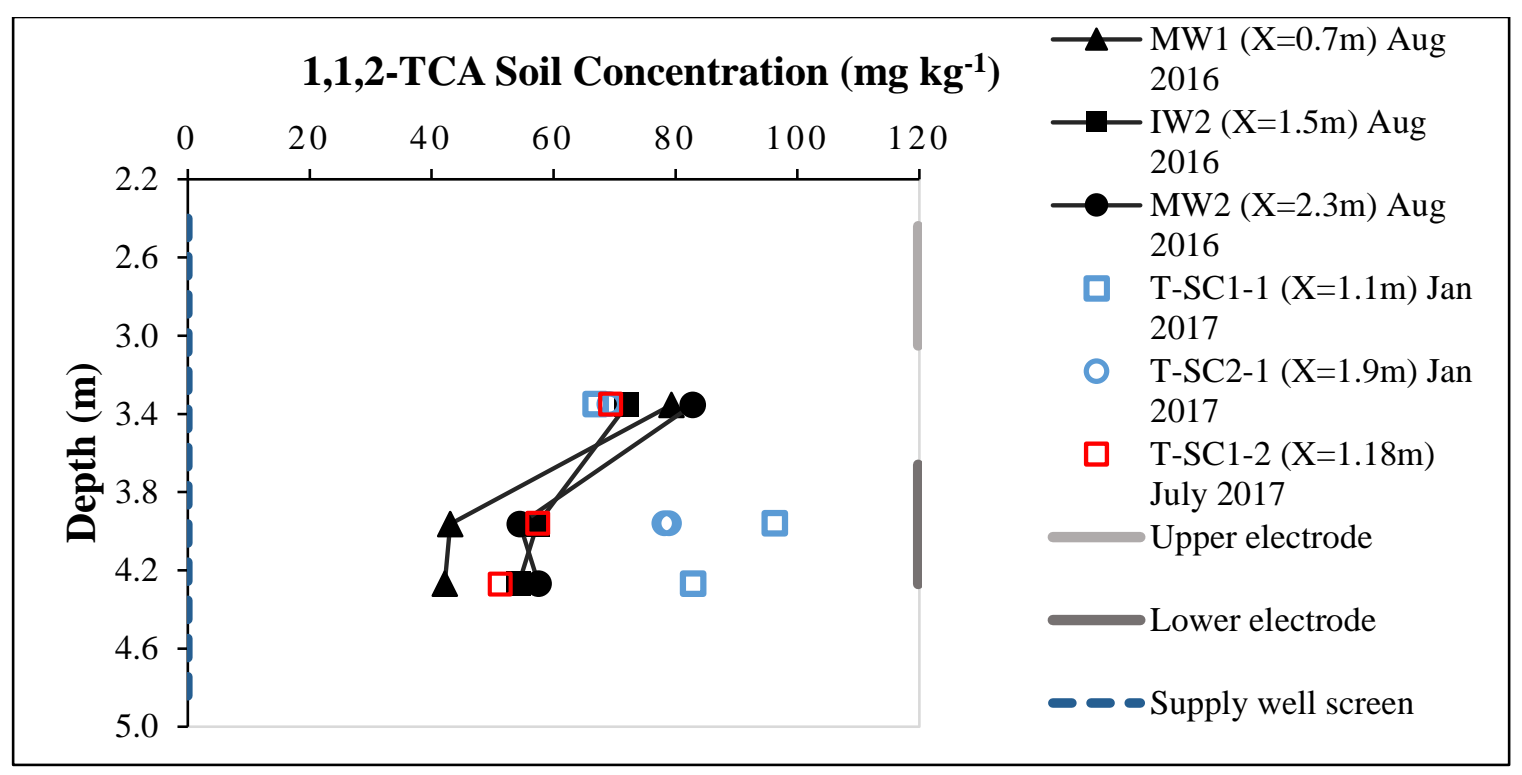

Figure A20: 1,1,2-TCA soil concentration $\left(\mathrm{mg} \mathrm{kg}^{-1}\right)$ with depth of boreholes MW1, SW2, MW2, T-SC1-1, T-SC2-1, and T-SC1-2. Sampling depths include $3.35 \mathrm{~m}, 3.96$ m, and $4.27 \mathrm{~m}$ (bgs). Black markers are boreholes completed before EK (i.e., MW1 and SW2), blue markers are boreholes (i.e., T-SC1-1 and TSC2-1) completed on day 125 during ERH, and red markers represent a borehole (i.e., T-SC1-2) completed on day 286 post-ERH.

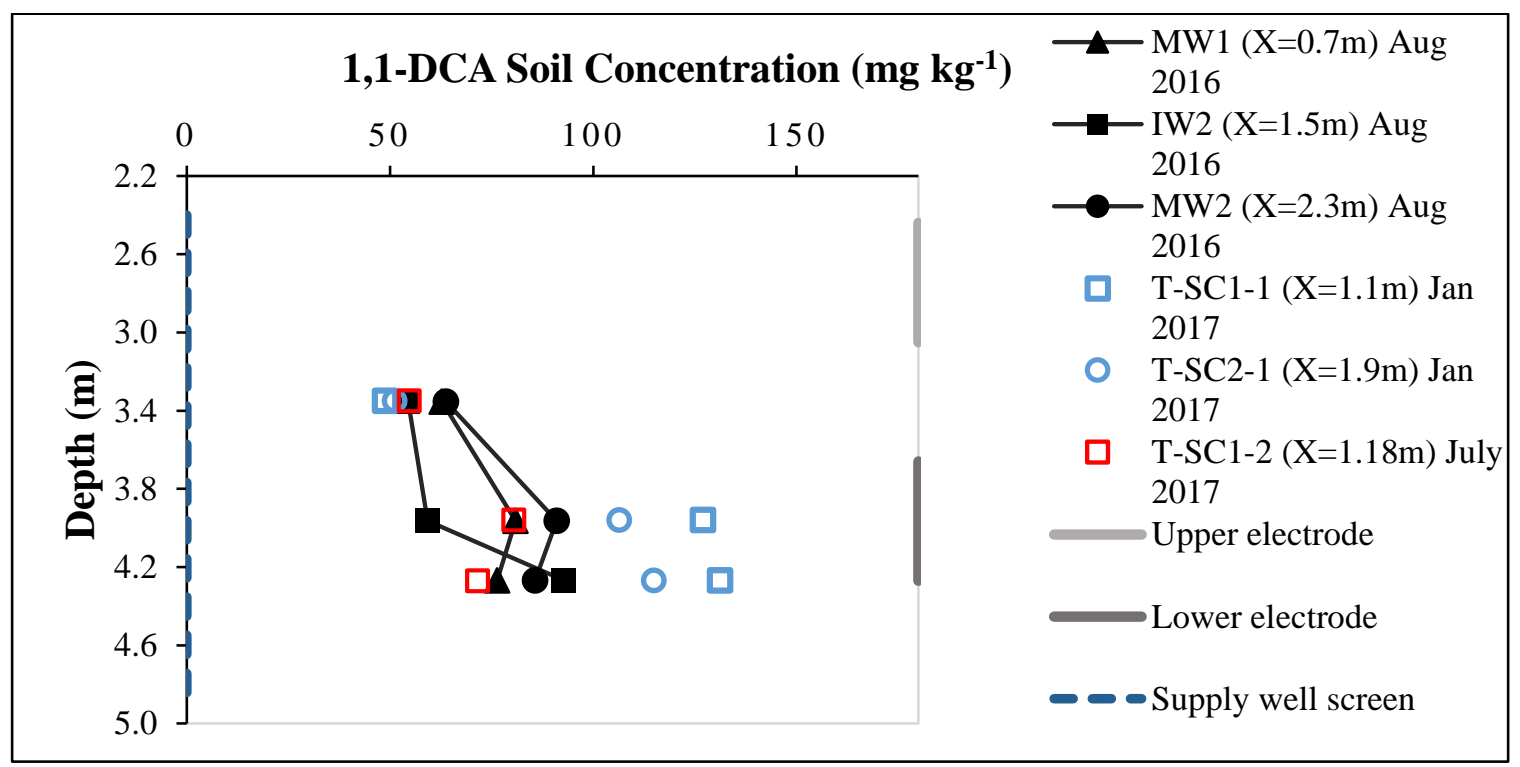

Figure A21: 1,1-DCA soil concentration ( $\left.\mathrm{mg} \mathrm{kg}^{-1}\right)$ with depth of boreholes MW1, SW2, MW2, T-SC1-1, T-SC2-1, and T-SC1-2. Sampling depths include 3.35 m, 3.96 $\mathrm{m}$, and $4.27 \mathrm{~m}$ (bgs). Black markers are boreholes completed before EK (i.e., MW1 and SW2), blue markers are boreholes (i.e., T-SC1-1 and TSC2-1) completed on day 125 during ERH, and red markers represent a borehole (i.e., T-SC1-2) completed on day 286 post-ERH. 

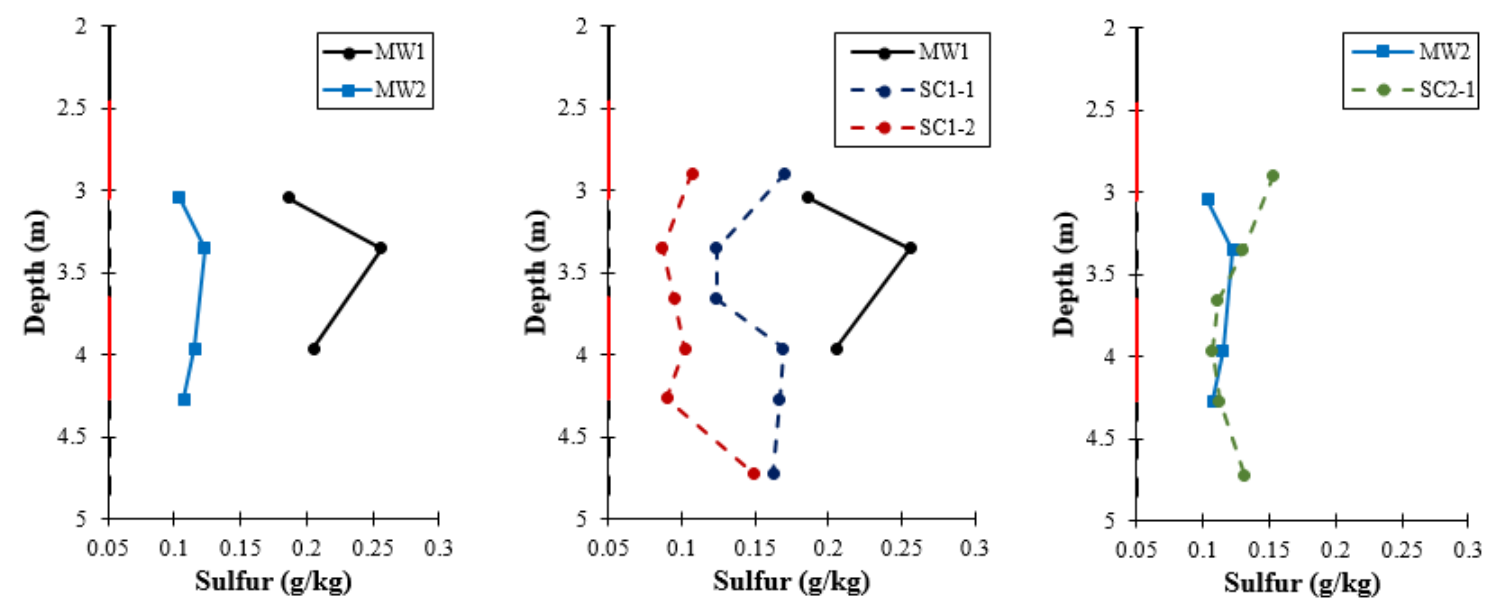

Figure A22: Soil concentration of sulfur $\left(\mathrm{g} \mathrm{kg}^{-1}\right)$ with depth of boreholes MW1, SC11, SC1-2, MW2, and SC2-1 of EK-TAP. The first panel shows sulfur $\left(\mathrm{g} \mathrm{kg}^{-1}\right)$ measured from background boreholes MW1 and MW2. The second panel displays a comparison of sulfur $\left(\mathrm{g} \mathrm{kg}^{-1}\right)$ between background and post-injection boreholes MW1, SC1-1, and SC1-2 due to their proximity. The third panel compares sulfur $\left(\mathrm{g} \mathrm{kg}^{-1}\right)$ between background and post-injection boreholes MW2 and SC2-1 due to their proximity. Boreholes SC1-1 and SC2-1 were completed on day 125 during ERH operations (i.e., day 57-196). Borehole SC1-2 was completed on day 286 post-ERH. The red vertical lines represent the depth of shallow (i.e., 2.44-3.05 $\mathrm{m}$ bgs) and deep (i.e., 3.66 $\mathrm{m}$ to $4.27 \mathrm{~m}$ bgs) electrodes. The black vertical dashed line represents the screening interval of the supply wells (i.e., 2.44-4.88 m bgs). 
Calculation A3: Expected sulfur breakthrough at SC1-2 and SC1-1 from injected persulfate at SW1.

Volume of persulfate injected at SW1 $=462.5 \mathrm{~L}$

Concentration of persulfate injected at SW1 $=32 \mathrm{~g} \mathrm{~L}^{-1}$

Mass of injected persulfate at SW1 $=14,800 \mathrm{~g}$

Mass of injected sulfur at SW1 $=2,470 \mathrm{~g}$

Control volume (electric field $)=$ width of electric field $\mathrm{x}$ height of electric field $\mathrm{x}$ distance of SW1 to SC1-2 and SC1-1

$$
\begin{aligned}
& =1.5 \mathrm{~m} \times 1.2 \mathrm{~m} \times 1.1 \mathrm{~m} \\
& =2 \mathrm{~m}^{3}
\end{aligned}
$$

Mass of soil in control volume $=$ control volume $\mathrm{x}$ soil bulk density

$$
\begin{aligned}
& =2 \mathrm{~m}^{3} \times 1,600 \mathrm{~kg} \mathrm{~m}^{-3} \\
& =3,200 \mathrm{~kg}
\end{aligned}
$$

Expected concentration of sulfur in control volume $=2,470 \mathrm{~g} / 3,200 \mathrm{~kg}$

$$
=0.77 \mathrm{~g} \mathrm{~kg}^{-1}
$$

*If all of the injected persulfate at SW1 was uniformly delivered into the control volume, an increase of $0.77 \mathrm{~g} \mathrm{~kg}^{-1}$ would be expected at boreholes SC1-1 and SC1-2. 
Calculation A4: Radius of influence of injected persulfate at SW1.

Volume of persulfate injected at SW1 $=0.463 \mathrm{~m}^{3}$

Height of SW1 screen $(\mathrm{h})=2.44 \mathrm{~m}$

Porosity of porous media $=0.4$

Volume of porous media occupied with injected persulfate $(V)=0.463 \mathrm{~m}^{3} / 0.4$

$$
=1.16 \mathrm{~m}^{3}
$$

Radius of influence from injected persulfate $(r)$ :

$$
\begin{aligned}
& \mathrm{V}=\pi r^{2} h \\
& 1.16 \mathrm{~m}^{3}=\pi \mathrm{r}^{2}(2.44 \mathrm{~m}) \\
& r=0.39 \mathrm{~m}
\end{aligned}
$$

*Assumptions include homogeneous porous media and that the porosity of the clay soil is 0.4 . 


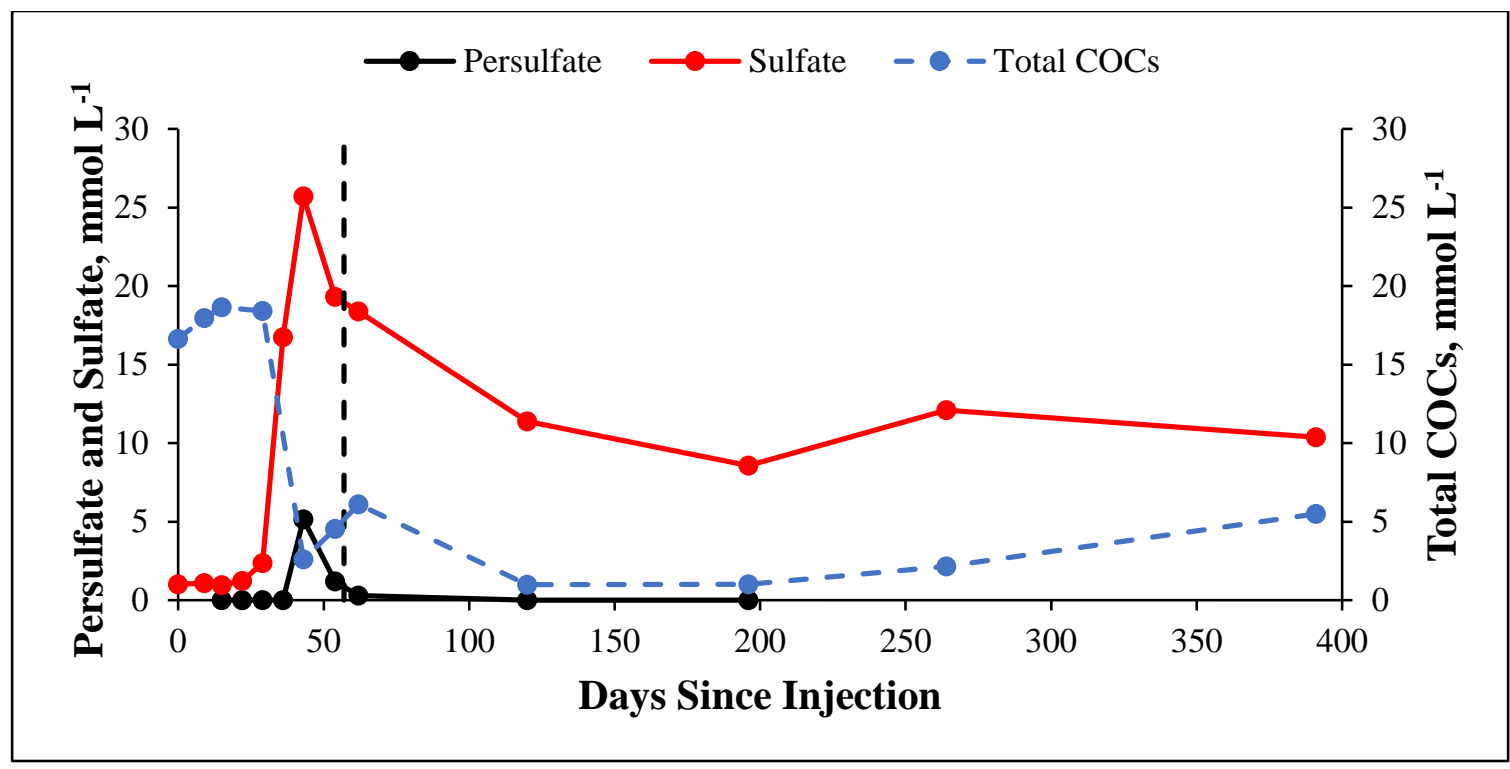

Figure A23: Groundwater concentration of persulfate, sulfate, and total COCs in MW1A of EK-TAP over the course of the field test. Black vertical dashed line shows the end of applied EK.

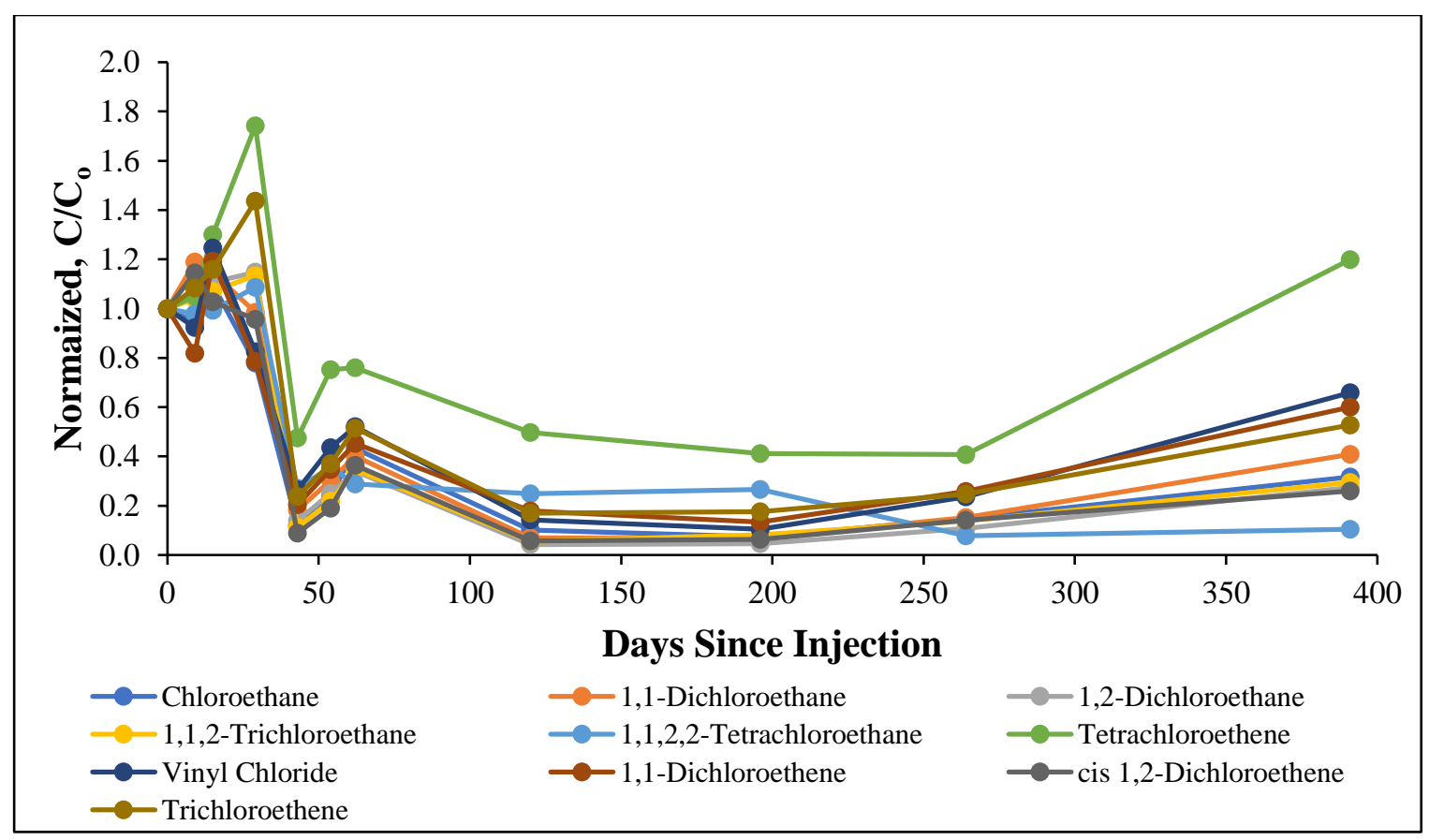

Figure A24: Normalized groundwater concentration of COCs and chloride to background (i.e., day 0) in MW1A of EK-TAP over the entire field test. 


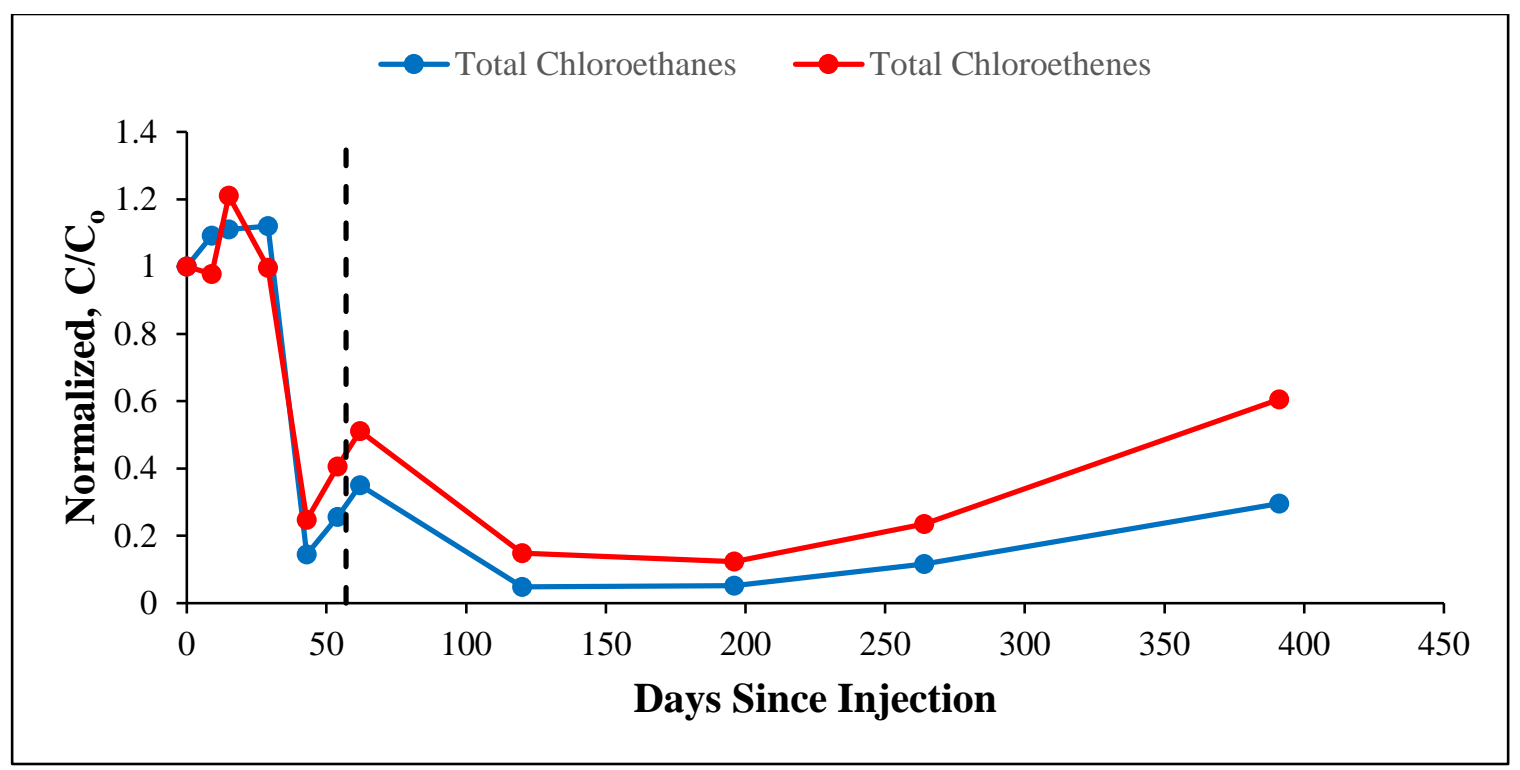

Figure A25: Normalized groundwater concentrations of total chloroethanes and chloroethenes in MW1A of EK-TAP over the course of the field test. Black vertical dashed line shows the end of applied EK.

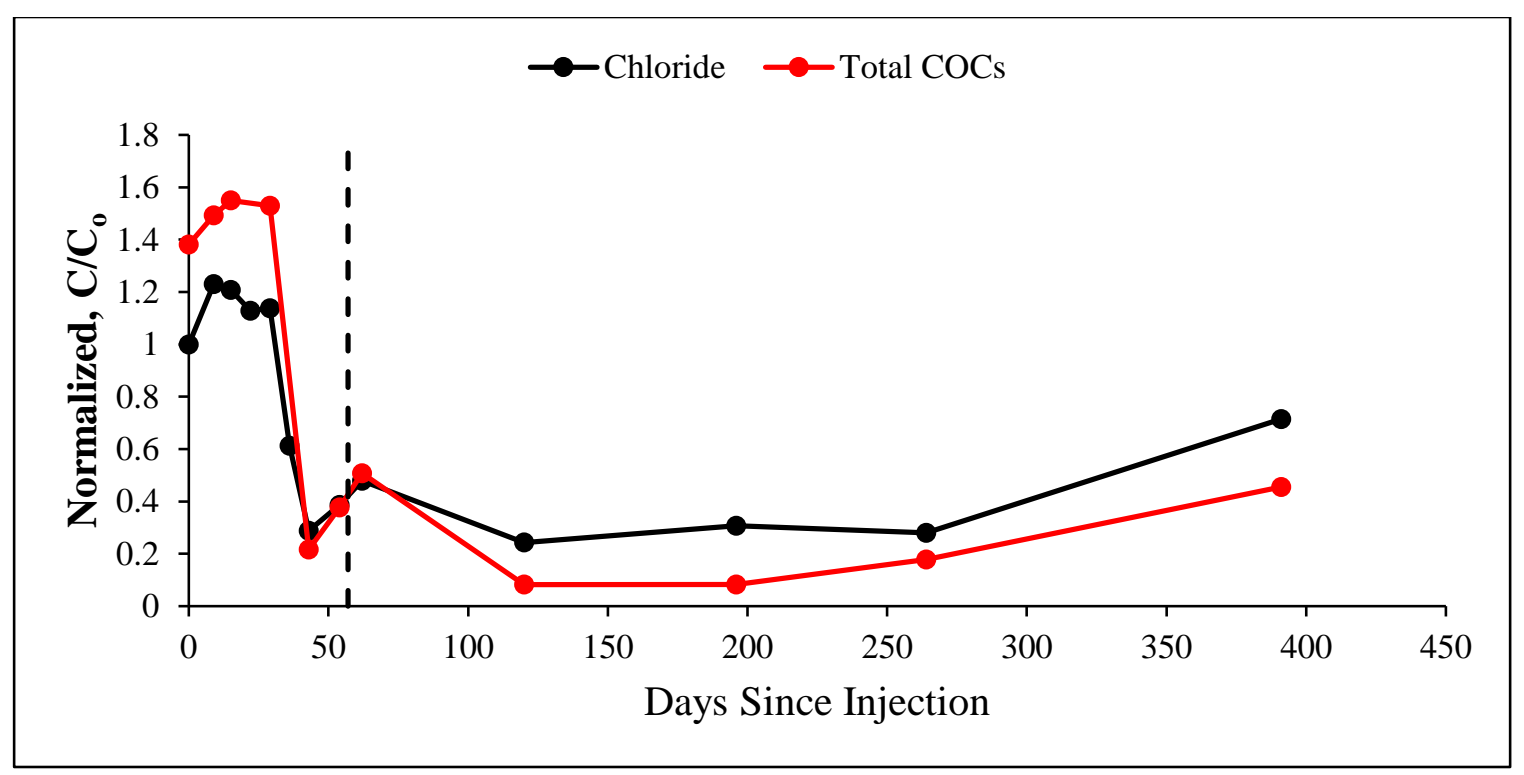

Figure 26: Normalized groundwater concentrations of chloride and total COCs in MW1A of EK-TAP over the course of the field test. Black vertical dashed line shows the end of applied EK. 
Calculation A5: Required concentration of persulfate to account for the decreases in COCs at MW1A of EK-TAP on day 43.

Full reaction (TCE): $\mathrm{C}_{2} \mathrm{HCl}_{3}+3 \mathrm{~S}_{2} \mathrm{O}_{8}^{2-}+4 \mathrm{H}_{2} \mathrm{O} \rightarrow 2 \mathrm{CO}_{2}+9 \mathrm{H}^{+}+3 \mathrm{Cl}^{-}+6 \mathrm{SO}_{4}^{2-}$

Full reaction (VC): $\mathrm{C}_{2} \mathrm{H}_{3} \mathrm{Cl}+5 \mathrm{~S}_{2} \mathrm{O}_{8}^{2-}+4 \mathrm{H}_{2} \mathrm{O} \rightarrow 2 \mathrm{CO}_{2}+11 \mathrm{H}^{+}+\mathrm{Cl}^{-}+5 \mathrm{SO}_{4}^{2-}$

Full reaction (1,1,2 TCA): $\mathrm{C}_{2} \mathrm{H}_{3} \mathrm{Cl}_{3}+4 \mathrm{~S}_{2} \mathrm{O}_{8}^{2-}+4 \mathrm{H}_{2} \mathrm{O} \rightarrow 2 \mathrm{CO}_{2}+11 \mathrm{H}^{+}+3 \mathrm{Cl}^{-}+5 \mathrm{SO}_{4}^{2-}$

Full reaction (1,2/1,1-DCA): $\mathrm{C}_{2} \mathrm{H}_{4} \mathrm{Cl}_{2}+5 \mathrm{~S}_{2} \mathrm{O}_{8}^{2-}+4 \mathrm{H}_{2} \mathrm{O} \rightarrow 2 \mathrm{CO}_{2}+12 \mathrm{H}^{+}+2 \mathrm{Cl}^{-}+10 \mathrm{SO}_{4}^{2-}$

Molar mass of persulfate $=192 \mathrm{~g} \mathrm{~mol}^{-1}$

Molar mass of chloride $=35.4 \mathrm{~g} \mathrm{~mol}^{-1}$

\begin{tabular}{|l|l|l|l|l|l|l|l|}
\hline Compound & $\begin{array}{l}\text { Conc., } \\
(\mathbf{M}) \\
\text { Day 29 }\end{array}$ & $\begin{array}{l}\text { Conc., } \\
(\mathbf{M}) \\
\text { Day 43 }\end{array}$ & $\begin{array}{l}\text { Total } \\
\text { Loss (M) }\end{array}$ & $\begin{array}{l}\text { Required } \\
\text { Molar } \\
\text { Ratio of } \\
\text { PS:COC }\end{array}$ & $\begin{array}{l}\text { Required } \\
\text { Conc. } \\
\text { Persulfate } \\
(\mathbf{M})\end{array}$ & $\begin{array}{l}\text { Molar } \\
\text { Ratio of } \\
\text { Cl':COC }\end{array}$ & $\begin{array}{l}\text { Conc. of } \\
\text { Chloride } \\
(\mathbf{M})\end{array}$ \\
\hline TCE & 0.00065 & 0.0001 & 0.00054 & 3 & 0.00162 & 3 & 0.00162 \\
\hline VC & 0.00099 & 0.00032 & 0.00067 & 5 & 0.00335 & 1 & 0.00067 \\
\hline $1,1,2-$ TCA & 0.00103 & 0.0001 & 0.000093 & 4 & 0.000372 & 3 & 0.000279 \\
\hline 1,1 -DCA & 0.00232 & 0.00043 & 0.00189 & 5 & 0.00945 & 2 & 0.00378 \\
\hline 1,2-DCA & 0.0132 & 0.00159 & 0.0116 & 5 & 0.0578 & 2 & 0.0232 \\
\hline Total & 0.0181 & 0.00254 & 0.0148 & & 0.0726 & & 0.0295 \\
\hline
\end{tabular}

*Breakthrough concentration of persulfate required to account for the total losses of COCs in MW1A of EK-TAP on day 43 is $13.9 \mathrm{~g} \mathrm{~L}^{-1}$.

*Total concentration of chloride produced in MW1A of EK-TAP on day 43 if COCs were completely oxidized by persulfate is $1,048 \mathrm{mg} \mathrm{L}^{-1}$ 


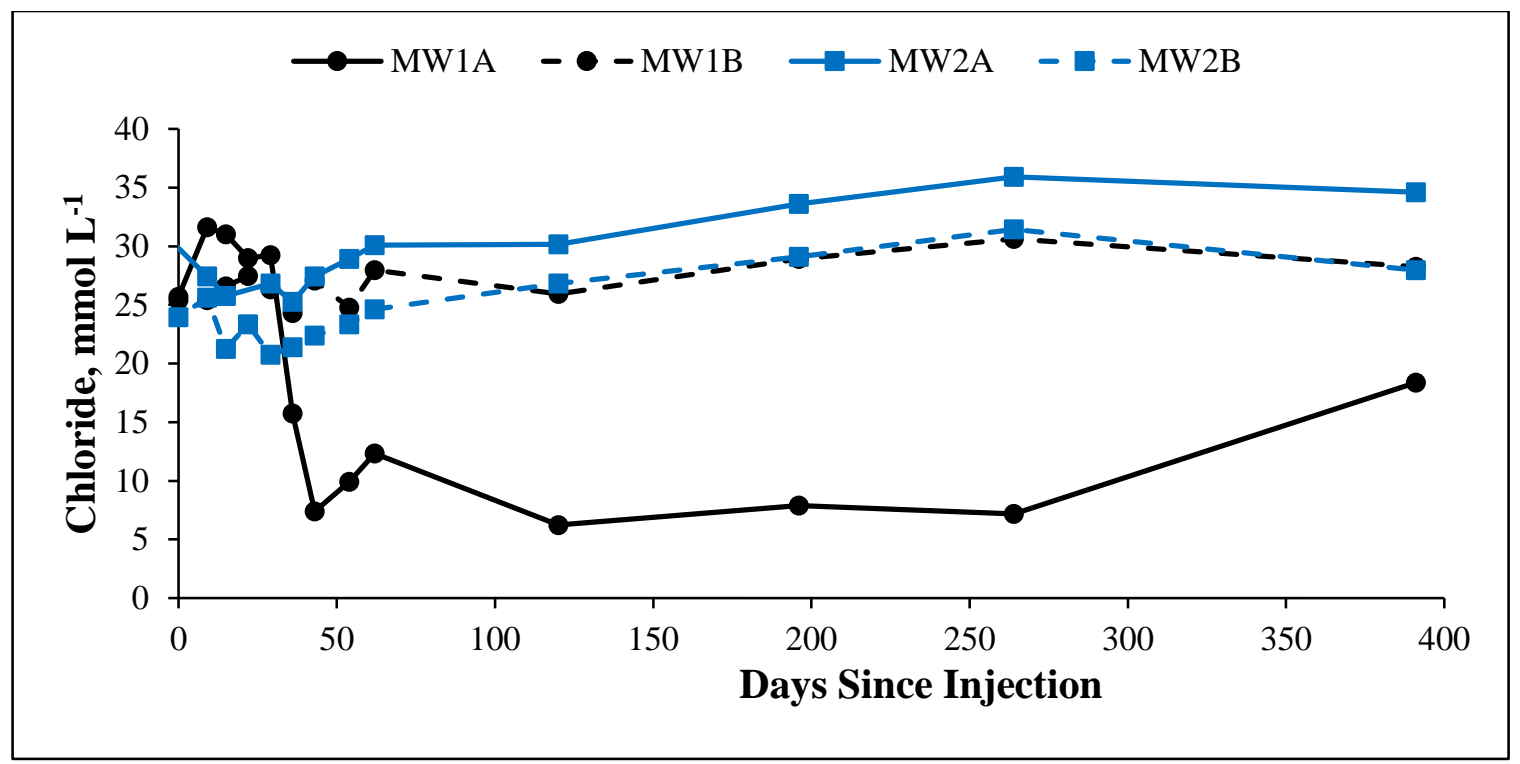

Figure A27: Groundwater concentration of chloride $\left(\mathrm{mmol} \mathrm{L}^{-1}\right)$ in all monitoring wells of EK-TAP over the entire field test.

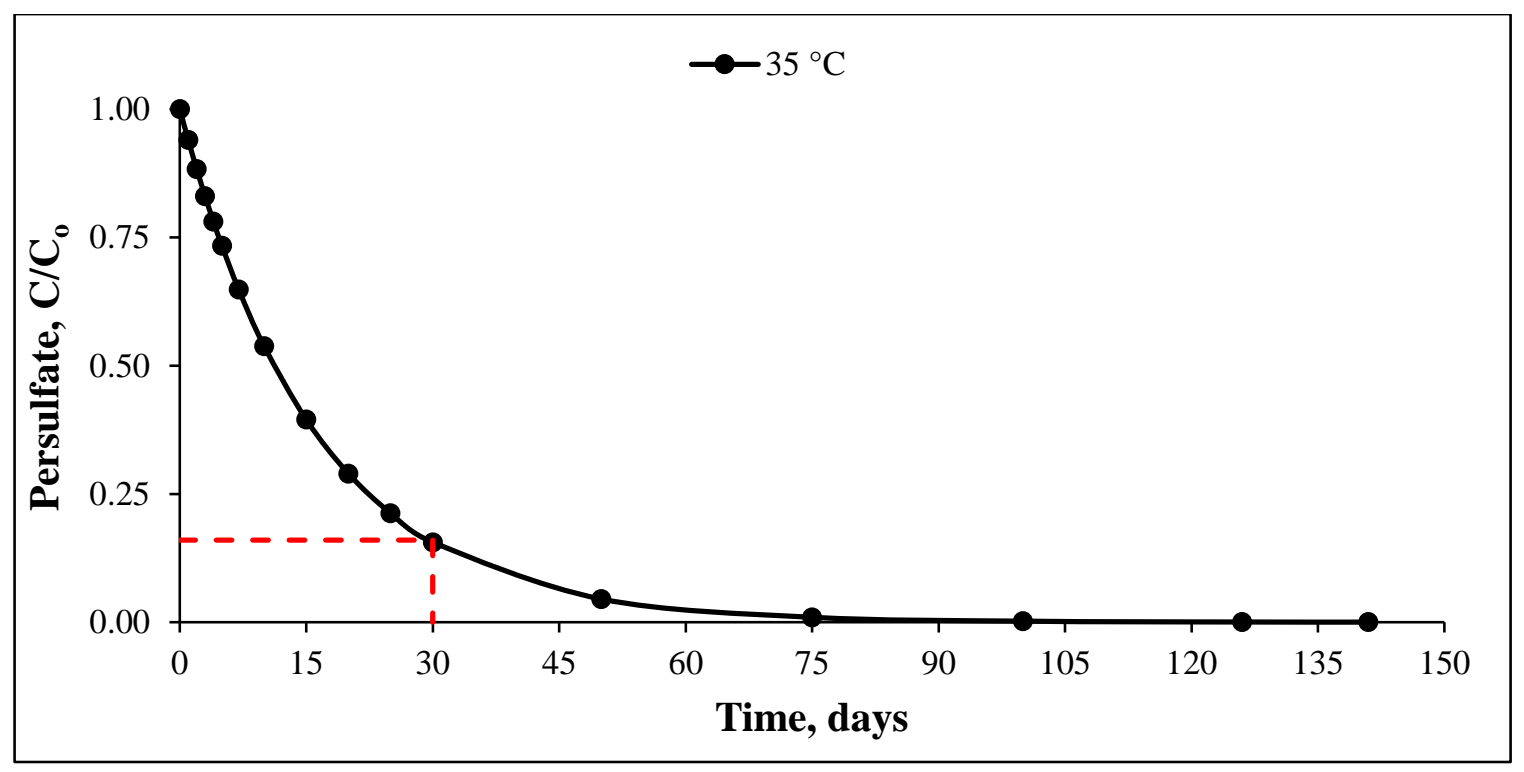

Figure A28: Normalized persulfate decomposition at $35^{\circ} \mathrm{C}$ with time. At 30 days, $\sim 85 \%$ persulfate decomposition would be expected. 


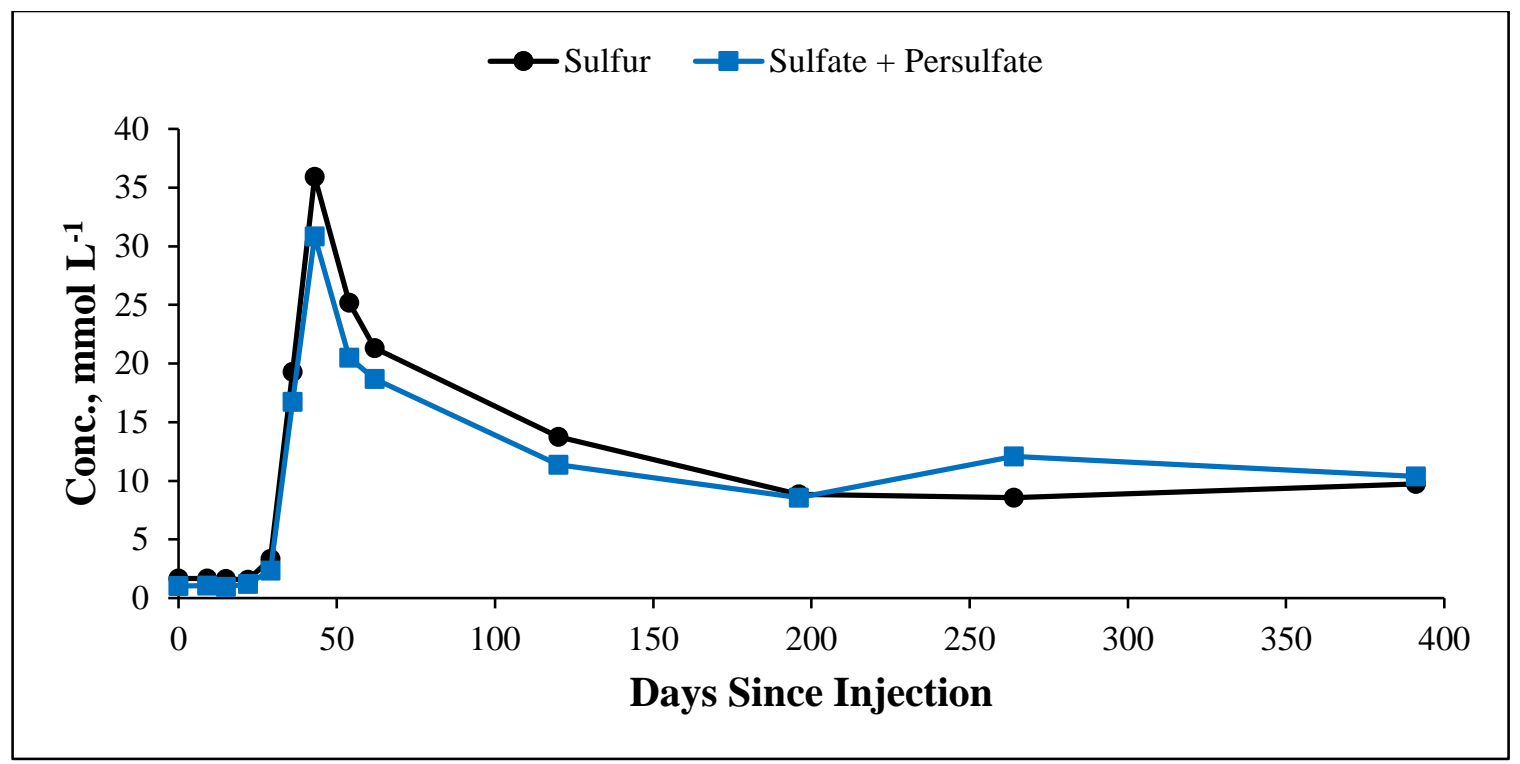

Figure A29: Correlation $\left(\mathrm{mmol} \mathrm{L}^{-1}\right)$ of persulfate and sulfate in relation to sulfur in MW1A of EK-TAP over the entire field test.

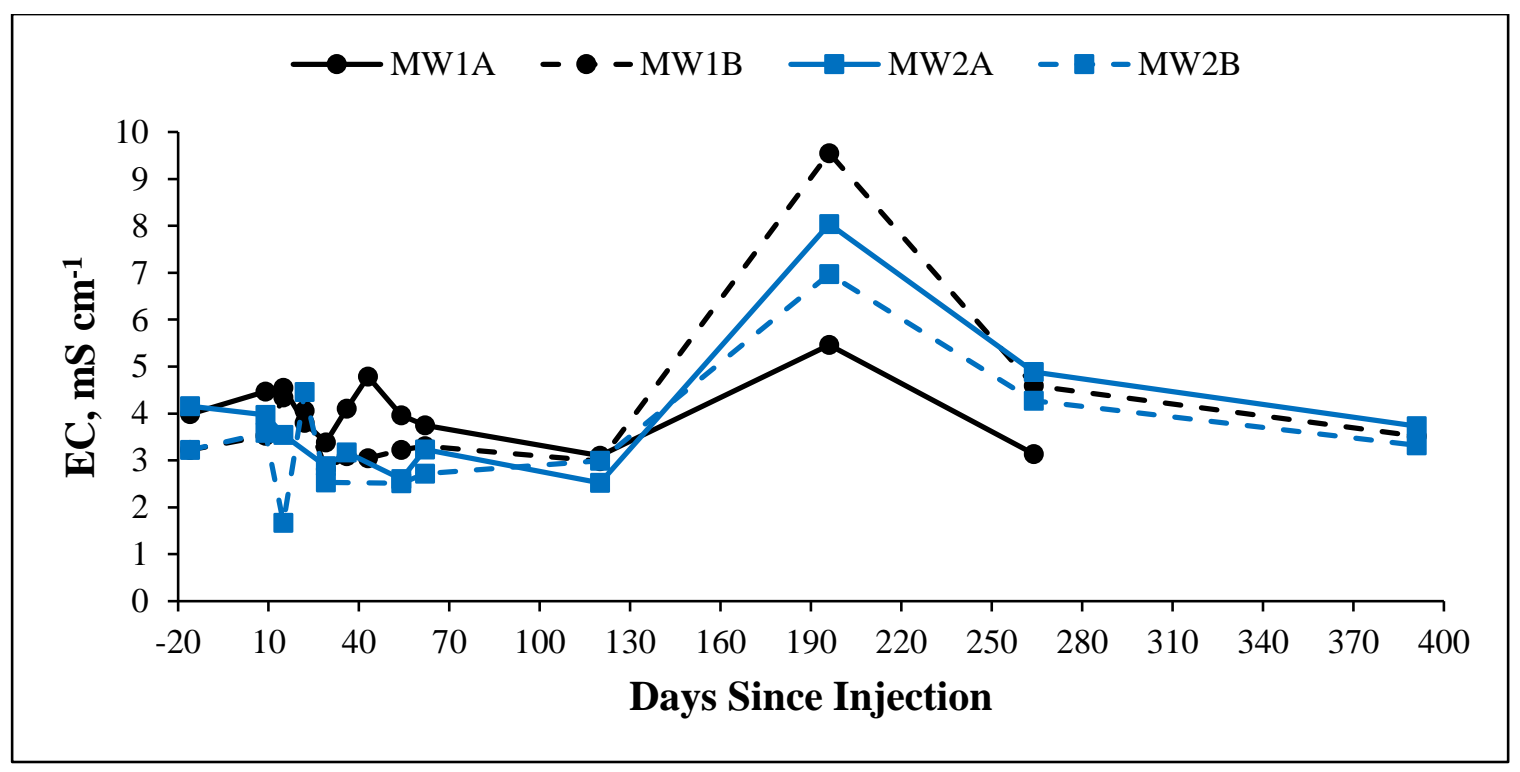

Figure A30: Groundwater electrical conductivity in all monitoring wells of EK-TAP over the entire field test. 


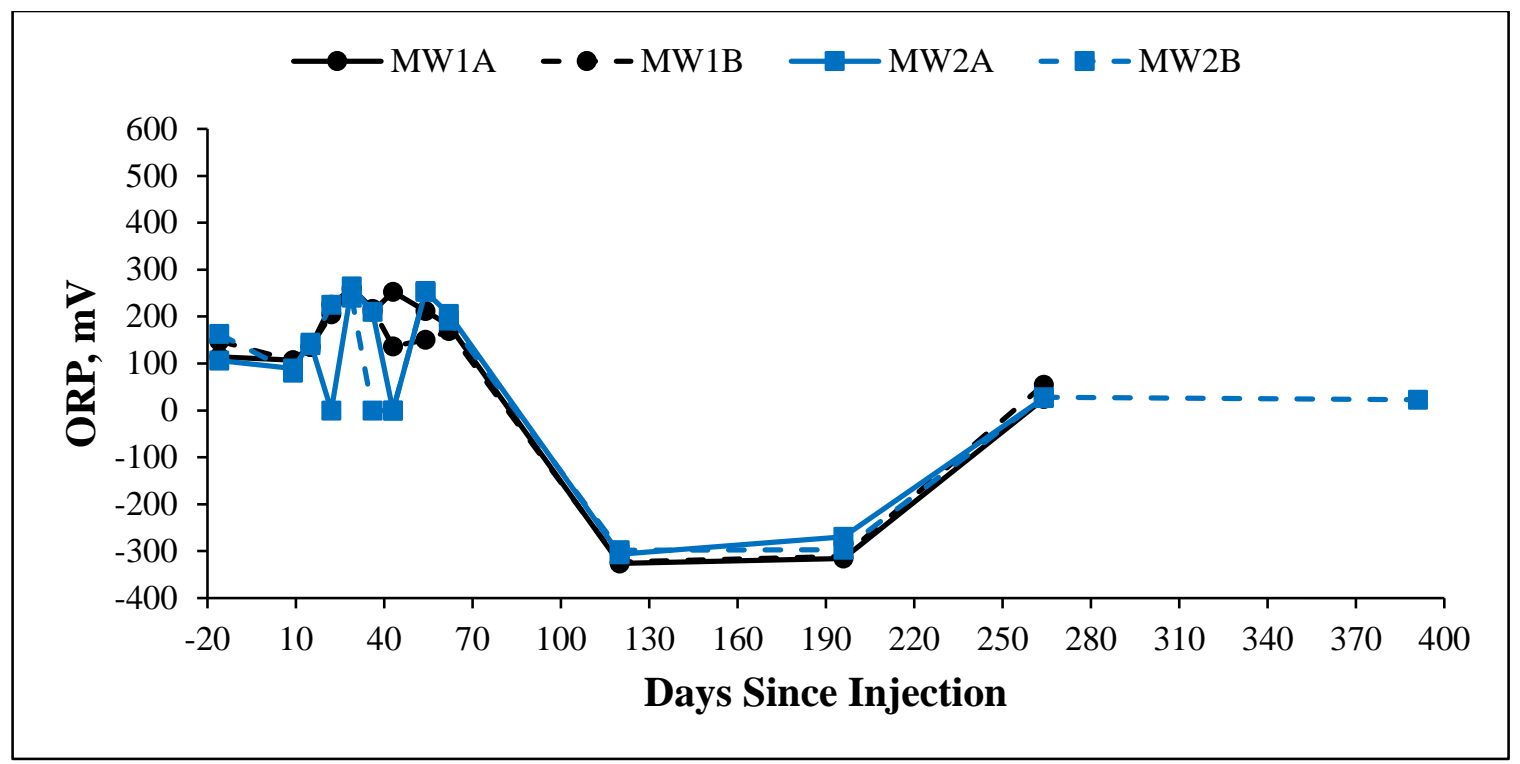

Figure A31: Groundwater oxidation-reduction potential in all monitoring wells of EK-TAP over the entire field test. 
Appendix B: EK-Control 


\section{$\underline{\text { Results and Discussion B1: Short-Circuiting Between EK-TAP and EK-Control }}$}

Sulfur and sulfate was observed to increase in MW1A of EK-Control starting on day 29 and 43, respectively. Maximum concentration of sulfur and sulfate occurred on day 54 and was measured to be $11.0 \mathrm{mmol} \mathrm{L}^{-1}$ and $9.19 \mathrm{mmol} \mathrm{L}^{-1}$, respectively (Figure B1 and B2, Appendix B). Due to the high concentrations of sulfur and sulfate as well as the proximity of EK-TAP to EK-Control, it is likely that short-circuiting occurred between transects during persulfate injection (Figure B3, Appendix B). No increases in sulfur and sulfate were observed in MW1B, MW2A, and MW2B of EK-Control (Figure B1 and B2, Appendix B). Maximum concentration of sulfur observed in MW1A amounted to $3.35 \%$ of injected concentration of sulfur in SW1 and SW2 of EK-TAP. Based on the time of appearance of sulfur in MW1A of EK-Control and distance to SW1 or SW2 of EK-TAP, the minimum required transport velocity of persulfate would have been $\sim 20.7 \mathrm{~cm} \mathrm{day}^{-1}$. This rate is outside of the range of EM and EO persulfate velocities observed in benchscale testing $\left(\sim 2 \mathrm{~cm} \mathrm{day}^{-1}\right)$, meaning that the short-circuit is likely caused by site heterogeneities (i.e., geology) than EK-enhancement (Chowhdury et al., 2017; Fan et al., 2014; Fan et al., 2016). Examining boreholes SW1 and SW2 of EK-TAP, T-EK-SC1-2, TEK-SC2-2, T-EK-SC3-2, and MW1A of EK-Control (Figure B3, Appendix B), the fill and brown clay interface between these transects resided between 2.1-2.9 m (bgs). Based on the screening interval of the supply wells in EK-TAP (2.4-4.9 m bgs), it is hypothesized that persulfate traveled along the geological interface from EK-TAP to EK-Control. Due to the presence of persulfate in EK-Control, it was no longer used as a control (EK without persulfate injection). 


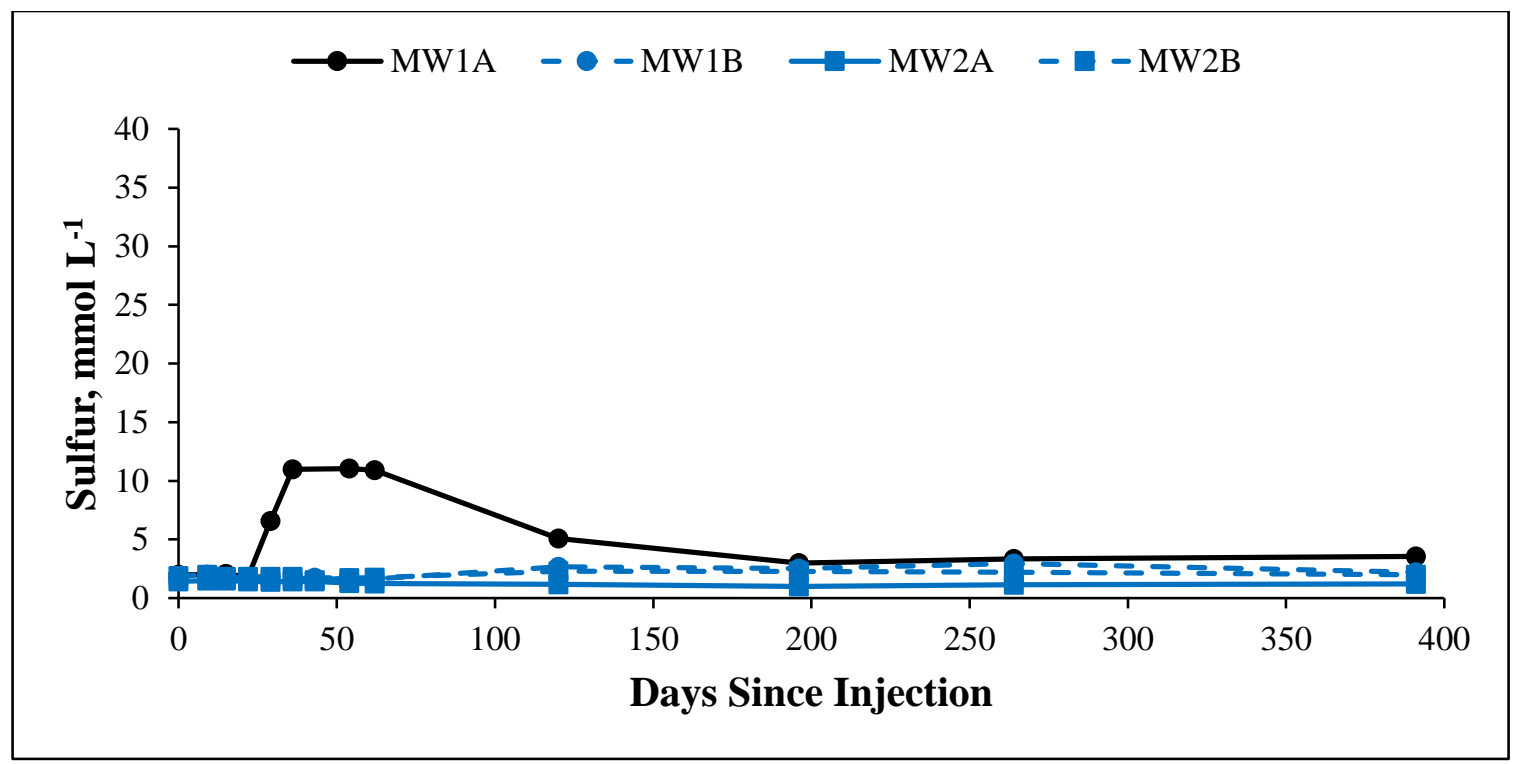

Figure B1: Groundwater concentration of sulfur $\left(\mathrm{mmol} \mathrm{L}^{-1}\right)$ in all monitoring wells of EK-Control over the entire field test.

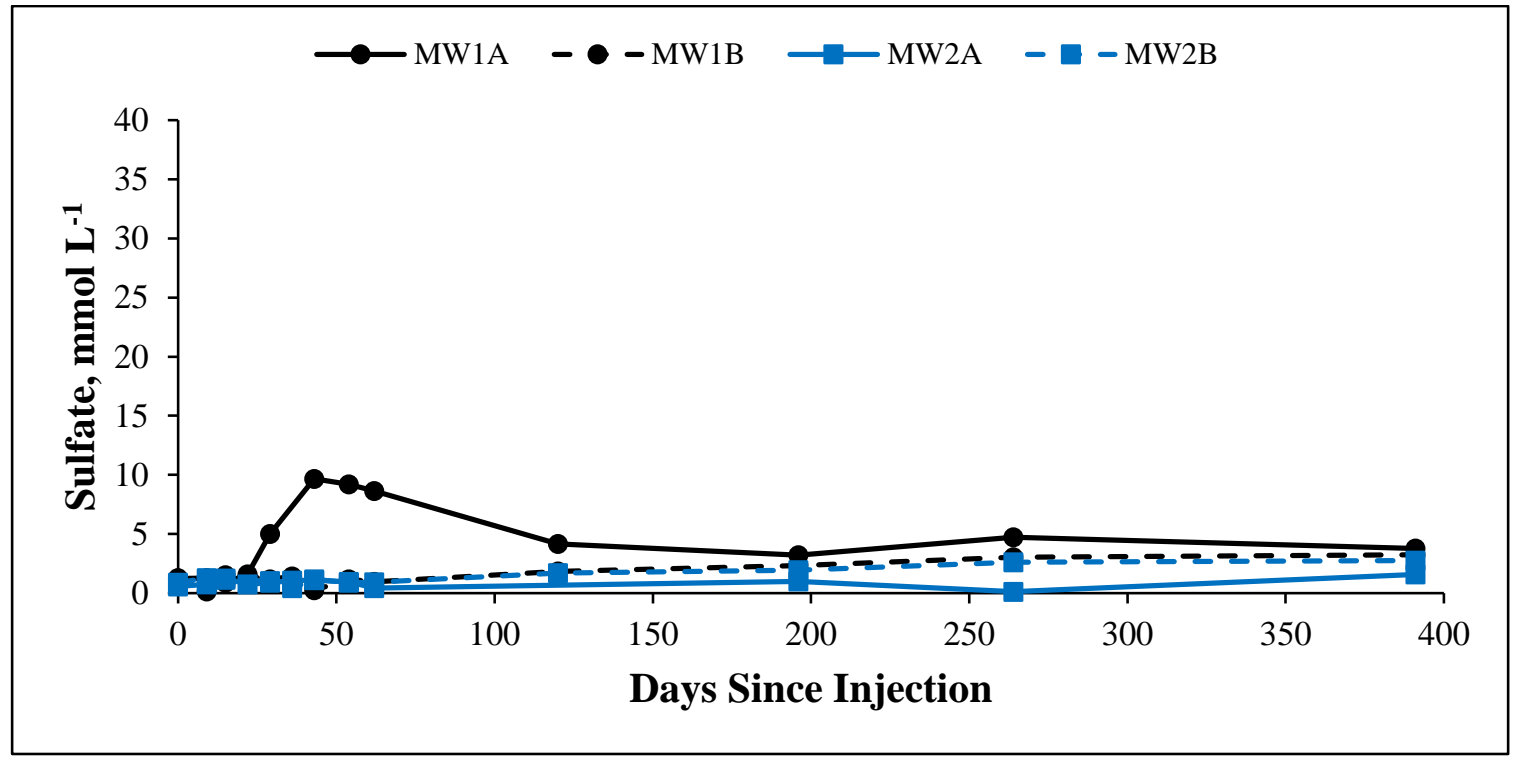

Figure B2: Groundwater concentration of sulfate $\left(\mathrm{mmol} \mathrm{L}^{-1}\right)$ in all monitoring wells of EK-Control over the entire field test. 


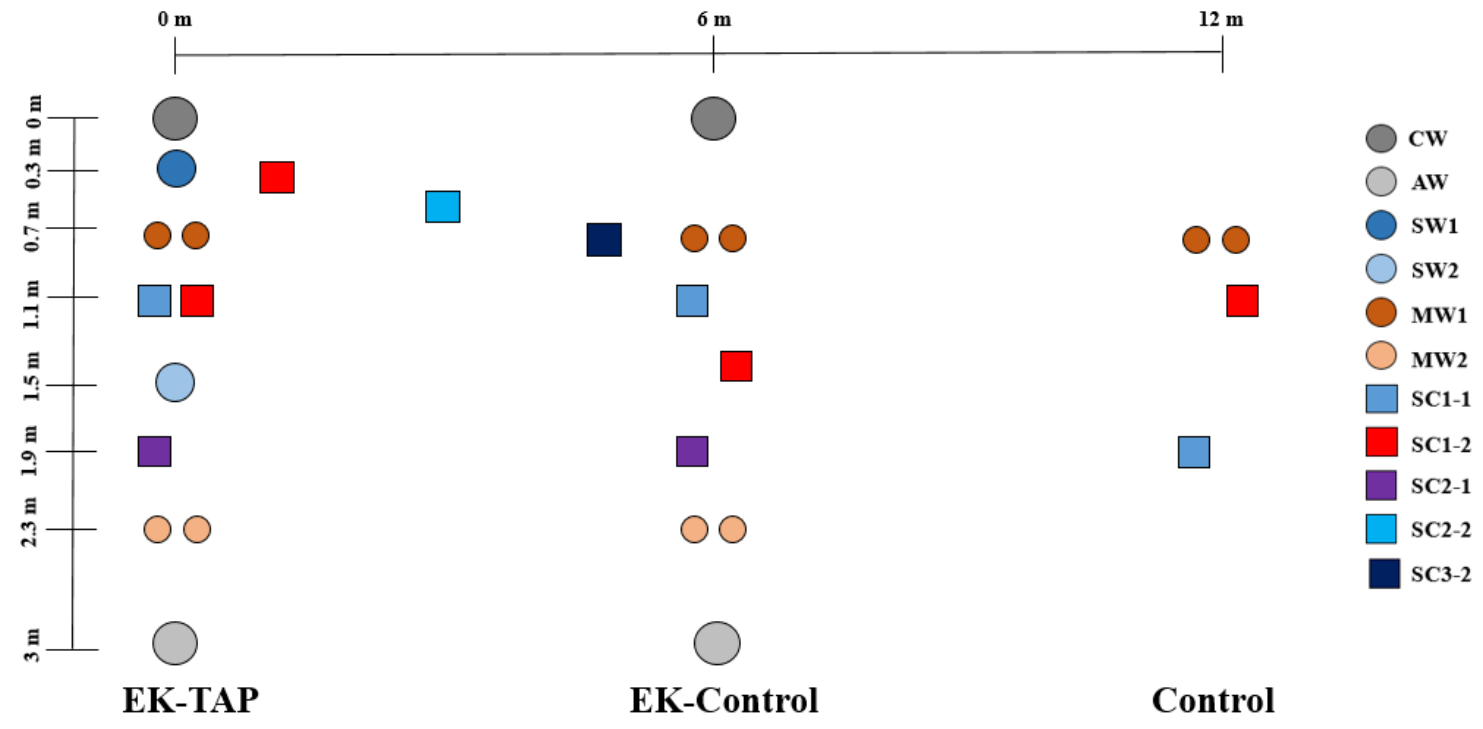

Figure B3: Plan view of test area displaying EK-TAP, EK-Control, and Control transects along with well (electrode wells, supply wells, monitoring wells) and borehole locations. 
Table B1: Background Groundwater Concentration $\left(\mathrm{mg} \mathrm{L}^{-1}\right)$ of COCs in EKControl

\begin{tabular}{|c|c|c|c|c|c|}
\hline \multirow[t]{2}{*}{ Compound } & \multicolumn{4}{|c|}{ EK-Control } & \multirow{2}{*}{$\begin{array}{c}\text { O. Reg 153/04 } \\
\text { Table } 3 \text { (Ind/Comm) }\end{array}$} \\
\hline & MW1A & MW1B & MW2A & MW2B & \\
\hline Vinyl Chloride & 62.63 & 85.50 & 136.40 & 95.07 & 0.0017 \\
\hline 1,1-Dichloroethene & 0.97 & 1.12 & 2.76 & 1.10 & 0.017 \\
\hline Dichloromethane & 0.25 & 0.24 & 0.33 & 0.25 & N/A \\
\hline 1,1-Dichloroethane & 164.66 & 168.78 & 328.06 & 178.53 & 3.1 \\
\hline cis-1,2-Dichloroethene & 6.04 & 4.15 & 13.42 & 3.59 & 0.017 \\
\hline Chloroform & 0.74 & 0.73 & 1.40 & 0.71 & 0.022 \\
\hline 1,1,1-Trichloroethane & 0.12 & 0.10 & 0.53 & 0.14 & 6.7 \\
\hline Carbon tetrachloride & 0.00 & 0.00 & 0.00 & 0.00 & 0.0084 \\
\hline Tetrachloroethene & 0.18 & 0.05 & 1.49 & 0.11 & 0.017 \\
\hline 1,1,2-Trichloroethane & 70.91 & 59.26 & 138.75 & 50.45 & 0.03 \\
\hline 1,1,1,2-Tetrachloroethane & 0.00 & 0.00 & 0.00 & 0.00 & N/A \\
\hline
\end{tabular}




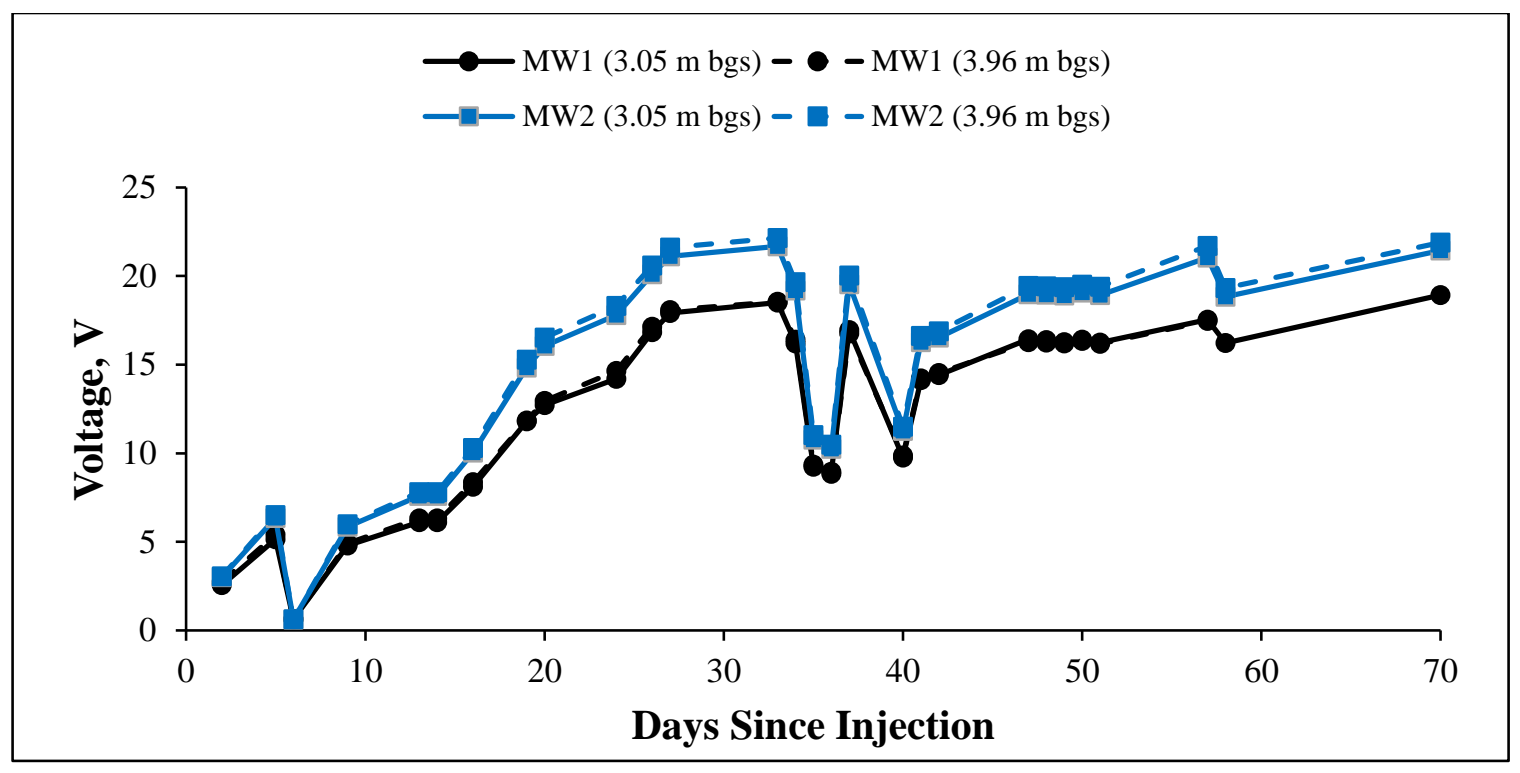

Figure B4: Voltage readings during EK operations (i.e., day 0-70) at MW1 and MW2 of EK-Control. Readings were taken from voltage probes installed at $3.05 \mathrm{~m}$ and 3.96 m (bgs) at each location. Voltage readings from MW1 and MW2 at $3.05 \mathrm{~m}$ (bgs) are representative of MW1A and MW2A, respectively, screened from 3.05-3.66 m (bgs). Voltage readings from MW1 and MW2 at $3.96 \mathrm{~m}$ (bgs) are representative of MW1B and MW2B, respectively, screened from 3.66-4.27 m (bgs). 

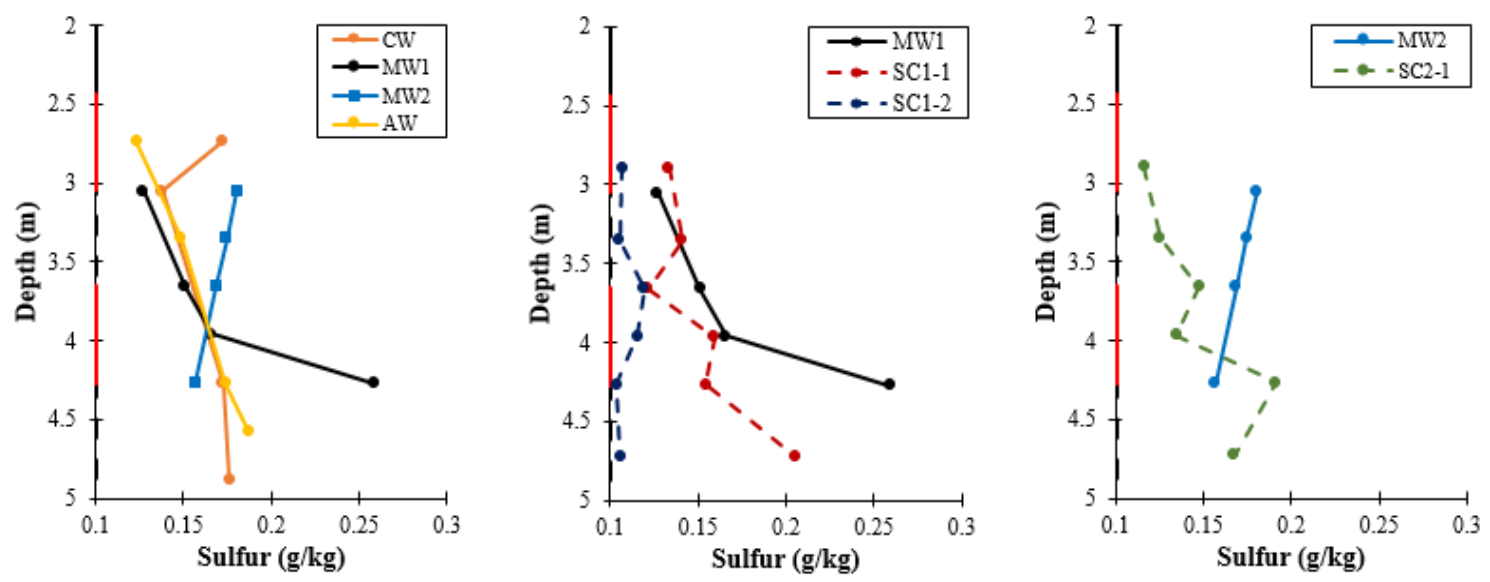

Figure B5: Soil concentration of sulfur $\left(\mathrm{g} \mathrm{kg}^{-1}\right)$ with depth of boreholes MW1, MW2, AW, CW, SC1-1 and SC2-1 of EK-Control. The first panel shows sulfur $\left(\mathrm{g} \mathrm{kg}^{-1}\right)$ measured from background boreholes MW1, MW2, AW, and CW. The second panel displays a comparison of sulfur $\left(\mathrm{g} \mathrm{kg}^{-1}\right)$ between background and post-EK boreholes MW1, SC1-1, and SC1-2 due to their proximity. The third panel compares sulfur (g $\mathrm{kg}^{-1}$ ) between background and post-EK boreholes MW2 and SC2-1 due to their proximity. Boreholes SC1-1 and SC2-1 were completed on day 125 post-EK operations (i.e., day 57-196). Borehole SC1-2 was completed on day 286 post-EK. The red vertical lines represent the depths of shallow (i.e., 2.44-3.05 $\mathrm{m}$ bgs) and deep (i.e., 3.66-4.27 $\mathrm{m}$ bgs) electrodes. The black vertical dashed line represents the screening depth of the supply wells (i.e., 2.44-4.88 m bgs). 


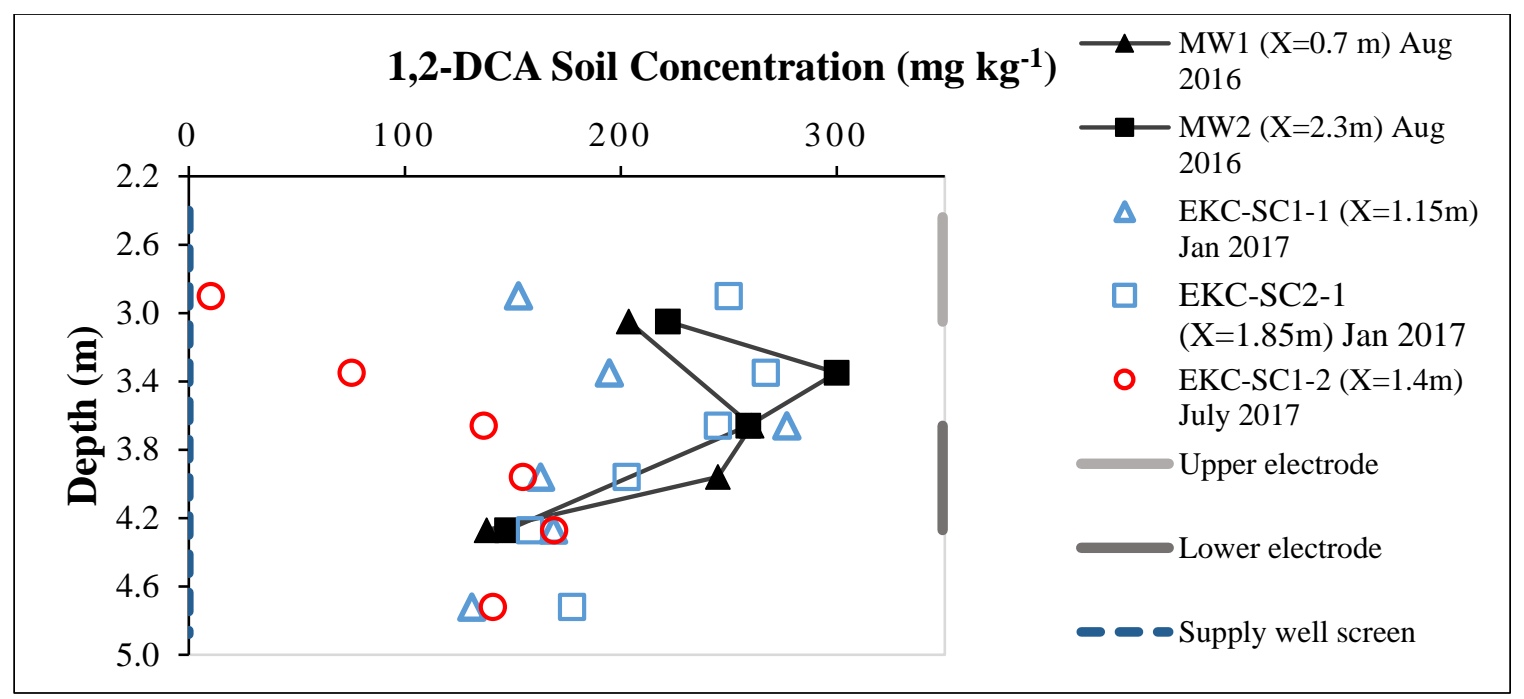

Figure B6: 1,2-DCA soil concentration $\left(\mathrm{mg} \mathrm{kg}^{-1}\right)$ with depth of boreholes MW1, SW2, MW2, EKC-SC1-1, EKC-SC2-1, and EKC-SC1-2. Sampling depths include 2.9 m, $3.05 \mathrm{~m}, 3.35 \mathrm{~m}, 3.66 \mathrm{~m}, 3.96 \mathrm{~m}$, and $4.27 \mathrm{~m}$ (bgs). Black markers are boreholes completed before EK (i.e., MW1 and MW2), blue markers are boreholes completed post-EK (i.e., EKC-SC1-1 and EKC-SC2-1) on day 125, and red markers is a borehole completed post-EK (i.e., EKC-SC1-2) on day 286.

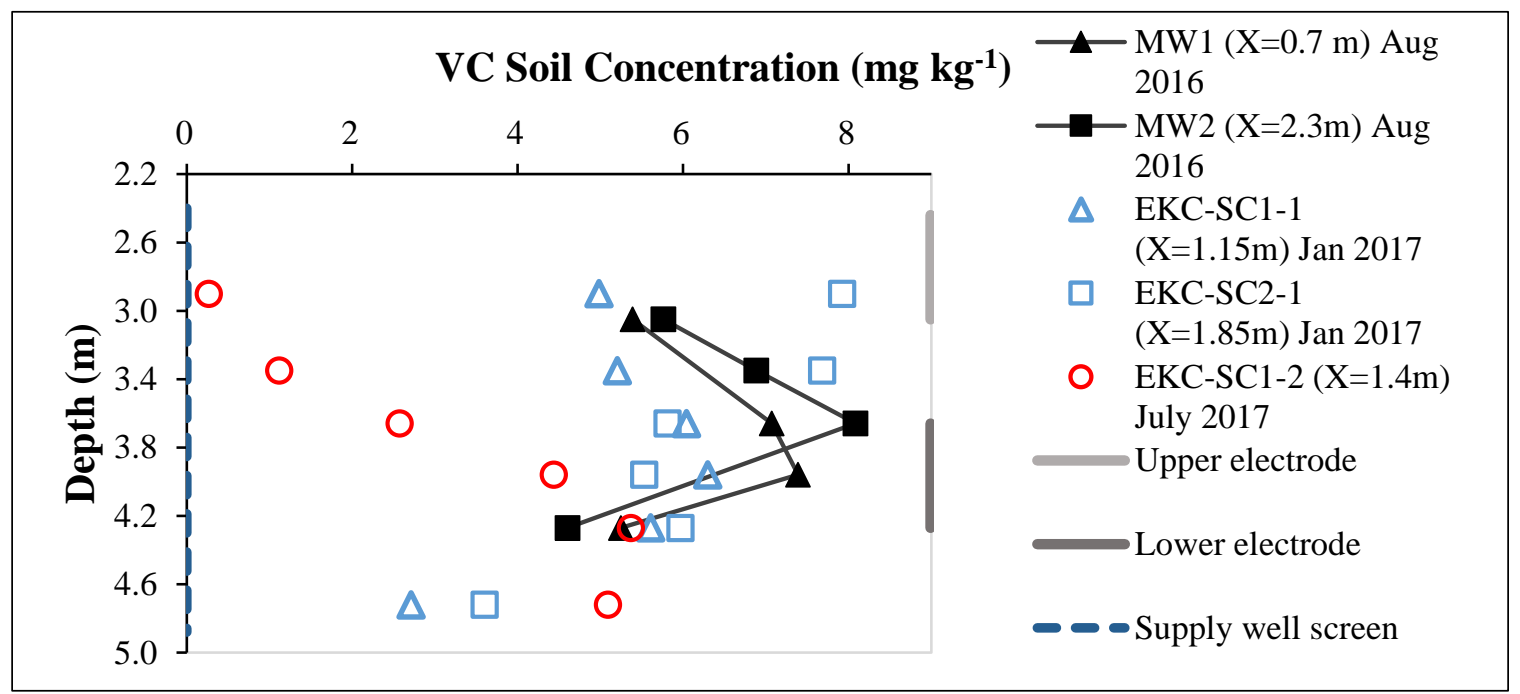

Figure B7: VC soil concentration $\left(\mathrm{mg} \mathrm{kg}^{-1}\right)$ with depth of boreholes MW1, SW2, MW2, EKC-SC1-1, EKC-SC2-1, and EKC-SC1-2. Sampling depths include 2.9 m, 3.05 m, 3.35 m, 3.66 m, 3.96 m, and 4.27 m (bgs). Black markers are boreholes completed before EK (i.e., MW1 and MW2), blue markers are boreholes completed post-EK (i.e., EKC-SC1-1 and EKC-SC2-1) on day 125, and red markers is a borehole completed post-EK (i.e., EKC-SC1-2) on day 286. 


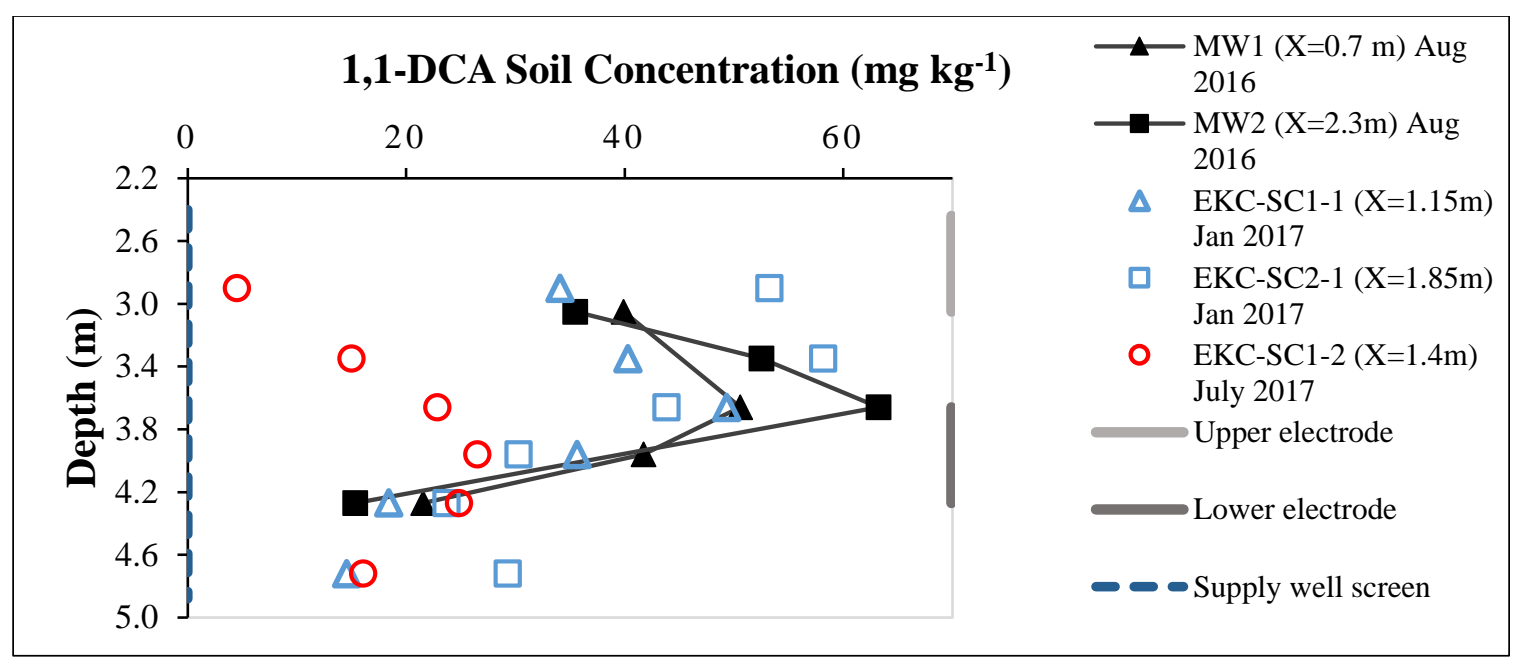

Figure B8: 1,1-DCA soil concentration $\left(\mathrm{mg} \mathrm{kg}^{-1}\right)$ with depth of boreholes MW1, SW2, MW2, EKC-SC1-1, EKC-SC2-1, and EKC-SC1-2. Sampling depths include $2.9 \mathrm{~m}$, $3.05 \mathrm{~m}, 3.35 \mathrm{~m}, 3.66 \mathrm{~m}, 3.96 \mathrm{~m}$, and $4.27 \mathrm{~m}$ (bgs). Black markers are boreholes completed before EK (i.e., MW1 and MW2), blue markers are boreholes completed post-EK (i.e., EKC-SC1-1 and EKC-SC2-1) on day 125, and red markers is a borehole completed post-EK (i.e., EKC-SC1-2) on day 286.

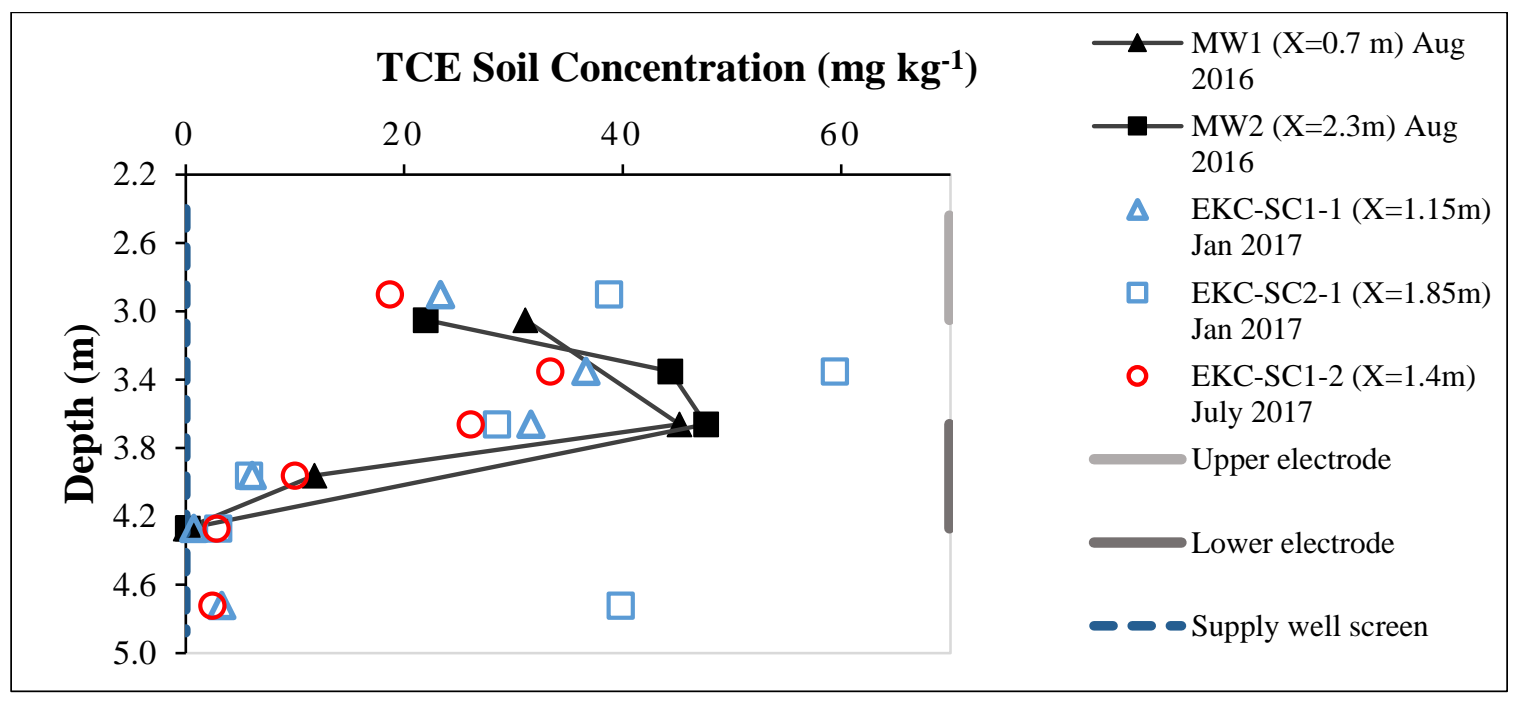

Figure B9: TCE soil concentration $\left(\mathrm{mg} \mathrm{kg}^{-1}\right)$ with depth of boreholes MW1, SW2, MW2, EKC-SC1-1, EKC-SC2-1, and EKC-SC1-2. Sampling depths include 2.9 m, $3.05 \mathrm{~m}, 3.35 \mathrm{~m}, 3.66 \mathrm{~m}, 3.96 \mathrm{~m}$, and $4.27 \mathrm{~m}$ (bgs). Black markers are boreholes completed before EK (i.e., MW1 and MW2), blue markers are boreholes completed post-EK (i.e., EKC-SC1-1 and EKC-SC2-1) on day 125, and red markers is a borehole completed post-EK (i.e., EKC-SC1-2) on day 286. 


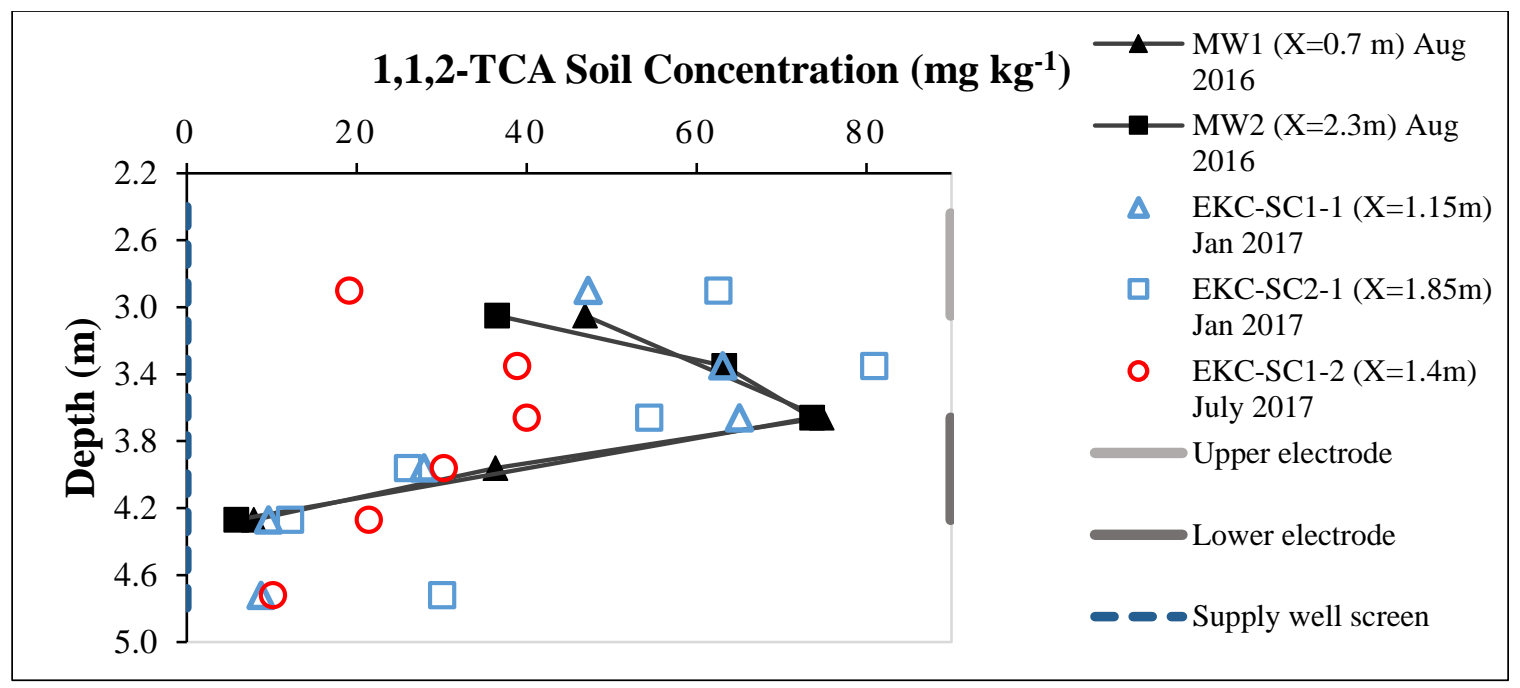

Figure B10: 1,1,2-TCA soil concentration $\left(\mathrm{mg} \mathrm{kg}^{-1}\right)$ with depth of boreholes MW1, SW2, MW2, EKC-SC1-1, EKC-SC2-1, and EKC-SC1-2. Sampling depths include 2.9 $\mathrm{m}, 3.05 \mathrm{~m}, 3.35 \mathrm{~m}, 3.66 \mathrm{~m}, 3.96 \mathrm{~m}$, and $4.27 \mathrm{~m}$ (bgs). Black markers are boreholes completed before EK (i.e., MW1 and MW2), blue markers are boreholes completed post-EK (i.e., EKC-SC1-1 and EKC-SC2-1) on day 125, and red markers is a borehole completed post-EK (i.e., EKC-SC1-2) on day 286.
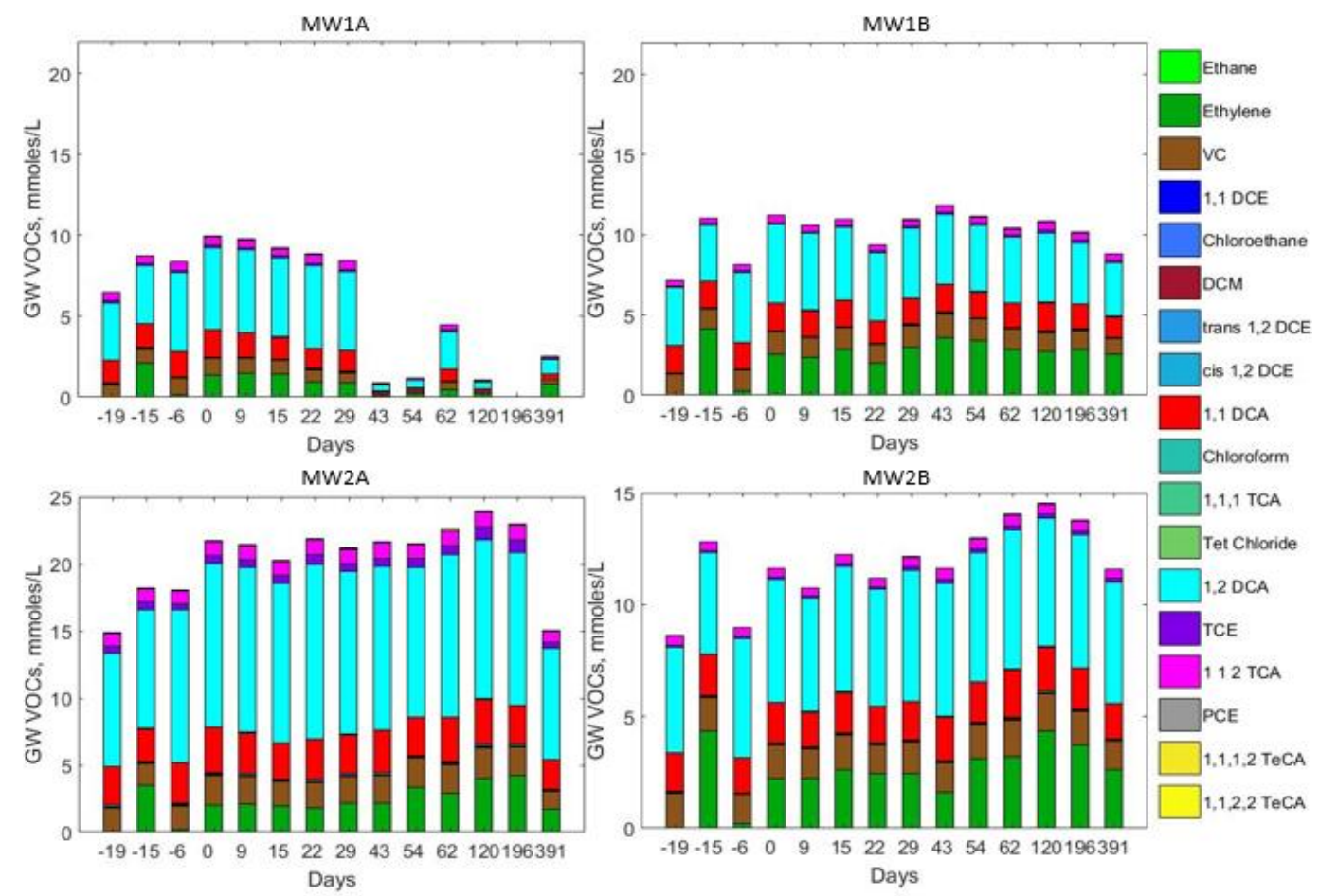

Figure B11: Groundwater concentration of COCs $\left(\right.$ mmoles $\left.\mathrm{L}^{-1}\right)$ in all monitoring wells of EK-Control over the entire field test. 


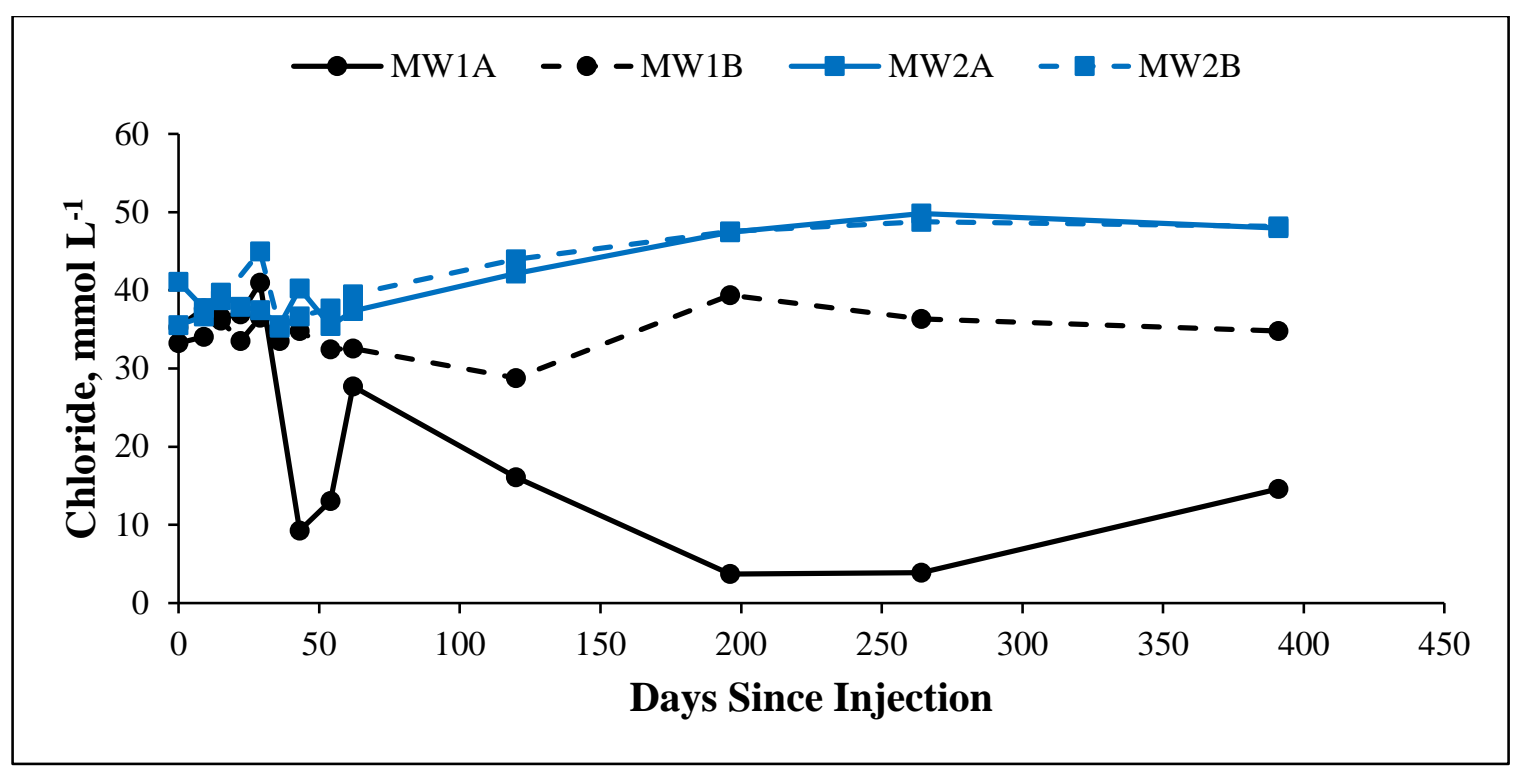

Figure B12: Groundwater concentration of chloride $\left(\mathrm{mmol} \mathrm{L}^{-1}\right)$ in all monitoring wells of EK-Control over the entire field test.

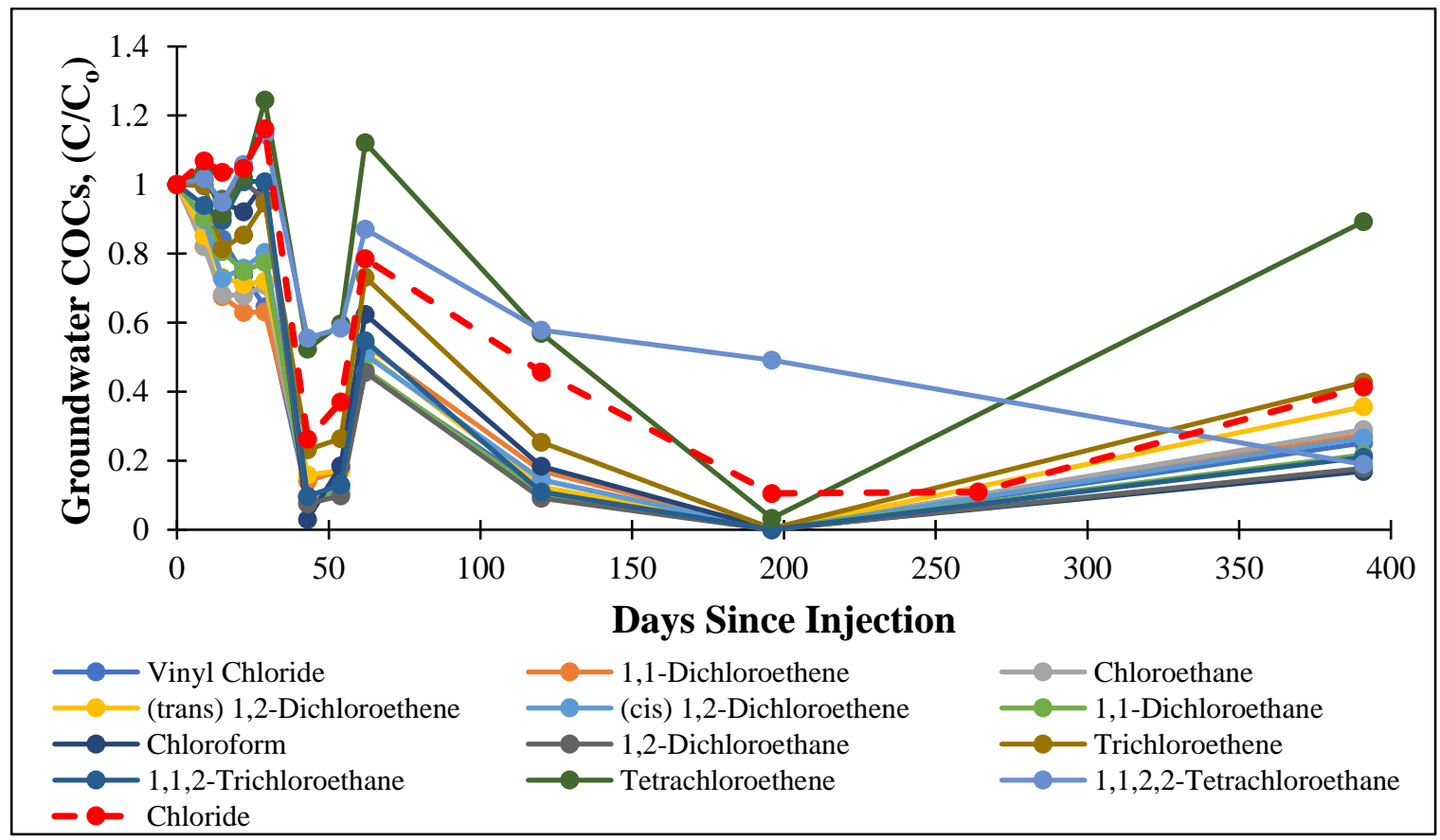

Figure B13: Normalized groundwater concentration of COCs and chloride to background (i.e., day 0) in MW1A of EK-Control over the entire field test. 


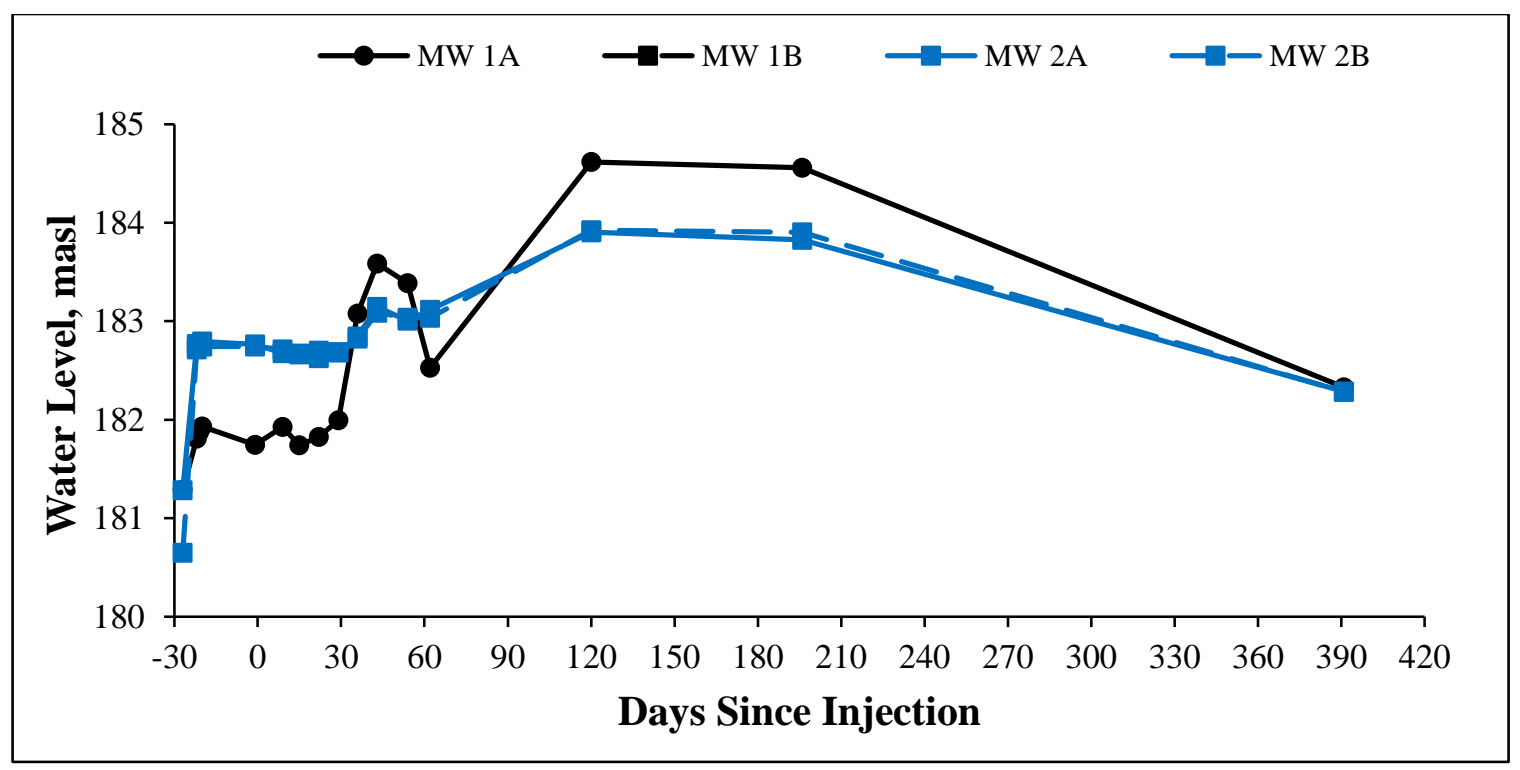

Figure B14: Water levels in all monitoring wells of EK-Control over the entire field test.

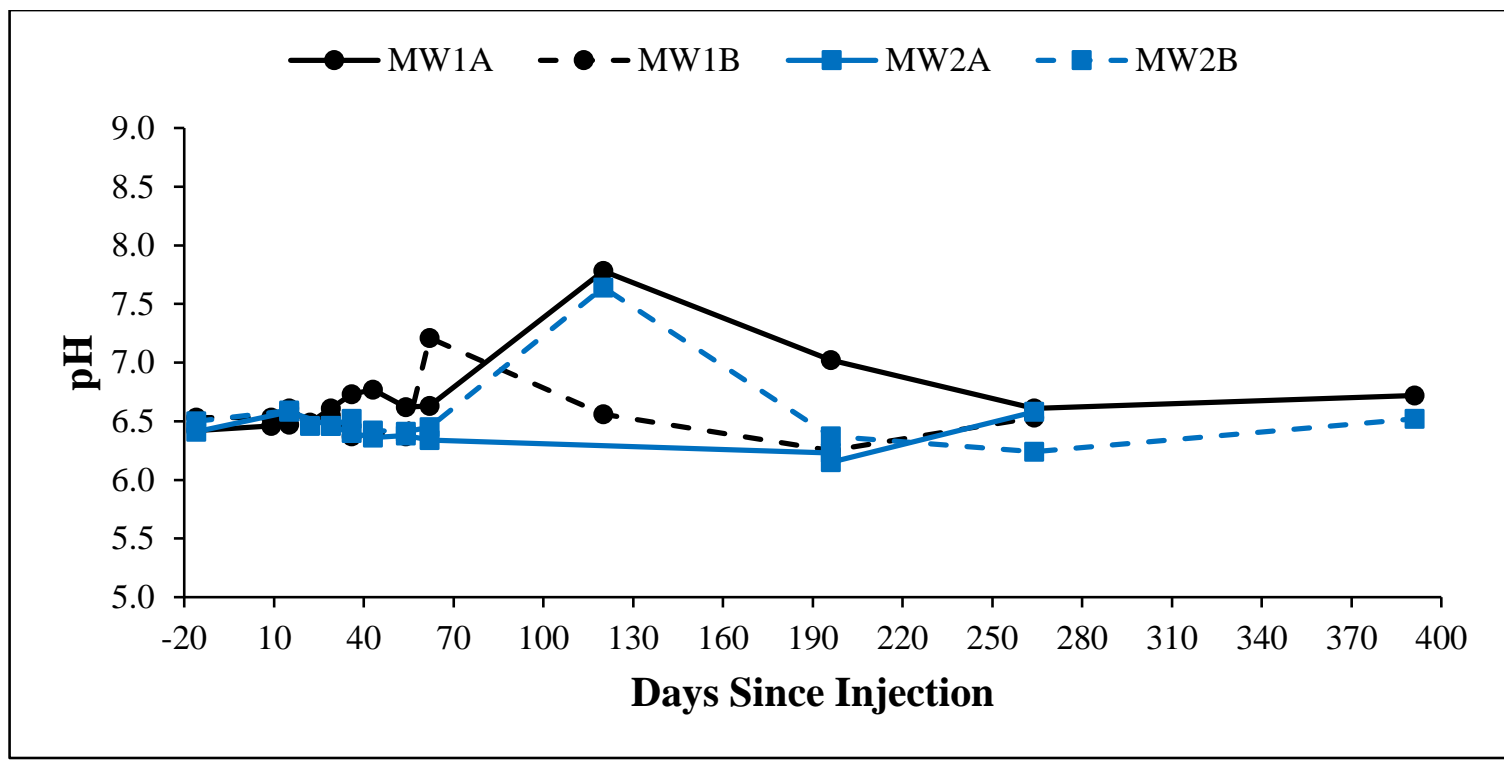

B15: Groundwater pH in all monitoring wells of EK-Control over the entire field test. 


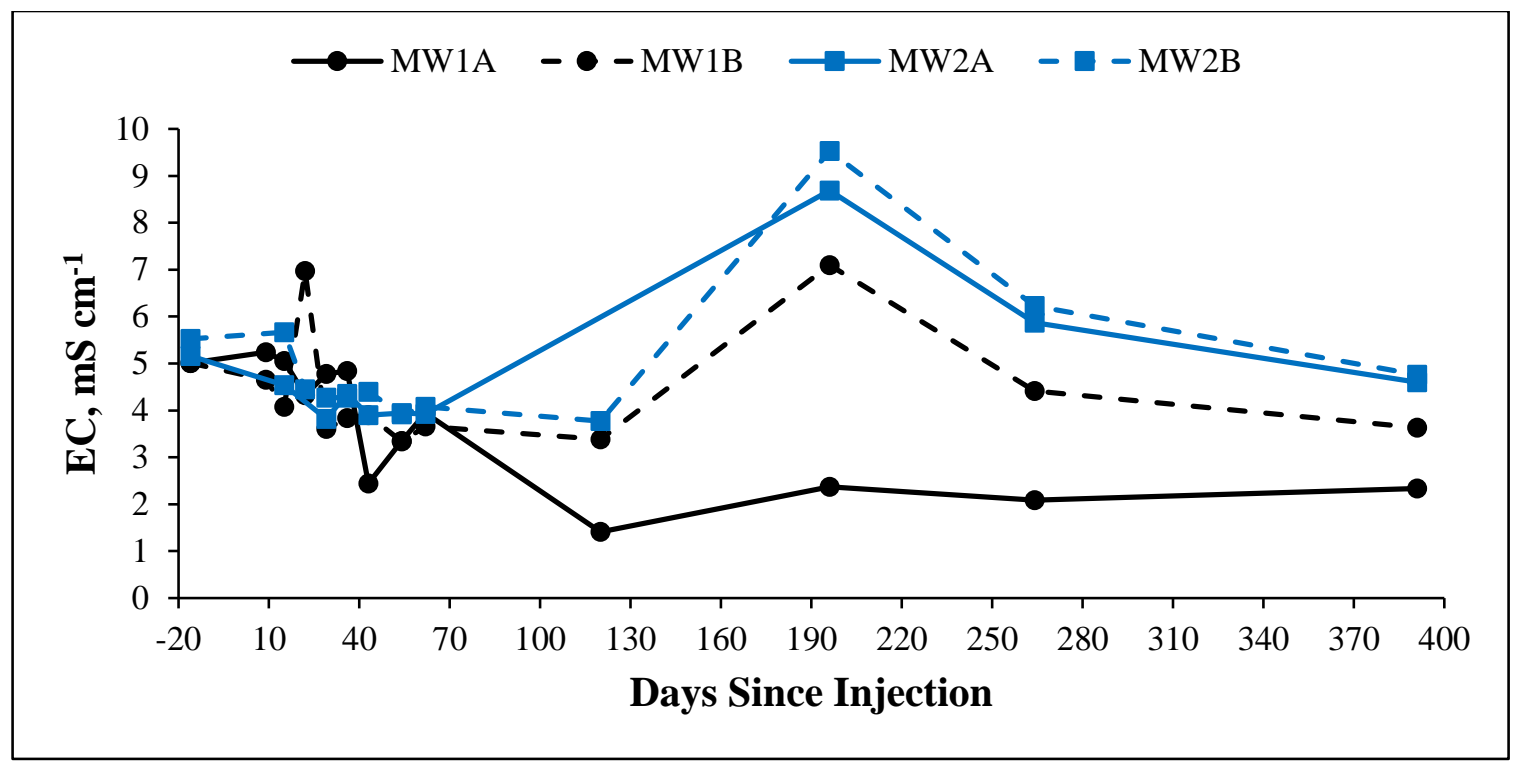

B16: Groundwater electrical conductivity in all monitoring wells of EK-Control over the entire field test.

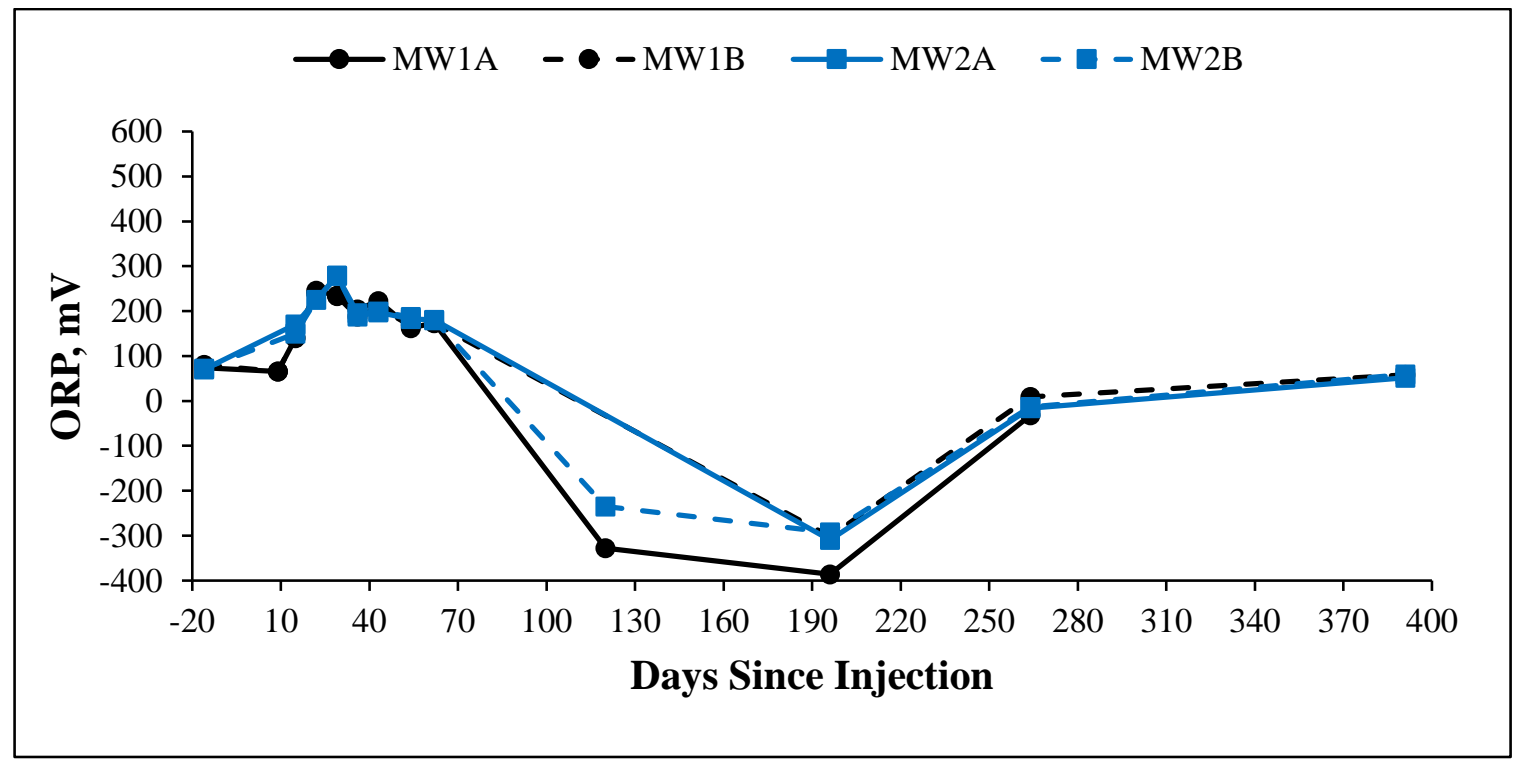

B17: Groundwater oxidation-reduction potential in all monitoring wells of EKControl over the entire field test. 
Appendix C: Control 


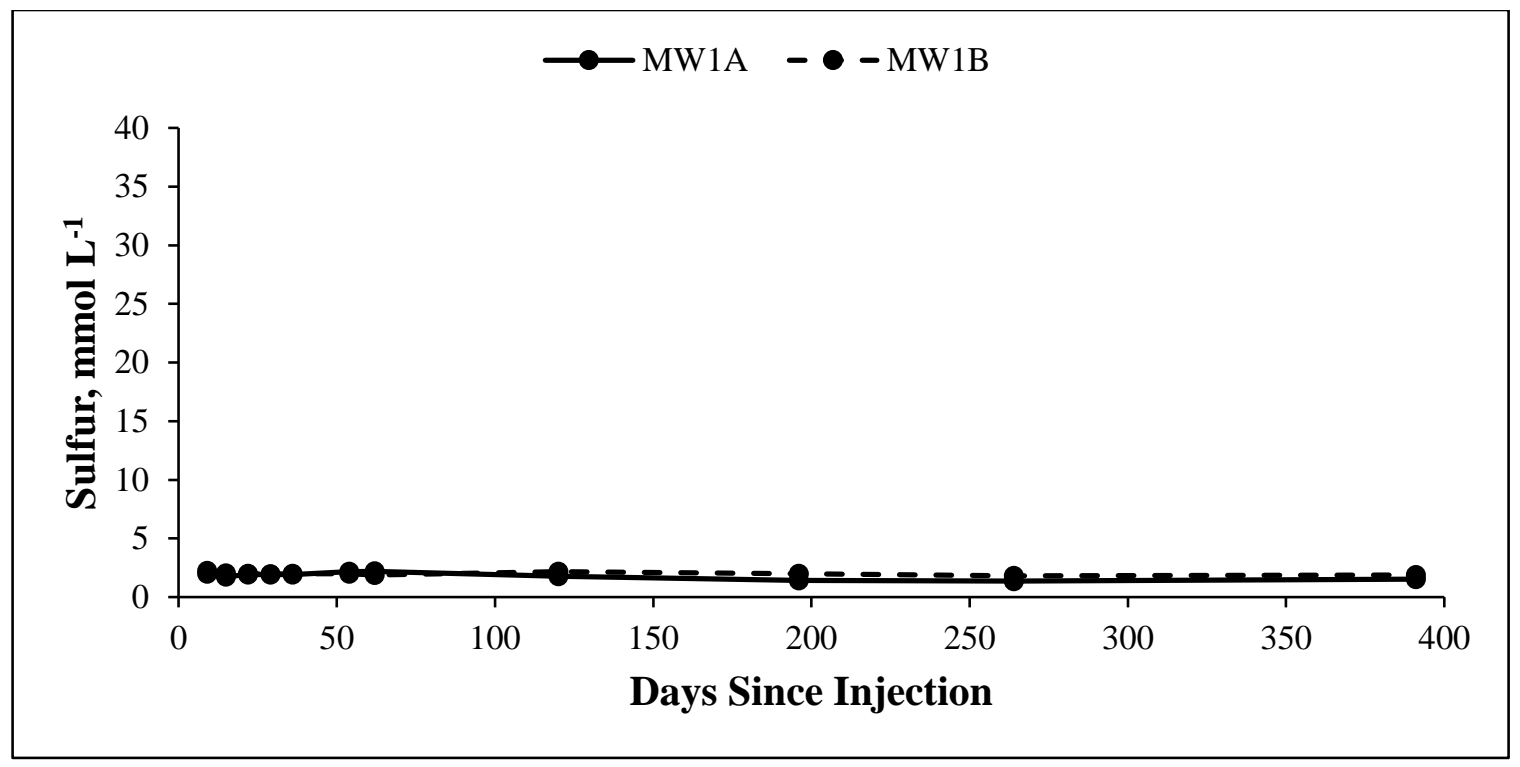

Figure C1: Groundwater concentration of sulfur $\left(\mathrm{mmol} \mathrm{L}^{-1}\right)$ in all monitoring wells of Control over the entire field test.

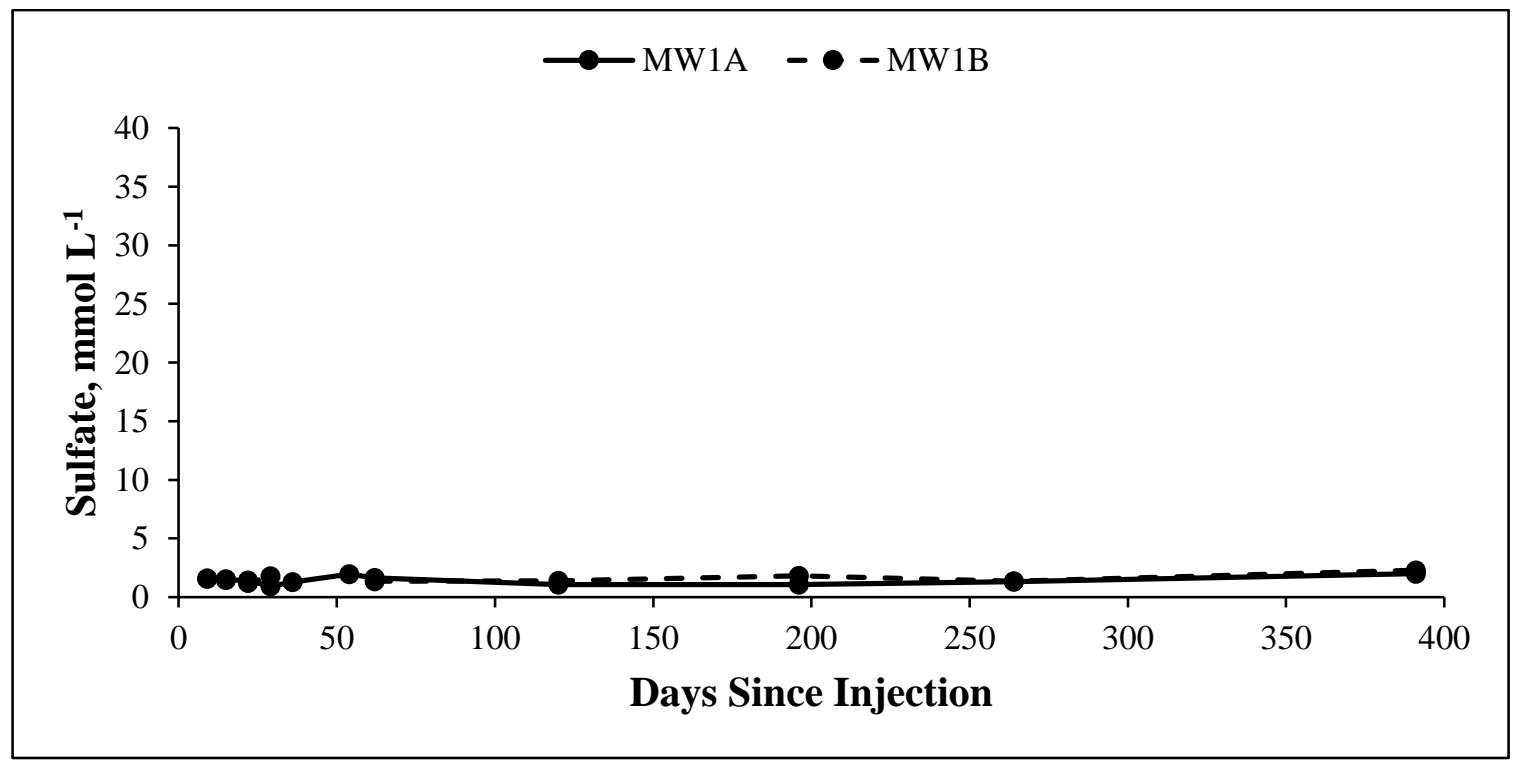

Figure C2: Groundwater concentration of sulfate $\left(\mathrm{mmol} \mathrm{L}^{-1}\right)$ in all monitoring wells of Control over the entire field test. 


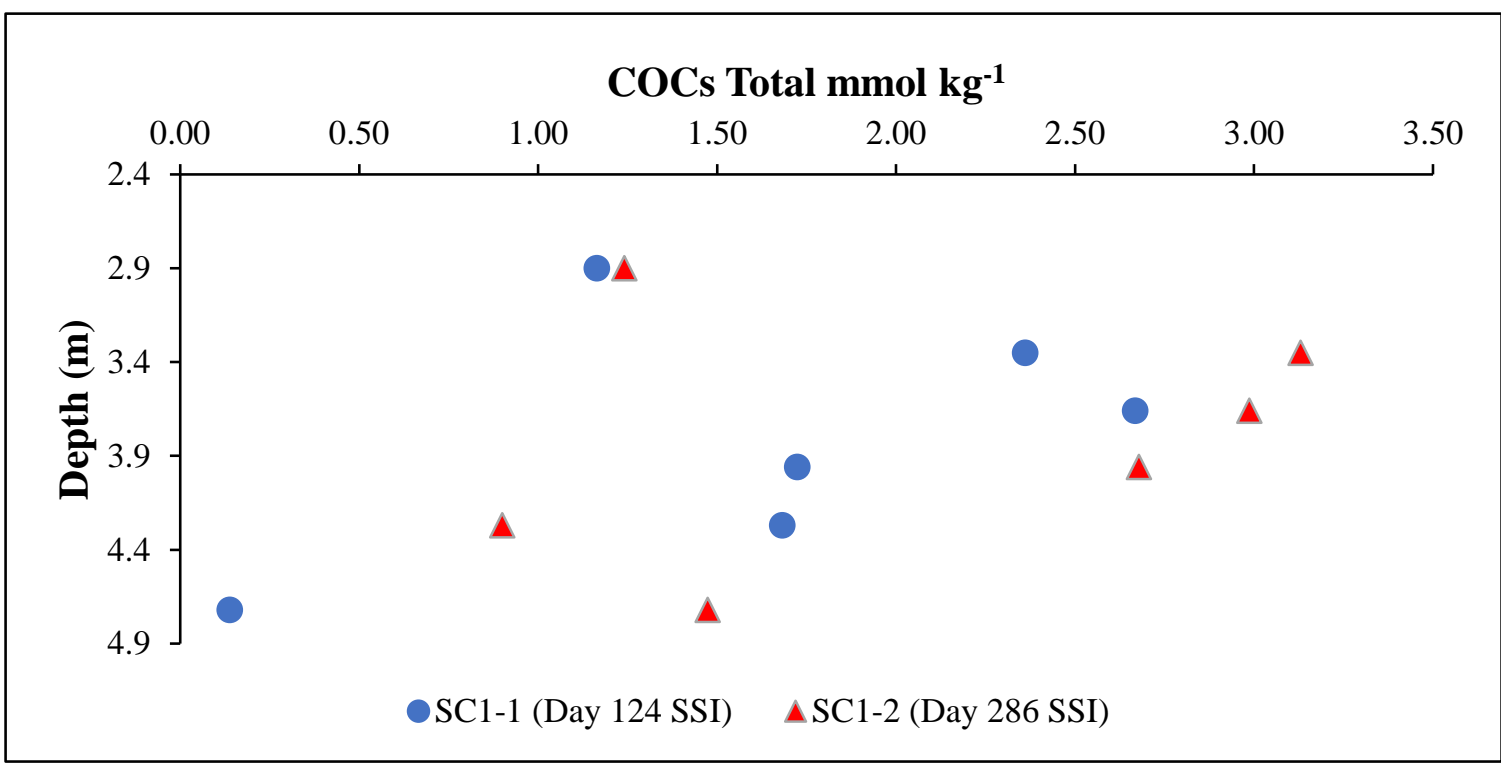

Figure C3: Soil concentration of COCs (total mmoles $\mathrm{kg}^{-1}$ ) with depth at SC1-1 and SC1-2 of Control. SC1-1 was completed on day 124 following EK operations. SC1-2 was completed on day 286 following EK operations.
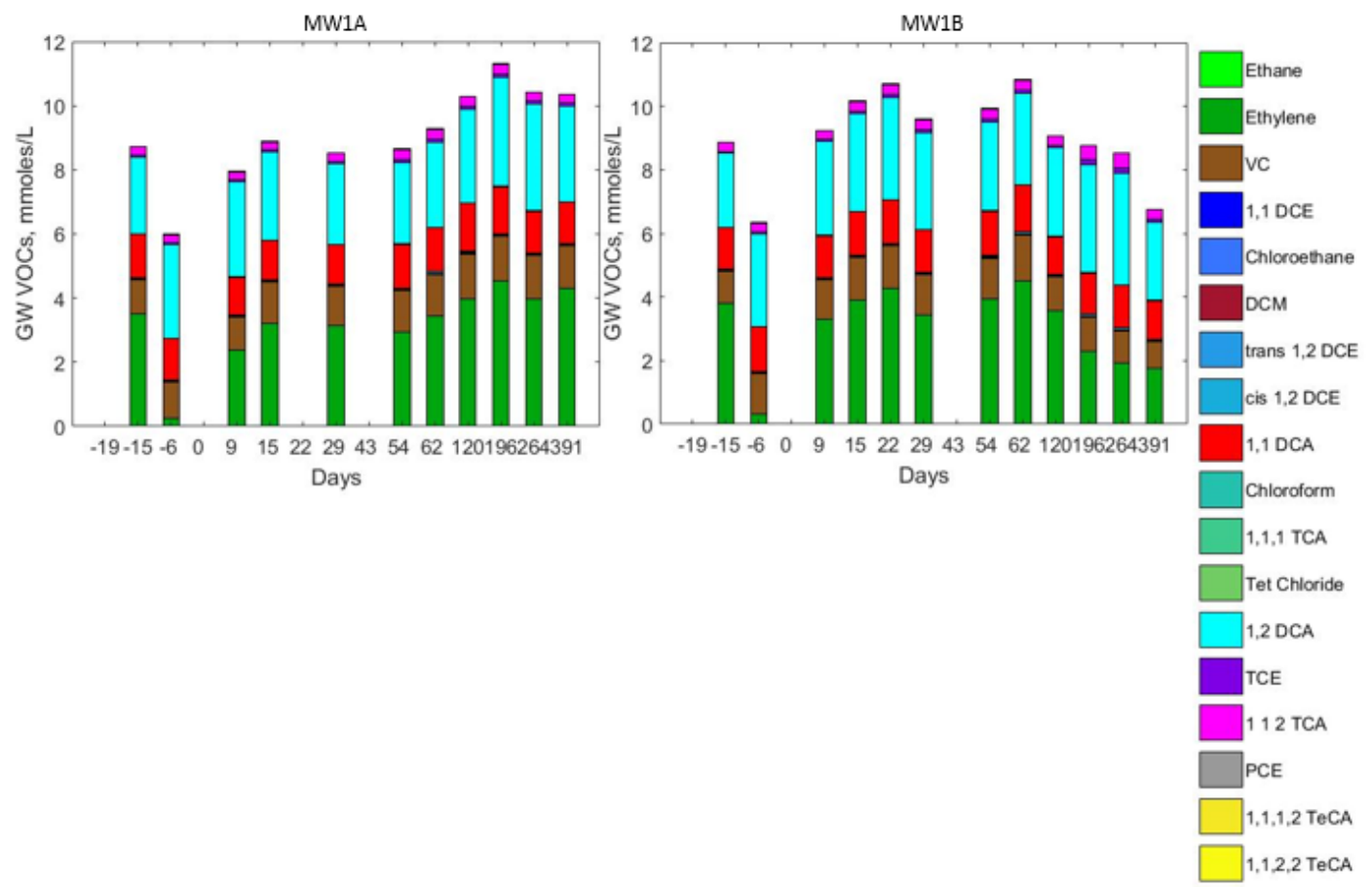

Figure C4: Groundwater concentration of COCs $\left(\right.$ mmoles $\left.\mathrm{L}^{-1}\right)$ in all monitoring wells of Control over the entire field test. 
Table C1: Background Groundwater Concentration $\left(\mathrm{mg} \mathrm{L}^{-1}\right)$ of COCs in Control

\begin{tabular}{|c|c|c|c|}
\hline \multirow[t]{2}{*}{ Compound } & \multicolumn{2}{|c|}{ Control } & \multirow{2}{*}{$\begin{array}{c}\text { O. Reg 153/04 } \\
\text { Table } 3 \text { (Ind/Comm) }\end{array}$} \\
\hline & MW1A & MW1B & \\
\hline Vinyl Chloride & 71.099 & 78.450 & 0.0017 \\
\hline Chloroethane & 1.280 & 1.452 & N/A \\
\hline 1,1-Dichloroethene & 0.768 & 0.897 & 0.017 \\
\hline Dichloromethane & 0.00 & 0.00 & N/A \\
\hline trans-1,2-Dichloroethene & 0.209 & 0.228 & 0.017 \\
\hline 1,1-Dichloroethane & 127.47 & 138.68 & 3.1 \\
\hline cis-1,2-Dichloroethene & 3.259 & 3.787 & 0.017 \\
\hline Chloroform & 0.444 & 0.462 & 0.022 \\
\hline 1,1,1-Trichloroethane & 0.044 & 0.041 & 6.7 \\
\hline Carbon tetrachloride & 0.00 & 0.00 & 0.0084 \\
\hline 1,2-Dichloroethane & 288.87 & 289.52 & 0.012 \\
\hline Trichloroethene & 10.157 & 9.178 & 0.017 \\
\hline Tetrachloroethene & 0.010 & 0.005 & 0.017 \\
\hline 1,1,2-Trichloroethane & 30.509 & 35.020 & 0.03 \\
\hline 1,1,1,2-Tetrachloroethane & 0.005 & 0.003 & N/A \\
\hline
\end{tabular}




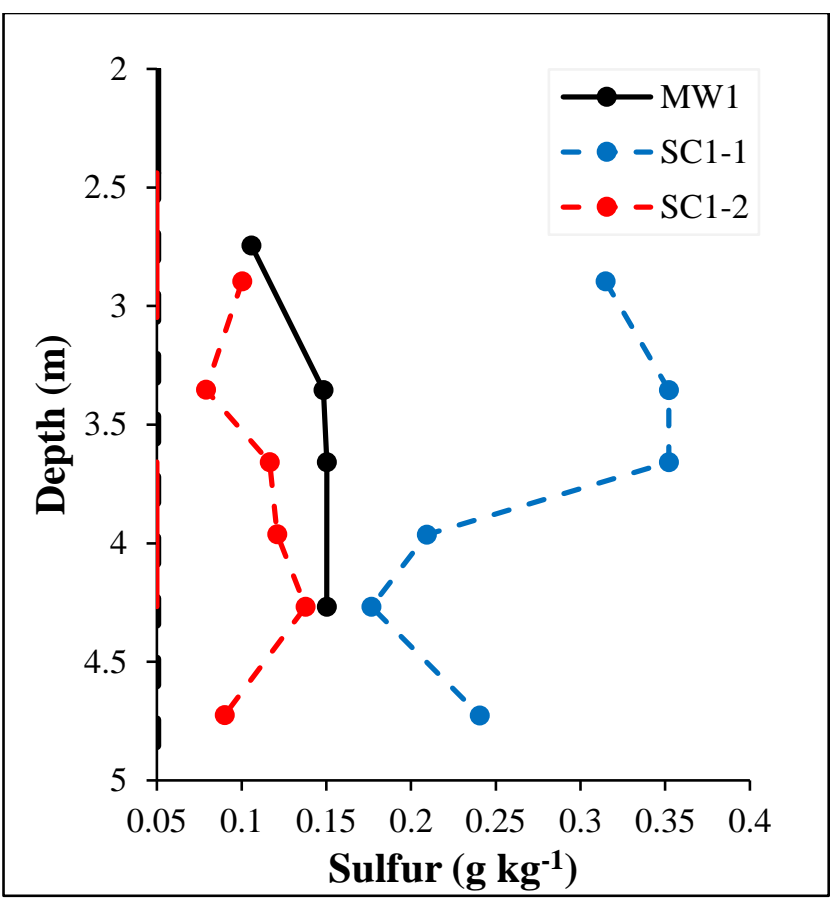

Figure C5: Soil concentration of sulfur $\left(\mathrm{g} \mathrm{kg}^{-1}\right)$ with depth of boreholes MW1, SC1-1, and SC1-2 in the Control transect.

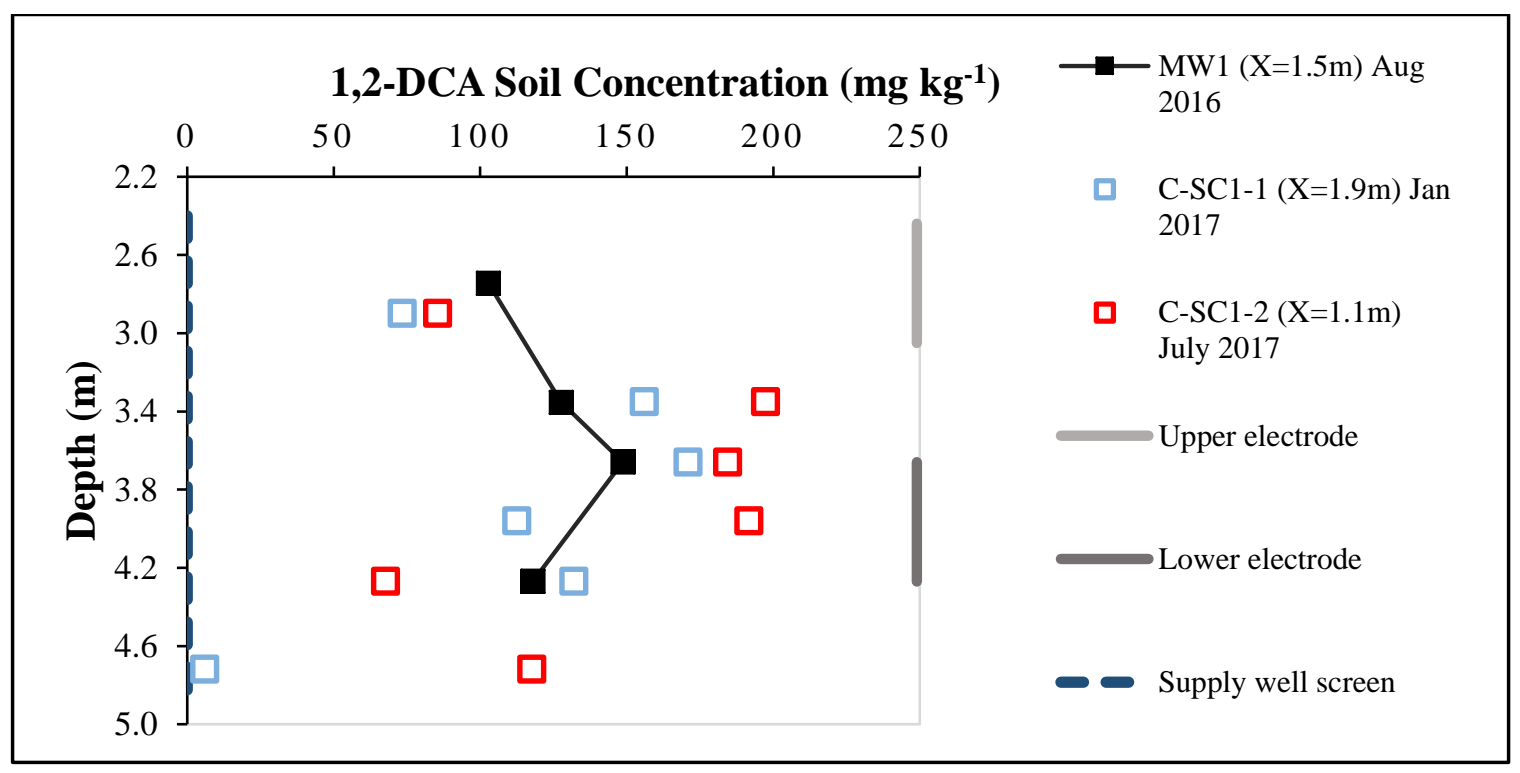

Figure C6: 1,2-DCA soil concentration $\left(\mathrm{mg} \mathrm{kg}^{-1}\right)$ with depth of boreholes MW1, CSC1-1, and C-SC1-2. Sampling depths include $2.74 \mathrm{~m}, 3.35 \mathrm{~m}, 3.66 \mathrm{~m}, 3.96 \mathrm{~m}, 4.27 \mathrm{~m}$, and $4.72 \mathrm{~m}$ (bgs). Black markers is a borehole completed before EK (i.e., MW1), blue markers is a borehole (i.e., $\mathrm{C}-\mathrm{SC1}$-1) completed on day 125 post-EK, and red markers is a borehole (i.e., C-SC1-2) completed on day 286 post-EK. 


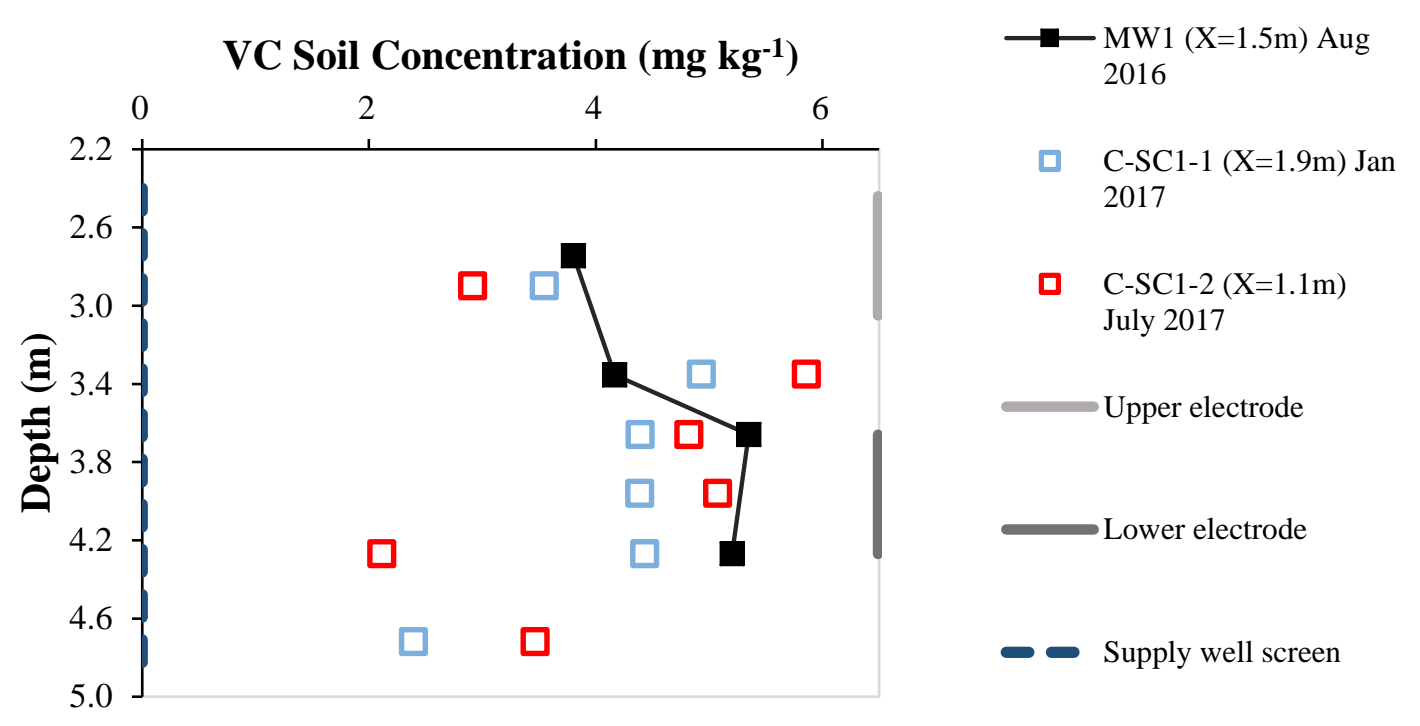

Figure C7: VC soil concentration $\left(\mathrm{mg} \mathrm{kg}^{-1}\right)$ with depth of boreholes MW1, C-SC1-1, and C-SC1-2. Sampling depths include $2.74 \mathrm{~m}, 3.35 \mathrm{~m}, 3.66 \mathrm{~m}, 3.96 \mathrm{~m}, 4.27 \mathrm{~m}$, and $4.72 \mathrm{~m}$ (bgs). Black markers is a borehole completed before EK (i.e., MW1), blue markers is a borehole (i.e., C-SC1-1) completed on day 125 post-EK, and red markers is a borehole (i.e., $\mathrm{C}$-SC1-2) completed on day 286 post-EK.

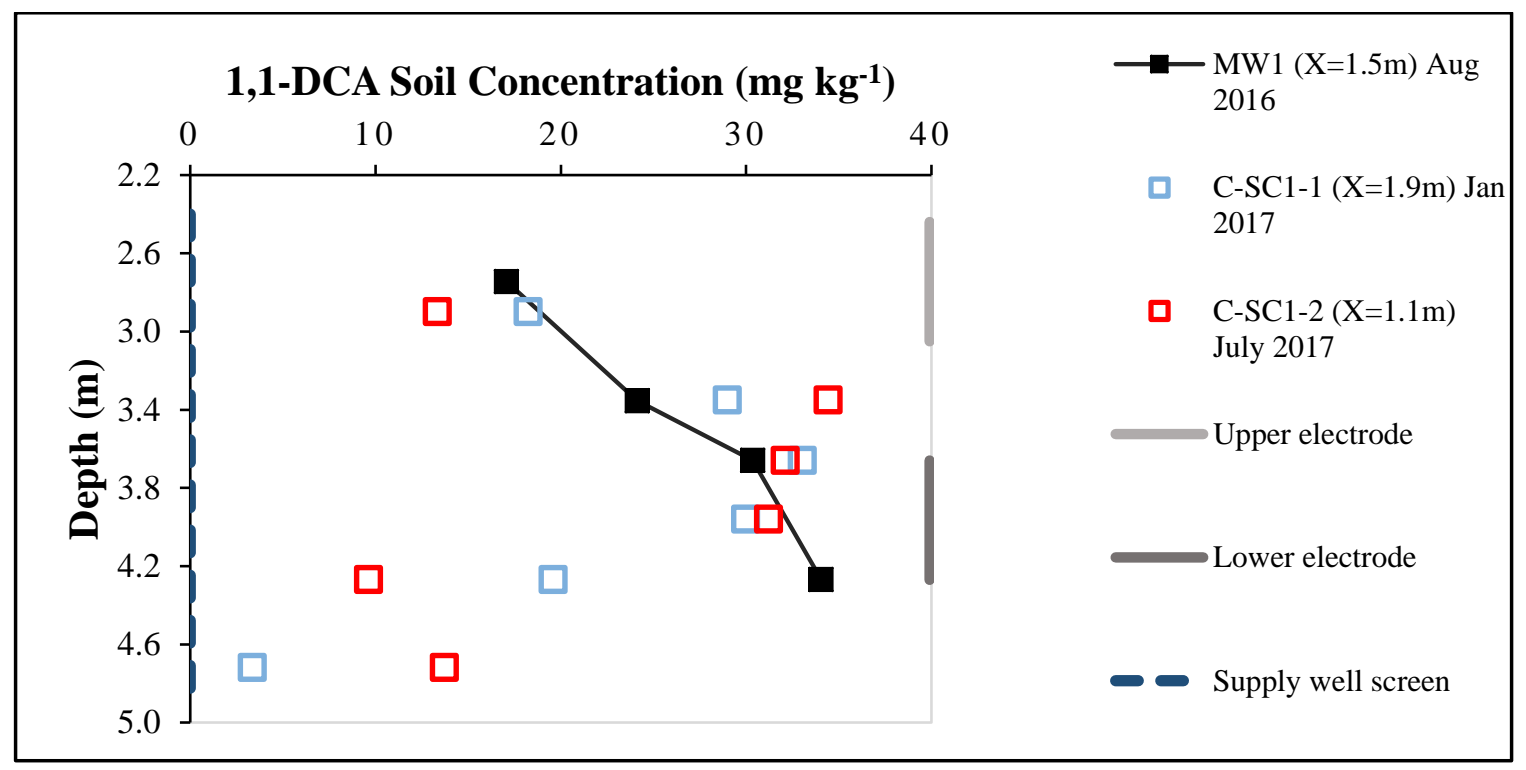

Figure C8: 1,1-DCA soil concentration ( $\mathrm{mg} \mathrm{kg}^{-1}$ ) with depth of boreholes MW1, CSC1-1, and C-SC1-2. Sampling depths include $2.74 \mathrm{~m}, 3.35 \mathrm{~m}, 3.66 \mathrm{~m}, 3.96 \mathrm{~m}, 4.27 \mathrm{~m}$, and $4.72 \mathrm{~m}$ (bgs). Black markers is a borehole completed before EK (i.e., MW1), blue markers is a borehole (i.e., C-SC1-1) completed on day 125 post-EK, and red markers is a borehole (i.e., C-SC1-2) completed on day 286 post-EK. 

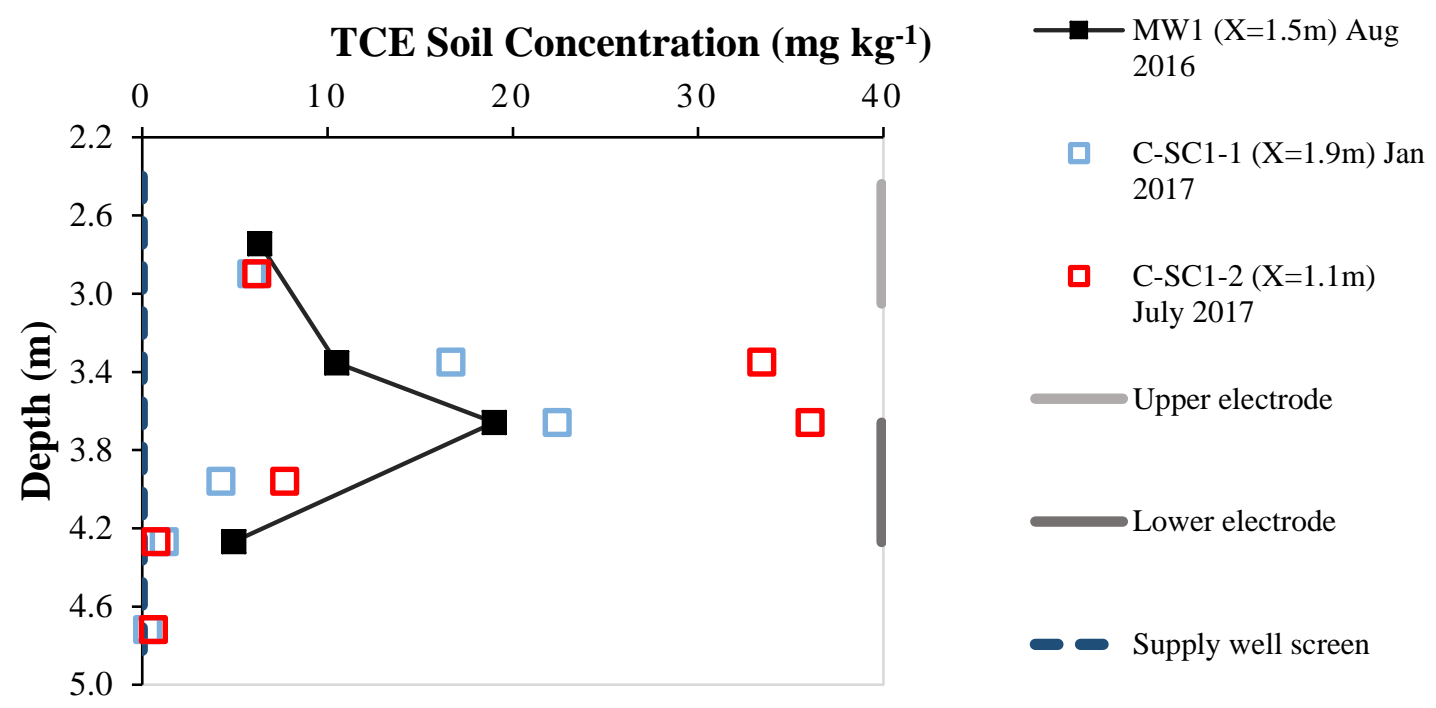

Figure C9: TCE soil concentration ( $\mathrm{mg} \mathrm{kg}^{-1}$ ) with depth of boreholes MW1, C-SC11, and C-SC1-2. Sampling depths include $2.74 \mathrm{~m}, 3.35 \mathrm{~m}, 3.66 \mathrm{~m}, 3.96 \mathrm{~m}, 4.27 \mathrm{~m}$, and $4.72 \mathrm{~m}$ (bgs). Black markers is a borehole completed before EK (i.e., MW1), blue markers is a borehole (i.e., $\mathrm{C}$-SC1-1) completed on day 125 post-EK, and red markers is a borehole (i.e., $\mathrm{C}$-SC1-2) completed on day 286 post-EK.

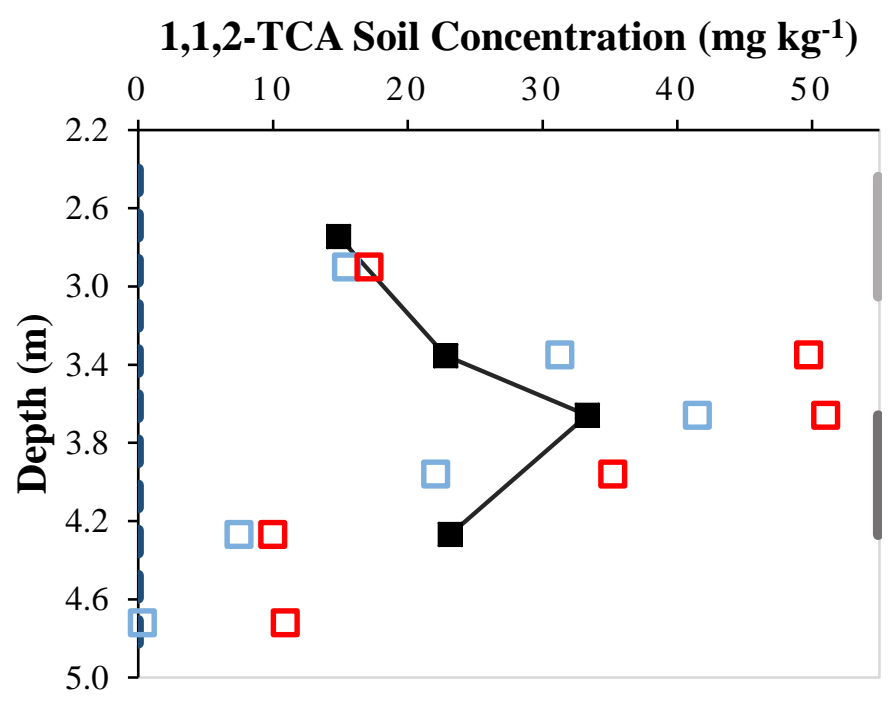

$\longrightarrow-\operatorname{MW} 1(\mathrm{X}=1.5 \mathrm{~m})$ Aug 2016

C-SC1-1 (X=1.9m) Jan 2017

ㅁ C-SC1-2 $(\mathrm{X}=1.1 \mathrm{~m})$ July 2017

Upper electrode

Lower electrode

Supply well screen

Figure C10: 1,1,2-TCA soil concentration ( $\left.\mathrm{mg} \mathrm{kg}^{-1}\right)$ with depth of boreholes MW1, CSC1-1, and C-SC1-2. Sampling depths include $2.74 \mathrm{~m}, 3.35 \mathrm{~m}, 3.66 \mathrm{~m}, 3.96 \mathrm{~m}, 4.27 \mathrm{~m}$, and $4.72 \mathrm{~m}$ (bgs). Black markers is a borehole completed before EK (i.e., MW1), blue markers is a borehole (i.e.,C-SC1-1) completed on day 125 post-EK, and red markers is a borehole (i.e., C-SC1-2) completed on day 286 post-EK. 


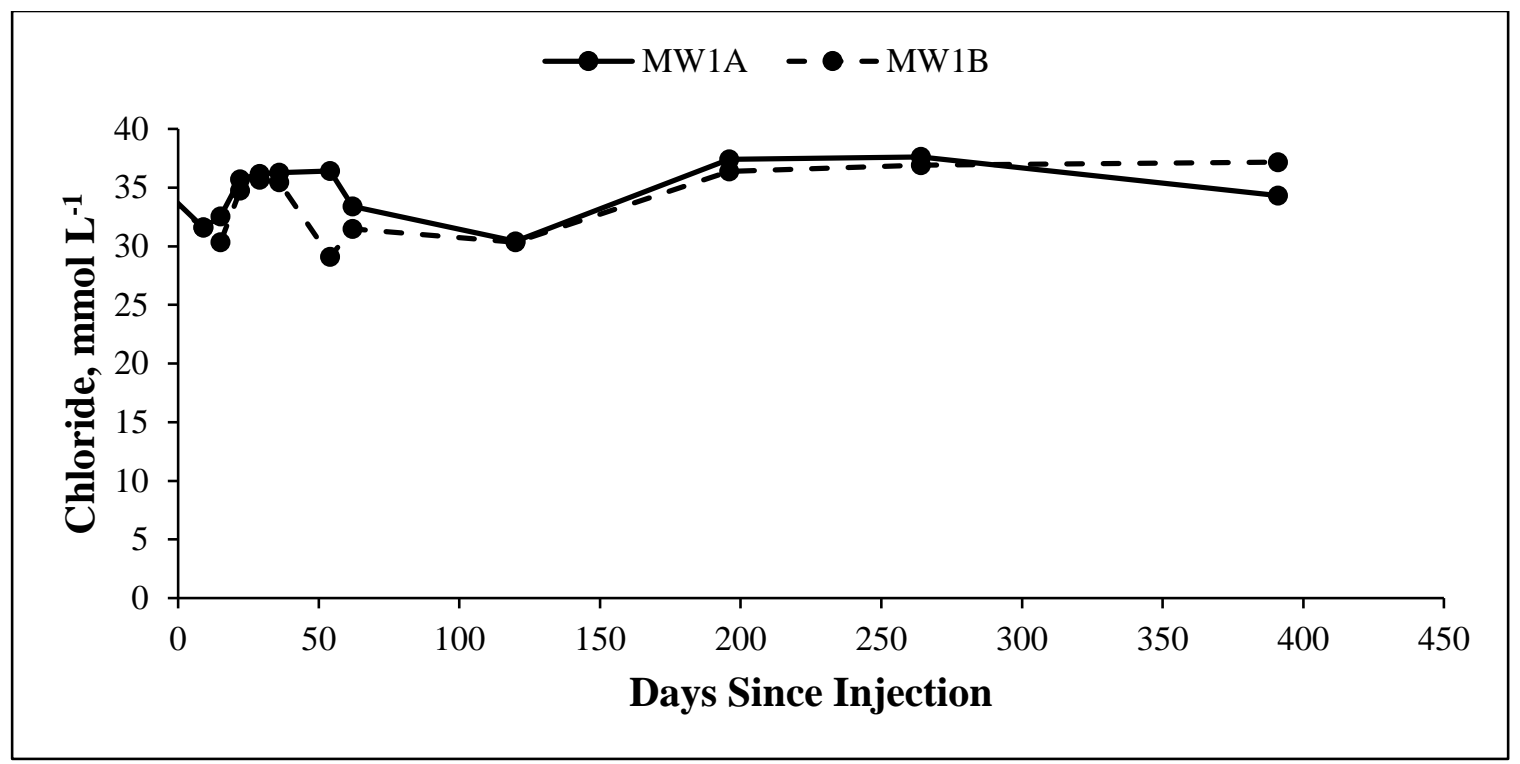

Figure C11: Groundwater concentration of chloride $\left(\mathrm{mmol} \mathrm{L}^{-1}\right)$ in all monitoring wells of Control over the entire field test.

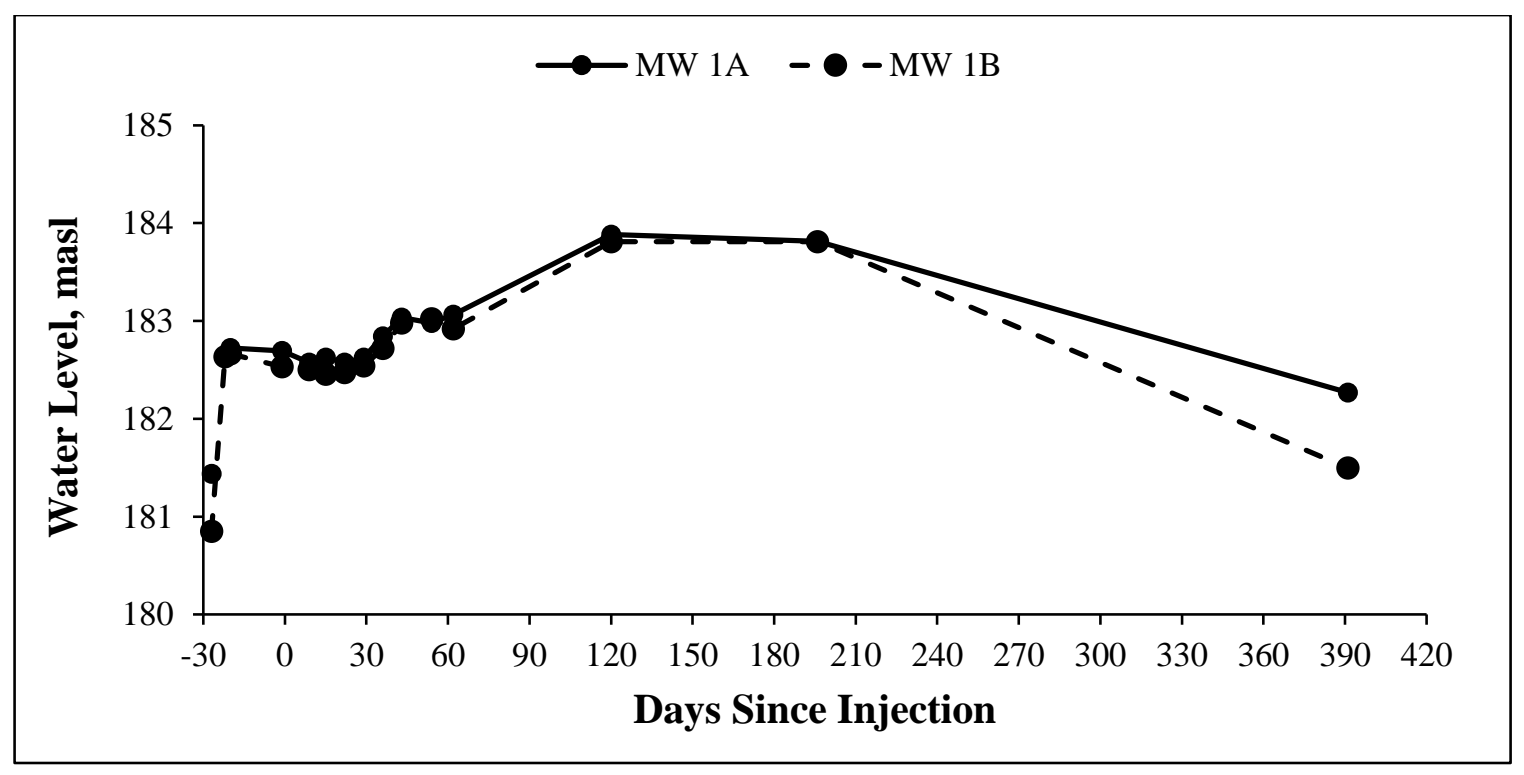

Figure C12: Water levels in all monitoring wells of Control over the entire field test. 


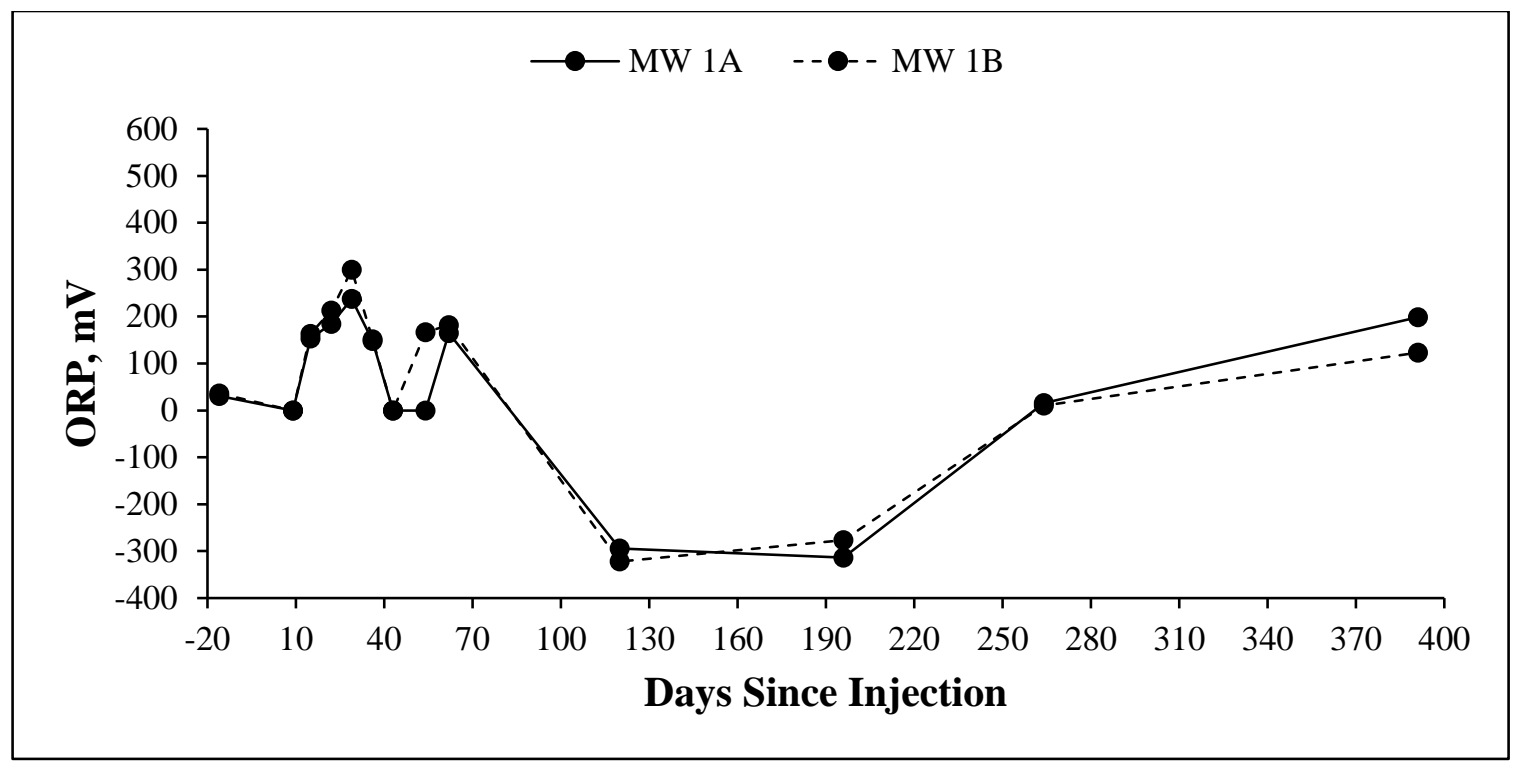

Figure C13: Groundwater oxidation-reduction potential in all monitoring wells of Control over the entire field test.

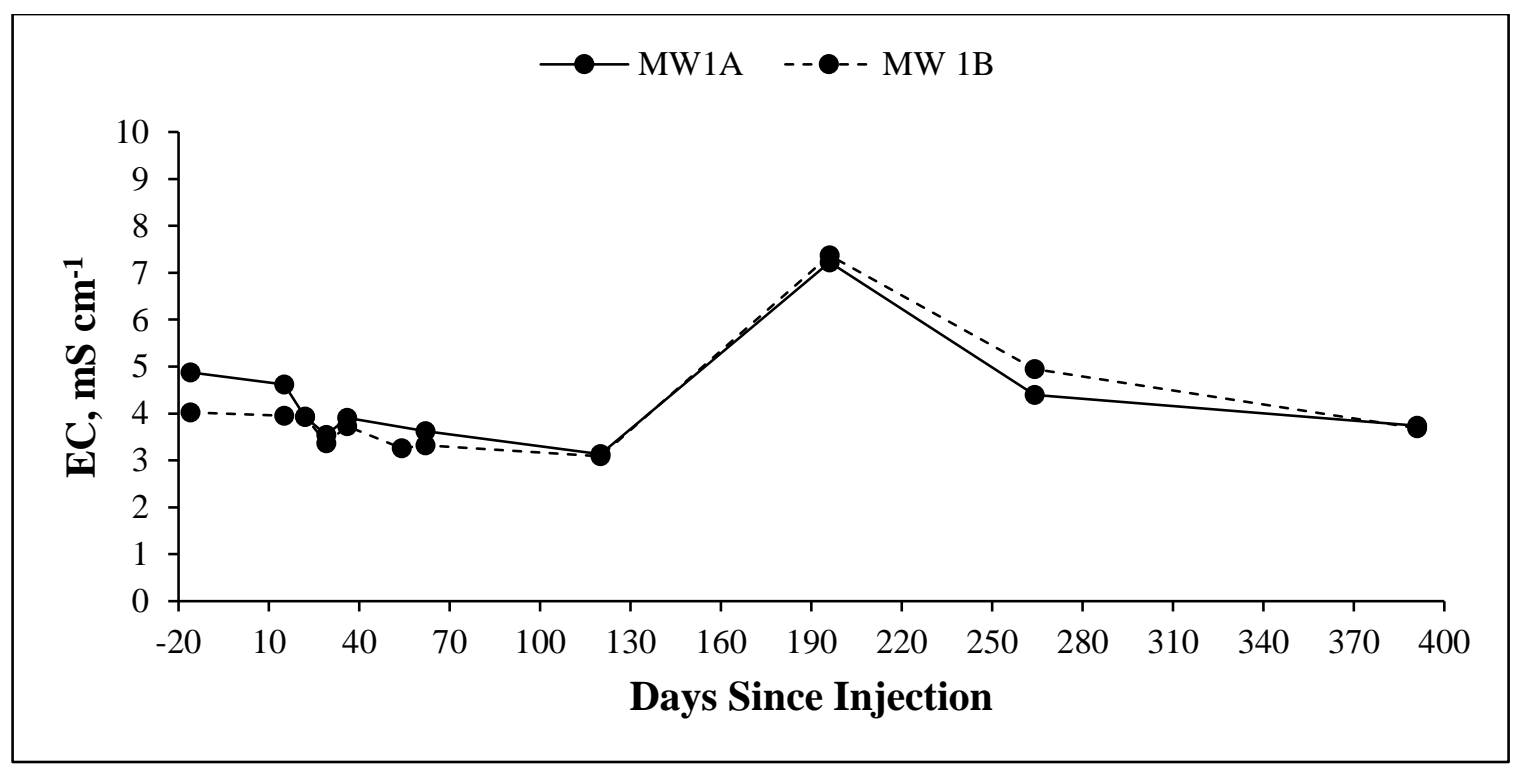

Figure C14: Groundwater electrical conductivity in all monitoring wells of Control over the entire field test. 


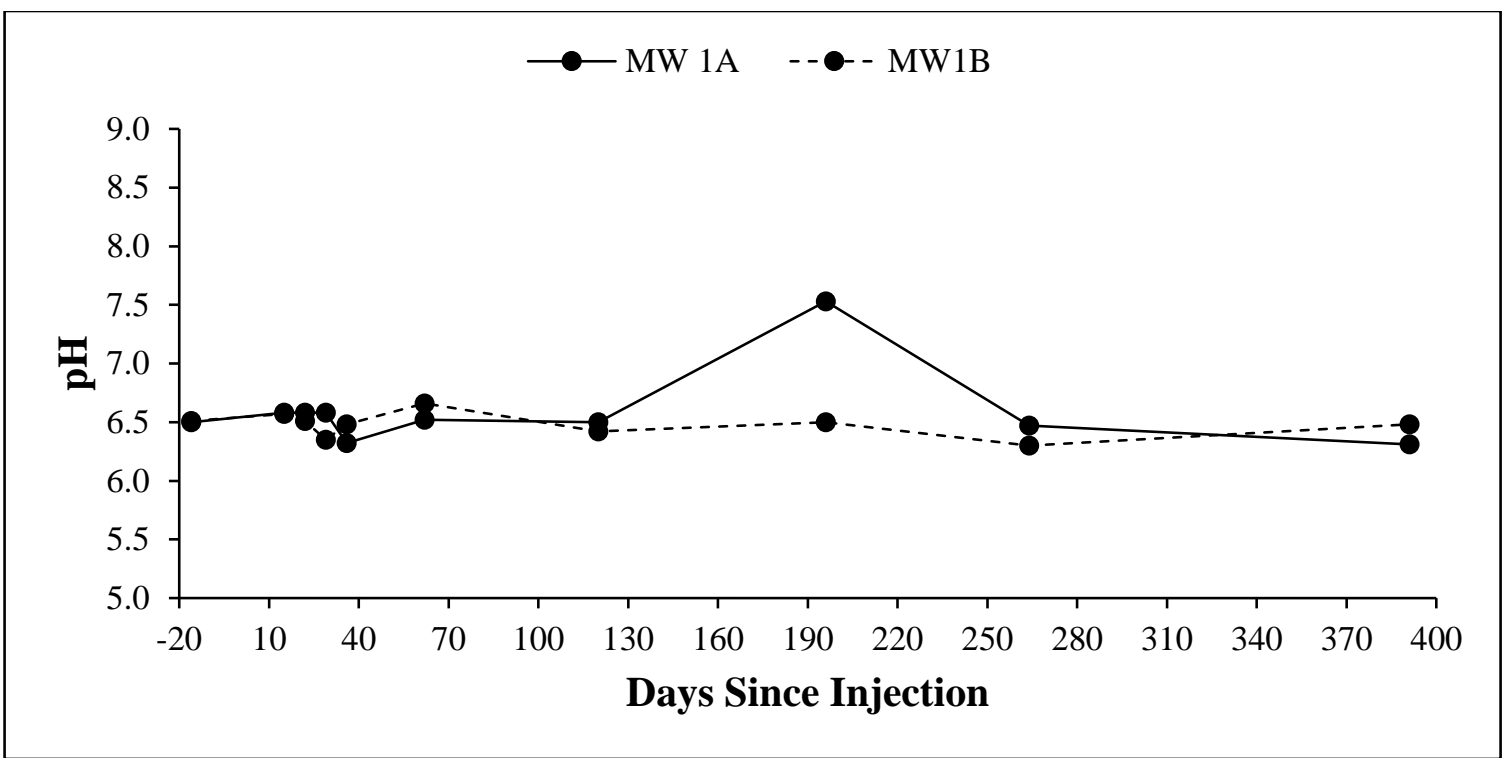

Figure C15: Groundwater pH in all monitoring wells of Control over the entire field test. 
Appendix D: Supplementary Information 

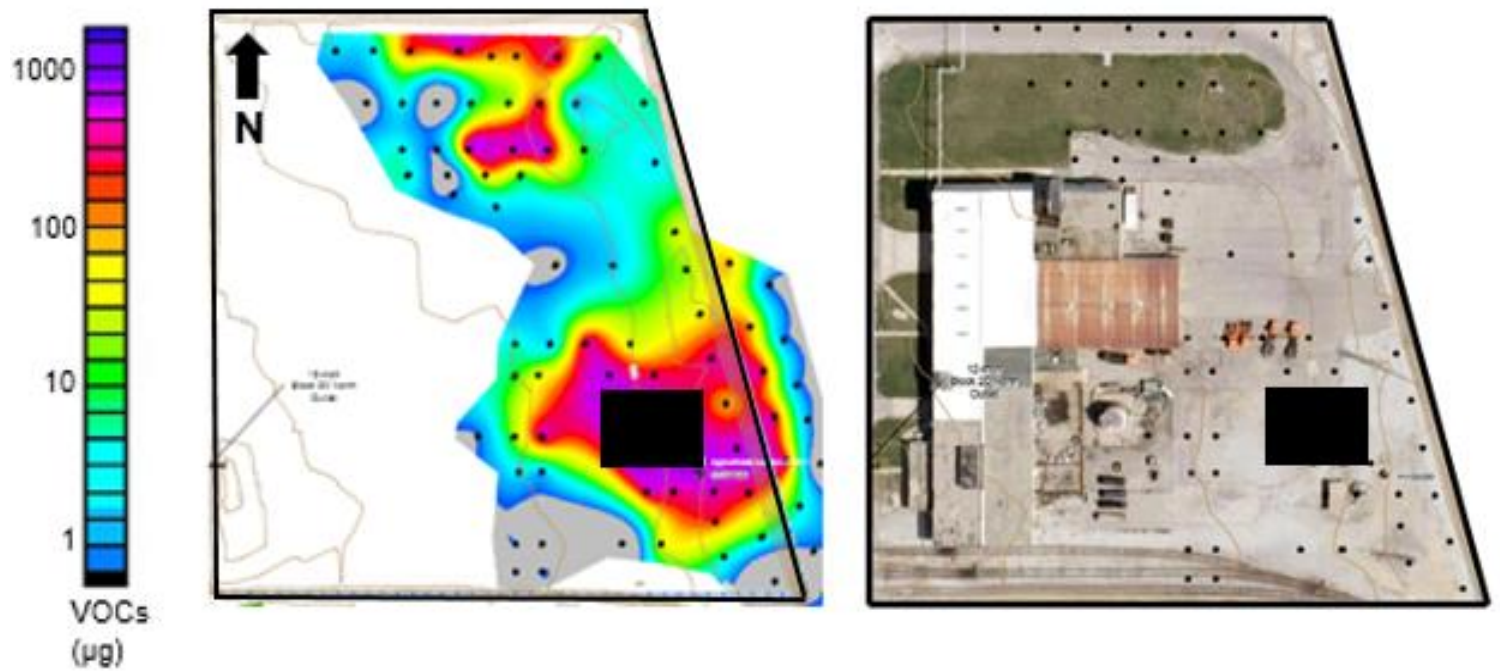

Figure D1: Right-hand image shows a plan view of the field site in 2006. Left-hand image shows a superficial map of the concentration of COCs at the field site. COCs were measured using a Gore-Sorber screening survey. Black boxes represent the location of the test area.

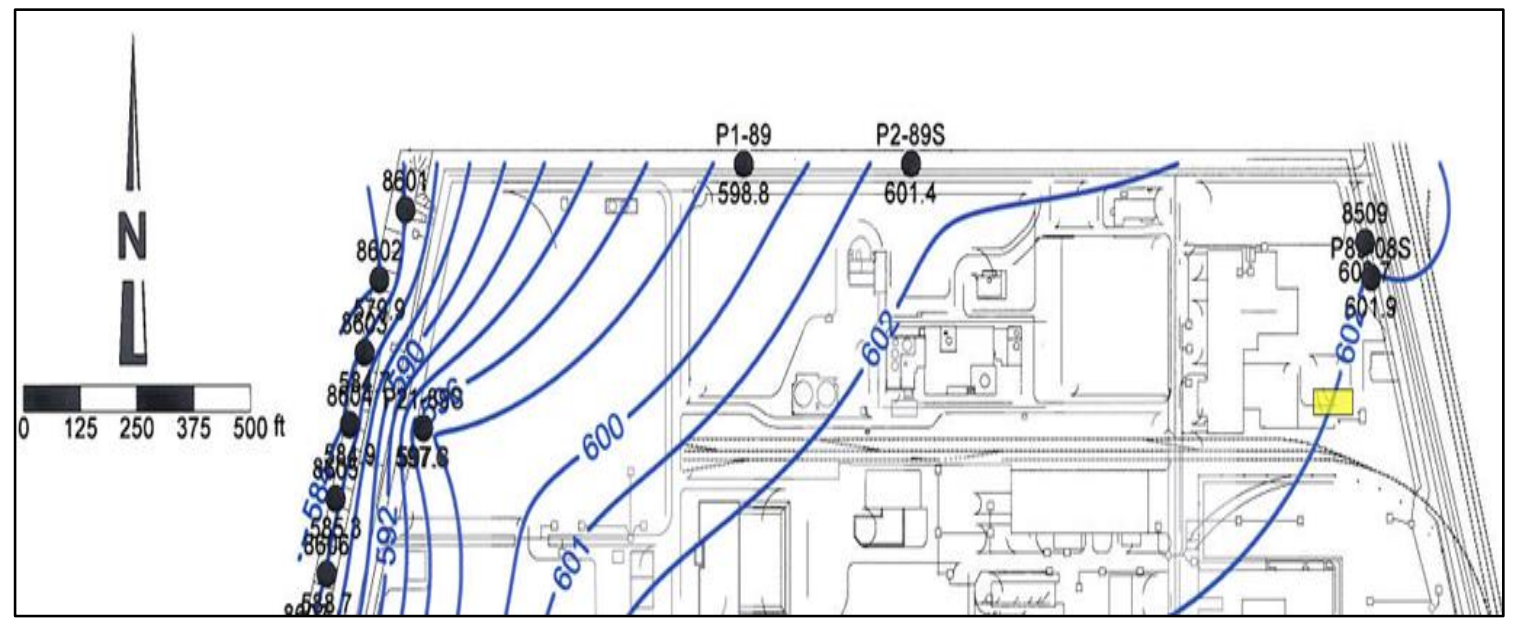

Figure D2: Contour map of the hydraulic gradient observed at the field site. The yellow box is the location of the test area. 


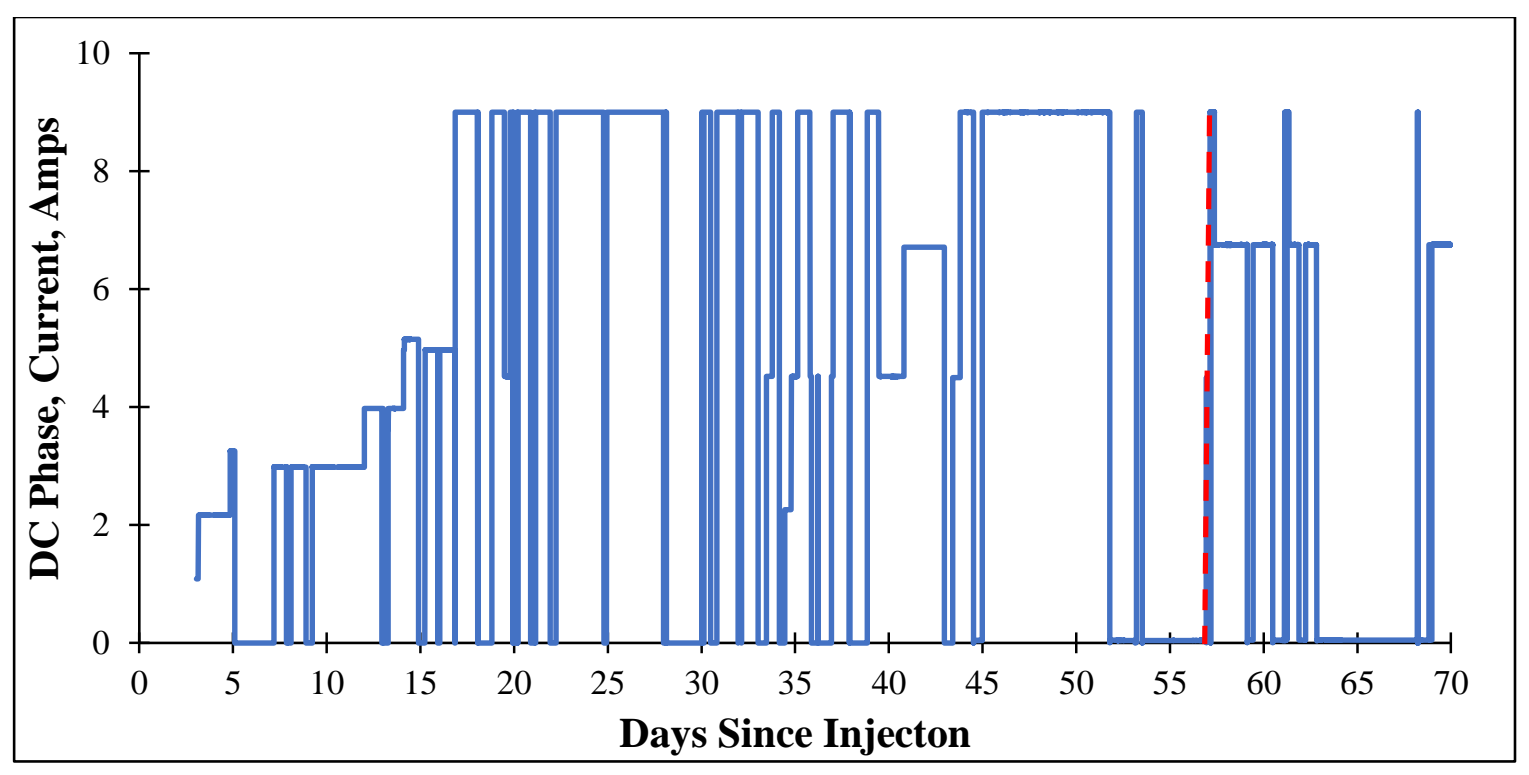

Figure D3: Constant DC applied to EK-TAP and EK-Control during EK operations. The red vertical dashed line represents the end of EK and start of ERH in EK-TAP.

Table D1: List of Analyzed COCs in EK-TAP, EK-Control, and Control Transects

\begin{tabular}{|l|c|c|}
\hline \multicolumn{2}{|c|}{ Measured Chlorinated Organic Compounds } \\
\hline Chlorinated Ethenes & Chlorinated Ethanes & $\begin{array}{c}\text { Chlorinated } \\
\text { Methanes }\end{array}$ \\
\hline Vinyl Chloride* & Chloroethane* & Dichloromethane* \\
\hline 1,1-Dichloroethene* & 1,1 -Dichloroethane* & Chloroform \\
\hline trans-1,2-Dichloroethene* & 1,2 -Dichloroethane & Carbon Tetrachloride \\
\hline cis-1,2-Dichloroethene* & $1,1,1$-Trichloroethane & \\
\hline Trichloroethene & $1,1,2$-Trichloroethane & \\
\hline Tetrachloroethene & $1,1,2,2$-Tetrachloroethane & \\
\hline & $1,1,1,2$-Tetrachloroethane & \\
\hline
\end{tabular}

Compounds measured by FID are noted by *. All other compounds are measured by ECD 


\section{Method D1: Analysis of $\mathrm{Fe}^{2+}$ Content of borehole SC1-2 in EK-TAP}

The $\mathrm{Fe}^{2+}$ content of borehole SC1-2 in EK-TAP was measured by the ferrozine method developed by Lovley and Phillips (1987). Approximately $0.1 \mathrm{~g}$ of wet sediment samples were taken from sectioned sub-cores of SC1-2 (i.e., at depths of 3.7-4.2 m bgs). The collected samples were then transferred to $5 \mathrm{~mL}$ of $0.5 \mathrm{M} \mathrm{HCl}$ in glass scintillation vials with a known weight. The sediments and acid were mixed with gentle swirling for about 30 seconds. The weight of the added sediments was determined. After 1-hour at ambient temperature, $0.1 \mathrm{~mL}$ samples of the extracts were added to $5 \mathrm{~mL}$ of $1 \mathrm{~g} \mathrm{~L}^{-1}$ ferrozine in 50 mM HEPES (N-2-hydroxyethylpiperazine-N'-2-ethanesulfonic acid) buffer at a pH of 7. After being mixed for 15 seconds, the mixtures were passed through $25 \mathrm{~mm}$ syringe filters with $0.45 \mu \mathrm{m}$ polyethersulfone membranes. The amount of $\mathrm{Fe}^{2+}$ was determined by measuring $\mathrm{A}_{562}$ of the filtrates. The extraction method has shown not to oxidize $\mathrm{Fe}^{2+}$ to $\mathrm{Fe}^{3+}$ and has been determined to be effective on ion-exchangeable $\mathrm{Fe}^{2+}, \mathrm{FeS}$, and $\mathrm{FeCO}_{3}$ species (Heron et al., 1994; Lovley and Phillips, 1986). All described procedures were completed in an anaerobic glove box to prevent oxidation of the samples. It should also be noted that sub-cores were sieved to $<25 \mathrm{~mm}$ and homogenized using a cone-quartering method. 


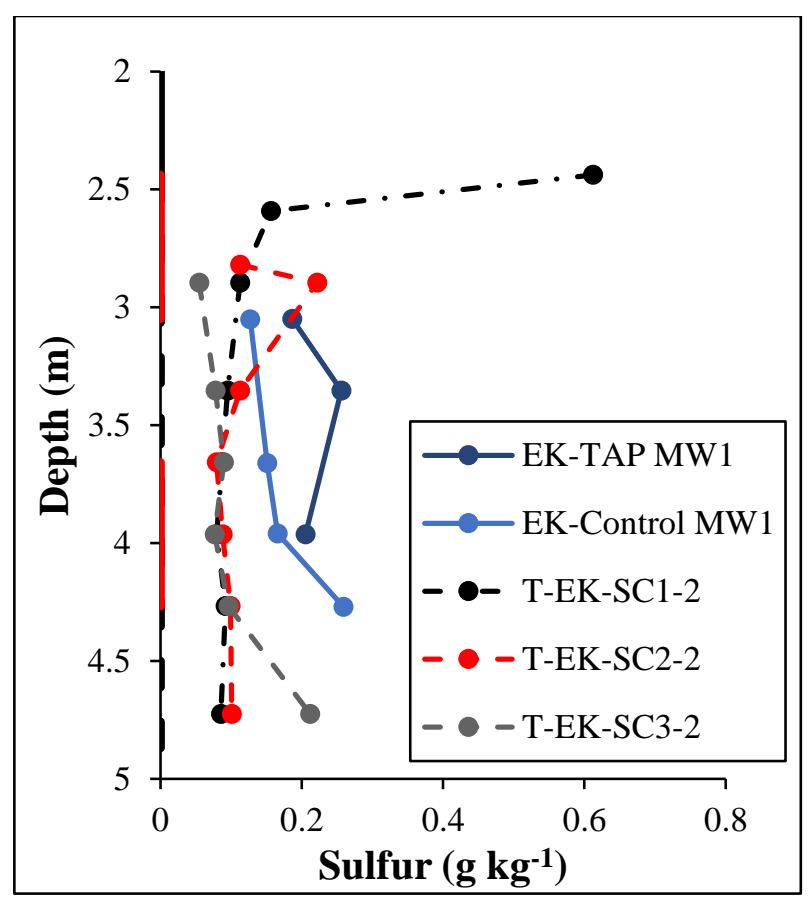

Figure D4: Soil concentration of sulfur $\left(\mathrm{g} \mathrm{kg}^{-1}\right)$ with depth of boreholes T-EK-SC1-2, T-EK-SC2-2, and T-EK-SC3-2 completed between EK-TAP and EK-Control.

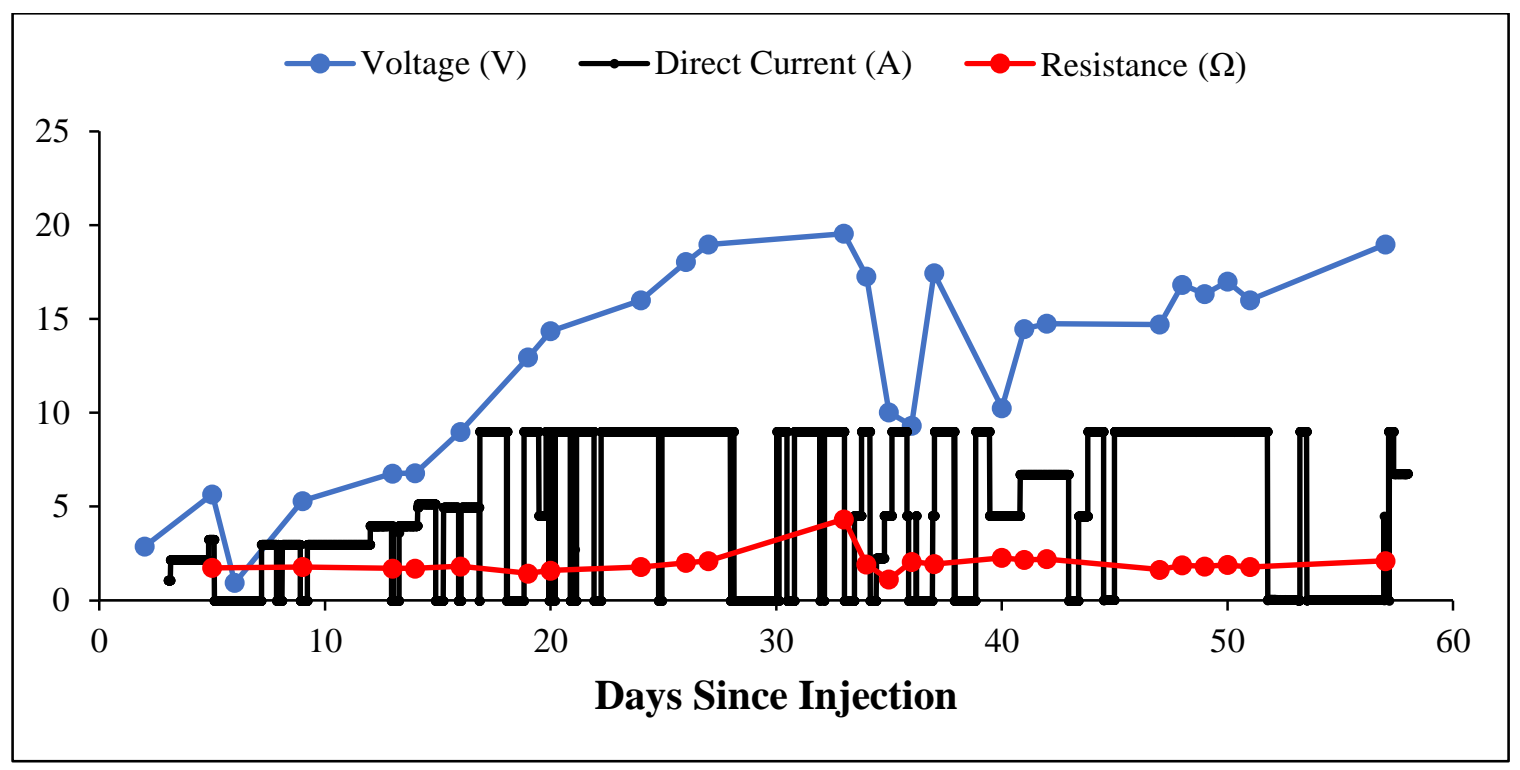

Figure D5: Voltage $(V)$, resistance $(\Omega)$, and constant DC (A) measured in EK-TAP during EK operations. Voltage was averaged from all readings taken at 3.05 and 3.96 m (bgs) from MW1, SW1, SW2, and MW2. Constant DC is what was applied from the site power supply (SL Series 1 Programmable DC Power Supply, Magna-Power Electronics) to EK-TAP and three additional EK cells. Resistance was calculated from the average voltage in EK-TAP and applied constant DC using Ohm's law (i.e., $\mathbf{V}=\mathbf{I R})$. 
Appendix E: Copywrite Permission 


\section{Copywrite Figure 2.1}

\section{ELSEVIER LICENSE \\ TERMS AND CONDITIONS}

Sep 03, 2018

This Agreement between The University of Western Ontario -- Nicholas Head ("You") and Elsevier ("Elsevier") consists of your license details and the terms and conditions provided by Elsevier and Copyright Clearance Center.

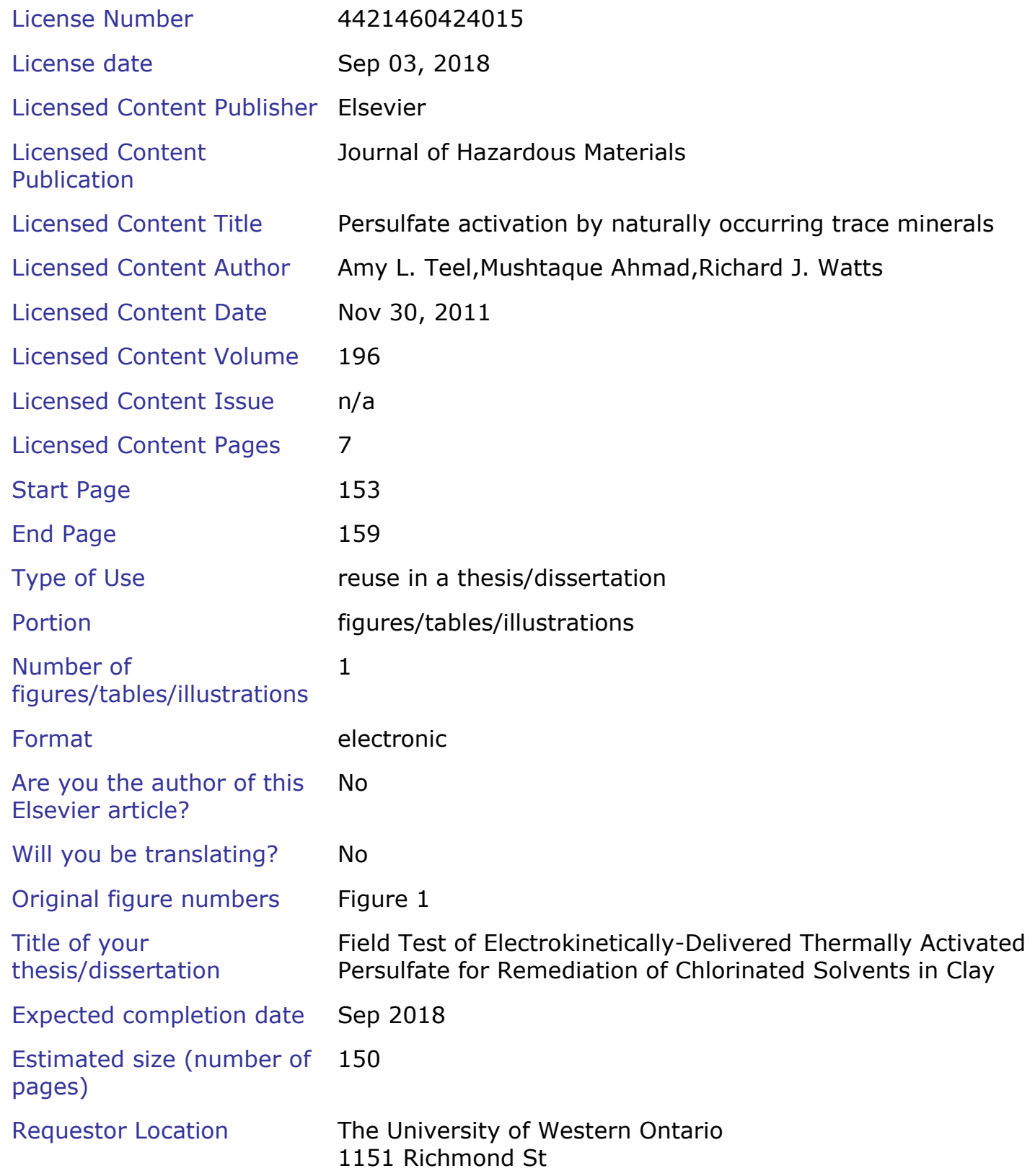


London, ON N6A 3K7

Canada

Attn: The University of Western Ontario

Publisher Tax ID

GB 494627212

Total

0.00 USD 


\section{Copywrite Figure 2.2}

ACS Publications Title:

Most Trusted. Most Cited Most Reod.

Author: Publication: Environmental Science \&

Publisher: American Chemical Society

Date: Dec 1, 2008

Copyright 02008 , American Chemical Society
Logged in as:

Nicholas Head

The University of Western

The Univen
Ontario

Account \#:

3001330295

tosour

\section{PERMISSION/LICENSE IS GRANTED FOR YOUR ORDER AT NO CHARGE}

This type of permission/license, instead of the standard Terms \& Conditions, is sent to you because no fee is being charged for your order. Please note the following:

- Permission is granted for your request in both print and electronic formats, and translations.

- If figures and/or tables were requested, they may be adapted or used in part.

- Please print this page for your records and send a copy of it to your publisher/graduate school.

- Appropriate credit for the requested material should be given as follows: "Reprinted (adapted) with permission from (COMPLETE REFERENCE CITATION). Copyright (YEAR) American Chemical Society." Insert appropriate information in place of the capitalized words.

- One-time permission is granted only for the use specified in your request. No additional uses are granted (such as derivative works or other editions). For any other uses, please submit a new request.

If credit is given to another source for the material you requested, permission must be obtained from that source.

\section{BACK CLOSE WINDOW}

Copyright (1) 2018 Cogyright Clearance Center, Inc, All Rights Reserved. Privacy statement, Terms and Conditions. Comments? We would like to hear from you. E-mail us at austamercarefincegrighticom 


\section{Copywrite Figure 2.3}

\section{ELSEVIER LICENSE \\ TERMS AND CONDITIONS}

Sep 03, 2018

This Agreement between The University of Western Ontario -- Nicholas Head ("You") and Elsevier ("Elsevier") consists of your license details and the terms and conditions provided by Elsevier and Copyright Clearance Center.




Estimated size (number of 150

pages)

Requestor Location

The University of Western Ontario

1151 Richmond St

London, ON N6A 3K7

Canada

Attn: The University of Western Ontario

Publisher Tax ID

GB 494627212

Total

0.0 USD 


\section{Curriculum Vitae}

Name:

Post-secondary Education and Degrees:

Related Work Experience
Nicholas Head

The University of Western Ontario London, Ontario, Canada 2016-2018 M.E.Sc.

McMaster University

Hamilton, Ontario, Canada

2012-2016 B.Sc.

Internship

Jacobs Engineering Group Inc.

2016-2018

Teaching Assistant

The University of Western Ontario 2016-2017 